\title{
Torben Lütjen
}

Dio Politik

ior Egholammor

Wisconsin und die ideologische Polarisierung der USA 
Torben Lütjen

Die Politik der Echokammer

Studien des Göttinger Instituts für Demokratieforschung zur Geschichte politischer und gesellschaftlicher Kontroversen

Herausgegeben von Franz Walter | Band II 
Torben Lütjen (Dr.) ist Politikwissenschaftler und lehrt in Düsseldorf und Göttingen. Er arbeitet hauptsächlich zu Politik, Geschichte und Gesellschaft der USA. 
TORBEN LÜTJEN

\section{Die Politik der Echokammer}

Wisconsin und die ideologische Polarisierung der USA

[transcript] 


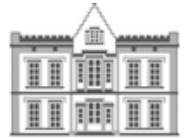

Göttinger Institut für

Demokratieforschung

\section{(9) (1) $\Theta \Theta$}

Dieses Werk ist lizenziert unter der Creative Commons Attribution-NonCommercial-NoDerivs 4.0 Lizenz (BY-NC-ND). Diese Lizenz erlaubt die private Nutzung, gestattet aber keine Bearbeitung und keine kommerzielle Nutzung. Weitere Informationen finden Sie unter https://creativecommons.org/licenses/by-nc-nd/4.o/deed.de/. Um Genehmigungen für Adaptionen, Übersetzungen, Derivate oder Wiederverwendung zu kommerziellen Zwecken einzuholen, wenden Sie sich bitte an rights@transcript-verlag.de

\section{(C) 2016 transcript Verlag, Bielefeld}

Die Verwertung der Texte und Bilder ist ohne Zustimmung des Verlages urheberrechtswidrig und strafbar. Das gilt auch für Vervielfältigungen, Übersetzungen, Mikroverfilmungen und für die Verarbeitung mit elektronischen Systemen.

\section{Bibliografische Information der Deutschen Nationalbibliothek}

Die Deutsche Nationalbibliothek verzeichnet diese Publikation in der Deutschen Nationalbibliografie; detaillierte bibliografische Daten sind im Internet über http://dnb.d-nb.de abrufbar.

Umschlagkonzept: Kordula Röckenhaus, Bielefeld

Druck: Majuskel Medienproduktion GmbH, Wetzlar

Print-ISBN 978-3-8376-3607-9

PDF-ISBN 978-3-8394-3607-3

Gedruckt auf alterungsbeständigem Papier mit chlorfrei gebleichtem Zellstoff. Besuchen Sie uns im Internet: http://www.transcript-verlag.de Bitte fordern Sie unser Gesamtverzeichnis und andere Broschüren an unter: info@transcript-verlag.de 


\section{Inhalt}

\section{HISTORISCHE VORAUSSETZUNGEN UND \\ KENNZEICHEN DER IDEOLOGISCHEN POLARISIERUNG DER USA}

I. Einleitung: Der Traum von der Versöhnung und die Realität der Spaltung | 9

II. Vorspiel zur Gegenwart: Das Zerbrechen des

Amerikanischen Konsens. Die USA 1964-1980 | 21

Land ohne Ideologien? | 21

Der Strategiewechsel der Demokratischen Partei

und das Southern Realignment I 31

Das „Scheitern“ der Great Society und die Silent Majority I 42

Die Transformation des amerikanischen Liberalismus 147

Culture War: Religion als neue Konfliktlinie I 54

III. Red and Blue America: Kennzeichen der Polarisierung im Zeitalter des Amerikanischen Dissens | 61

Klasse und Kultur: Über das Verschmelzen zweier Konfliktlinien I 61

Partisan Nation: Die Stabilisierung des amerikanischen Elektorats I 65

Expansion und Lagerbildung: Das Comeback der

amerikanischen Parteien und Parteilichkeit als Ordnungsprinzip 170

\section{EXPEDITION IN DAS HERZ DER ECHOKAMMER: DIE WISCONSIN-FELDSTUDIE}

IV. Lebenswelten, Milieus, echo chambers: Zum Prozess gesellschaftlicher Segmentierung in historischer Perspektive | 79

V. Zwei aus Dreitausend: Methodische Vorüberlegungen $\mid 89$

Amerikas Hochburgen: Die Wahltopographie der USA und die Theorie des Big Sort 189

Begründung der Fallauswahl | 100

Methodischer Feldzugang, Materialarten und Datenlage | 105 
VI. Spielfeld und Akteure:

Madison, Wisconsin, Februar 2011 | 111

VII. Die Geburt der Hochburg | 121

Dane County: Von der Counter Culture zur Cyber Culture I 121

„A little piece of land“: Waukesha County und der

Republican Flight | 144

VIII. Die Soziologie der Hochburg | 169

„No one I know voted for Scott Walker":

Soziale Homophilie und Netzwerkhomogenität I 169

Der Effekt der Echokammer:

Gruppenpolarisierung und die

„Radikalisierung“ der Mehrheitskultur | 181

Soziale Kontrolle und die ideologische Durchdringung

der Zivilgesellschaft - oder: Warum es Republikaner

in Dane County schwerer haben $\mid 188$

IX. Die (Lokal-)Politik der Hochburg | 207

Dane County: Polarisierung als Erfolgsstrategie 1210

Waukesha County: Die Tea Party in der Lokalpolitik | 221

X. Zum Schluss:

Sonderweg oder Laboratorium der Zukunft?

Die ideologische Polarisierung der USA als Fall

Paradoxer Individualisierung | 235

\author{
Anhang | 247 \\ Danksagung | 247 \\ Liste der Gesprächspartner I 249 \\ Quellen- und Literaturverzeichnis | 252 \\ Fragebogen der Dane-Waukesha-Polarization-Study (DWPS) I 275
}




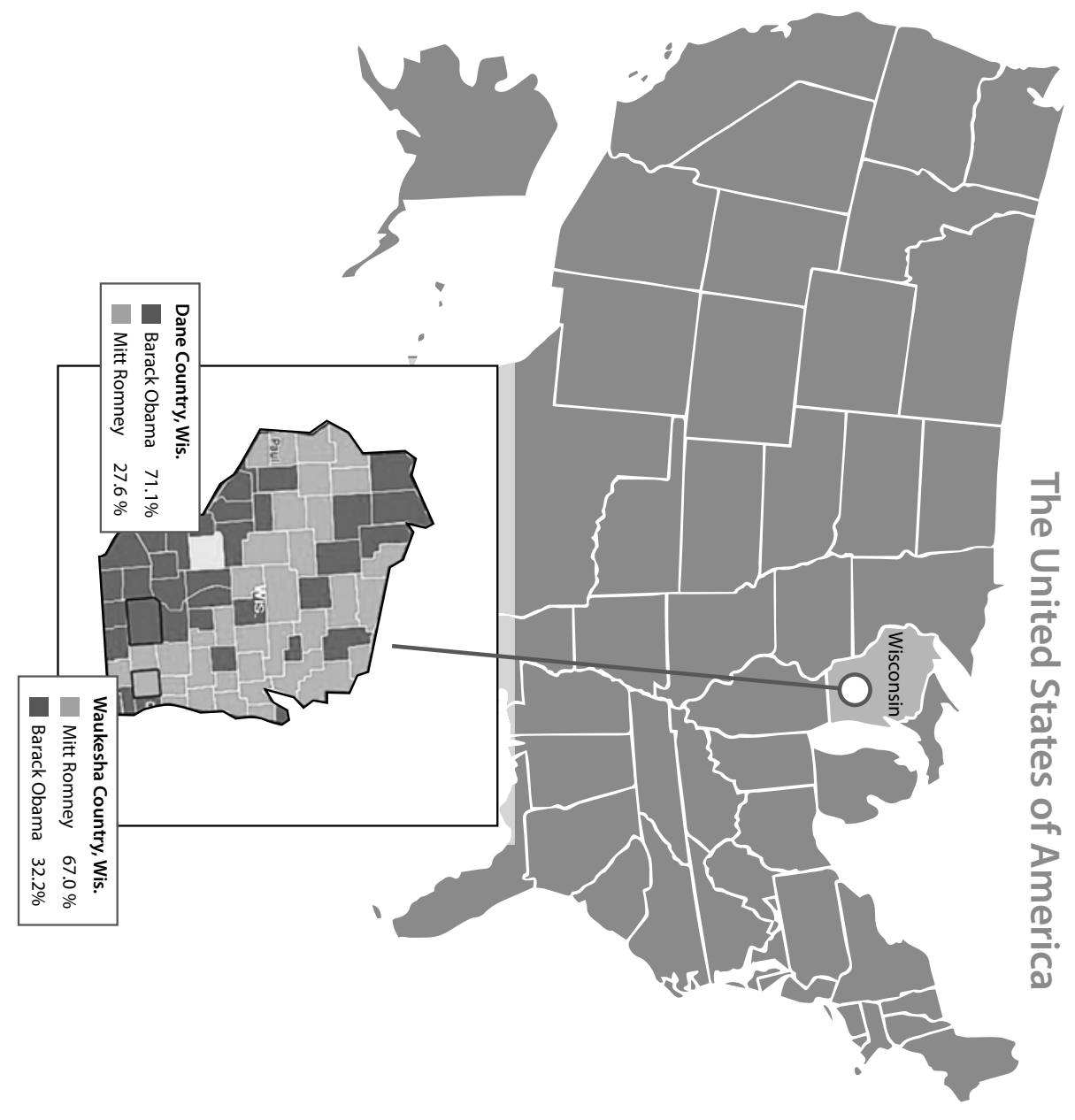


Historische Voraussetzungen und Kennzeichen der ideologischen Polarisierung der USA 


\title{
I. Einleitung: Der Traum von der Versöhnung und die Realität der Spaltung
}

\begin{abstract}
„Now even as we speak, there are those who are preparing to divide us, the spin masters and negative ad peddlers who embrace the politics of anything goes. Well, I say to them tonight, there's not a liberal America and a conservative America; there's the United States of America"1
\end{abstract}

Das Zitat stammt von Barack Obama. Es steht, buchstäblich, ganz am Anfang seiner Karriere. Es sind Sätze aus seiner Rede auf dem Nominierungsparteitag der Demokratischen Partei für John Kerry in Boston 2004, als Obama wohl so plötzlich wie niemand vor ihm auf die Bühne nationaler Politik katapultiert wurde. Er sollte noch viele solcher Sätze in den folgenden vier Jahren sagen: dass die Amerikaner viel mehr eine, als sie trenne; dass die Polarisierung des Landes ein Kunstprodukt sei, erfunden von zynischen Wahlkampfmanagern; dass man eben One Nation Under God sei. Es ist die Erzählung, die ihn bis ins Weiße Haus getragen hat, sie existiert daher in einer beinahe unendlichen Zahl von Varianten.

Vielleicht war das auch der Grund, warum er so lange nicht von ihr lassen konnte - auch dann noch, als jedermann längst sehen konnte, dass die Idee einer großen Versöhnung der politischen Lager eine große Chimäre war. In dem Augenblick jedenfalls, da diese Zeilen geschrieben werden, im Herbst 2015, sind die USA als Nation mindestens so gespalten wie zuvor. Nichts hat sich seit 2008 an der grundsätzlichen Statik der amerikanischen Politik verändert. Bei keinem einzigen seiner innenpolitischen Reformvorhaben konnte Obama Unterstützung aus dem gegnerischen Lager mobilisieren. Als der Kongress 2010 über den „Affordable Care Act" abstimmte, heute allgemein als Obamacare bekannt, da vo-

1 Das Transkript der Rede vom 27. Juli 2004 ist abrufbar unter: http://www. washingtonpost.com/wp-dyn/articles/A19751-2004Jul27.html (zuletzt abgerufen am 28.09.2015) 
tierte nicht ein einziger der 188 republikanischen Abgeordneten im Repräsentantenhaus und keiner der 40 republikanischen Senatoren für den Gesetzesentwurf. Und Obamacare war keine Ausnahme. Von der Sozial- und Wirtschaftspolitik, der Umweltpolitik, über Themen der Gesellschaftspolitik bis hin zur Außenpolitik: nirgendwo haben sich die politischen Lager in der Ära Obama angenähert, sind politische oder gesellschaftliche Koalitionen oder Bündnisse entstanden, die das Lagerdenken überwunden hätten. Stattdessen scheint das Land in einer ausweglosen Endlosschleife von politischen Blockaden gefangen, die selbst mit dem drohenden Staatsbankrott vor Augen nicht mehr aufgelöst werden. Auf dem Capitol Hill, traditionell ein Ort, an dem für die meisten wichtigen Gesetzesvorhaben temporäre, überparteiliche Bündnisse geschmiedet wurden, herrscht heute eine Fraktionsdisziplin, die an das Abstimmungsverhalten von Abgeordneten in den parlamentarischen Regierungssystemen Westeuropas erinnert; für eine solche Frontstellung entlang der Parteilinien freilich ist das amerikanische Institutionensystem mit seinem komplizierten System von „checks and balances“ niemals konzipiert gewesen.

Westeuropa ist in der Tat das Stichwort. Denn in vielerlei Hinsicht scheinen die USA heute ein scharfes Kontrastprogramm zu bieten. Zwar ist von einer Vertrauenskrise der Bürger gegenüber der politischen Klasse auf beiden Seiten des Atlantiks die Rede. Und hier wie da, so ist mancherorts nachzulesen, seien die Profiteure der Krise vor allem populistische Bewegungen und Parteien: von der Tea Party bis zum „Front National““. In Wahrheit allerdings könnten die Unterschiede kaum größer sein. Während man in den USA die unüberbrückbare ideologische Kluft zwischen den Parteien als Ursprung der Systemkrise wahrnimmt und einige prominente Beobachter angesichts der um sich greifenden „Vetocracy“ ernsthaft einen Abbau demokratischer Verfahrensregeln zugunsten technokratischer Entscheidungsprozesse anmahnen², ätzen Europas Intellektuelle über das genaue Gegenteil. Die Kritik gilt der normativen und weltanschaulichen Erschöpfung der etablierten Parteien, dem Mangel an Alternativen, der intellektuellen Armut und Phantasielosigkeit einer politischen Klasse, die die Gegenwart nur noch verwalte. Die beiden vermutlich einflussreichsten Bücher der letzten 10 Jahre über die Krise der politischen Repräsentation in Europa, Colin Crouchs „Postdemokratie“ und Chantal Mouffes „Über das Politische“ nehmen exakt diesen Mangel an substantiellen politischen Unterschieden zwischen den Parteien zum Ausgangspunkt ihrer Kritik. ${ }^{3}$ Mouffe etwa beklagt das Ende des „Modells der Gegnerschaft“

2 Vgl. Francis Fukuyama: America in Decay, in: Foreign Affairs, Vol. 93 (5), 2014, S. 3 26.

3 Vgl. Colin Crouch: Postdemokratie, Frankfurt a. Main, 2003; Chantal Mouffe: Über das Politische. Wider die kosmopolitische Illusion, Frankfurt a. Main 2007. 
durch die programmatische Angleichung der etablierten Parteien. Erst hierdurch habe die simple Dichotomie des modernen Populismus - hier die korrupten politischen Eliten, dort das ehrliche Volk - an scheinbarer Plausibilität gewinnen können. Ein Mangel an Streit als Krisendiagnose - auf der anderen Seite des Atlantiks klingt das wie ein Problem, das man gerne hätte.

Es handelt sich auch nicht um reine Diskursphänomene ohne empirische Basis. Die amerikanische Politik trägt heute tatsächlich jene Kennzeichen einer intensiven, stabilen Lagerpolarisierung, die im „Zeitalter der Ideologien“ die politische Landschaft Europas prägten. In den USA ist es, im Gegensatz zum Trend in den meisten europäischen Demokratien, zu einer Stärkung der ideologischen Profile in der amerikanischen Wählerschaft gekommen: Amerikaner wählen stabil für eine der beiden Parteien, drücke eine hohe Identifikation mit der republikanischen oder demokratischen Partei aus und nehmen viel stärker als in der Vergangenheit ideologisch konsistente Positionen bei Sachfragen ein. Während Europas einst stolze Mitgliederparteien weiter ausbluten, haben sich Amerikas Parteien - traditionell aufgrund ihrer rudimentären Organisation bemitleidet und wegen ihrer weltanschaulichen Inkonsistenz belächelt - zu schlagkräftigen, gesellschaftlich stark verwurzelten, ideologisch fokussierten und von vielen hunderttausend enthusiastischen Basisaktivisten getragenen Organisationen entwickelt. Wenig ist daher auch in den USA die Rede von der Krise konventioneller Formen politischer Beteiligung. Die schroffe Frontstellung zwischen Republikanern und Demokaten hat vielmehr einen Partizipationsschub ausgelöst. Nicht nur wiesen die Präsidentschaftswahlen 2008 und 2012 die höchste Beteiligung seit den 1960er Jahren aus. Mehr Amerikaner als in der Vergangenheit spenden heute auch Geld für Wahlkämpfe, klopfen an die Türen ihrer Nachbarn, um sie von der Wahlentscheidung zu überzeugen oder tragen zumindest einen Sticker an der Brust, mit dem sie ihre Unterstützung für einen Kandidaten zum Ausdruck bringen. Überdies hat sich das gesamte politische System entlang des liberal vs. konservativ-Kontinuums polarisiert. Orte allgemein akzeptierter politischer Neutralität und damit auch Autorität sind praktisch verschwunden. Stattdessen: Ein Supreme Court, der zum umkämpften Schauplatz fundamental anderer Auslegungen der amerikanischen Verfassung geworden ist; Interessengruppen und Lobby-Organisationen, die für ihre Anliegen nur noch die Klinken der einen Partei putzen; ein Mediensystem, in dem klar parteilich ausgerichtete Formate - seien es die großen Kabelnachrichtensender oder politische Blogs im Internet - den Markt mittlerweile dominieren.

Im Grunde aber verkörpert das politische Schicksal Barack Obamas - und zwar im Guten wie im Schlechten - am eindringlichsten, aus welch unterschiedlichen Stoffen die Politik auf beiden Seiten des Atlantiks derzeit gewoben wird. Was sich zwischen Barack Obama und seiner Anhängerschaft zwischen 2004 und 
2008 vollzog, das erinnert tatsächlich an jenen Prozess emotionaler Vergemeinschaftung, für den Max Weber den Begriff des Charisma ursprünglich in den sozialwissenschaftlichen Diskurs eingeführt hat ${ }^{4}$ - und wie man ihn sich für die europäischen Gesellschaften der Gegenwart nur noch schwer vorzustellen vermag. Wohlgemerkt ist dabei nicht von jenem Charisma die Rede, mit dem heute inflationär noch jeder belegt wird, der irgendwann einmal als auch nur mittelmäßig kommunikativ oder telegen aufgefallen ist. Wer Charisma verstehen will, der muss nicht den Träger des Charismas studieren, sondern die Sehnsüchte und Bedürfnisse der Anhänger, die ihm diese Wirkung zuschreiben. Im Weberschen Sinne bedeutet Charisma schließlich: eine als außeralltäglich wahrgenommene "Gnadengabe“, durch die Anführer eine Form von Heiligkeit und Auserwähltheit zugesprochen bekommen, die sich in primitiven oder traditionellen Gesellschaften noch im Besitz von Schamanen oder Propheten befand, in modernen Gesellschaften jedoch nur noch höchst selten und nur in akuten Krisensituationen auftaucht. Wenn alle überkommenen Methoden und Regeln erschöpft sind, das etablierte Personal abgewirtschaftet und mit seinem Latein am Ende ist - dann erst schlägt die Stunde des Charismatikers. Von dieser Transzendenzerwartung rührte die sakrale Stimmung auf den Massenkundgebungen Obamas 2008, bei denen man kein Religionssoziologe zu sein brauchte, um die Ähnlichkeit mit Gottesdiensten zu erkennen - einschließlich dem von der "Gemeinde“ laut gesprochenen Glaubensbekenntnis „YES WE CAN“ am Ende jedes Absatzes seiner „Predigten.“ Einmal in dieser Zeit des atemlosen politischen Taumels der amerikanischen Linken registrierte der Comedian Jon Stewart konsterniert in der „Daily Show“ (dem heimlichen Lagerfeuer des liberalen Amerika), dass das Publikum im Studio bei Obama-Witzen sich offensichtlich nicht mehr recht traute, zu lachen. In der charismatischen Konstellation wird, um sich eine Unterscheidung Emil Durkheims zu borgen, plötzlich wieder heilig, was zuvor noch profan erschien. ${ }^{5}$

Und es gehört zur bitteren Ironie dieser Geschichte, dass es gerade Obamas Charisma war, das anstatt einer Aussöhnung zwischen den politischen Lagern eher für eine Eskalation der Polarisierungsdynamik sorgte. Denn die großen Erwartungen auf große Veränderungen innerhalb der Gemeinde des Charismatikers, von Weber als „revolutionäre Macht“ bezeichnet, müssen bei allen anderen zwangsläufig Ängste und Befürchtungen vielerlei Art auslösen. Es ist daher nicht nur so, dass Charismatiker zu Lebzeiten stets polarisierende Figuren sind - Messias für die einen, Gottseibeiuns für die anderen. Charisma wächst eben auch nur auf dem

4 Vgl. Max Weber: Wirtschaft und Gesellschaft. Grundriss der verstehenden Soziologie, Tübingen 1972, S. 140ff.

5 Vgl. Emil Durkheim: Die elementaren Formen des religiösen Lebens, Frankfurt am Main 2007. 
Grund polarisierter, aufgewühlter und zerrissener Gesellschaften. Man braucht schließlich scharfe Kontraste: strahlende Helden und wirklich finstere Schurken; eine als miserabel empfundene Gegenwart und die Möglichkeit einer leuchtenden Zukunft, die gleichzeitig anders und um einiges besser ist als der Ist-Zustand. ${ }^{6}$

So war Obamas Mission der Versöhnung der politischen Lager von vornherein zum Scheitern verurteilt. Die amerikanische Politik war polarisiert lange vor Beginn seiner Präsidentschaft; und sie wird es noch eine ganze Weile bleiben, ganz gleich, wer ab Januar 2017 als Hausherr in 1600 Pennsylvania Avenue residiert. Die Neigung der Medien zur Personalisierung struktureller Probleme verdeckt eine im Grunde banale Tatsache: wo die ideologischen Unterschiede wirklich substantiell sind, wo sich politische Lager mit markanten, ja unversöhnlichen weltanschaulichen Gegensätzen gegenüberstehen, da verhallen alle Rufe nach Moderation und Mäßigung, nach Kooperation und Konsens gänzlich ungehört. Die politische Klasse der USA verharrt deswegen in einem so zähen ideologischen Stellungskrieg, weil dies die strukturellen Realitäten eines tatsächlich ideologisch gespaltenen Landes widerspiegelt - so gesehen erfüllen die Abgeordneten des amerikanischen Kongresses ihren Repräsentationsauftrag wirklich perfekt. Die Demokraten und Republikaner von Washington werden von Menschen gewählt und in die Hauptstadt entsandt, die die Welt aus fundamental anderen Blickwinkeln betrachten und deren Realitätswahrnehmungen in extremer Weise divergieren. Denn es ist nicht einfach so, dass Republikaner und Demokraten, Konservative und Liberale, für die Probleme des Landes jeweils andere Lösungen präferieren. Es gibt vielmehr völlig unterschiedliche Vorstellungen darüber, worin die Probleme des Landes eigentlich überhaupt bestehen. Welchen Sinn aber soll es haben, nach einem Kompromiss für Maßnahmen gegen den Klimawandel zu suchen, wenn doch eine der beiden Seiten diesen Klimawandel für einen einzigen aber dafür umso gewaltigeren Schwindel hält?

Viel gravierender noch als die Einstellung zu eingrenzbaren politischen Sachfragen ist die Tatsache, dass das liberale und konservative Amerika mittlerweile sehr unterschiedliche Erzählungen darüber pflegen, was den Kern des Landes ausmacht, wofür es stehen sollte und welche Richtung daher einzuschlagen ist. In der Erzählung der einen Seite, des liberalen Amerika, sind die USA ein wunderbares Versprechen - das jedoch in der Geschichte oft genug uneingelöst blieb, von der Vernichtung der Kultur der Ureinwohner, der Sklaverei bis hin zu den vielen Opfern eines ungezügelten Kapitalismus. Amerika, so geht diese Erzählung weiter, kam seinen Idealen immer dann am nächsten, wenn es sich aufmachte, diese Un-

6 Vgl. Torben Lütjen: Barack Obama und das Charisma der Fremdheit, in: Universitas, September 2012, Heft 9, S. 19-27. 
gerechtigkeiten zu beseitigen. Aus diesem Kampf sind folgerichtig die Heldenfiguren des amerikanischen Liberalismus geboren: Abraham Lincoln, Franklin D. Roosevelt, Martin Luther King, die Kennedy-Brüder - die mit einer Ausnahme allesamt den Märtyrer-Tod sterben. Manches wurde so erreicht; doch viele andere Ungleichheiten bestehen fort. Ein aktiver Staat muss daher dafür sorgen, dass der ungezügelte Kapitalismus des Landes gezähmt, die Reichen höher besteuert und der Sozialstaat ausgebaut wird. Außerdem muss er sicherstellen, dass Frauen, Homosexuellen und ethnischen Minderheiten die gleichen Chancen eingeräumt werden.

Dann ist da noch eine andere Erzählung. Es ist jene des konservativen Amerika. Nach dieser Erzählung waren die USA einmal das Land der Freiheit, Zufluchtsort all jener, die vor den Feudalregimen und späteren Diktaturen Europas geflohen waren, um dort ein Leben jenseits staatlicher Autorität und Repression zu führen. So blühte das Land, prosperierte, schuf Reichtum für alle oder zumindest die Möglichkeit dazu, wurde zum leuchtenden Beispiel der Welt - eine verwirklichte, gelebte Utopie. Dann aber, irgendwann in der ersten Hälfte des 20. Jahrhunderts, erfolgte der Sündenfall. Gegründet als lockere Föderation souveräner Einzelstaaten, riss die Zentralregierung in Washington immer weitere Politikund Lebensbereiche an sich, und implementierte ein konfiskatorisch motiviertes Steuersystem, das versuchte, den Reichtum von oben nach unten umzuverteilen was fundamental den Prinzipen des amerikanischen Traums wiederspricht, nach denen jeder, der hart genug arbeitet, reüssieren kann. Später dann verfiel auch die öffentliche und private Moral: Amerikas Familien zerbrachen, die Kriminalität weitete sich aus. Amerika verlor buchstäblich seinen Glauben, als immer mehr Bürger sich von den Prinzipien des Christentums abwendeten. Schließlich, der letzte Schritt in diesem Szenario des Niedergangs, wurde Amerika zu schwach, zu weich, zu dekadent, um seinen äußeren Feinden noch entschlossen entgegenzutreten, weshalb sich im Nahen Osten und anderswo eine Niederlage an die andere reiht. Das Antidot zum „American Decline“ ist schnell benannt: der Staat muss zurückgedrängt, die private Selbstinitiative gestärkt, die öffentliche Moral wiederhergestellt werden.

Diese Arbeit versucht zu ergründen, wie es dazu kam, dass Amerika in zwei Lager zerfiel, deren Erzählungen nicht länger miteinander kompatibel sind. Den Konflikt auf diese Weise zu schildern, deutet die grobe Richtung meiner Antwort bereits an. Entgegen einer mittlerweile zwar minoritären, doch noch immer einflussreichen Strömung innerhalb der amerikanischen Politikwissenschaft halte ich die ideologische Polarisierung der USA keineswegs nur für ein Phänomen, das auf die Einstellungen der politischen Klasse begrenzt ist. 
Besonders die Arbeiten von Morris Fiorina, allen voran sein Buch „Culture War? The Myth of a Polarized America“" ${ }^{\text {, }}$, haben zwischenzeitlich die These populär gemacht, wonach Amerikas tiefe ideologische Spaltung im Grunde ein reines Elitenphänomen sei: Während Demokraten und Republikaner in Washington sich in ihren ideologischen Schützengräben verschanzt hätten, gäbe es in der amerikanischen Gesellschaft noch immer eine breite Mitte, die ideologisch moderate Positionen vertritt. Im Grunde genommen ist dies die politologische Variante von Obamas Losung einer in Wahrheit gar nicht gespaltenen Nation. Sie klingt schon intuitiv unwahrscheinlich, weil sie, konsequent zu Ende gedacht, auf eine nun bereits mehrere Jahrzehnte währende Lücke politischer Repräsentation hinauslaufen würde. Dafür hat sie etwas ungemein Tröstliches, da sie hoffen lässt, das Ganze sei ein Betriebsunfall, den man ungeschehen machen könnte, wenn man einige der falschen Anreizstrukturen in der politischen Wettbewerbsordnung beseitigt.

Tatsächlich gibt es mittlerweile eine Fülle von erdrückenden empirischen Belegen, die Fiorina widerlegen und die in dieser Arbeit auch noch genauer dargestellt werden (vgl. Kap. 3). Gleichwohl hat dies nichts daran geändert, dass der Mainstream der Forschung weiterhin institutionelle Gründe - in einem weiten Sinne definiert - für die Spaltung des Landes verantwortlich macht. Als Erklärung dient dabei z.B. das amerikanische Vorwahlsystem, durch welches es einer Minderheit radikaler Basisaktivisten gelungen sei, den Nominierungsprozess der Parteien zu kontrollieren. ${ }^{8}$ Andere machen die Manipulation der Kongressbezirke hierfür verantwortlich, das so genannte gerrymandering, da so künstliche Wählerhochburgen entstanden seien, deren Repräsentanten auf Minderheitsmeinungen keine Rücksicht mehr zu nehmen hätten. ${ }^{9}$

7 Vgl. Morris P. Fiorina/ Samuel J. Abrams/Jeremy C. Pope: Culture War? The Myth of a Polarized America, New York 2005.

8 Vgl. u.a. David Brady/Hahrie Han/Jeremy C. Pope: Primary Elections and Candidate Ideology: Out of Step with the Primary Electorate? , in: Legislative Studies Quarterly, 32, 2007: S. 79-105; Bary Burden: The Polarizing Effects of Congressional Primaries, in: P. F. Galderisi/M. Lyons (Hg.): Congressional Primaries and the Politics of Representation, Baltimore 2001; Barry Burden: Candidate Positioning in US Congressional Elections, in: British Journal of Political Science 34, 2004:S. 211-227.

9 Vgl. u.a. Jamie L. Carson/Michael H. Crespin/Charles J. Finocchiaro/David W. Rohde: Redistricting and Party Polarization in the U.S. House of Representatives, in: American Politics Research, Vol. 35 (6), 2007, S. 878-904; Sean M. Theriault: Party Polarization in Congress, New York 2008. 
Eine weitere Erklärung ist der immense Geldfluss in der amerikanischen Politik, durch den sich ideologisch extrem eingestellte Interessengruppen ungebührend Gehör verschafft hätten. ${ }^{10}$ Außerdem wurde argumentiert, dass durch eine Reihe von Änderungen der Geschäftsordnung im Kongress die Macht der Parteiführungen gestiegen sei, die so von ,ihren“ Abgeordneten eine stärkere Parteidisziplin einfordern könnten. ${ }^{11}$ Alle diese Erklärungen sind intensiv diskutiert worden; und gegen alle existieren gewichtige Gegenargumente. ${ }^{12}$ Es ist so in jedem Fall eine nachgerade monumentale Literatur zum Thema zusammengetragen worden, angesichts derer ein Forscher schon vor einigen Jahren resignierte, dass sie von keinem Literaturbericht mehr auch nur annährend erfasst werden könne. ${ }^{13}$

Die Sache ist zum Glück die: Es muss an dieser Stelle gar nicht entschieden werden, welche dieser Argumente mehr Erklärungskraft besitzen als andere. Es kann schon sein, dass manche dieser Faktoren einen Beitrag zur Polarisierung zwischen den Parteien geleistet haben. Gleichzeitig aber erscheinen sie allesamt unbefriedigend, weil sie nicht die spezifische Natur des Konfliktes deutlich machen: die starke affektive und moralische Aufladung der Auseinandersetzung, das manichäistische Weltbild, das auf beiden Seiten anzutreffen ist, und durch welches sich das Land in Freund und Feind geteilt hat. Vor allem aber hilft keine dieser Erklärungen zu verstehen, warum sich heute in den USA zwei ideologische Lager gegenüberstehen, deren Anhänger längst in alternativen Diskurs-Universen leben, wenngleich die bizarrsten Auswüchse vor allem bei einer Seite zu beobachten sind. Wer begreifen will, warum $43 \%$ der Anhänger der Republikanischen Partei Barack Obama auch im September 2015 weiterhin für einen Muslim halten ${ }^{14}$, dem hilft das Studium der Geschäftsordnung des amerikanischen Kongresses nicht wirklich weiter. Beim Betrachten der USA der Gegenwart fühlt man sich häufiger

10 Vgl. Lawrence Lessig: Republic Lost: How Money Corrupts Congress - and a Plan to Stop it, New York 2011.

11 Vgl. u.a. Gary Cox/Mathew McCubbins: Setting the Agenda: Responsible Party Government in the U.S. House of Representatives, New York 2005.

12 Vgl. für die derzeit aktuellste Zusammenfassung, inklusiver knapper Literaturhinweise, Michael J. Barber/Nolan McCarty: Causes and Consequences of Polarization, in: Nathaniel Persily: Solutions to Political Polarization in America, Cambridge 2015, S. 15-58.

13 Vgl. Matthew S. Levendusky: The Microfoundations of Mass Polarization, in: Political Analysis, 17 (2009): S. 162-176, hier: S. 163.

14 Vgl. Sarah Pulliam Bailey: A startling number of Americans still believe President Obama is a Muslim, in: Washington Post vom 14. September 2015, https://www. washingtonpost.com/news/acts-of-faith/wp/2015/09/14/a-startling-number-of-ameri cans-still-believe-president-obama-is-a-muslim/ (zuletzt abgerufen am 22.09.2015) 
an einen berühmten Satz Pascals aus dem 17. Jahrhundert erinnert: „Wahrheit diesseits der Pyrenäen, Irrtum jenseits. " ${ }^{15}$ Im Informationszeitalter sind Gebirgsketten kein Grund mehr für solche Divergenzen, doch bedeutet das offensichtlich nicht, dass das Phänomen radikal anderer Wahrnehmungen von Realität aufgehört hätte zu existieren.

In dieser Arbeit wird daher primär ein soziokultureller bzw. wissenssoziologischer Ansatz verfolgt. Die Wurzeln ideologischer Polarisierung werden dort gesucht, wo diese unterschiedlichen Realitätswahrnehmungen ihren Ursprung haben: in den diese Realität konstruierenden konservativen bzw. liberalen Lebenswelten. Amerikas tiefe ideologische Spaltung, so die These dieser Arbeit, verdankt sich der massenhaften Ausweitung von sozialen Räumen, in denen vor allem Gleichgesinnte miteinander kommunizieren. In der populären Zeitdiagnostik und zunehmend auch in den Sozialwissenschaften - hat sich zur Beschreibung dieser Arten von Räumen der Begriff der „echo chamber“, der Echokammer etabliert: schalldichte Räume, in die von außen kaum etwas hineindringt, während im Inneren die bereits vorhandenen Stimmen um ein Vielfaches verstärkt werden. In Echokammern kann es daher zu einem Prozess kommen, der in der Sozialpsychologie als Gruppenpolarisierung bekannt ist: Aufgrund des fehlenden Widerspruchs werden die bestehenden mentalen Dispositionen verstärkt, und die Gruppenmeinung bewegt sich in Richtung ihres ideologisches Poles. ${ }^{16}$ Es gibt für die USA derzeit eine Fülle von Beispielen für die Existenz und auch die rasante Verbreitung solcher Echokammern. Die erste gedankliche Assoziation führt fraglos in den Bereich der sozialen Medien und auch der sozialen Netzwerke. Schließlich waren diese vor nicht allzu langer Zeit noch mit großen Erwartungen auf eine bessere, transparentere, deliberativere Form von Demokratie verknüpft - gelten mittlerweile jedoch als Sammelplatz gesellschaftlicher Ressentiments und als Vehikel der ungehemmten Triebabfuhr unter Gleichgesinnten.

In dieser Arbeit aber wird es nicht um virtuelle Echokammern gehen, sondern vielmehr um jene der realen, physisch erfahrbaren Welt: im Mittelpunkt der Arbeit steht eine Fallstudie über zwei Counties in Wisconsin, einem Bundesstaat im Mittleren Westen der USA. Eines dieser beiden Counties, Dane County, ist eine extreme Hochburg der Demokratischen Partei - Barack Obama hat dort 2012 über

15 Blaise Pascal: Gedanken. Mit einem Kommentar von Eduard Zwierlein, Berlin 2012, S. 63.

16 Vgl. Serge Moscovi/Marisa Zavalloni: The Group as a Polarizer of Attitudes, in: Journal of Personality and Social Psychology, Vol. 12 (2) 1969: S. 125-135; in jüngerer Zeit Cass S. Sunstein: Going to Extremes - How Like Minds Divide and Unite, Oxford 2009. 
$71 \%$ der Stimmen erhalten. Nur 30 Meilen östlich von Dane County liegt Waukesha County, dass so republikanisch und konservativ ist wie Dane County demokratisch und liberal ist. Dort hat Mitt Romney bei der Präsidentschaftswahl 2012 $67 \%$ der Stimmen geholt. Dane und Waukesha County stehen gleichwohl nur für einen allgemeineren Trend: In den USA hat sich die Zahl politischer Hochburgen in den letzten drei Jahrzehnten rasant erhöht. Es sind Orte wie das liberale Dane und das konservative Waukesha County, die die Wahrnehmungen und Weltsichten der Parteianhänger beider Seiten prägen. Um mit Pascal zu sprechen: Was in Dane die Wahrheit ist, das ist in Waukesha der Irrtum.

Interessant aber sind Dane und Waukesha - und mit ihnen andere politische Hochburgen - vor allem aus einem sehr spezifischen Grund. Hinter ihnen verbirgt sich möglicherweise ein Phänomen, dessen Verständnis unsere Ansichten über das Verhältnis von Ideologie und Moderne insgesamt modifizieren könnten. Denn es wird vermutet, dass die rasante Ausbreitung politischer Hochburgen das Resultat eines gewaltigen, inneramerikanischen Migrationsprozesses ist: immer mehr Amerikaner entscheiden sich bei einem Umzug, fortan in der Nachbarschaft von Gleichgesinnten zu leben: Demokraten also ziehen in die Nachbarschaft anderer Demokraten, Republikaner dorthin, wo bereits viele andere Republikaner wohnen. Dieser Prozess, den der Publizist Bill Bishop und der Soziologe Robert Cushing als „Big Sort ${ }^{617}$ bezeichnet haben, muss nicht direkt aus politischen Gründen geschehen, kann viel mehr die Nebenfolge stark voneinander abweichender Lebensstilpräferenzen sein, die allerdings aufs engste mit ideologischen Orientierungen korrelieren. Wenn aber die These von der Binnenmigration als Grund für die Ausbreitung von Räumen von Gleichgesinnten zutreffend ist, dann haben wir es mit einem Prozess der ideologischen Selbstselektion zu tun. Amerikas Echokammern sind, mit anderen Worten, Orte einer ganz bewussten und selbst gewählten Perspektivverengung, damit letztlich das Resultat eines forcierten Individualisierungsprozesses. Das aber steht ganz offenkundig im Widerspruch zu einem noch immer deutungsmächtigen Strang der Gegenwartssoziologie sowie der populären Zeitdiagnostik insgesamt. Denn hier dominiert die Ansicht, dass Individualisierung ja gerade zur Entbindung führt, zur Loslösung aus kollektiven Strukturen, damit aber fraglos auch zum Verschwinden jener homogenen, weltanschaulich durchtränkten Lebenswelten, um die es in der Folge gehen soll.

Und zugegeben: Das alles klingt zunächst durchaus plausibel - denkt man etwa an den Zusammenhang zwischen der Erosion soziokultureller Milieus und dem Verlust der Parteien an weltanschaulicher Orientierung in der deutschen So-

17 Vgl. Bill Bishop/Robert Cushing: The Big Sort. How the Clustering of Like-Minded Americans ins Tearing us Apart, New York 2008. 
zialgeschichte. Doch ausgerechnet in den USA, der vermutlich am stärksten individualisierten Gesellschaft überhaupt, haben die Bürger den Zuwachs an Optionen und die gesteigerten Möglichkeiten zur Autonomisierung der eigenen Lebensführung möglicherweise nicht dazu genutzt, um fröhlich-postmodern zwischen den verschiedenen Sinnangeboten zu flottieren, sondern all die Freiheit vielmehr zur freiwilligen Optionsverengung und Selbstbeschränkung eingesetzt. Was sich in Dane und Waukesha County vollzieht - und natürlich anderswo im Land - könnte man als Paradoxe Individualisierung bezeichnen: Man wählt, nicht ständig die Wahl zu haben, entscheidet sich damit für ein Leben in maximaler Eindeutigkeit.

So könnte es jedenfalls sein. In Wahrheit nämlich wissen wir nämlich nur sehr wenig über das Innenleben dieser Hochburgen, was gewiss auch etwas mit der methodischen Ausrichtung nicht nur der amerikanischen Politikwissenschaft zu tun hat. Daher wird sich diese Arbeit auf eine Expedition nach Dane und Waukesha County begeben. Dabei soll mit Hilfe der Kombination einer ethnographischen Feldstudie mit den Daten einer eigens für diese Studie konzipierten und in Auftrag gegebenen repräsentativen Umfrage die Black Box politischer Hochburgen geborgen werden.

$\mathrm{Zu}$ alledem ist selbstverständlich viel mehr zu sagen. Doch weitere theoretische Implikationen, und dann natürlich vor allem die methodische Herangehensweise an die Feldstudie, sollen später erläutert werden. Diese Vertagung begründet sich durch den Aufbau der Arbeit. Denn es wäre ein wenig anmaßend, zu behaupten, die ideologische Spaltung der USA allein mit zwei Counties im Mittleren Westen der USA erklären zu können. Daher werde ich in Kap 2. zunächst mit einer historischen Vogelperspektive beginnen: es soll darum gehen, die historischen Bruchlinien und veränderten Konfliktachsen in der amerikanischen Gesellschaft und der amerikanischen Politik in den Jahren von ca. 1964-1980 nachzuzeichnen. Es ist eine zeitliche Periode, die man als die Sattelzeit der amerikanischen Polarisierung bezeichnen kann. In diesen Jahren wurden die Weichen gestellt für eine viel deutlichere ideologische Abgrenzung von Demokraten und Republikanern, die sich damals als Parteien nachgerade neu erfanden. Mit dieser allgemeinen Geschichte sollte man vertraut sein, auch deswegen, weil es sonst unmöglich wäre, das Denken und den Horizont der Akteure meiner späteren Feldstudie angemessen zu verstehen. Kap. 3 wird dann die Resultate dieser Jahre der Umwälzung in Augenschein nehmen: das Ineinandergreifen und das Verschmelzen verschiedener Konfliktlinien; die Stabilisierung des amerikanischen Elektorats und die Stärkung der Parteibindungen; und schließlich die Revitalisierung der amerikanischen Parteien. 
Das wird deutlich machen, dass Amerikas Politik und Gesellschaft heute tatsächlich einige jener Kennzeichen von ideologischer Polarisierung tragen, die früher einmal Europa im „Zeitalter der Ideologien“ prägten.

Dann schließlich wird von dieser Vogelperspektive allmählich nach Wisconsin hineingezoomt. Es folgt also die Feldstudie. In Kap 4 werden die theoretischen Prämissen noch einmal vertieft, insbesondere in Bezug auf historische Vorläufer und Analogien zum Konzept der Echokammer. Auch die These der Paradoxen Individualisierung soll dort genauer vorgestellt werden. In Kap. 5 wird ein Überblick zum Thema politischer Hochburgen in den USA gegeben, die Fallauswahl begründet und der methodische Feldzugang sowie die Material-und Datenlage der Studie beschrieben. Kap. 6 stellt einen erzählerischen Einstieg ins Thema dar, eine Art Exposition über die Orte der Studie, die Akteure, um die es dabei geht und den Diskursraum, den sie „bewohnen“. Denn im Winter 2011 kam es in Wisconsin zu einem Konflikt, der aus dem Badger State eine Art Ground Zero der amerikanischen Polarisierungsdebatte machte, als 100000 Demonstranten wochenlang gegen die Politik des republikanischen Gouverneurs Scott Walker demonstrierten. Zumindest die Grundumrisse dieses Konfliktes sollte man kennen, da er für die Akteure der Studie eine besondere Bedeutung hat.

Schließlich folgt der empirische Teil der Feldstudie, der sich in drei Teile unterteilt: Kap. 7 handelt von der Geburt der Hochburg und soll vor allem aufzeigen, dass Migration tatsächlich eine bedeutende Rolle in der Entwicklung von Dane und Waukesha zur demokratischen bzw. republikanischen Hochburg spielte. Kap. 8 beschäftigt sich mit der Soziologie der Hochburg: wie undurchlässig für abweichende Meinungen sind die Wände dieser Echokammer, und kommt es dabei tatsächlich zu einem Prozess der Gruppenpolarisierung? Wie unterscheiden sich Demokraten in Hochburgen von solchen in der Diaspora? Und wie stark durchdringt die Ideologie der „Mehrheitskultur“ das soziale und gesellschaftliche Leben dort? Kap. 9. schließlich widmet sich der Politik der Hochburg: Welche Art von Lokalpolitik wird im Zeitalter der Polarisierung an Orten betrieben, die politisch so einseitig sind? Wird auch sie zum Schauplatz ideologischer Konflikte, oder bleibt die lokale Politik am Ende doch ein Hort des pragmatischen Miteinanders?

Am Ende dieser Expedition soll so ein Bild entstehen, das den spezifischen Beitrag politischer Hochburgen zur Polarisierung der amerikanischen Politik deutlich macht. 


\section{Vorspiel zur Gegenwart: Das Zerbrechen des amerikanischen Konsens. Die USA 1964-1980}

\section{LAND OHNE IDEOLOGIEN?}

Die zentrale These dieser Arbeit lautet also, dass ideologischer Konflikt ganz primär als Resultat der Entstehung von homogenen Lebenswelten zu verstehen ist, die sich gegenseitig voneinander abgeschottet haben und deren Bewohner daher andere Erfahrungen sozialer Wirklichkeit machen und somit schließlich auch anderen Realitätsinterpretationen folgen. Und doch hieße es, diese primär soziokulturelle bzw. wissenssoziologische Sichtweise auf die Entstehung von Ideologie und ideologischem Konflikt zu weit zu treiben, wenn man davon ausginge, dass dieser Prozess völlig ohne die Deutungskraft politischer Eliten auskäme, ohne die Intellektuellen als Haupt-Produzenten von Ideologie, ohne die Kommunikationsund Multiplikationsleistung von Parteien und anderen politischen Organisationen. Kurzum: Es käme schon einer Hybris gleich, die ideologische Polarisierung der USA ohne jeden historischen Vorgriff allein mit einer Studie zweier Counties im Mittleren Westen der USA erklären zu wollen. Aus diesem Grunde steht also vor Wisconsin und vor der Expedition in Amerikas politische Hochburgen noch eine andere, allgemeinere Geschichte: wie einem Land, das bis in die 1960er Jahre als Musterbeispiel einer stark konsensual geprägten Gesellschaft galt, dieser Konsens abhandenkam und eine Ära des ideologischen Konfliktes begann. Im Grunde kann man diese Umbruchszeit ziemlich genau lokalisieren: Sie reicht in etwa von der Zäsur des Jahres 1964 und der „Great Society“ Lyndon B. Johnsons bis zum Einzug Ronald Reagans ins Weiße Haus 1980. In diesen Jahren schält sich jene Konfliktmatrix heraus, die auch heute noch das Denken und Handeln der Parteianhänger und Ideologen beider Seiten so maßgeblich bestimmt - ob in Wisconsin oder anderswo. 
Wer allerdings beschreiben will, wie der „American Consensus“ zerbrach, der muss zunächst einen Schritt zurückgehen und mit einer anderen Frage beginnen: Gab es diesen Konsens jemals wirklich, oder ist er nur ein Mythos? Stimmt also die Binsenweisheit, wonach die USA sich historisch durch weniger ideologisch motivierten Konflikt auszeichneten aus als andere westliche Gesellschaften? Es ist eine verwickelte, komplizierte Frage, bei der vieles von Definitionen abhängt und es daher schnell zu Missverständnissen kommen kann. ${ }^{1}$ Eine lange Tradition hat sie in jedem Fall. Auch hier lässt sich, wie bei wohl so ziemlich allem anderen, mit Tocqueville beginnen, der schon in den 1830er Jahren feststellte, dass, ganz im Gegensatz zu seinem Heimatland Frankreich, ,in den Vereinigten Staaten politische Körperschaften nie dermaßen in allgemeine Ideen verliebt $[\ldots]$ gewesen sind; nie begeisterte sich das ganze amerikanische Volk in gleicher Weise wie das französische des 18. Jahrhunderts für diese, und nie zeigte es einen so blinden Glauben an den Wert und die unbedingte Wahrheit irgendeiner Theorie." ${ }^{2}$ Amerikaner, so Tocqueville, hatten es „,nicht nötig, ihre Denkweise den Büchern zu entnehmen; sie fanden sie in sich selbst. ${ }^{\text {‘3 }}$ Das lag nach Ansicht des Franzosen nicht so sehr in ihrer individualistischen Werthaltung begründet. Vielmehr war es die ausgebliebene Revolution und die Tatsache, dass sie bereits als freie Menschen in der Neuen Welt angekommen seien: insofern habe es keiner Theorie bedurft, keiner großen Ideen, um nach der Legitimation für den Sturz einer überkommenen Ordnung zu suchen.

In der Tradition Tocquevilles haben viele den vermeintlich pragmatischen, ideologiefreien Charakter des Landes beschreiben - wohlgemerkt stets vor dem Hintergrund des weltanschaulich zerklüfteten Europas. Auch Karl Mannheim, der 1929 mit seinem Buch „Ideologie und Utopie“ mit der Wissenssoziologie das moderne Analyseinstrument zum Verständnis der Ideologien einführte, hielt die Amerikaner für immun gegenüber großen Plänen. Dort schließlich habe es nie die für europäische Gesellschaften so charakteristische Spannung zwischen Idee und Wirklichkeit gegeben. Mannheim sprach vom ,amerikanischen Bewusstsein“ als einer Geisteshaltung, die primär mit der „organisatorisch-technischen Wirklichkeitsbeherrschung" befasst sei, und wenig Gedanken an radikale Transformationen verschwende. ${ }^{4}$ In eine ganz ähnliche Richtung gingen in den 1960er Jahren auch die Überlegungen des italienischen Politikwissenschaftler Giovanni Sartori,

1 Vgl. John Higham: The Cult of the „American Consensus”: Homogenizing Our Past, in: Commentary, 27, February 1959, S. 93-101.

2 Vgl. Alexis de Tocqueville: Über die die Demokratie in Amerika. Beide Teile in einem Band, Deutscher Taschenbuch-Verlag, München 1976, S. 502.

3 Ebd., S. 488.

4 Vgl. Karl Mannheim: Ideologie und Utopie, Bonn 1929, S. 240-241. 
der zwischen „rationalistischen“ Kulturen einerseits und „empiristischen“ Kulturen anderseits unterschied. In rationalistischen Kulturen werde primär deduktiv gedacht: die Doktrin sei wichtiger als die Praxis, das Ziel wichtiger als die Mittel zu dessen Erreichung, Scheitern würde mit einer falschen Praxis erklärt. Anders die Kulturen des Empirismus. Sie gingen primär induktiv vor: Praxis sei wichtiger als Doktrin, die Mittel wichtiger als das Ziel, für ein Scheitern werde daher die Fehlerhaftigkeit der Theorie verantwortlich gemacht. Kulturen des Empirismus waren für Sartori die angelsächsischen Demokratien, Beispiele für Kulturen des Rationalismus Frankreich oder auch Deutschland. Die USA waren demnach - potentiell - ideologiefrei, während Frankreich und Deutschland eine ,ideological mentality“ besäßen. Es war nicht schwer zu erkennen, welcher Kultur Sartori den Vorzug gab. ${ }^{5}$

Und Legion sind natürlich all die ungezählten Charakterisierungen der prinzipiellen Prinzipienlosigkeit der amerikanischen Parteien. Tocqueville lästerte über sie ebenfalls bereits in „Demokratie in Amerika“: „Als große Parteien bezeichne ich die, die sich mehr an die Grundsätze als an deren Folgen halten; sie befassen sich mit dem Allgemeinen und nicht mit den Einzelfällen, mit den Ideen und nicht mit den Menschen [...] Amerika hat große Parteien gehabt; sie bestehen heute nicht mehr." ${ }^{\prime 6}$ James Bryce, nach Tocqueville der zweite große europäische Amerikaversteher, ging rund 60 Jahre später noch einen Schritt weiter, als er die amerikanischen Parteien als „Empty Bottles“ bezeichnete, die allenfalls unterschiedliche Etiketten trügen. Schließlich: „Neither party has anything definite to say on issues; neither party has any principles, any distinctive tenets." "7

Ihre Hochzeit und intellektuelle Verdichtung erfuhr die These von Amerikas glücklichem Entkommen von jenen ideologischen Konflikten, die die alte Welt fest im Griff hielten, fraglos nach 1945, unter dem Druck des Kalten Krieges. Es waren vor allem die Historiker der sogenannten „Consensus School“, die argumentierten, dass Amerikas Ideologiefreiheit Teil des „American Exceptionalism“ sei. Wobei „Ideologiefreiheit“" vielleicht etwas zu weit geht und wohl allenfalls bei einem der Vertreter dieser Schule, Daniel J. Boorstin, zutreffend war. ${ }^{8}$ Andere hingegen argumentierten im Grunde nicht mit der Ideologiefreiheit der USA, sondern stärker mit dem Argument der Hegemonie einer einzelnen Ideologie. ${ }^{9}$

5 Giovanni Sartori: Ideology and Belief Systems, in: American Political Science Review, 63, 1969, S. 398-441.

6 Tocqueville: Über die Demokratie in Amerika, a.a.O, S. 199-200.

7 Viscount James Bryce: The American Commonwealth, Indianapolis 1888, S. 344.

8 Daniel J. Boorstin: The Genius of American Politics, Chicago 1953, S. $8 \mathrm{ff}$.

9 Vgl. zu dieser Unterscheidung: Bernhard Sternsher: Consensus, Conflict, and American Historians. Bloomington 1970, S. 4-7. 
Diese Ansicht stand auch Pate bei dem häufig zitierten Diktum Richard Hofstadters: „As a nation, it had been our fate not to have ideologies but to be one." ${ }^{\text {“10 }}$

Der prominenteste Vertreter dieser Interpretation war allerdings fraglos Louis Hartz, dessen Buch „The Liberal Tradition in America“ bis heute als inoffizielle Programmschrift der amerikanischen Consensus School gilt. ${ }^{11}$ Nach Hartz habe sich in den USA aus verschiedenen Gründen - Fehlen einer feudalen Vergangenheit, fehlendes Klassenbewusstsein, die schiere Größe des Landes mit seinen Unmengen an freiem Raum - einzig eine liberale Ideologie im Sinne John Lockes durchsetzen können. Hartz selbst sprach von einem ideologischen „Monolithen“, neben dem sich andere Weltanschauungen nicht hätten entwickeln können.

Obgleich sich solche Charakterisierungen bis vor vielleicht zwei Jahrzehnten noch in zahlreichen Lehrbüchern zum politischen System der USA finden ließen, gelten sie vielen Historikern und Ideengeschichtlern heute als reichlich einseitige und idealisierte Interpretation der amerikanischen Geschichte. ${ }^{12}$ Es ist vielleicht kein Zufall, dass die Kritik an Hartz und anderen besonders virulent wurde, als diese Deutung spätestens ab den 1970er Jahren mit der Gegenwart eines zunehmend polarisierten Landes immer weniger in Einklang stand und man die ideologischen Bruchlinien des Landes in die Vergangenheit zurückprojizierte. Kritisiert wurde vornehmlich die einseitige Betonung liberaler Mentalitäten zu Gunsten zahlreicher dezidiert antiliberaler Stränge des politischen Denkens. Vor allem Rogers M. Smith hat zu zeigen versucht, dass neben den von Hartz identifizierten Einflüssen auch stets andere Denktradition existierten - bisweilen im Zentrum politischer Macht und der amerikanischen Gesellschaft. Vor allem auf dem Gebiet des amerikanischen Südens, so Smith, habe eine quasi-feudale, reaktionäre Parallelgesellschaft existiert. Und schließlich, auch dies ein häufiger Einwand gegen die Argumente der Consensus Historians, habe das Land im Namen einer Idee der Abschaffung der Sklaverei - gar einen blutigen Bürgerkrieg geführt. ${ }^{13}$

10 Richard Hofstadter: Anti-Intellectualism in American Life, New York 1963, S. 43.

11 Louis Hartz: The Liberal Tradition in America, 2. Auflage, New York 1991.

12 Vgl. hierzu James T. Kloppenberg: Requiescat in Pacem: The Liberal Tradition of Louis Hartz. In: Hulliung, Mark (Ed.): The American Liberal Tradition Reconsidered. The Contested Legacy of Louis Hartz., Kansas 2010, S. 90-124.; Sean Wilentz: American Political Histories. History and Historians since 1907. In: Organization of American Historians (OAH) Magazine of History, 21 (2), 2007, 23-27.; Carol Nackenoff: Locke, Alger, and Atomistic Individualism Fifty Years Later: Revisiting Louis Hartz's Liberal Tradition in America, in: Studies in American Political Development 19 (2) (2005), S. 206-215.

13 Rogers M. Smith: Beyond Tocqueville, Myrdal, and Hartz. The Multiple Traditions in America, in: American Political Science Review 87 (3), 1993, S. 549-566. 
Andererseits: Lässt man den normativen Überschuss weg, der bei Hartz und anderen fraglos eine große Rolle spielte und einige der maßloseren Übertreibungen dieser Darstellung, und wählt dabei - und das ist in Wahrheit das Entscheidende - eine historisch vergleichende Perspektive, dann bleibt ein harter, unwiderlegbarer Kern dieser Thesen doch gültig. Zwar gab es natürlich ideologischen Konflikt in den USA. Auch waren die Parteien weltanschaulich nicht ganz so beliebig, wie es Bryce Aperçu von den „Empty Bottles“ glauben machen wollte. Insbesondere John Gerring hat gezeigt, dass die amerikanischen Parteien ihre gesamte Geschichte hindurch zu vielen nationalen Streitfragen gegensätzliche Standpunkte eingenommen haben. ${ }^{14}$ Und gewiss wiesen die USA theoretisch die gesamte Brandbreite ideologischer Alternativen auf, vom Ku-Klux-Klan bis zur Kommunistischen Partei. Nur: Welche dieser Bewegungen wäre damit jemals ins Zentrum der amerikanischen Politik vorgedrungen? Auch wenn es eine schon fast triviale Übung in historischer Komparatistik ist, sollte man es noch einmal durchdeklinieren: Es gab in den USA, ein Land in dem die Arbeitskämpfe fraglos häufig mit besonderer Bereitschaft zur militanten Gewalt ausgefochten wurden, keine sozialistische Bewegung und Partei, die mit irgendeiner Aussicht auf Erfolg die kapitalistische Wirtschaftsordnung herausgefordert hätte. ${ }^{15}$ Ebenso gab es keine Partei, die sich der Restauration einer alten feudalen Ordnung verschrieben hätte (denn es gab nie eine), oder aber, als diese Hoffnung endgültig zur Fiktion geworden war, sich wenigstens auf die Verteidigung der Prinzipen des Christentums zurückgezogen hätte. Auch dies lag darin begründet, dass die amerikanischen „Revolutionäre" nicht den Kampf gegen eine Staatskirche hatten führen müssen und daher auch weder antiklerikal noch antireligiös eingestellt waren. Doch wo es keinen Robespierre gab, da konnte es auch keinen de Maistre geben. So fehlten bereits die zwei wesentlichen Achsen der europäischen Cleavage-Struktur. Im Übrigen war auch der Zentrums-Peripherie-Konflikt, der für die Herausprägung der Konfliktlinien in Europa ebenfalls von großer Bedeutung war, in den USA zunächst sehr viel weniger ausgeprägt - schließlich war das Land bei seiner Gründung ein Konglomerat von Peripherien gewesen, nämlich die 13 abgefallenen Kolonien, die sich unter dem Dach einer schwachen Zentralregierung vereinten - ,a union of peripheries. ${ }^{* 16}$

14 Vgl. John Gerring: Party Ideologies in America 1828-1996, Cambridge 2001.

15 Vgl. Seymour Martin Lipset/ Gary Marks: It Didn’t Happen Here: Why Socialism Failed In The United States, New York 2001.

16 Vgl. Sergio Fabbrini: Compound Democracies. Why the United States and Europe are Becoming Similar, Oxford 2007, S. 109ff. 
Wenn sich in den USA Entwicklungen krisenhaft zuspitzten, dann traten keine Gegeneliten mit völlig alternativen Rezepten auf den Plan, sondern es erfolgte eine Reformation und Reformulierung auf der Grundlage des bestehenden Systems. Paradigmatisch dafür steht Roosevelts „New Deal“, und zwar gerade weil es eine der Phasen des radikalsten Umbaus der Architektur von Staat und Gesellschaft in der amerikanischen Geschichte war. Und doch stimmen die meisten Historiker darin überein, dass dem „New Deal“ nicht nur jedes revolutionäre Potenzial fehlte, sondern letztlich auch jedes klare Programm, es sich vielmehr um ein Sammelsurium disparater Reformvorstellungen handelte. ${ }^{17}$ Exemplarisch hierfür scheint noch immer Roosevelts Satz während des Wahlkampfes 1932 zu stehen „What the county need is bold, persistent experimentation. It is common sense to take a method and try it; if it fails, admit it frankly and try another. But above all, try something. “18 Das scheint die Meinung Sartoris und anderer zu bestätigen: Amerikaner waren eben Empiristen, nicht Rationalisten. Zwar gab es in diesen als Krise wahrgenommenen Phasen auch sozialen Protest, oft von eruptiver Gewalttätigkeit begleitet. Aber entweder blieb dieser so peripher und marginalisiert, dass die Wirkung gleich null war. Oder es gilt, was der israelische Soziologe S.M. Eisenstadt über die Zielorientierung amerikanischer Protestbewegungen, ob nun Populisten, Progressives bis noch hin zur schwarzen Bürgerrechtsbewegung, schrieb: Anders als in Europa betonten diese Protestbewegungen nie den Bruch mit den Werten der Mehrheitskultur, sondern zielten auf das normativ-ideelle „Zentrum“ der amerikanischen Gesellschaft: Es ging um Anerkennung, Teilhabe, um ein Stück vom Kuchen des „amerikanischen Traums“ “ ${ }^{19}$ Keine dieser Gruppen brach daher grundsätzlich mit den Prämissen der breiten amerikanischen Integrationsideologie - sondern forderte deren Erneuerung und Einhaltung. Und jede dieser Gruppen fürchtete nichts mehr als den Vorwurf, ,unamerikanisch“ zu sein und damit außerhalb der nationalen Gemeinschaft gestellt zu werden. Selbst auf dem Höhepunkt der Krise des kapitalistischen Systems, in der Großen Depression der 1930er Jahre, warb die Kommunistische Partei der USA für ihre Ideen mit dem

17 Sehr pointiert Richard Hofstadter, The Age of Reform. From Bryan to FDR, New York 1955.

18 Zitiert nach David M Kennedy: Freedom from Fear. The American People in Depression and War 1929-1945, Oxford 1999, S. 104.; vgl. hierzu auch die Darstellung über den New Deal und den amerikanischen Liberalismus bei Michael Foley: American Credo. The Place of Ideas in US Politics, Oxford (UK) 2007.

19 Vgl. Shmuel N. Eisenstadt: Die Vielfalt der Moderne, Weilerswist 2000, insbesondere, S. $46 \mathrm{ff}$. 
Slogan, dass Kommunismus nichts anderes sei als „twentieth century Americanism.“20 Sie wären wohl im Traum nicht auf den Gedanken verfallen, auf diesen Vorwurf so zu antworten, wie es etwa 100 Jahre zuvor Karl Marx und Friedrich Engels im „Kommunistischen Manifest“ getan hatten, als sie in radikaler Weise den Erwartungshorizont des bürgerlichen Klassenfeindes unterliefen: „Den Kommunisten ist ferner vorgeworfen worden, sie wollten das Vaterland, die Nationalität abschaffen. Die Arbeiter haben kein Vaterland. Man kann ihnen nicht nehmen, was sie nicht haben." ${ }^{\prime 21}$

In Europa konkurrierten eben universalistische, transnationale Ideologien mit nationaler Identität; in den USA aber war dies anders, weil Amerika selbst eine Idee, kein organisch gewachsenes, durch linguistische oder ethnische Grenzen definiertes Gemeinwesen war. Man wurde nicht durch sein Blut Amerikaner, sondern durch Zustimmung zu dieser Idee, hielt aber auch danach einen Teil seiner ethnischen Wurzeln und Identität aufrecht. Und diese Idee, die im Inneren der amerikanischen Gesellschaft übermächtig herrschte, lässt sich in der Tat am besten noch immer mit Samuel Huntington und anderen als „American Creed“ bezeichnen. Zum „Creed“ gehören Werte wie Freiheit, Gleichheit, Demokratie und Individualismus. Wem diese Aufzählung ein wenig widersprüchlich anmutet wie z.B. die Zusammenführung von Gleichheit und Freiheit -, der irrt nicht unbedingt. Der „American Creed“, wie Huntington ihn beschrieben hat, war und ist eben keine Ideologie im Europäischen Sinne, die nach Kohärenz gestrebt hätte, sondern, so Huntington, ein „amorphus amalgam of goals and values”. ${ }^{22} \mathrm{Im}$ „American Creed“ wurde nicht zwischen diesen verschiedenen Elementen priorisiert, sondern die einzelnen Elemente standen ohne Hierarchie nebeneinander. Freilich, was dem „Creed“ an Bestimmtheit fehlte, das machte er mehr als wett durch seine beträchtliche Reichweite, da sich auf dieses reichlich unpräzise IdeenKonglomerat die meisten Amerikaner verständigen konnten, oder jedenfalls jene, die als gesellschaftliche und politische Eliten den Takt des Landes weitgehend

20 Vgl. E.J. Dionne: Our Divided Political Heart: The Battle for an American Idea in an Age of Discontent, New York 2012, S. 54.

21 Marx-Engels-Werke, Bd.4, Institut für Marxismus und Leninismus beim ZK der SED in Berlin, Berlin 1977, S. 479; vgl. auch Philipp Erbentraut/Torben Lütjen: Eine Welt $\mathrm{zu}$ gewinnen. Entstehungskontext, Wirkungsweise und Narrationsstruktur des „Kommunistischen Manifests“, in: Johanna Klatt/Robert Lorenz: Manifeste. Geschichte und Gegenwart des politischen Appells, Bielefeld 2011. S. 73-98.

22 Samuel P. Huntington: American Politics and the Promise of Disharmony, Cambridge 1981, S. 15. 
bestimmten. Das schloss, wie in jeder guten monotheistischen Religion, auch intensiven Konflikt natürlich nicht aus, doch drehte sich dieser um die Auslegung, nicht um die Infragestellung des „American Creed“.

Aus dieser Perspektive ist die Aussage, wonach die USA historisch über eine geringere ideologische Pluralität als die alte Welt verfügte, und sich weniger durch den Konflikt rivalisierender, unversöhnlicher Ideologien auszeichnete, natürlich gültig. Und wenn solche Interpretationen - auch da, wo sie in ihrer Beschreibung übertrieben waren - in den Jahren nach 1945 besondere Konjunktur hatten, so lag das wohl nicht nur am Kontrast zwischen der amerikanischen Geschichte und dem Horror der jüngeren Europäischen Historie. Überdies erschien die amerikanische Gesellschaft in den 1950er Jahren geradezu als Zuspitzung der gerade beschriebenen Entwicklungsimperative, da die noch bestehenden Differenzen in diesen Jahren weiter an Bedeutung zu verlieren schienen. Die USA dieser Epoche waren das Land des sogenannten „Konsensliberalismus“: eine Mischung aus freier, aber keynesianisch abgestützter Marktwirtschaft, Wohlfahrtsstaatstaatlichkeit und technokratischer Gesellschaftsplanung, flankiert freilich von einem strikten Antikommunismus. Unter den Intellektuellen des Landes galt diese Synthese quasi als der Endpunkt jedweder ideologischen Evolution. ${ }^{23}$ „These, without doubt, are the years of the liberal“, schrieb triumphal der Ökonom John Kenneth Galbraith, ein Vordenker des Konsensliberalismus, noch im Jahr 1964. „Almost everyone now so describes himself." ${ }^{24}$ Die in diesen Jahren äußerst präsente Diskussion um ein mögliches „Ende der Ideologien“ war zwar eine transatlantische Diskussion, da man glaubte, ähnliche Entwicklungen auch in Europa zu beobachten. ${ }^{25}$ Doch es war kein Zufall, dass der prominenteste Vertreter dieser Diskussion ein amerikanischer Soziologe war: Daniel Bell. ${ }^{26}$ Die Propagandisten der Idee vom Heraufdämmern eines postideologischen Zeitalters dachten letztlichen aus einer ungebrochenen Modernisierungsperspektive heraus: Moderne Gesellschaften waren auf Ideologien im Grunde nicht länger angewiesen - was die USA als Protoptyp

23 Vgl. mit Bezug auch auf die besondere Ausstrahlungskraft nach Europa: Julia Angster: Konsenskapitalismus und Sozialdemokratie. Die Westernisierung von SPD und DGB, München 2003; Michael Hochgeschwender: Freiheit in der Offensive? Der Kongreß für kulturelle Freiheit und die Deutschen, München 1998.

24 Vgl. John Micklethwait/Adrian Wooldridge: The Right Nation, New York 2005, S. 9.

25 Vgl. die Beiträge in Chaim Waxman: The End of Ideology Debate, Touchstone 1969; Russel Jacoby: The End of Utopia, New York 1999.

26 Daniel Bell. The End of Ideology: On the Exhaustion of Political Ideas in the Fifties, New York 1960. 
moderner Gesellschaften besonders dazu prädestinierte, auf dem Weg der Entideologisierung voranzuschreiten. ${ }^{27}$

Trotz all der Kübel voller Spott, die man später über Bell und andere Verlautbarer eines wohl etwas zu voreilig ausgerufenen „Ende der Ideologien“ ausgießen sollte: wer sich die USA der Eisenhower-Jahre anschaute, kam wohl kaum umhin, solche Ideen zumindest im Ansatz plausibel zu finden. Im amerikanischen Kongress musste man schon mit der Lupe suchen, um wirkliche weltanschauliche Differenzen zwischen den Parteien zu finden. Es war insofern wenig verwunderlich, dass „Ike“ sich im Vorfeld seiner Präsidentschaftskampagne 1952 lange mit der Entscheidung plagte, ob er denn nun das Demokratische oder Republikanische "Ticket" annehmen sollte - angetragen worden war ihm die Präsidentschaft schließlich von beiden Seiten. Es war nicht etwa so, dass Eisenhower sich ideologisch in der Mitte zwischen diesen beiden Parteien wähnte. Vielmehr war es nicht ganz einfach zu sagen, welche der beiden Parteien denn nun „linker“ oder ,rechter“" bzw. „liberaler“ oder „,konservativer“" war. Demokraten und Republikaner waren „Umbrella Parties“, die unter ihrem breiten Schirm eine denkbar bunte Koalition von Gruppen beheimateten. Das Organisationsprinzip amerikanischer Parteien war der Faktionalismus im Sinne einer Akzeptanz einer möglichst breiten ideologischen Koalition unter größtmöglicher Gewährung von Autonomie der regionalen Gliederungen der Partei. ${ }^{28}$ Im Grunde erklärt dieses Organisationsprinzip den Erfolg amerikanischer Parteien, andere Wettbewerber effektiv auszuschalten, da es den Akteuren vor Ort erlaubte, so weit wie möglich auf die Präferenzen ihrer Wählerbasis einzugehen und deren Bedürfnisse und Wünsche flexibel in die eigene Plattform einzubauen.

Besonders heterogen war dabei die Koalition der Demokratischen Partei. Spätestens seit dem New Deal waren sie zwar zu jener Partei geworden, die Staatseingriffen sehr viel positiver gegenüber stand als die Republikaner. Auch vertrat sie, aller regionalen Differenzen ungeachtet, sehr viel mehr Wähler aus der Arbeiterklasse. Allerdings beheimatete die von Roosevelt geschmiedete New Deal-Koalition eben auch Demokraten aus dem Süden. Wirtschafts- und sozialpolitisch standen auch diese insgesamt im ,linken“ Lager; in anderen Fragen aber tendierten sie weit nach rechts. Viele von ihnen waren ganz offene Befürworter der Rassentrennung, zudem oft Anhänger einer sehr konservativen Spielart des Protestantismus, die uns in diesem Kapitel noch beschäftigen wird.

27 Vgl. sehr prägnant Robert E. Lane: The Decline of Ideology in a Knowledgeable Society, in: American Sociological Review, Vol. 31 (5), 1966, S. 649-662.

28 Vgl. Leon Epstein: Political Parties in the American Mold, Wisconsin 1986; Daniel Di Salvo: Engines of Change. Party Factions in American Politics, Oxford 2012. 
Auf dem Gebiet der alten Konföderation galten die Republikaner auch in den 1960er Jahren zunächst noch vor allem als die Partei des Sklavenbefreiers Abraham Lincoln und waren damit für die meisten Weißen praktisch unwählbar, während Afro-Amerikaner durch die diskriminierende „Jim-Crow"-Gesetzgebung von Wahlen fast vollständig ferngehalten wurden. Zwischen North Carolina und Louisiana war die „Grand Old Party“ nirgendwo auch nur annährend wettbewerbsfähig. Im amerikanischen Süden, für die Demokraten als „Solid South“ bezeichnet, herrschte ein faktisches Ein-Parteien-System.

Die Konsequenz war, dass die Parteien im Kongress in Washington bunt zusammengewürfelte Formationen waren. Nach Ansicht manchen Beobachters verbarg sich in diesen Jahren unter der Oberfläche eines Zwei-Parteien-Systems eigentlich ein Vier-Parteien-System: liberale und moderate Demokraten und Republikaner, größtenteils von der Ost- und Westküste und aus den Industrieregionen des Mittleren Westens, konservative Demokraten aus dem Süden und konservative Republikaner aus dem Mittleren Westen und anderen ländlichen Regionen. ${ }^{29}$ Das ist eine gewiss etwas holzschnittartige Darstellung, die dem tatsächlichen ideologischen und regionalen Pluralismus auf dem Capitol Hill nur teilweise gerecht wird. Sie macht jedoch deutlich, dass irgendeine Form von Fraktionsdisziplin auf dem Capitol Hill nur ein frommer Wunsch sein konnte. Am meisten schien die Beliebigkeit der amerikanischen Parteien die Zunft der amerikanischen Politologen zu frustrieren. 1950 etablierte die „American Political Science Association“ gar eine Task Force, die sich mit dem - nach Meinung der meisten Politologen des Landes - erbärmlichen Zustand der weltanschaulich angeblich völlig beliebigen und ununterscheidbaren amerikanischen Parteien beschäftigen sollte. Die Autoren, unter ihnen fraglos die damals größten Autoritäten ihrer Zunft, empfahlen eine Orientierung auf die parlamentarischen Systeme Westeuropas mit ihrem eindeutigen ideologischen Dualismus (oder Pluralismus). ${ }^{30}$ An diesen Report ist in den letzten Jahren oft erinnert worden, scheint er doch ein exzellentes Beispiel für die Mahnung zu sein, man solle mit seinen Wünschen vorsichtig vorgehen - sie könnten schließlich wahr werden. ${ }^{31}$

29 Vgl. Ronald Brownstein: The Second Civil War: How Extreme Partisanship has Paralyzed Washington and Polarized America, New York 2008, S. 62.

30 Committee on the Political Parties. Toward A More Responsible Two-Party System A Report of the Committee on Political Parties, American Political Science Associa tion, 1950.

31 Vgl. Nicol C. Rae: Be Careful What You Wish For: The Rise of Responsible Parties in American National Politics, in: Annual Review of Political Science, 10, 2007, S. 169171. 
Kurzum: Nichts schien zu Beginn der 1960er Jahre dafür zu sprechen, dass die USA in nicht allzu langer Zeit zu einem Treibhaus ideologischer Polarisierung werden könnten. Doch unter der Oberfläche des Parteienkonsenses hatten sich längst Kräfte formiert, die in eine ganz andere Richtung drängten. Mit dem Zusammenbruch des „Amerikanischen Konsenses“ verhielt es sich ein wenig wie mit der französischen Revolution in einer der Charakterisierungen Tocquevilles: so unvorhergesehen, und doch so unvermeidlich.

\section{Der Strategiewechsel der Demokratischen Partei UND DAS SOUTHERN REALIGNMENT}

Die Anomalie eines Ein-Parteien-Systems in den Südstaaten ist der erste Dominostein der fällt und durch den alles Weitere in Bewegung gesetzt wird. Welches andere Ereignis auch sonst an der ideologischen Spaltung Amerikas mitgewirkt hat - ohne das sogenannte „Southern Realignment“", verlöre jede andere Erklärung ihren Sinn. Gemeint ist damit die schrittweise Abwendung weißer, konservativer Südstaatler von der Wählerkoalition der Demokratischen Partei und ihre Hinwendung zu den Republikanern. In der Politikgeschichte der USA ist dies fraglos der folgenreichste Prozess der zweiten Hälfte des 20. Jahrhunderts. Das „Southern Realignment" wird nicht nur die New Deal Koalition Franklin D. Roosevelts pulverisieren. Sie wird auch dafür sorgen, dass langfristig beide Parteien in ihrem Kern homogener werden, während die Unterschiede zwischen ihnen beträchtlich wachsen sollten. Erst das aber schuf überhaupt die Voraussetzung für einen ideologisch sehr viel akzentuierteren Parteienwettbewerb, wodurch es für nationale Parteieliten zu einer rationalen Strategie wurde, ideologisch sehr akzentuierte Botschaften auszusenden, auch an Orte außerhalb des amerikanischen Südens - an Orte etwa wie Dane und Waukesha County in Wisconsin.

Hinter dem politischen Repräsentanzwechsel des amerikanischen Südens steckte, jedenfalls zu Beginn, noch keine ausgeklügelte Strategie der Republikanischen Partei. Es waren die Demokraten, die diesen Prozess einleiteten - aber erst nach schweren und heftigen innerparteilichen Auseinandersetzungen zwischen dem liberalen und dem konservativen Parteiflügel. Der Spaltpilz war die Frage der faktischen Rassentrennung im Süden der USA und wie man auf die seit den 1950er Jahren dort stetig erstarkende schwarze Bürgerrechtsbewegung reagieren sollte. 
Der liberale Flügel der Partei, der seine Basis ganz überwiegend im Nordosten des Landes hatte, sympathisierte zwar mit den Zielen der Bewegung, wie man überhaupt außerhalb des Gebietes der alten Konföderation die Verhältnisse in den Südstaaten auch weiterhin für die große Schande und klaffende moralische Wunde im Inneren der amerikanischen Gesellschaft hielt.

Der Supreme Court hatte in seiner Entscheidung „Brown vs. Board of Education" die faktische Rassentrennung im Süden bereits 1954 als verfassungswidrig verurteilt. Dennoch ging die Aufhebung der Segregation nur sehr schleppend voran. Es gab spektakuläre Aktionen, wie 1957 in Little Rock, Arkansas, als Präsident Eisenhower zunächst die Nationalgarde und dann schließlich sogar die 101. Luftlandedivison schickte, um neun schwarzen Schülern den Zugang zu einer Schule zu ermöglichen, vor dem ein weißer Mob randalierte. Von solchen spektakulären Aktionen abgesehen aber blieben die Verhältnisse katastrophal, insbesondere in den Staaten des „Deep South“ wie Alabama, Mississippi oder Louisiana. Die liberalen Parteieliten der Demokratischen Partei scheuten in den 1950er Jahren aus strategischen Gründen den offenen Konflikt mit den konservativen „Parteifreunden“ aus dem Süden. Das galt auch Anfang der 1960er Jahre noch für den mit großen Erwartungen ins Amt gekommenen John F. Kennedy. Denn die Koalition, der er seinen äußerst knappen Sieg bei den Präsidentschaftswahlen $1960 \mathrm{zu}$ verdanken hatte, war ebenfalls extrem heterogen und ohne die Unterstützung konservative Südstaatler kaum möglich gewesen.

Das alles änderte sich erst, als das Civil Rights Movement unter der Führung von Martin Luther King Anfang der 1960er in immer spektakuläreren Protestaktionen, die immer heftigere, brutalere Reaktionen von Justiz und Polizei im Süden der USA provozierten, endgültig die nationale Aufmerksamkeit absorbierte. ${ }^{32}$ Insbesondere in den liberalen, aufgeklärten, urbaneren Regionen des Landes - dort also, wohin die Macht innerhalb der demokratischen Partei während der letzten drei Jahrzehnte sukzessive hingewandert war - war man über die Exzesse der staatlichen Autoritäten, aber auch das Verhalten vieler normaler Bürger in der Staaten der alten Konföderation, entsetzt. Die Forderungen, gegen diese Verhältnisse - fast genau 100 Jahre nach dem Ende der Sklaverei - viel energischer als bisher vorzugehen, wurden immer drängender und vehementer. Auch hatte seit Ende der 1950er Jahre im amerikanischen Kongress sukzessive ein Generations-

32 Vgl. Doug McAdam: The Framing Function of Movement Tactics: Strategic Dramaturgy in the Civil Rights Movement, in: Doug McAdam, John D. McCarthy, Mayer N. Zald (Hg.): Comparative Perspectives on Social Movements. Political Opportunities, Mobilizing Structures, and Cultural Framings, Ann Arbor 1996. 
wechsel stattgefunden. Jüngere Abgeordnete, sensibler für Fragen der Gleichberechtigung zwischen schwarz und weiß, waren nachgerückt. ${ }^{33}$ Ein weiterer Faktor war die Migration vieler Afroamerikaner seit den 1940er Jahren aus dem Süden in den Nordosten des Landes und in die Industrieregionen des Mittleren Westens. Sie wurden dort in einigen Bundesstaaten zu einer entscheidenden und daher stark umworbenen Wählergruppe. ${ }^{34}$ Mit diesen Entwicklungen veränderte sich die Kalkulation der demokratischen Parteieliten: Anfang der 1960er Jahre schien der Bruch mit dem Südstaaten-Flügel der Partei plötzlich nicht mehr so abwegig wie noch einige Jahre zuvor und seit dem Sommer 1963 steuerte auch Kennedy auf diesen Konflikt offen zu.

Kennedys Ermordung im November 1963 beschleunigte diesen Prozess. Nach den Schüssen von Dallas fühlte sich der amerikanische Liberalismus moralisch eindeutig in der Offensive. So wuchs die Entschlossenheit, auch auf Kosten eines innerparteilichen Konfliktes sehr viel entschiedenere Maßnahmen zu ergreifen: Im Juli 1964, unter der Präsidentschaft von Kennedys Nachfolger Lyndon B. Johnson, wurde der „Civil Rights Act“ erlassen, der eine Reihe von Maßnahmen vorsah, um die faktische Rassentrennung in den USA aufzuheben und dabei dem Justizministerium in Washington weitreichende Befugnisse zur Durchsetzung einräumte. Lyndon B. Johnson selbst hatte wenig Illusionen darüber, welche Konsequenzen seine Unterschrift unter das neue Gesetz haben würde: „We delivered the South to the Republican Party for your lifetime and mine" teilte er einem engen Berater noch am Abend nach der Unterzeichnung in einem Anflug böser Vorahnungen mit. ${ }^{35}$ Es war eine Prophezeiung, die schon bald in Erfüllung gehen sollte, aber nicht ganz präzise war: Der Verlust sollte noch viel länger nachwirken.

Es war in der Tat der Anfang vom Ende des „Solid South“ für die Demokraten. Schon 1968 sollte Richard Nixon vor allem auf seine „Southern Strategy“ setzten und damit das Weiße Haus erobern. Und da die Republikaner parallel hierzu ihre Bastionen an der liberalen Ost- und Westküste verloren, schuf das Southern Realignment sehr viel homogenere Parteibasen und beendete den extremen Faktionalismus, der bis dahin die Kultur beider Parteien bestimmt hatte. Ein paar Mal sollte das Pendel noch umschlagen, etwa 1976, als der Demokrat Jimmy Carter, ein gläubiger evangelikaler Christ aus Georgia, den Süden gewann bei seinem Einzug ins Weiße Haus. Auch Bill Clinton sollte bei seinen Siegen 1992 und 1996 noch

33 Vgl. Edward Carmines/James Stimson: Issue Evolution: Race and the Transformation of American Politics, Princeton 1990.

34 Vgl. Keneshia Grant: Relocation and Realignment: How the Great Migration Changed the Face of the Democratic Party, Dissertation, 2014, Syracuse University, online abrufbar unter: http://surface.syr.edu/cgi/viewcontent.cgi?article=1121\&context=etd

35 Zit. nach Bruce J. Dierenfield: The Civil Rights Movement, Edinburgh 2008, S. 94. 
einige Staaten in „Dixie-Land“ für sich gewinnen, und im Kongress waren noch bis in die 1990er Jahre konservative Demokraten vertreten, was belegt, wie lange der Homogenisierungsprozess dauerte. Langfristig aber war der Siegeszug der Republikaner dort nicht aufzuhalten.

Und doch hat diese scheinbar so einfache, lineare Erzählung ihre ganz eigenen Aporien. Denn auch wenn es liberale Demokraten waren, die diese Wende einleiteten und besonders stark auf die Verabschiedung des Civil Rights Act drängten: zwingend war es nicht, dass allein schon deswegen die Republikaner zur Partei konservativer Südstaatler wurden. Das zeigt schon die Analyse des Abstimmungsverhaltens im amerikanischen Kongress. Im Senat etwa hatte es 27 Gegenstimmen gegen den Civil Rights Act gegeben. Nur sechs der Gegenstimmen aber waren von Republikanern gekommen - 21 hingegen von demokratischen Senatoren, allesamt aus dem Süden der USA.

Wenn die Grand Old Party dennoch in kurzer Zeit zur Heimat konservativer Wähler zwischen North Carolina und Texas werden sollte, dann lag dies in einer folgenschweren Koinzidenz begründet. Zur selben Zeit nämlich, aber eben zunächst gar nicht ursächlich mit diesem Konflikt verknüpft, setzte sich innerhalb der Republikanischen Partei der lange Zeit marginalisierte konservative Parteiflügel durch - und zwar in Person des Präsidentschaftskandidaten von 1964, Barry Goldwater. Er war einer der sechs republikanischen Senatoren gewesen, die gegen den Civil Rights Act gestimmt hatten. Der Senator aus Arizona hatte dies mit dem Verweis auf die Verteidigung der Rechte der Einzelstaaten getan, der State Rights, die die Bundesregierung in Washington zu respektieren hätten - ein Argumentationsmuster, das fortan von Konservativen häufig herangezogen wurde, wenn man mit der in Washington beschlossenen Politik nicht zufrieden war. Für die Konservativen innerhalb der Partei, damals noch immer in der Minderheit, war Goldwater jedoch schon zuvor zum Helden geworden. Spätestens seitdem er 1960 mit einem Manifest mit dem Namen „Conscience of a Conservative“ hervorgetreten war, galt er als eine der lautstärksten Stimmen gegen den liberalen Nachkriegskonsens. Nach der Veröffentlichung des Buches waren Hunderte von „Goldwater for America“ Clubs im ganzen Land wie Pilze aus dem Boden geschossen und finanziell äußerst potente Unternehmer hatten ihn seitdem förmlich bekniet, um die republikanische Präsidentschaftskandidatur anzutreten. ${ }^{36}$ Denn kaum jemand hatte so aggressiv und brachial gegen die Weiterführung der Politiken des New Deal agitiert wie Goldwater. Seinen nationalen Aufstieg hatte er größtenteils seiner Opposition gegen die Gewerkschaften zu verdanken. Den Chef der mächtigen Auto-

36 Vgl. Rick Perlstein: Before the Storm: Barry Goldwater and the Unmaking of the American Consensus, New York 2001. 
Gewerkschaft UAW, Walter Reuther, hielt er nach eigenem Bekunden für eine größere Gefahr für die Freiheit Amerikas als das gesamte Zentralkomitee der KPDSU - es waren harte Sätze von einem Mann, der seinerseits immerhin als militanter Anti-Kommunist galt. Auch den republikanischen Präsidenten der Jahre 1952-1960, Dwight D. Eisenhower, trafen Goldwaters Tiraden: dieser nämlich sei den „Sirenensängen“ des Sozialismus verfallen. Nichts bedrohe so sehr die Freiheit in Amerika wie der schleichende Prozess des „socialism through welfarism“ ${ }^{37}$ Wem diese Worte merkwürdig aktuell erscheinen, der täuscht sich nicht: Mit Goldwater war die undifferenzierte Gleichsetzung jedes staatlichen Engriffes mit dem Wort „Sozialismus“, die insbesondere in den Jahren nach 2008 ff. wieder große Konjunktur auf der amerikanischen Rechten bekommen sollte, zum ersten Mal in den Mainstream der Republikanischen Partei eingesickert.

1964 gelang es Goldwater tatsächlich, die Nominierung als Präsidentschaftskandidat der Republikanischen Partei zu erringen. Die wahren Mehrheitsverhältnisse in der Partei spiegelte das zu diesem Zeitpunkt noch nicht wieder, diese wurde weiterhin vom liberalen Flügel dominiert. Goldwaters Nominierung verdankte sich vor allem einer äußerst effizienten Organisationsarbeit an den Graswurzeln der Partei, wodurch er viele Delegiertenstimmen für den Nominierungsparteitag in San Francisco einsammeln konnte (1964 gab es erst sehr wenige Vorwahlen, die meisten Delegierten wurden in der Regel von den State Parties entsandt), sowie den amourösen Eskapaden seines liberalen innerparteilichen Widersachers, Nelson D. Rockefeller. Die Goldwater-Kandidatur spaltete die Partei zutiefst, auf dem Nominierungsparteitag der Republikaner im Juli 1964 in San Francisco spielten sich tumultartige Szenen ab. Aber alle Versuche des liberalen Parteiflügels, seine Kandidatur noch zu verhindern, scheiterten. In der Tat pflügte Goldwater mit seinem auf Provokationen und Tabubrüche ausgerichteten Wahlkampf die bis dahin an der Oberfläche so konsensuale amerikanische Politik einmal komplett um. Er hatte angekündigt ,,a choice, not a echo“ zu präsentieren, und er hielt sein Versprechen. Den Demokraten fiel es vom ersten Tag an leicht, ihn als gefährlichen Extremisten darzustellen, dem man wohl kaum das höchste Amt des Staates inklusive des Nuklearwaffen-Arsenals einer Supermacht anvertrauen könnte. Auch abseits seiner Attacken gegen die Gewerkschaften und den Sozialstaat ließ er kaum eine Provokation aus. Im Kampf gegen den Vietkong hatte Goldwater angeregt, auf kleine taktische Atombomben zu setzen. Er schreckte ebenfalls nicht davor zurück, einen nicht gerade kleinen Teil des Landes pauschal zu beleidigen: „Sometimes I think this country would be better off, if we could

37 James T. Patterson: Grand Expectations. The United States, 1945-1974, Oxford 1996, S. 557. 
just saw off the Eastern seabord and let it float out to the sea ${ }^{\text {“38, }}$, meinte Goldwater, als er sich wieder einmal frustriert über die vermeintliche Arroganz des liberalen Ostküsten-Establishments zeigte. „In your heart you know he is right“, lautete der Slogan der Goldwater-Kampagne; „In your gutts you know he's nuts“, texteten daraufhin Johnsons Wahlkampfmanager zurück; letzteres schien in den Augen der meisten Amerikaner der Realität näher zu kommen. Selbst innerhalb der eigenen Partei versagten viele Goldwater die Unterstützung und sprachen sich öffentlich für Johnson aus.

So kam, was kommen musste: Goldwater verlor die Wahl. Und zwar auf fast schon epische Weise. Gerade einmal sechs von 50 Bundesstaaten konnte er gewinnen und erreichte gerade einmal 38\% der Stimmen. Es war ein Desaster, und niemand schien überrascht, wahrscheinlich nicht einmal Goldwater selbst, dem es eher darum gegangen war, die Fronten zu klären, als dass er ernsthaft daran geglaubt hätte, Präsident zu werden. Den Zeitgenossen erschien Goldwater als eine Fußnote der Geschichte, eine kurzzeitige Abweichung vom Pfad des amerikanischen Konsenses - und nicht, wie wir heute wissen, als Anfang vom Ende desselbigen. Für Amerikas damals fraglos deutungsmächtigsten Historiker, Richard Hofstadter, war das, was Goldwater zu sagen hatte, überhaupt keine Ideologie, nicht einmal ein Programm, ja im Grunde nicht mal Politik, sondern eine klinisch zu diagnostizierende Pathologie. Hofstadter nannte es einen „Pseudo-Konservativismus", gespeist aus Status-Unsicherheiten und einer kräftigen Prise Paranoia. ${ }^{39}$ „When, in all our history”, hatte er bereits wenige Monate vor der Wahl im Oktober 1964 im New York Review of Books geschrieben, „has anyone with ideas so bizarre, so archaic, so self-confounding, so remote from the basic consensus, ever got so far?" ${ }^{\prime 4}$ Nur ein Gutes, meinte Hofstadter etwas später, habe das Ganze vielleicht gehabt, sei der Wahlkampf doch so etwas wie eine gigantische Psychotherapie für Goldwaters Anhänger gewesen, die auf diese Weise von ihrer mentalen Krankheit vielleicht ein Stück weit genesen könnten: ein letztes, reaktionäres Hurra auf dem Weg zu einer modernen, toleranten, aufgeklärten, eben: liberalen Gesellschaft. ${ }^{41}$

Doch Hofstadter lag falsch - und mit ihm beinahe die gesamte Deutungselite des Landes. Goldwater hatte fast überall im Land grandios verloren; doch viel

38 Zitiert nach Theodor White. The Making of the President 1964, New York 1965, S. 109.

39 Vgl. Richard Hofstadter: Goldwater and Pseudo-Conservative Politics, in: ders. (Hg.), The Paranoid Style in American Politics and other Essays, New York 2008, S. 93-141.

40 Vgl. ders.: A Long View: Goldwater in History, in: The New York Review of Books, 8. Oktober 1964.

41 Vgl. ebd. 
interessanter war, wo er nicht verloren hatte: abgesehen von seinem Heimatstaat Arizona eben vor allem im tiefen Süden der USA. Doch es war nicht das „Southern Realignment“ allein. Die Kampagne von 1964 fand auch anderswo im Land ein Echo. Denn entgegen all den luziden Gegenwartsdiagnosen war Goldwater natürlich keineswegs einfach nur ein exzentrischer, etwas kauziger Außenseiter. Für die Positionen, die er vertrat, hatte es in der amerikanischen Gesellschaft schon immer eine Basis gegeben, nur, dass diese Traditionslinien in den 1960er Jahren, als die Vorherrschaft des Liberalismus so unerschütterlich erschien, verschüttet waren. Es war die Idee eines quasi uneingeschränkten Individualismus, gepaart mit der Ablehnung staatlicher Regulierung, aus denen sich Goldwaters Aversion gegen die vermeintliche Sozialdemokratisierung des Landes nährte. Insbesondere in der Zeit des Gilded Age zum Endes des 19. Jahrhunderts - nicht umsonst jene Ära, die heute von vielen Republikanern für das goldene Zeitalter vor dem Sündenfall gehalten wird - hatte dieses Laissez-Faire-Denken, gepaart mit einem kräftigen Schuss Sozialdarwinismus, das Denken der politischen und wirtschaftlichen Eliten maßgeblich bestimmt. ${ }^{42}$ Auch die aus europäischer Sicht schon paranoide Angst vor der Macht der Zentralregierung hatte natürlich sehr alte, historische Wurzeln, die sich bis in die Diskussionen der Gründerzeit der USA, als Federalists und Anti-Federalists über die Verfassung der Union und die Befugnisse der Bundesregierung stritten, zurückverfolgen lassen.

Doch konstituierten sich die verschiedenen Stränge dieses Denkens erst unter dem Eindruck der Bedrohung und des Hegemonieverlusts zur Ideologie. Zumindest in der Retrospektive wird deutlich, dass die Anfänge des amerikanischen Konservativismus in der Zeit des New Deal in den 1930er Jahren lagen: gegründet als Oppositionsbündnis gegen die massiven wirtschaftlichen Interventionen Roosevelts und seines Versuches, die USA ein Stück weit näher an das Modell europäischer Wohlfahrtsstaatlichkeit heranzurücken. ${ }^{43}$ In dieser Zeit begannen auch die Begriffe liberalism und conservatism mit ihrer heutigen Bedeutung aufgeladen zu werden. Denn Roosevelt stellte seinen New Deal in die Tradition des amerikanischen Liberalismus, um ihm auf diese Weise Legitimation zu verschaffen. Es war der typische Versuch, über eine Begriffsumwidmung Hegemonie zu erlangen. Der Versuch seiner Gegner, den Begriff ihrerseits zu besetzten, scheiterte. Zunächst widerwillig, dann aber immer bereitwilliger nannten sie sich

42 Vgl. Nell Irvin Painter: Standing at Armageddon: A Grassroots History of the Progressive Era, New York 2008; Robert W. Cheney: American Politics in the Gilded Age, 1868-1900, Wheeling 1997.

43 Vgl. für diese These vom Ursprung des amerikanischen Konservativismus in den 1930er Jahren Kim Philips-Fein: Invisible Hands: The Business Men's Crusade against the New Deal, New York 2010. 
schließlich Conservatives. ${ }^{44}$ In der republikanischen Partei sammelten sich Amerikas Konservative hinter dem Senator von Ohio, Robert Taft, der zwischen 1940 und 1952 drei Mal bei dem Versuch scheiterte, Präsidentschaftskandidat der Partei zu werden. Im Zentrum des Widerstandes gegen den New Deal standen aber vor allem amerikanische Industrielle, die sich in Lobbyvereinigungen wie in der „Liberty League" organisiert hatten.

Nach dem Krieg erhielten sie schließlich die intellektuelle Munition für einen langen, teuren Feldzug gegen „Big Government“. Denn als der Keynesianismus den politischen Diskursraum noch ziemlich uneingeschränkt beherrschte und die politische Klasse der USA die Rezepte des britischen Ökonomen parteiübergreifend für das letzte Wort moderner Wirtschaftspolitik hielt, hatte sich unter Ökonomen längst eine radikale Oppositionsbewegung herausgebildet, zunächst angeführt von europäischen Denkern: Der österreichische Ökonom Ludwig von Mises z.B., aber vor allem dessen Schüler Friedrich August von Hayek, dessen Buch „The Road to Serfdom“ davor warnte, dass jede Form der staatlichen Planung unweigerlich zum Totalitarismus führe. ${ }^{45}$ In den USA fiel dieses Buch schnell auf fruchtbaren Boden und gewann eine große, treue Anhängerschaft. ${ }^{46}$ Später wurde der Chicagoer Ökonom Milton Friedman der Bannerträger dieser Gruppe von Renegaten - die freilich ihrerseits schnell zu einer neuen Orthodoxie aufstiegen. Und seit den 1950er Jahren begannen Amerikas Konservative über Zeitungen, Magazine und dann schließlich durch den Aufbau finanziell äußerst potenter Think Tanks mit dem Aufbau einer konservativen Gegenöffentlichkeit, wenngleich Letzteres zu Goldwaters Zeiten noch im embryonalen Status verblieb.

Kurz gesagt: Ganz so heimatlos, wie es viele Beobachter des Jahres 1964 darstellten, waren Goldwaters Ideen gewiss nicht. Schon 1947 war Ayn Rands Roman „The Fountainhead“ erschienen und 1957 schließlich ihr größtes Werk „Atlas Shrugged“, millionenfach verkaufte Bestseller, die in hymnischer Weise ein Loblied auf die Tugend des uneingeschränkten Eigennutzes sangen und bis heute als „Einstiegsdroge“ in die Gedankenwelt eines radikalen Libertarismus gelten. ${ }^{47}$ Und natürlich, es braucht kaum erwähnt zu werden, war auch der scharfe, ja fast schon

44 Vgl. zur semantischen Verschiebung der Begriffe unter anderem David Farber: The Rise and Fall of Modern American Conservatism. A Short History, Princeton 2010, S. $4 \mathrm{ff}$.

45 Friedrich Hayek: The Road to Serfdom, London 1944.

46 Vgl. George H. Nash: The Intellectual Conservative Movement in America since 1945, Wilmington (Delware) 2006.

47 Vgl. Jennifer Burns: Goddess of the Market. Ayn Rand and the American Right, Oxford 2009, S. 4. 
paranoide Anti-Kommunismus des Senators aus Arizona keineswegs den Wahnvorstellungen eines Einzelnen entsprungen. Denn wie sonst ließ sich der kurze, aber dafür umso fulminantere Siegeszug des Joe McCarthy erklären, als Anfang des 1950er Jahre ein ganzes Land im Bann seines Kreuzzuges gegen die vermeintliche kommunistische Unterwanderung stand? Eine Episode, die Amerikas Liberale merkwürdig schnell vergessen hatten. Und schließlich: Goldwater mochte wenige Wähler gehabt haben; aber er hatte viele bedingungslose Anhänger. Eine ganze Generation amerikanischer Konservativer machte 1964 das erste Mal Bekanntschaft mit Grassroots-Politics. Goldwater hatte allein eine Million individuelle Spender - nur vier Jahre zuvor hatten für Richard Nixon, der die Wahl gegen Kennedy nur knapp verlor, gerade einmal 44000 Menschen das Scheckbuch gezückt. $^{48}$

Goldwater nahm die Angst vor dem Kommunismus ebenso auf wie die zuvor zitierten libertären intellektuellen Impulse und Traditionsstränge. Aber, und darin lag in Wahrheit seine historische Leistung für den amerikanischen Konservativismus, er verwob sie noch mit etwas anderem: er gab einer Bewegung von marginalisierten Intellektuellen und Wirtschaftslobbyisten zum ersten Mal einen maskulin-populistischen Zug und erst dadurch konnte sich der amerikanische Konservativismus - bis dahin eine nicht weniger elitäre Veranstaltung als seine Europäischen Pendants - langfristig als Massenbewegung konstituieren. ${ }^{49}$ Mit Goldwater begann die „Westernisierung“ der Republikanischen Partei. In Wahrheit speiste sich das Weltbild des Senators aus Arizona nämlich vor allem aus jener „FrontierMythologie“, der zufolge erst im Aufeinanderprallen zwischen europäischer Zivilisation und der unberechenbaren Wildnis der Neuen Welt entlang der stetig gen Westen verschobenen Besiedlungsgrenze der amerikanische Nationalcharakter geformt wurde. ${ }^{50}$ Erst die Frontier machte aus dem Europäer einen Amerikaner, erzog sie ihn doch zu Wagemut, Unerschrockenheit, Härte gegenüber sich selbst ebenso wie gegenüber anderen, und zu einem rauen Individualismus. Und nach dieser Erzählung kann und konnte das wahre Amerika nur möglichst weit entfernt von der Washingtoner Zentralregierung liegen. Arizona war für Goldwater, der sich gerne mit Cowboyhut, Winchester und auf dem Pferd inszenierte (wie nach ihm Ronald Reagan und George W. Bush) ein Symbol, wie der Pioniergeist selbst die menschenfeindlichste Wüstenödnis erobern, erschließen und besiedeln konnte - selbstverständlich alles ohne Unterstützung ,Washingtoner Bürokraten“.

48 Vgl. Nicol C. Rae: The Decline and Fall of the Liberal Republicans: From 1952 to the Present, Oxford 1989, S. 58.

49 Vgl. John Micklethwait/Adrian Wooldridge: The Right Nation, New York 2005.

50 Jackson Tuner: The Significance of the Frontier in American History, Chicago 1893. 
„We didn't know the federal government. Everything that was done, we did it ourselves " ${ }^{\text {"51 }}$, so beschrieb Goldwater, der Sohn eines wohlhabenden Kaufhausbesitzers, einmal den Aufstieg der eigenen Familie. Natürlich war das eine recht selektive Auslegung der Fakten. Schließlich waren es erst die von der Bundesregierung mit gewaltigem Aufwand betriebenen Staudammprojekte wie der „Roosevelt“- und dann der „Hoover-Dam“ gewesen, durch die Arizona urbar gemacht wurde. Ohne den verhassten New Deal Roosevelts hätte der Wüstenstaat niemals blühen können. Doch welche Rolle spielten solche Details schon angesichts einer derart kraftvollen Erzählung?

Der Westen und Südwesten der USA - die mit großem Abstand am schnellsten wachsende Regionen des Landes - sollte dementsprechend neben dem Süden zu einer starken Wählerbasis der Republikanischen Partei werden. Das hatte auch damit zu tun, welche Art von sozialem Raum dort entstand. Die Sozialplaner des amerikanischen Liberalismus waren in dieser Phase - der Ära der „Great Society“ - zutiefst davon überzeugt gewesen, dass es keine Alternative zum Ausbau des öffentlichen Sektors gab. In einer sich rapide urbanisierenden Gesellschaft, so glaubten sie, würde die vermehrte Bereitstellung öffentlicher Güter von den meisten Amerikanern zudem mit großer Zustimmung aufgenommen werden. Allerdings: Die Frage war eben, was man unter „,urban“ verstand. Überall in den USA, besonders aber in den boomenden Regionen des „Sunbelt“ - in Barry Goldwaters Arizona, in New Mexico, vor allem aber in Süd-Kalifornien - war etwa seit den 1940er Jahren ein sozialer Raum ganz eigener Art entstanden: Die sogenannten „Suburbs“. In diesem Fall scheint es angemessen, den englischen (bzw. amerikanischen) Begriff zu verwenden, denn mit deutschen Vororten haben amerikanische Suburbs nicht viel gemeinsam. Diese wuchernden Siedlungen außerhalb großer Metropolen wuchsen ja - zumindest außerhalb des Nordostens - in der Regel nicht in kleinere Städte oder Dörfer hinein, sondern entstanden buchstäblich aus dem Nichts. Es entstanden soziale Räume ohne geographischen Kern oder Zentrum, endlose Konglomerate von Wohngebieten, Highways und dann natürlich die riesigen Einkaufstempel der Malls. Es waren Orte, die in vielerlei Hinsicht nicht unbedingt die Einsicht förderten, dass man für die bezahlten Steuern eine faire Gegenleistung erhielt. Denn dort nutzte man das Auto, keine öffentlichen Verkehrsmittel, schickte die eigenen Kinder vielleicht gar auf private und nicht auf öffentliche Schulen, lebte insgesamt ein Leben in großer Privatheit, für das Räume öffentlicher Begegnung keine Rolle spielten. Für großzügige Sozialprogramme etwa durfte man dort nicht auf große Sympathie hoffen. Denn die Armut konzentrierte sich ja vor allem in jenen Orten, die die Bewohner von Suburbia bewusst

51 Perlstein: Before the Storm, a.a.O. S. 4. 
zurückgelassen hatten, und genau dort sollte sie auch bleiben: In den Innenstadtkernen der großen Städte. Viele der Suburbs waren ethnisch außerordentlich homogen, nämlich beinahe ausschließlich von Weißen bewohnt. In den amerikanischen Großstädten blieben hingegen vor allem die sozial Schwachen zurück, unter ihnen große Minderheiten von Schwarzen und Hispanics. Und viele derjenigen, die seit den 1950er Jahren in die boomenden Staaten des Sunbelt umgezogen waren, hatten dort einen rasanten persönlichen Aufstieg erlebt, der sie ebenfalls stärker empfänglich machte für eine politische Botschaft, die vor allem für niedrigere Steuern stand. ${ }^{52}$

Geradezu paradigmatisch für all dieses stand Orange County, eine mit grandioser Geschwindigkeit wachsende Ansammlung von Suburbs südlich von Los Angeles. Auch dort hatte Barry Goldwater 1964 gewinnen können - ganz so wie in anderen rasant an Bevölkerung zunehmenden Suburbs an den Rändern von Amerikas großen Metropolregionen. In Orange County und in anderen dieser Orte war die Rüstungsindustrie oft einer der wichtigsten Wirtschaftszweige. Es war insofern nicht verwunderlich, dass der harte Anti-Kommunismus des sich formierenden Konservativismus mit seiner Ablehnung der zu nachgiebigen ContainmentDoktrin und der Befürwortung eines aggressiven „Rollback“ dort verfangen konnte. Gleichwohl: Die Menschen von Orange County entsprachen in keiner Weise dem von Hofstadter und anderen entworfenen Bild einer von Status-Unsicherheiten geplagten Schicht bedrängter und rückwärtsgewandter Nostalgiker: Orange County boomte, war wohlhabend, gebildet, seine Bewohner trotz der Heidenangst vor dem Kommunismus insgesamt optimistisch, was die Segnungen des amerikanischen Traums betraf, dessen Essenz sie in der beispiellosen und kaum von Regulierungen behinderten Expansion von „Suburbia“ verkörpert sahen. Kurzum: Goldwaters Konservativismus wies ganz unverkennbar in die Zukunft, und nicht in die Vergangenheit. ${ }^{53}$

Die amerikanischen Suburbs sollten in Zukunft nicht überall zu republikanischen Hochburgen werden. Das hing von weiteren Faktoren ab: Wie nah an den Innenstädten waren sie gelegen? Wie streng waren die Bauvorschriften und wie groß durften oder sollten die Häuser sein? Waren sie ausschließlich weiß, oder gab es, zumindest in späteren Jahren, auch Platz für Minderheiten? Wie schwerwiegend waren die sozialen Probleme in der angrenzenden City? Wie war ansonsten

52 Vgl. Darren Dochuk: From Bible Belt to Sun Belt. Plain-Folk Religion, Grassroots Politics, and the Rise of Evangelical Conservatism, New York 2010.

53 Vgl. die brillante Studie über Orange County von Lisa McGirr: Suburban Warriors. The Origins of the New American Right, Princeton 2001. 
die regionale Kultur $?^{54}$ Sehr republikanisch waren in der Regel die besonders zersiedelten Suburbs (für die sich aufgrund ihrer weiten Entfernung vom Kern der City schon der Begriff „Exurb“ etablierte), die wohlhabend waren und ethnisch sehr homogen. Viele, aber beileibe nicht alle davon befinden sich im Süden, Westen und Südwesten. Auch im Mittleren Westen gab es eine weiße Mittelschicht, die massenweise den Städten den Rücken kehrte und hinauszog - so wie in Waukesha County, Wisconsin, dem konservativen Beispiel unserer Fallstudie. Dort war man allerdings 1964 noch nicht so weit und zeigte Goldwater in diesem Jahr noch die kalte Schulter; es war freilich das letzte Mal, das ein Demokrat in Waukesha gewinnen sollte.

1964 war die Mischung aus radikaler Marktgläubigkeit, Frontier-Romantik und Anti-Intellektualismus, für die Barry Goldwater stand, noch nicht reif, um im Land insgesamt mehrheitsfähig zu sein. In den folgenden Jahren aber sollte sich das ändern, ein wenig schon mit der Wahl Richard Nixons 1968 - aber vollends dann erst mit Ronald Reagan 1980. Doch um das zu verstehen, muss man den Blick noch einmal auf die andere Seite des Konfliktes werfen: Auf den Höhepunkt und den folgenden Niedergang des amerikanischen „Konsensliberalismus“.

\section{DAS „SCHEITERN“ DER GREAT SOCIETY UND DIE SILENT MAJORITY}

Im Jahr 1965 sollte der amerikanische Liberalismus seinen Scheitelpunkt erleben. Nach seinem grandiosen Wahlsieg war Johnsons Mandat so stark und seine Mehrheit im Kongress so überwältigend, dass er ein ambitioniertes Reformvorhaben nach dem anderen ins Werk setzen konnte: Gesundheitsversicherung für Arbeitslose und Rentner („Medicare“ und „Medicaid“); eine weitaus stärkere Rolle des Bundes in der Bildungspolitik; und schließlich den „Voting Rights Act“ als Ergänzung zum „Civil Rights Act“ - all dieses (und einiges andere mehr) wurde innerhalb weniger Monate durch den Kongress gebracht. Fraglos hielt man sich innerhalb der Johnson-Administration für die Herausforderungen der Zukunft so gut gerüstet wie nur möglich. Dabei ging es im Grunde um mehr als „nur“ um einen Ausbau des Wohlfahrtsstaates, der endlich europäisches Niveau erreichen

54 Vgl. Juliet F. Gainsborough: Fenced Off: The Suburbanization of American Politics, Washington D.C. 2011; Thad Williamson: Sprawl, Spatial Location, and Politics: How Ideological Identification Tracks the Built Environment, in: American Politics Research, Volume 36 Number 6, November 2008, S. 903-933. 
sollte. Der Ehrgeiz der linksliberalen Reformer ging sehr viel weiter. In diesen Jahren schien eine finale Lösung von Problemen möglich, die man in skeptischeren Zeiten womöglich noch für unabänderlich gehalten hätte. Die Mitte der 1960er Jahre waren, nicht nur in den USA, eine Hochphase technokratischer Politikvorstellungen: Plante man nur sorgfältig, bediente man sich nur des Sachverstandes von Experten und Fachleuten, dann war die Politik nicht länger den Launen des Zufalls unterworfen, sondern wurde zu einer berechenbaren Angelegenheit. Im Grunde war dieser Glaube an die Verwissenschaftlichung von Politik in Wahrheit vielleicht sogar der weltanschaulich harte Kern des ansonsten eher ideologisch kryptischen, weil extrem inklusiven Konsensliberalismus. ${ }^{55}$

Der technokratische Impetus galt besonders für die Wirtschaftspolitik, die man in den Händen einer klugen keynesianischen Elite von Ökonomen, allen voran dem Council on Economic Advisors und seinem Star-Ökonomen Walter Heller, gut aufgehoben fühlte. Aber auch andere Wissenschaften sollten zur Mehrung des nationalen Wohls beitragen. Die „National Science Foundation“ begann gar ein Forschungsprojekt, mit dem das Wetter kontrolliert werden sollte. Es war eben nie weit vom Optimismus zur Hybris. Als „Cult of Expertise“ bezeichnet der Historiker Steven Hayward die Geisteshaltung im Innern des amerikanischen Reformliberalismus der 1960er Jahre. ${ }^{56}$

Nirgendwo war die überbordende Erwartungshaltung spürbarer als in dem von Johnson und seinen Beratern ausgerufenen „War Against Poverty.“ Aufgeschreckt von Michael Harringtons Bestseller „The other America“, welches die Malaise insbesondere der afro-amerikanischen Unterschicht in deprimierenden Farben schilderte, gedachte man, die Wurzeln der Armut in den USA - immerhin 32 Millionen Amerikaner leben 1965 unterhalb der Armutsgrenze ${ }^{57}$ - ein für alle Mal auszurotten. Das war fraglos eine mutige Ankündigung. Es gab, insbesondere in den Ghettos amerikanischer Großstädte, eine verfestige Armut, die sich mit Subventionen für Stadtteilinitiativen, Bildungsprogrammen, Lebensmittelkarten und anderen Maßnahmen nur schwer bekämpfen ließ. Zwar sank das Armutsniveau in den prosperierenden 1960er Jahre zunächst sogar, aber gemessen an den

55 Vgl. Nils Gilman: Mandarins of the Future: Modernization Theory in Cold War America, Baltomore 2003; Torben Lütjen: Vom „Gospel of Efficiency” zum „War of Ideas”. Zum Verhältnis von Wissenschaft, Politik und Ideologien in den Vereinigten Staaten, in: Archiv für Sozialgeschichte, Band 50, 20120,S. 373-391.

56 Vgl. Steven F. Hayward: The Age of Reagan. The Fall of the Old Liberal Order 19641980, New York 2001, S. xxvii.

57 Vgl. Maurice Isserman und Michael Kazin: America Divided. The Civil War of the 1960s, Oxford 2004, S.202. 
großen Erwartungen, empfanden die meisten Amerikaner - ganz unabhängig davon, wo sie politisch standen - den „War on Poverty“ als gescheitert. Die konservativen Gegner der Programme argumentierten freilich vom ersten Tag an, dass dadurch eine „Kultur der Abhängigkeit“ geschaffen werde, die es den Empfängern von sozialstaatlichen Leistungen unmöglich mache, auf eigenen Beinen zu stehen - ein Gedankengang, der bis heute eine große Rolle spielt beim republikanischen Widerstand gegen ähnliche Programme.

$\mathrm{Zu}$ diesen Kritikern gehörte auch eine Gruppe von Ex-Liberalen, die aus dem vermeintlichen Scheitern der Great Society eine radikale Konsequenz zogen und eine vollständige politische Konversion vollzogen: Als „Neoconservatives“ gingen diese Konvertiten in die Geschichte ein..$^{58}$ Der prominenteste unter ihnen war Irving Kristol. Der über lange Jahre intellektuell so überaus marginalisierte Konservativismus erhielt dadurch bedeutsame Verstärkung. Die Neoconservatives strickten die überwölbende Erzählung zum Scheitern der Great Society: dass selbsternannte „Sozialingenieure“ im blinden Glauben an die Unfehlbarkeit technischer Rationalität den Bogen überspannt hätten und mit ihrer Politik der Intervention ständig nicht beabsichtigte Nebenfolgen schafften. Einem Teufelskreis gleich würden schließlich wiederum neue Eingriffe erforderlich, die wiederum neue Nebenfolgen produzierten würden - usw. Das Ideal liberaler Planer sei eine Welt perfekter technischer Rationalität, in der ein Rädchen in das andere griff. Verglichen damit musste aber die wirkliche Welt - unvollkommen, wie sie nun einmal war - unweigerlich fehlerhaft erscheinen und der ständigen Überarbeitung bedürfen; die liberalen Technokraten sähen, mit anderen Worten, Probleme, wo in Wahrheit gar keine existierten. ${ }^{59}$

Der Abfall der Neokonservativen war ein sicheres Zeichen dafür, dass Amerikas Konservative bereits auf dem Weg waren, eine intellektuelle Gegenöffentlichkeit aufzubauen. Diese und auch intellektuell weniger elaborierte Polemiken gegen den „War on Poverty“ blieben jedenfalls nicht ohne Echo. In der weißen Arbeiterklasse, auch außerhalb des amerikanischen Südens, wuchsen die Vorurteile gegen „Welfare Queens“ und „Poverty Pimps“, die es sich im neuen Sozialsystem gemütlich gemacht hätten. Hinzu kam, dass auch der große Rückhalt für die Bürgerrechtsbewegung nördlich der „Mason-Dixon-Linie“ bei weißen Amerikanern seit Mitte der der 1960er Jahre deutlich zurückgegangen war. Seit 1965 kam es immer wieder zu aggressiven Unruhen in den amerikanischen Großstädten. Viele

58 Vgl. Justin Vaisse: Neoconservatism. The Biography of a Movement, Cambridge (MA) 2010; Vgl. auch zu den verschiedenen konservativen Strömungen nach 1945 Torben Lütjen: Aufstieg und Anatomie des amerikanischen Konservativismus. Ein Forschungsbericht, in: Archiv für Sozialgeschichte, Band 54, Bonn 2014.

59 Vgl. Lütjen: Vom „Gospel of Efficiency“ zum „War of Ideas“, a.a.O. 
Schwarze waren bitter enttäuscht, dass sich trotz all der Maßnahmen der JohnsonRegierung nur wenig an der systematischen Diskriminierung änderte, die sozialen Verhältnisse weiter wie zementiert blieben. Die Riots von Los Angeles, Detroit und anderen Orten produzierten Bilder, die allesamt natürlich Abend für Abend in die Wohnzimmer auch des weißen Amerikas flimmerten und dort für einen Schock sorgten. 1964 hatten noch 68\% der Weißen außerhalb der Südstaaten die Bürgerrechts-Initiativen Johnsons unterstützt; nur zwei Jahre später war plötzlich eine Mehrheit der Meinung, dass die Regierung viel zu schnell vorging bei ihren Bemühungen um Integration. ${ }^{60}$ Auch die Strategien der Bürgerrechtsbewegung funktionierten außerhalb des offen rassistischen Südens sehr viel weniger. Dort waren die Diskriminierungen subtiler und ließen sich kaum mit Bundesgesetzten und notfalls dem Einsatz der Nationalgarde aus dem Weg schaffen. Für die Herstellung wirklich gleicher Lebensverhältnisse brauchte es wesentlich massivere Eingriffe.

Und diese Eingriffe erfolgten, sowohl von Seiten der Bundesregierung in Washington, als auch von Seiten der Bundesstaaten. Besonders umstritten war etwa die Praxis des Busing, durch die Kinder teilweise in wahren Odysseen mit dem Schulbus quer durch die Stadt gefahren wurden, um eine ausgeglichenere ethnische Zusammensetzung der Schulen zu gewährleisten. Solche Maßnahmen machten die Idee der „Great Society“ nicht unbedingt populärer in der weißen Mittelschicht und schufen dort eine stärkere Empfänglichkeit für eine konservative Ideologie, die staatliche Eingriffe generell für schädlich hielt. In den 1960er fusionierten somit dauerhaft zwei Konfliktthemen miteinander: Sozialpolitik und Race. Denn dort wo offener Rassismus immer weniger tolerierbar wurde, nahm der Wiederstand gegen „Welfare“ oft diesen Platz ein, eine Art Ersatz-Ressentiment, das sich äußern ließ, ohne dabei gleich als Mitglied des Ku-Klux-Klans verdächtigt zu werden - und doch stets mit der gedanklichen Assoziation auf ethnische Minderheiten. ${ }^{61}$

Überhaupt: Die republikanische Partei hätte für die Ideologie des Small Government kaum so viel Unterstützung erhalten, wenn es dabei ausschließlich um Fragen der Ökonomie gegangen wäre. Wie bereits erwähnt, stand der konservative Süden, als Region fraglos der Hauptprofiteur der gewaltigen Arbeitsprogramme des New Deal, traditionell ja keineswegs für den unbedingten Glauben an die Segnungen eines ungezügelten Kapitalismus. Aber mit dem Widerstand gegen den „Civil Rights Act“ erschien vielen Südstaatlern eine Ideologie, die jede

60 Vgl. Maurice Isserman/Michael Kazin: America Divided. The Civil War of the 1960s, Oxford 2004, S. 207.

61 Vgl. Martin Gilens: Why Americans Hate Welfare: Race, Media, and the Politics of Antipoverty Policy, Chicago 2000. 
Form von Staateingriffen für potentiell schädlich hielt, mit einem mal sehr viel plausibler. ${ }^{62}$ Dass der Staat zu einem bürokratischen Monster geworden war, dem Einhalt zu gebieten war, es viel zu viele Regulierungen und Verbote aus Washington gab und das mit alledem die Idee von Amerika verraten wurde - mit dieser Parole konnten sich am Ende libertäre Suburbanites an der Westküste der USA, offene Befürworter der Rassentrennung im Süden, Waffenliebhaber aus dem Mittleren Westen und texanische Rancher gleichermaßen identifizieren. Diese eifernde Staatsfeindschaft war der kleinste gemeinsame Nenner der Konservativen Bewegung - der anderseits jedoch so klein eben nicht war, ließ sich mit ihm doch eine kraftvolle Erzählung schmieden, die vortrefflich mit den Gründungsmythen des Landes verbunden werden konnte.

Mit Richard Nixons Sieg 1968 kamen diese Gruppen das erste Mal mehrheitsfähig zusammen. Insofern war er gewiss eher Profiteur, nicht der eigentliche Schöpfer der von ihm reklamierten ,Silent Majority. “Überhaupt: Nixon war nicht wirklich ein Konservativer in der Goldwater-Tradition. Schon lange bevor er sich als eine der moralisch zweifelhaftesten Personen entpuppte, die jemals im Weißen Haus saßen, war das Misstrauen unter Konservativen ihm gegenüber groß gewesen. Einmal ins Amt gekommen, dachte er gar nicht daran, den dominierenden keynesianischen Konsens in Frage zu stellen, die Sozialprogramme zurückzufahren oder gar den „Civil Rights Act“ umzukehren. Nixon war ein Opportunist, kein Ideologe. Und doch lieferte er in stilistischer Hinsicht die vorerst letzte Zutat für den modernen amerikanischen Konservativismus. Was bei Goldwater schon in Ansätzen vorhanden gewesen war, darüber verfügte Nixon in verschwenderischem Überfluss: einen aggressiven Populismus, der sich vor allem in Anti-Intellektualismus und Anti-Elitismus niederschlug. ${ }^{63}$ Wenn schon nicht der Erfinder, so waren Nixon und sein Vizepräsident Spiro Agnew doch die virtuosen Popularisierer des politischen Kampfbegriffes von den „liberalen Eliten.“ Gemeint war damit eine abgehobene und versnobte upperclass, die zwar eine ethnische und sexuelle Minderheit nach der anderen für geschehenes Unrecht der Vergangenheit kompensierte, dafür aber die Sorgen und Ängste des „,hard-working American“ aus den Augen verloren hätte. Die ,liberale Elite“ war gottlos, dekadent, unpatriotisch, aber vor allem unendlich bigott, denn während sie vorgab, den Unterprivilegierten zu helfen, ging es ihr in Wahrheit nur darum, andere zu bevormunden. Für die „liberale Elite“ war es natürlich ein Leichtes, für die rassische Integration

62 Vgl. hierzu auch die exzellente Fallstudie von Kevin Kruse: White Flight. Atlanta and the Making of Modern Conservatism, Princeton 2005.

63 Vgl. Michael Kazin: The Populist Persuasion. An American History, New York 1995, S. 248-255. 
von öffentlichen Schulen zu werben - verwahrten sie angeblich doch ihre eigenen Zöglinge sicherheitshalber lieber auf teuren Privatschulen.

Der Begriff war so flüchtig wie bald schon ubiquitär, niemand mochte genau zu sagen, wo die „liberale Elite“ ihr Zentrum hatte oder wer überhaupt dazu gehörte. Aber das war gerade die Stärke dieser populistischen Erzählung, erweckte sie doch den Eindruck, einer ebenso machtvollen wie klandestinen Allianz von Deutungseliten gegenüber zu stehen. Dazu gehörten wahlweise die Professoren an den Elite-Universitäten der Ostküste, die politische Redaktion der New York Times, Regierungsbürokraten, liberale Unternehmer, Bürgerrechtsaktivisten und überhaupt alle, mit denen „Tricky Dick“ über Kreuz lag und die auf Nixons offizieller ,enemy list“" standen. Selbst jene, die gegen den Vietnam-Krieg protestierten - und sich gewiss dagegen gewehrt hätten, mit den Politikern der Demokratischen Partei und anderen Mitgliedern des „Establishment“ in einem Atemzug genannt zu werden - saßen angeblich gleich mit im Boot bei dieser Verschwörung. Schließlich ruinierten sie die Moral an der der Heimatfront, und außerdem: waren es nicht die gut situierten Söhne und Töchter der , ,liberalen Eliten“ die da protestierten? Drückten sich nicht die meisten dieser Söhne ohnehin mit fadenscheinigen Argumenten vom Kriegsdienst oder wurden von vornherein gar nicht eingezogen? Nixons Attacken gegen die Gegner des Vietnam-Krieges waren äußerst effizient, selbst dann noch, als sich eine Mehrheit in Umfragen längst gegen die Rolle der USA in Südostasien aussprach. Denn in der Tat begann sich ein Teil der Bewegung zu radikalisieren, agitierte gegen den amerikanischen „Imperialismus“, solidarisierte sich mit dem Freiheitskampf der Vietcong und verbrannte amerikanische Flaggen. In der weißen Arbeiterklasse und Mittelschicht wurde nichts von alledem goutiert. Und Nixon, ein Mann, der nicht viel mehr war als die Summe seiner Ressentiments, spürte das sehr genau. Bei seiner Wahl 1968 sollte die Republikanische Partei zum ersten Mal eine Mehrheit der Stimmen aus der Arbeiterklasse und von Katholiken bekommen: Nixons ausgerufene „Silent Majority“ hatte die tatsächliche Mehrheit errungen.

\section{DiE TRANSFormation DES AMERIKANISCHEN LIBERALISMUS}

So entglitt der Demokratischen Partei allmählich die während des New Deal erlangte Dominanz innerhalb der weißen Mittelschicht und der weißen Arbeiterklasse. In der zweiten Hälfte der 1960er Jahre begann für den amerikanischen Konsensliberalismus - diese Verkörperung politischen Zentrismus und vermeintlich unpolitischen Expertentums - ein auswegloser Zwei-Fronten-Krieg, den er 
kaum gewinnen konnte. Denn da war ja nicht nur die Formierung, Transformation und Erstarkung der noch wenige Jahre zuvor für hoffnungslos unterlegen gehaltenen konservativen Bewegung. Ungemach für den amerikanischen Konsens drohte auch von der gegenüberliegenden Seite des politischen Spektrums: nämlich von ganz links. Zwar sorgte hier der Protest gegen den Vietnam-Krieg mit Abstand für die größte Mobilisierungswelle, und blieb als identitätsstiftendes Ereignis der Protestgeneration der 1960er Jahre überaus wichtig. Aber für die politische Konfliktstruktur der USA waren andere Themen und andere Gruppierungen - auch wenn diese sich mit der Anti-Kriegsbewegung oft personell stark überschnitten - gleichwohl wichtiger. Denn während große Teile der weißen Mittelschicht und Arbeiterklasse die Veränderungen der 1960er Jahre zutiefst ängstigten, ging es anderen bei weitem nicht schnell genug voran.

Wahrscheinlich ist dies fast eine historische Gesetzmäßigkeit: Jede erfolgreiche Emanzipation wird mit dem Ruf nach mehr Emanzipation beantwortet, jede Tendenz zur Liberalisierung mit der Einforderung weiterer Freiheiten erwidert. In den USA der 1960er Jahre gab es - von der bereits erwähnten schwarzen Bürgerrechtsbewegung abgesehen - viele andere zuvor marginalisierte Randgruppen, die jetzt vehement an die Öffentlichkeit drängten: Die Chicano-Bewegung, die Frauen-Bewegung, schließlich die Bewegung für die Rechte Homosexueller usw. Es ist eine bunte Allianz, die seit den 1960er Jahren, von der ganz anderen Seite des politischen Spektrums kommend, den Status Quo herausforderte. In anderen Fällen schien es gar nicht unmittelbar um Politik zu gehen: Sex, Drugs und Rock'n Roll stehen für viele aus der Baby Boomer Generation im Vordergrund. Theodore Roszak erfindet in dieser Zeit den Begriff der „Counter Culture“ für eine Jugendkultur, die sich von den traditionellen Normen der Gesellschaft abgewandt hat und auch nicht länger versucht, sie zu verändern. ${ }^{64}$ Traditionelle Formen von Autorität freilich fordern alle heraus - manche eben durch unmittelbare politische Aktionen, andere durch alternative Lebensweisen. Einige verließen dabei in der Tat den Rahmen des „American Creed“. Sie drängen nicht länger auf Teilhabe am amerikanischen Traum, der in ihren Augen für viele Amerikaner stets nur ein Alptraum gewesen war. Dies gilt vor allem für den radikalisierten Flügel der schwarzen Bürgerrechtsbewegung wie die „Black Panther“ oder die „Nation of Islam“ des Malcolm X. Die einen fordern die maoistische Revolution, die anderen in einer radikalen Umkehr der Ideen Kings und der Bürgerrechtsbewegung die Loslösung von den USA und die Konstituierung einer eigenen Nation.

64 Vgl. Theodore Roszak: The Making of a Counter Culture: Reflections on the Technocratic Society and Its Youthful Opposition, Berkeley 1969. 
Freilich: diese Gruppen blieben die Ausnahme. Die meisten anderen Bewegungen wurden - eben darum sind sie hier von Interesse - vom politischen System der USA integriert. ${ }^{65}$ In Bezug auf die Protestkultur der 1960er Jahre ähnelten sich die Entwicklungen in Europa und den USA ${ }^{66}$ - wohl mit dem Unterschied, dass das Chiffre „1968“, in Deutschland und Frankreich so übermächtig, in den USA eine geringere Rolle spielte. Zwar ist dies auch dort ein besonders turbulentes Jahr, aber da die Entwicklungen in den USA etwas früher einsetzen - das „Free Speech Movement“" in Berkeley bildete sich bereits im September $1964^{67}$ - stellte 1968 mit der Ermordung Martin Luther Kings und Bobby Kennedys und der Wahl Richard Nixons zum US-Präsidenten eher Endpunkt als Höhepunkt der Entwicklung dar.

Was für unseren Kontext wichtig ist: Der Aufruhr dieser Jahre sollte nicht nur weiter zum konservativen Backlash beitragen und die Bewegung mit weiterer $\mathrm{Mu}-$ nition versorgen. Er sollte langfristig auch die Demokratische Partei verändern.

Auf der liberalen, progressiven Seite ist diese Geschichte jedoch weitaus schwieriger zu erzählen als in Bezug auf die Formierung des amerikanischen Konservativismus. Zwar sollten auch nach Goldwaters Kampagne von 1964 noch einmal 16 Jahre vergehen, bis die konservative Revolution mit Reagan endgültig an ihr Ziel gelangt war, auch hier kämpften moderate und konservative Gruppen bis dahin um die Vorherrschaft in der Partei. Doch verblasst dieser Konflikt im Vergleich mit den Friktionen auf der anderen Seite: Dort standen weite Teile der Protestgeneration in schroffer Frontstellung zur Regierung Lyndon B. Johnsons. Beim Parteitag der Demokraten 1968 in Chicago kam es zu gewalttätigen Auseinandersetzungen zwischen Anhängern der Neuen Linken, für die Lyndon B. Johnson nichts anderes als ein Kriegsverbrecher war („Hey hey LBJ, how many kids did you kill today?“" skandieren die Protestierenden), und der Polizei. Die Partei selbst war über Vietnam tief gespalten und droht daran beinahe zu zerbrechen. Chicago produzierte Bilder, die der Demokratischen Partei in diesem Wahlkampfjahr nicht unbedingt halfen und Munition lieferten für Richard Nixons Anspruch, die Stimme der „Silent Majority“ zu sein.

1972 dann allerdings schien es zunächst so, als habe die Neue Linke die Demokratische Partei ähnlich furios erobert, wie es den Goldwater-Republicans 1964 mit der GOP gelungen war. Die Partei nominierte George McGovern, den Senator

65 Vgl. zum Verhältnis von sozialer Bewegung und Partei in den USA allgemein Manfred Brocker: Integration durch Partizipation. Soziale Bewegungen im politischen System der USA. In: Zeitschrift für Politikwissenschaft 19/2, 2009, S. 237-274.

66 Vgl. Norbert Frei: 1968. Jugendrevolte und globaler Protest, München 2008.

67 Wahrscheinlich hängt dies damit zusammen, dass der Baby Boom in den USA einige Jahre früher einsetzte als in Westeuropa, vgl. Frei: 1968, a.a.O., S. 214. 
aus South Dakota, zu ihrem Präsidentschaftskandidaten. McGovern war ein früher Gegner des Vietnam-Krieges gewesen und stand auch bei anderen Themen auf dem extrem linken Flügel seiner Partei. Auch seine Nominierung war, wie bei Goldwater, zwar ein Vorzeichen, für alles was noch kommen mochte, verdankte sich zu diesem Zeitpunkt aber eher einem Machtvakuum innerhalb der Partei und den diversen Fehltritten und Ausfällen der eigentlichen Favoriten. Auch McGovern lebte von der Unterstützung hochmotivierter Basisaktivsten, die ein träges Partei-Establishment förmlich überrollten: 1972 spielten in der Demokratischen Partei innerparteiliche Vorwahlen zum ersten Mal eine entscheidende Rolle. Der Nominierungsparteitag in Miami Beach 1972 sollte zwar weniger gewalttätig, aber ähnlich erinnerungswürdig verlaufen wie jener vier Jahre zuvor in Chicago, nur, dass der Tumult sich dieses Mal eher in der Halle anstatt davor abspielte. Viele der Delegierten waren schon habituell der Neuen Linken zuzuordnen. McGovern selbst hatte großen Anteil an dieser Zusammensetzung der Delegiertenschaft gehabt. Denn nach den chaotischen Vorgängen vier Jahre zuvor hatte die Partei in der Zwischenzeit eine Kommission eingesetzt, deren Beschlüsse für die künftige Ausrichtung der Partei historische Bedeutung haben sollte, und den Vorsitz hatte praktischer Weise er selbst inne gehabt: Die sognannte McGovern/Fraser-Kommission. ${ }^{68}$ Sie legte u.a. fest, dass auf dem Parteitag Minderheiten repräsentativ vertreten sein mussten und dementsprechend ungewöhnlich war die $\mathrm{Zu}$ sammensetzung des Delegiertenkörpers im Vergleich zu früheren Konventen: 38\% der Delegierten waren Frauen (1968: 14\%). 14\% waren Afro-Amerikaner (1968: 5\%). Und während vier Jahre zuvor nur 2\% der Anwesenden unter 30 Jahre alt gewesen waren, waren es 1972 23\%. Von allen Zahlen war dies jedoch wohl die Interessanteste: $80 \%$ der Delegierten waren zum ersten Mal bei einem Nominierungsparteitag der Demokraten dabei. ${ }^{69}$

Es war insofern nicht verwunderlich, dass auch dieser Parteitag als ähnlich chaotisch in Erinnerung blieb wie Chicago vier Jahre zuvor. Nicht alle verabschiedeten Resolutionen waren von größter Ernsthaftigkeit geprägt, wie z.B. die 39köpfige Vorschlagsliste für das Amt des Vizepräsidentschaftskandidaten, auf der sich neben dem Namen Mao Zedongs auch die Frau des Kampagnenmanagers von Richard Nixon befand..$^{70}$ Demokraten, die den Idealen der Studenten,- Frauen oder Anti-Kriegsbewegung nicht nahestanden, reagierten entsetzt auf die Vorgänge von Miami Beach. Konservative Südstaatler hatten schon seit 1964/1965 damit begonnen, die Partei in Scharen verlassen. Jetzt folgten, wenngleich in geringerem

68 Vgl. hierzu vor allem Byron E. Shafer: Quiet Revolution. The Struggle for the Democratic Party and the Shaping of Post-Reform Politics, New York 1983.

69 Vgl. Patterson: Grand Expectations, a.a.O. S. 760.

70 Vgl. Isserman/Kazin: America Divided, a.a.O., S.237. 
Ausmaß, auch viele Gewerkschaftsführer, denen die Kultur der 1960er Jahre ebenfalls nicht behagte - mehr vielleicht noch, als die Politik, um die es dabei ging. Ihre Unzufriedenheit lag auch darin begründet, dass durch die Parteireformen der McGovern/Fraser-Kommission die Macht der alten Parteicliquen gebrochen wurden: fortan würden Kandidaturen nicht länger von den „Bossen“ der Parteien und Gewerkschaften in rauchgeschwängerten Hinterzimmern ausgeknobelt werden. In den Parteien - auch die Republikaner begannen von nun stärker mit der Ausweitung des Vorwahlsystems - setzte eine neue Kultur der Partizipation ein, durch die sich für motivierte Basisaktivisten ganz neuartige Formen der Beeinflussung ergaben. ${ }^{71}$

Die Gewerkschaften sollten langfristig in die Wählerkoalition der Demokratischen Partei zurückfinden, den Tumulten von Miami Beach zum Trotz. Aber ihre Bedeutung würde nie wieder so stark werden wie vor dieser Zäsur, und das nicht nur wegen des Nachlassens ihrer organisatorischen Schlagkraft aufgrund hoher Mitgliederverluste. Es bestimmten zunehmend auch andere Themen die Agenda. Den diversen Protestgruppen, die durch McGovern in die Partei eingedrungen waren, so unterschiedlich sie ansonsten im Einzelnen auch waren, ging es stark um Identitätspolitik. Politisch zu werden hieß demnach, nicht auf universalistische Werte zu rekurrieren, sondern das eigene und sodann das Bewusstsein der Umwelt für die eigene Position und Identität zu schärfen. ${ }^{72}$ In der Tradition linker Politik ging es dabei zwar weiter um Ungleichheiten - nur dass diese nicht mehr allein ökonomischer Natur waren, da es um die Benachteiligung aufgrund anderer Merkmale ging: weil man eine andere Hautfarbe hatte, ein anderes Geschlecht, eine andere sexuelle Orientierung usw. Deswegen verschwanden die klassischen Themen sozialer Ungleichheit natürlich nicht von der Agenda der Partei, allein schon, weil man das eine vom anderen ja faktisch kaum trennen konnte. Aber mindestens bis zur Mitte der Nuller-Jahre des 21. Jahrhunderts - als das Thema der sozialen Ungleichheit mit Nachdruck zurückkehrte - wurden die alten Brot-und-ButterThemen in ihrer Bedeutung deutlich von den Themen der Identity Politics überschattet. Insgesamt förderte das einen Trend - nicht unbedingt zum Vorteil der

71 Vgl. Shafer: Quiet Revolution, a.a.O.

$72 \mathrm{Vgl}$. für den Unterschied zwischen den klassischen Ideologien und moderer Identitätspolitik John Schwarzmantel: Ideology and Politics. London 2008, S. 109-130; für die Bedeutung der Identity Politics in der neuen Linken in den USA Andrew Hartman: A War for the Soul of America. A History of the Culture Wars, Chicago 2015, S. 18-37. 
Demokraten - dem auch Gruppen innerhalb der Republikanischen Partei zuarbeiteten: Auf Themen der Gesellschaftspolitik zu setzten anstatt auf solcher sozioökonomischer Natur.

Was sich dort vollzog, unterschied sich im Grunde nicht sehr von der Entstehung einer neuen, postmaterialistischen Konfliktachse in Westeuropa ${ }^{73}$ Allerdings konnte sich in den USA aus bekannten Gründen keine Dritte Partei mit Aussicht auf Erfolg gründen - wie in Kontinentaleuropa die Grünen - weshalb der Konflikt zwischen Alter und Neuer Linke noch stärker innerhalb einer Partei ausgetragen wurde. Und die Protagonisten der Protestbewegung in den USA fanden sehr viel schneller zu einem pragmatischen Umgang mit der Situation. Tom Hayden etwa, einer der führenden Köpfe der „Students for a Democratic Society“ (SDS) und der Hauptautor des „Port Huron Statements“, dem Gründungsmanifest der Neuen Linken in den USA, war 1972 bereits Delegierter beim Konvent in Miami Beach - nachdem er 1968 bei den Straßenschlachten in Chicago noch von der Polizei festgenommen und verhaftet worden war. Der wichtigste und folgenschwerste Unterschied zu Europa war freilich, dass die neue Identitätspolitik in den USA auch einem Gegner von ganz anderem Kaliber gegenüberstand, da Amerikas tiefe Religiosität größere Ressourcen für die Verteidigung traditioneller Moralvorstellungen bereithielt, und die Fundamentalliberalisierung des letzten Drittels des 20. Jahrhundert daher auf deutlich größeren Widerstand stieß.

George McGovern verlor 1972 so krachend wie Barry Goldwater 1964. Seine absolute Stimmenzahl war ähnlich niedrig, aber in Bezug auf das Electoral College war das Ergebnis noch weitaus deprimierender: McGovern hatte gerade mal einen einzigen von 50 Bundesstaaten gewonnen, Massachusetts. Was der Konvent und der anschließende Wahlkampf bereits angedeutet hatten, war nach der Wahl außerdem zur Gewissheit geworden: Die Demokraten hatten offenkundig endgültig ihre einst dominante Rolle innerhalb der weißen Arbeiterklasse verloren, die Richard Nixon mit 70\% für sich gewann (das beste Ergebnis, das Republikaner in diesem Segment jemals erzielen sollten.) Und doch: Bei genauer Betrachtung spiegelten sich in McGoverns Wählerkoalition bereits die Potenziale dessen, was John Judis und Rudy Texeira 30 Jahre später als „Emerging Democratic Majority“ bezeichnen sollten. ${ }^{74}$ Unter nicht-weißen Wählern, also vor allem Afro-Amerikanern und Hispanics, schnitt McGovern besser ab als Hubert Humphrey vier Jahre zuvor (87\%). McGovern verlor überdies zwar auch eine Mehrheit der Stimmen der Frauen - lag in der Gruppe berufstätiger Frauen jedoch vorne. Und auch bei

73 Vgl. Ronald Ingelehart/Paul R. Abramson: Value Change in Global Perspective, Michigan 1995.

74 Vgl. John B. Judis/Ruy Teixeira: The Emerging Democratic Majority, New York 2002. 
Akademikern schnitt er trotz seiner katastrophalen Niederlage besser ab als Humphrey 1968. Es waren allesamt Gruppen, die in der Zukunft wachsen sollten. ${ }^{75}$

Und ebenso wie bei Goldwater war auch bei McGovern interessant, wo er eben gerade nicht verloren, sondern sogar dazugewonnen hatte: z.B. in Orten, die stark durch die Präsenz großer Universitäten geprägt waren. Einer dieser Orte war Madison, Dane County, das liberale Fallbeispiel unserer späteren Feldstudie: Dort fand McGovern Tausende begeisterter Anhänger, die für seinen Wahlkampf auf die Straße gingen.76 Hätte es sich dabei nur um eine Handvoll verträumter College-Towns gehandelt, wären diese Erfolge vielleicht weniger interessant gewesen. Aber das waren gleichzeitig die Orte, die durch die Nachbarschaft forschungsstarker Universitäten bald zu den Epizentren der technologischen Revolution wurden und beträchtlich wachsen sollten. Die Wahl 1972 deute daher nicht nur an, dass die Partei in Zukunft ethnisch bunter und weiblicher werden würde. Mit McGovern schälte sich in Umrissen auch die Dominanz der Demokraten unter hochqualifizierten Arbeitskräften im postindustriellen Informationszeitalter an. ${ }^{77}$

Doch wie bereits angedeutet: Die Geschichte der weltanschaulichen Homogenisierung der Demokratischen Partei ist deutlich komplizierter als die der Republikaner. Die Demokraten zogen aus der krachenden Niederlage von 1972 andere, pessimistischere Schlüsse als die Republikaner 1964 dies getan hatten. In den Folgejahren blieben sie oft genug ängstlich darauf bedacht, bloß nicht zu sehr mit dem Radikalismus der Protestbewegung identifiziert zu werden. Gänzlich unberechtigt waren diese Ängste nicht: Die Phase liberaler Hegemonie, die man grob von 1932 bis 1968 veranschlagen kann, ${ }^{78}$ ging zu Ende und der amerikanische Liberalismus fühlte sich zunehmend in der Defensive. In den 40 Jahren von 1968 bis 2008 saß 28 Jahre lang ein Republikaner im Weißen Haus. Und die einzigen beiden Demokraten, denen es in dieser Zeit gelang, zu triumphieren, waren Demokraten aus dem konservativen Süden. Vor allem die Präsidentschaft des Zentristen Bill Clinton, der in der Sozialpolitik viele Impulse des amerikanischen Konservativismus aufnahm, ${ }^{79}$ schien Bestätigung der These zu sein, dass Demokraten

75 Vgl. ebd. S.37-38.

76 Vgl. Bruce Miroff: The Liberals' Moment. The McGovern Insurgency and the Identity Crisis of the Democratic Party, Lawrence 2007.

77 Vgl. Judis/Teixeira: The Emerging Democratic Majority, a.a.O.

78 Dies ist eine gängige Zäsurensetzung, vgl. aber besonders pointiert Sam Tanenhaus: The Death of Conservatism, New York 2009.

79 Vgl. Gil Troy: the Reagan Revolution. A Very Short Introduction, Oxford 2009, S. 122-124. 
nur dann gewinnen konnten, wenn sie so weit wie möglich in die politische Mitte rückten.

Andererseits: Unter ihrer Oberfläche veränderte sich die Partei langfristig dennoch in jene Richtung, die sie mit McGovern eingeschlagen hatte. Noch in der Clinton-Ära verschwanden konservative Südstaatler endgültig aus der Partei - ein Schicksal, dass dann etwas später auch andere, eher als ideologisch moderat zu bezeichnende Politiker traf. Die Partei wurde weiblicher, weniger weiß und säkularer. Sie nahm neue Themen auf, wie die Umweltpolitik, die während der McGovern-Kampagne zum ersten Mal auf der Agenda der amerikanischen Politik auftauchte. Und während sie bei wirtschafts- und sozialpolitischen Themen insbesondere in den 1990er Jahren dem konservativen - in Europa würde man sagen: neoliberalem Zeitgeist - weit entgegenkam, blieb sie auf dem Feld der Gesellschaftspolitik den Idealen der 1960er weitgehend treu. 2008 schließlich gewann Obama mit einer Wählerkoalition, die in den Augen vielen Beobachter der McGovern-Koalition verblüffend ähnelte. ${ }^{80}$

\section{Culture War? Religion als neUe KonfliktLinie}

Mit der Integration der Neuen Linken in die Demokratische Wählerkoalition war ein weiterer, wichtiger Baustein der ideologischen Konfliktmatrix der Gegenwart hinzugefügt. Das letzte Element war spätestens mit der Vollendung der konservativen Revolution durch Ronald Reagan 1980 in den Fokus der politischen Auseinandersetzung gerückt: Religion. Erstaunlicherweise hatte diese in all den fundamentalen Auseinandersetzungen der 1960er Jahre noch keine wirklich überragende Rolle gespielt. Zwar hatte es unter den viele Anti-Kommunistischen Gruppen, die seit den 1950er Jahren im Land aufblühten, eine Reihe von stark christlich inspirierten Aktivisten gegeben. ${ }^{81}$ Und gewiss war der Widerstand gegen die moralischen „Exzesse“ der Counterculture nur verständlich, wenn man sich die starke christliche Prägung der USA vergegenwärtigte. Dennoch sucht man etwa prominente Kirchenführer in der Goldwater-Bewegung noch vergeblich. Auf der

80 Vgl. Ross Douthat: The Obama Realignment, in: New York Times vom 7. 11.2012, abrufbar unter: http://campaignstops.blogs.nytimes.com/2012/11/07/douthat-the-oba ma-realignment/ (zuletzt abgerufen am 12.08.2014).

81 Vgl. Kenneth D. Wald/Allison Calhoun-Brown: Religion and Politics in the UnitedStates, 6. Auflage, Lanham 2011, S. 204; Leo Ribuffo: The Old Christian Right. The Protestant Far Right form the Great Depression to the Cold War, Philadelphia 1983. 
progressiven Seite sah dies fraglos anders aus: Hier war es immerhin der Baptistenprediger Martin Luther King gewesen, der über die Southern Christian Leadership Conference die Bürgerrechtsbewegung anführte und in dessen Reden neben dem Verweis auf den „American Creed“ auch christliche Motive der Versöhnung eine große Rolle spielten.

Überhaupt war der amerikanische Protestantismus - von der Abschaffung der Sklaverei bis hin zu den verschiedenen Reformprojekten des Progressive Movement - in der amerikanischen Geschichte sehr häufig auf der progressiven Seite zu finden gewesen. ${ }^{82}$ Konservative Christen hingegen hatten sich nach einer Reihe schwerer Niederlagen zu Beginn des 20. Jahrhunderts aus dem öffentlichen Leben weitgehend zurückgezogen. Auch in den 1960er Jahren schien sich diese Grundtendenz zunächst zu bestätigen. Als Amerika - wie andere westliche Gesellschaften - einen rasanten Wertewandel erlebte, durch den traditionelle Moralvorstellungen fundamental in Frage gestellt wurden, standen Amerikas konservative Christen an der Seitenlinie. Jerry Falwell, der spätere Initiator und Anführer der 1979 gegründeten „Moral Majority“, bekannte sich noch im turbulenten Jahr 1965 zur Abwendung von allem Weltlichen und lehnte es ab, sich für den Kampf gegen den Kommunismus oder die Bürgerrechtsbewegung vor den Karren einer Partei spanen zu lassen: „Preachers are not called upon to be politicians but to be soul winners. “ ${ }^{63}$

Das änderte sich in den 1970er Jahren, als gerade die Entscheidungen des liberalen Supreme Court - vor allem die Legalisierung von Abtreibungen in der Entscheidung Roe vs. Wade - zu einer massenhaften Mobilisierung des evangelikalen Amerika führte. Auch der soziale Aufstieg vieler evangelikaler Christen im Süden der USA, so ist bisweilen argumentiert worden, habe diese Mobilisierung gefördert - zum einen, weil ein höher sozialer Status grundsätzlich Partizipation fördert, aber auch, weil andere materielle Interessen nun besser zur Programmatik der republikanischen Partei passten und damit ein Bündnis nahe lag. ${ }^{84}$ Dabei ist das Wort „evangelikal“ nicht sonderlich präzise, sondern eine begriffliche Hilfskonstruktion, mit der sich angesichts der Vielfalt der vielen protestantischen Kirchen oder "Sekten“ in den USA zumindest jene unter einem Label zusammenfassen lassen, die, zunächst in theologischer Hinsicht, als konservativ gelten können. Es sind vor allem zwei Merkmale, anhand derer sich evangelikale Kirchengemein-

82 Vgl. George Marden: Understanding Fundamentalism and Evanglicalism, Grand Rapids 1991, S. 2.

83 Zitiert nach Geoffrey Layman: The Great Divide. Religious and Cultural Conflict in American Party Politics, New York, 2011.

84 Vgl. Wald/Calhoun: Religion and Politics, a.a.O. S. 216-221. 
den von den liberalen protestantischen Kirchen des sogenannten „Mainline Protestantism" abgrenzen lassen: zum einen der Glaube an die wörtliche Interpretation der Bibel, und zum anderen eine persönliche, intime Gottesbeziehung der Gläubigen, die sich in der Regel durch ein Konversionserlebnis auszeichnet (daher die Überzeugung ein „,born-again“, ein „wiedergeborener“ Christ zu sein). ${ }^{85}$

In der Retrospektive ist jedenfalls offensichtlich, dass es seit Beginn der 1970er Jahre überall im Land zu Vorfällen kam, die zunächst nur lokaler Natur zu sein schienen, sich jedoch zu häufig wiederholten, um reiner Zufall zu sein: z.B. der Streit um die Evolutionslehre in Schulbüchern an einer Schule in West Virginia 1974, woraufhin Tausende von Eltern einen Schulboykott organsierten; oder ein Referendum 1977 in einem County in Florida gegen eine Verordnung, die die berufliche Diskriminierung von Homosexuellen verbot - und zahllose andere Bürger-Proteste, die zunächst nur von lokaler Bedeutung zu sein schienen, deren Häufung aber darauf hindeutete, dass Amerikas Liberalisierung der 1960er Jahre längst eine Gegenreaktion, einen „backlash“, unter Amerikas konservativen Protestanten ausgelöst hatten.

Dennoch war nicht sofort offensichtlich, wohin das stärkere politische Erwachen des Amerikanischen Protestantismus parteipolitisch führen würde. Es lag jedenfalls eine gewisse Ironie darin, dass es mit Jimmy Carter ein Demokrat war, der 1976 mit seinem Versprechen der moralischen Erneuerung nach dem Watergate-Skandal maßgeblich zur Mobilisierung evangelikaler Christen beitrug und sie quasi damit endgültig in die politische Arena hineinzog. ${ }^{86} 1976$ hatte der Erdnussfarmer aus Georgia in der Gruppe evangelikaler Christen noch eine Mehrheit erringen können. Gleichwohl: Langfristig war dieses Segment angesichts der diametral entgegengesetzten ideologischen Richtungen, in der die beiden Parteien sich bewegten, nicht von der Demokratischen Partei zu halten. 1979 gründet sich unter Jerry Falwell die „Moral Majority“, die sich zum Ziel setzte, dem moralischen Niedergang des Landes entgegenzuwirken. Für viele liberale Zeitgenossen, aufgewachsen im Glauben an die Säkularisierung moderner Gesellschaften, waren die spektakulären Mobilisierungserfolge von Falwells Organisation ein regelrechter Schock: Nach nur einem Jahr ihrer Existenz hatte allein die „Moral Majority“, die Ende der 1980er Jahre wieder von der Bildfläche verschwand aber durch eine Reihe anderer Organisationen wie „Focus on the Family“ ersetzt wurde, vier Millionen Mitglieder und zwei Millionen Spender, von denen nicht wenige auch

85 Vgl. Michael Lienish: Redeeming America: Piety and Politics in the New Christian Right, Chapel Hill 1993.

86 Vgl. Andrew P. Hogue: Stumping God. Reagan, Carter, and the Invention of Political Faith, Waco 2012. 
selbst als freiwillige Helfer aktiv in Präsidentschafts-und Kongresswahlen mitmischten. ${ }^{87} \mathrm{Zu}$ Ronald Reagans Sieg 1980 trug die „Moral Majority“ maßgeblich bei. Seitdem waren evangelikale Christen ein fester Bestandteil der Republikanischen Wählerkoalition: der letzte republikanische Präsidentschaftskandidat, Mitt Romney, erhielt von ihnen bei der Wahl 2012 79\% der Stimmen.

Die starke, auch mediale Konzentration auf den amerikanischen Evangelikalismus verdeckt allerdings häufig den Blick auf noch eine andere und vielleicht noch wichtigere Entwicklung: der Abschied von den Konfessionsschranken. Diese hatten bis dahin das Wahlverhalten der Amerikaner bestimmt, nicht etwa die Religiosität oder Frömmigkeit eines US-Bürgers. Katholiken wählten traditionell stärker demokratisch, Protestanten mehrheitlich republikanisch.

Mit Glaubensfragen an sich hatte das wenig zu tun. In der großen Einwanderungswelle um 1900 waren die Demokraten ganz einfach zur Interessenpartei von katholischen Einwanderern aus Europa geworden waren, während Amerikas „WASPs“ - kurz für „White Anglon-Saxon Protestants“ - mehrheitlich republikanisch wählte. Wie auch in anderen protestantisch dominierten Ländern hielt man Katholiken auch in den USA für unzuverlässige Patrioten, die es im Zweifel mit Rom hielten. Aber die Moralisierung der amerikanischen Politik, und die Bedrohung durch eine säkulare und sexuell promiskuitive Jugendbewegung ließen neben dem sozialen Aufstieg vieler Katholiken - die Konfessionsunterschiede in den Hintergrund rücken. Schon 1968 hatte mit Richard Nixon zum ersten Mal ein republikanischer Präsidentschaftskandidat die Mehrheit der Stimmen der Katholiken für sich gewinnen können. Seit den 1970er Jahren beobachteten Wahlforscher, dass die konservativen Elemente in beiden Konfessionen nun stärker für die gleiche Partei wählten und das gleiche galt andersherum auch für liberale Christen bzw. Konfessionslose. Konservative Protestanten sowie konservative Katholiken wählten tendenziell stärker republikanisch, liberale Christen beider Konfessionen stärker demokratisch. Bei der Präsidentschaftswahl 2012 erhielt Mitt Romney von Amerikanern, die einmal oder mehrmals die Woche beteten, über 60\% der Stimmen. ${ }^{88}$ Unter weißen Amerikanern allein fällt diese Verteilung sehr viel drastischer aus, da sich unter Obamas Wählern schließlich viele Hispanics und AfroAmerikaner befinden, die ebenfalls durch eine starke Religiosität auffallen.

87 Vgl. Clyde Wilcox: Onward Christian Soldiers? Boulder 1996, S. 96.

88 Vgl. den Report des Pew Research Centers vom 12. Mai 2015: America's Changing Religious Landscape, abrufbar unter: http://www.pewforum.org/2015/05/12/americaschanging-religious-landscape/ (zuletzt abgerufen am 03.08.2015). 
Vor allem die 1980er und 1990er Jahre wurden durch den Aufstieg der Christlichen Rechten dann die Jahre der „Culture Wars“. Abtreibung, Homosexualität, Schulgebet und schwieriger zu kategorisierende, weil sehr viel diffusere Themen, in denen es um die „Seele Amerikas“ ging und die Frage, ob das Land im „,moralischen Abstieg“ („,moral decline“) befindlich war, prägten die Diskussionen. Den Begriff des „Culture War“ hatte der Soziologe James Davison Hunter 1991 in die Diskussion eingeführt. Nach Hunter teilte sich das Land zunehmend in zwei Lager mit Weltsichten, die kaum länger miteinander zu versöhnen waren.

Auf der einen Seite, so Hunter, stand das ,orthodoxe“ Amerika: dort glaubte man an eine transzendente Autorität, überlieferte Normen und Werte, an eindeutige moralische Unterscheidungen zwischen Gut und Böse. Auf der anderen Seite des "Culture War" stand das „progressive“ Amerika: dort glaubte man an die Emanzipation von überkommenen Werten, an gesellschaftlichen Fortschritt, und an die Relativität moralischer Grundsätze.$^{89}$ Es war dieser tiefe moralische Konflikt, der die amerikanische Politik seit Ende der 1970er Jahren prägte. Und Ronald Reagan gelang es, das gewaltige Wählerreservoir der evangelikalen Christen für sich zu erschließen. Dabei war Reagan selbst eher kein tief religiöser Mensch, aber gerade in seiner bewussten rhetorischen Zuspitzung des Konfliktes zwischen den USA und der Sowjetunion stellte er eine starke emotionale Bindung her. Es war auch kaum ein Zufall, dass Reagan seine berühmte „Evil Empire“-Rede über die Sowjetunion ausgerechnet bei der Tagung des wichtigsten Dachverbandes der evangelikalen Kirchen in den USA, der National Associaton of Evangelicals, hielt.

Eines freilich sollte man bei allen Schilderungen über den großen Einfluss der Religion auf die amerikanische Politik - oder genauer: den Einfluss der religiösen Rechten auf die Republikanische Partei - nicht vergessen: Letzten Endes handelte es sich um ein Rückzugsgefecht. Amerika blieb bzw. bleibt zwar bis ins 21. Jahrhundert ein tief religiöses Land, zumindest im Vergleich zu anderen westlichen Gesellschaften. ${ }^{90}$ Doch einen Rückgang institutionalisierter Religion erlebten auch die USA, eine Entwicklung, die sich in den letzten 10 Jahren weiter beschleunigt hat. Nach einer Studie des Pew Research Centers bezeichnen sich mittlerweile fast 23\% der Amerikaner als Agnostiker und Atheisten. Betrachtet man wiederum die Situation in den verschiedenen Konfessionen genauer, so fällt - neben der re-

89 Vgl. James Davison Hunter: Culture Wars: The Struggle to Define America, New York 1991.

90 Vgl. Steven Pfaff: The Religious Divide: Why Religion Seems to Be Thriving in The United States and Waning in Europe, in: Jeffrey Kopstein/Sven Steinmo (Hg.): Growing Apart: America and Europe in the Twenty-First Century, New York 2008, S. 24-52. 
lativen Stabilität bei Katholiken durch hispanische Migration - vor allem die Veränderung im amerikanischen Protestantismus auf. Beispiellos zusammengeschrumpft sind im Verlauf der der letzten ca. 40 Jahre die Kirchen des sogenannten „Mainline Protestantism“: Liberale Glaubenskongregationen, die seit Beginn des 20. Jahrhunderts versuchten, Aufklärung und Wissenschaft mit dem Christentum zu versöhnen. Der größte Teil der politischen Klasse Amerikas hatte sich jahrelang aus den Rängen des Mainline Protestantism rekrutiert. Steil angestiegen ist hingegen im gleichen Zeitraum die Anzahl der Amerikaner, die sich als Mitglieder evangelikaler Kirchen bzw. allgemeiner als „,born-again-Christians“, als widergeborene Christen, bezeichnen: mittlerweile sind es über ein Viertel der Amerikaner. ${ }^{91}$

Der Politik gar nicht unähnlich, wuchsen also auch im Bereich der organisierten Religion die Ränder - besonders konservative, bibeltreue Christen auf der einen Seite und Menschen ohne jede christliche Bindung auf der anderen Seite während die religiöse Mitte zunehmend verwaiste. Es war ein idealer Nährboden für kulturellen Konflikt.

91 Vgl. den Report des Pew Research Centers vom 12. Mai 2015: America's Changing Religious Landscape, abrufbar unter: http://www.pewforum.org/2015/05/12/americaschanging-religious-landscape/ (zuletzt abgerufen am 03.08.2015). Vgl. insgesamt als Überblick für die Veränderungen der letzten Jahrzehnte Robert D. Putnam/David E. Campbell: American Grace. How Religion Divides and Unites Us, New York 2010. 



\section{Red and Blue America: Kennzeichen der Polarisierung im Zeitalter des Amerikanischen Dissens}

\section{KLASSE Und Kultur: ÜBER das Verschmelzen ZWEIER KONFLIKTLINIEN}

Mit dem Heraufziehen des „Culture War“ und der Infusion religiöser Themen in den politischen Diskurs waren schließlich die toxischen Zutaten für Amerikas ideologische Polarisierung der nächsten Jahre zusammengerührt. Natürlich traten seitdem auch neue Themen hinzu, die polarisierend wirkten: Der Krieg gegen den Terror nach 9/11 etwa, oder die Frage der Einwanderungsreform. Auch die Umweltpolitik besaß 1980 natürlich bei weitem noch nicht die Dimension, die sie heute hat. Und gewiss wechselten die Konjunkturen: Das Thema soziale Ungleichheit etwa besitzt heute wieder einen weitaus höheren Stellenwert als in den 1980 und 1990er Jahren. Gleichwohl dockten die meisten Themen der nächsten dreißig Jahre an die ideologische Konfliktmatrix dieser drei politischen Felder an: die Frage nach dem Einfluss des Staates und dem Vorrang des Marktes; die Frage der Chancengleichheit zwischen Menschen verschiedener Hautfarben und was der Staat tun sollte, um dieser Gleichheit näher zu kommen; und drittens dann die Kluft zwischen einem traditionellen, christlich inspirierten Gesellschaftsbild einerseits und einem progressiven, säkularen auf der anderen Seite. Auch die gesellschaftlichen Koalitionen und Allianzen, die beide Parteien bis in die Gegenwart tragen, bildeten sich im Großen und Ganzen in den formativen Jahren zwischen 1964 bis 1980 heraus.

Zeitgenössische Beobachter registrierten nicht sofort, dass sich damit ein dauerhaftes soziales und ideologisches „Realignment“ ergeben hatte, und man nun in eine lange Phase stabiler Polarisierung zwischen den Parteien eintreten würde. In der Tat schienen beide Wählerkoalitionen in ihrer sozialen Heterogenität sehr fragil. 
Da war ja nicht nur der bereits beschriebene Konflikt zwischen Alter und Neuer Linker in der demokratischen Partei. Auch die Republikaner hatten 1980 eine denkbar bunte Koalition zusammengefügt. In ihr versammelten sich christliche Fundamentalisten, die teilweise durchaus mit Skepsis auf die großen sozialen Ungleichheiten in den USA schauten, ebenso wie radikallibertäre Steuersenkungsaktivisten, die den Themen der religiösen Rechten wenig Sympathien abgewinnen konnten. Wie sollten diese Gruppen langfristig einträchtig zusammenbleiben? Amerikas politische Landschaft schien weiterhin von „cross-cutting-cleavages“ sich überschneidenden Konfliktlinien - geprägt, die im Normalfall eher zu einer Abschwächung der Konfliktintensität führen sollten, da politische Eliten darauf zu achten haben, keinen Teil ihrer Wählerkoalition zu verprellen. ${ }^{1}$ Unter diesen Umständen scheint es z.B. für einen Demokraten, der zum Präsidenten gewählt werden will, nicht besonders klug zu sein, Themen wie Abtreibung oder gleichgeschlechtliche Ehe zu stark zu thematisieren - da es in der weißen Arbeiterklasse nur bedingte Sympathie für diese Themen gibt.

In der Folgezeit allerdings passierte etwas sehr Erstaunliches. Zwar blieben diese Spannungen grundsätzlich erhalten, was angesichts der Abbildung einer so heterogenen Bevölkerung in einem Zwei-Parteien-System ja auch kaum überrascht. Gleichzeitig aber bewirkte die extreme Polarisierung, dass es zwischen den verschiedenen Wählersegmenten innerhalb der jeweiligen Parteikoalitionen zu einem ideologischen Angleichungsprozess kam, den amerikanische Politologen als Issue Conversion bezeichnet haben²: Wer vor dreißig Jahren durch die christliche Rechte politisch aktiviert wurde, mobilisiert etwa durch seine Opposition zu Pornographie und Abtreibung und dadurch seinen Weg in die Republikanische Partei fand, der neigt heute viel stärker dazu, für niedrigere Steuern einzutreten als noch vor Jahren - obgleich die Logik diese Verbindung nicht unbedingt zwingend macht. Das Gleiche gilt, im Fall der Demokratischen Partei, für den Zusammenhang zwischen der Unterstützung für den Sozialstaat und dem Eintreten für die Homo-Ehe oder den Schutz der Umwelt. Durch diesen Prozess nahmen die ideologischen Differenzen innerhalb der Parteien ab, was es den Parteieliten ermöglichte, sehr viel eindeutigere Botschaften auszusenden. Folgerichtig lässt sich dieser Prozess auch bei den Abgeordneten des amerikanischen Kongresses erkennen: Republikanische Mitglieder des Repräsentantenhauses etwa, die besonders stark

1 Vgl. Seymour M. Lipset/Stein Rokkan: Party Systems and Voter Alignments: CrossNational Perspectives. New York 1967.

2 Thomas M. Carsey/Geoffrey C. Layman: Changing Sides or Changing Minds? Party Identification and Policy Preferences in the American Electorate, in: American Journal of Political Science, Vol. 50, No. 2, April 2006, S. 464-477. 
für niedrige Steuern eintreten, sind heute oftmals auch bei gesellschaftspolitischen Themen sehr weit rechts positioniert. ${ }^{3}$

Ausnahmen existieren weiterhin, wie etwa bei dem Segment sehr konsistent libertärer US-Bürger in der amerikanischen Gesellschaft. Sie lehnen grundsätzliche jede Form von Staatseingriffen ab, womit sie sich damit bei wirtschaftspolitischen Themen näher an der Republikanischen Partei befinden, bei den meisten anderen Themen aber viel stärker zu den Demokraten neigen. Für die meisten politisch stark aktivierten US-Bürger aber stellt sich die Frage der ideologischen Inkonsistenz eher seltener. Erklärbar ist dies wohl vor allem durch die extreme Freund-Feind-Codierung der amerikanischen Politik: die tiefe Aversion gegenüber der anderen Seite, die dazu führt, dass man notfalls sogar seine Meinung zu politischen Themen ändert - vielleicht nicht einmal so sehr, um in Übereinstimmung mit der eigenen Partei zu sein, sondern vor allem, um auf keinen Fall mit der anderen Seite einer Meinung zu sein. Außerdem ist diese Angleichung auch der Integrations- und Kommunikationsleistung politischer Eliten zu verdanken. Ein gutes Beispiel dafür ist das seit Ronald Reagan im Umlauf befindliche konservative Narrativ, wonach wohlfahrtsstaatliche Leistungen nicht nur teuer und ineffizient seien, sondern damit zugleich auch traditionelle Familienmodelle in Frage gestellt würden.

Insofern ist es schwierig, die inhaltlichen Dimensionen des ideologischen Konfliktes in den USA exakt zu bestimmen. Geoffrey Layman und Thomas Carsey haben die Gleichzeitigkeit des Auftretens ganz verschiedener Konflikte gerade als das Besondere der gegenwärtigen Konstellation bezeichnet und sie so von anderen, ebenfalls konfliktträchtigen Perioden in der amerikanischen Geschichte unterschieden: Während Demokraten und Republikaner in der Vergangenheit allenfalls entlang einer Konfliktdimension polarisiert gewesen seien (während des New Deal z.B. anhand einer sozio-ökonomischen Konfliktdimension), fände heute eine Polarisierung anhand multipler Achsen statt. ${ }^{4}$ Und welche dieser Konfliktthemen dabei dominant sind, ist nur schwer zu beantworten.

3 Vgl. Michael J. Barber/Nolan McCarty: Causes and Consequences of Polarization, in: Nathaniel Persily: Solutions to Political Polarization in America, Cambridge 2015, S. 15-58, hier: S. 20.

4 Vgl. Geoffrey C. Layman/Thomas M. Carsey: Party Polarization and „Conflict Extension" in the American Electorate, in: American Journal of Political Science, Vol. 46 (4), 2002, S. 786-802. 
Die Diskussion kreist vor allem um die Frage, ob eine sozioökonomische oder eine eher kulturelle Konfliktlinie, im Sinne des „Culture War“, das Wahlverhalten bestimmt. ${ }^{5}$ Eine einfache Antwort darauf aber gibt es nicht. Wie noch im Hauptteil der Arbeit zu zeigen sein wird, ist vor allem der Faktor Geographie dabei kaum zu unterschätzen. So ist die These vom „Rechtsruck“ der weißen Arbeiterklasse für manche Teile des Landes zweifelsohne zutreffend - etwa in den Regionen der „Great Plains“" und auch in einigen Staaten des Mittleren Westens. ${ }^{6}$ Anderswo jedoch, so hat es vor allem Andrew Gelman gezeigt, wählt die weiße Arbeiterklasse auch weiterhin demokratisch. ${ }^{7}$ Des Weiteren widersprüchlich erscheint, dass einerseits heute die Frage der Religiosität ein sehr viel besserer Indikator für das Wahlverhalten der US-Bürger ist als der soziökonomische Status, andererseits jedoch Themen wie Abtreibung und andere „moral“ oder „social issues“ bei Umfragen in ihrer Wichtigkeit stets weit hinter den Brot-und-Butter-Themen der amerikanischen Politik, wie z.B. die Schaffung von Arbeitsplätzen, rangieren.

Vielleicht aber konstruiert die Frage „Klasse oder Kultur“ auch eine falsche Dichotomie. Derzeit besitzen fast alle kontrovers diskutierten Sachfragen in den USA eine starke moralische Textur. So ist eben auch die Antwort auf die Frage, welcher Kandidat oder welche Partei am ehesten in der Lage ist, Arbeitsplätze zu schaffen, mit kulturell-moralischen Aspekten verknüpft, da auch hier Vorstellungen von Gerechtigkeit und Arbeitsethik eine Rolle spielen können. Um rationale Evaluationen der Erfolgsaussichten von Programmen dürfte es sich jedenfalls auch bei solchen Fragen kaum handeln, hat doch mittlerweile eine große Zahl amerikanischer Sozialpsychologen ein erstaunliches Bild individueller Meinungsbildung gezeichnet, demnach Affekte und Vorurteile maßgeblich die politische Urteilskraft bestimmen. ${ }^{8}$

Jedenfalls: Statt für eine Abschwächung der Konfliktintensität zu sorgen, forciert das simultane Auftreten verschiedener Streitthemen und ihre Integration unter dem Dach zweier sehr inklusiver Ideologien eher noch die Polarisierung des Landes.

5 Vgl. als guten Überblick Mark D. Brewer/Jeffrey D. Stonecash: Split. Class und Cultural Divides in American Politics, Washington 2007.

6 Popularisiert hat diese These vor allem Thomas Frank: What's the Matter with Kansas? How Conservatives Won the Heart of America, New York 2004.

7 Vgl. Andrew Gelman: Red State, Blue State, Rich State Poor State, Princeton 2010.

8 Vgl. Drew Westen: The Political Brain. The Role of Emotions in Deciding the Fate of the Nation: How We Make Up Our Minds Without Using Our Heads, New York 2006; Jonathan Haidt: The Righteous Mind. Why Good People are Divided by Politics and Religion, New York 2013. 


\section{Partisan Nation: Die Stabilisierung des AMERIKANISCHEN ELEKTORATS}

In der Konsequenz aller dieser Entwicklungen verfestigen sich seit den 1980er Jahren die Wählerbindungen der US-Amerikaner, und zwar in einer Weise, die im markanten Gegensatz steht zur Erosion der Wählerbindungen in Europa. ${ }^{9}$ Das erste Anzeichen hierfür war, dass Parteiidentifikation und ideologische Selbsteinschätzung der US-Bürger im Verlauf der letzten Jahrzehnte zunehmend kongruenter wurden. Das ist weniger banal als es klingt. Das Konzept der Parteiidentifikation ist nicht zufällig in den USA entstanden und erst dann nach Europa transferiert worden, da sich alleine mit den ideologischen Profilen der Wähler Wahlentscheidungen lange Zeit kaum erklären ließen. ${ }^{10}$ Bis in die 1970 Jahre hinein finden sich unter den Anhängern beider Parteien ebenso wie unter den Parteileiten sowohl starke liberale als auch konservative Bataillone. ${ }^{11}$ Das aber ist heute Geschichte: Nur noch ein sehr geringer Teil liberaler Wähler entscheidet sich heute für die Republikanische Partei, ebenso wie es kaum noch konservative Amerikaner gibt, die demokratisch wählen. ${ }^{12}$

Während über diesen als „Party Sorting“13 bezeichneten Prozess völliger Konsens herrscht, sieht dies bei der Diskussion um die Stärke der Parteiidentifikation ein wenig anders aus.

9 Vgl. u.a. Peter Mair: Ruling The Void. The Hollowing of Western Democracy, London 2013; Russell J. Dalton/Martin P. Wattenberg (Hg.): Parties without Partisans: Political Change in Advanced Western Democracies, Oxford 2002. Vgl. Für den generellen Zusammenhang zwischen der Stärke der Parteiidentifikation und der Polarisierung des Parteiensystems Noam Lupu: Party Polarization and Mass Partisanship: A Comparative Perspective, in: Political Behaviour, Vol. 37, 2015: S. 331-356; Hermann Schmitt: Partisanship in Nine Western Democracies. Causes and Consequences, in: John Bartle /Paolo Belluci (Hg.): Political Parties and Partisanship. Social Identity and Individual Attitudes, Abingdon 2009, S. 75-87.

10 Vgl. für die Schwierigkeiten des Transfers des eigentlich amerikanischen Konzeptes von Parteiidentifikation in den europäischen Kontext vor allem Donald Green /Brad Palmquist/Eric Schickler: Partisan Hearts and Minds. Political Parties and Social Identities of Voters, Yale 2002: S. 164ff.

11 Vgl. Matthew Levendusky: The Partisan Sort. How Liberals Became Democrats and Conservatives Became Republicans, Chicago 2009.

12 Vgl. ebd.

13 Vgl. ebd. 
Die These von der Polarisierung als Massenphänomen verträgt sich schließlich nicht besonders gut mit der auch medial immer wieder verbreiteten Behauptung, wonach es in den USA vor allem auf das stetig wachsende Segment der „Independents", also parteilich ungebundene Wähler, ankomme. Das freilich ist eine Ansicht, die auf einer oberflächlichen Interpretation der Daten beruht. Gewiss: Wenn man Amerikanern die Frage stellt, ob sie sich a) als Demokrat, b) als Republikaner, oder c) als Independent betrachten, dann erhält man zwar im Zeitverlauf in der Tat eine wachsende Zahl von „Independents“. Bei der Folgefrage jedoch: „Steht ihnen die eine Partei näher als die andere“? benennen über zwei Drittel der „Independents" eine der beiden Parteien. Das alleine mag den Mythos der vielen unabhängigen Wähler vielleicht noch nicht erschüttern. Entscheidender ist noch, dass eine weitere Frage nach der tatsächlichen Stimmabgabe schließlich enthüllt, dass diese sogenannten „Independent Leaners“ mit gar noch größerer Beständigkeit für „ihre“ Partei votieren als jene Amerikaner, die sich zuvor als „Weak Democrats“ oder „Weak Republicans“ zu erkennen gegeben haben. ${ }^{14}$ Kurzum: Wer sich als Independent bezeichnet, muss deswegen noch lange keiner sein. Unter ihnen befinden sich zahlreiche „Undercover“ oder „Closet Partisans.“" kleine Minderheit der amerikanischen Wähler präferiert auch auf Nachfrage keine der beiden Parteien. Das sind die sogenannten „Pure Independents“ oder, nach einer anderen Terminologie, „Independent Independents“. Deren Zahl aber ist im Verlauf der letzten vier Jahrzehnte eher rückläufig und beträgt gerade noch um die $10 \%$. Nahe dem historischen Höchststand befindet sich hingegen die Zahl derjenigen, die sich als besonders loyale Parteianhänger zu erkennen geben - die „strong partisans“, deren Zahl heute zwischen 30- 35\% liegt. ${ }^{16}$ Und was entscheidend ist: „Strong Partisans“ sind eben wesentlich stärker politisch aktiviert, als dies bei „Weak Partisans“ oder den „Independent Leaners“ der Fall ist, von „Pure Independents" ganz zu schweigen: sie gehen regelmäßiger wählen, insbesondere in den Vorwahlen der Parteien, spenden mehr Geld an Kandidaten, gehen häufiger zu politischen Veranstaltungen usw.

14 Vgl. David B. Magleby/Candice J. Nelson/Mark C. Westlye: The Myth of the Independent Voter Revisited, in: Paul Sniderman/Benjamin Highton (Hg.): Facing the Challenge of Democracy: Explorations in the Analysis of Public Opinion and Political Participation, Princeton 2011, S. 238-262.

15 Vgl. ebd. Der Begriff des „Undercover Partisans“ findet sich bereits bei Angus Campbell/Philip Converse/Warren Miller: The American Voter, Chicago 1960: S. 123.

16 Vgl. Alan Abramowitz/Steven Webster: All Politics is National: The Rise of Negative Partisanship and the Nationalization of US House and Senate Elections in the 21st Century, Paper, Prepared for presentation at the Annual Meeting of the Midwest Political Science Association, Chicago, Illinois, April 16, 2015. 
Kurz gesagt: Ihr Einfluss auf den politischen Prozess und die Mehrheitsverhältnisse ist noch wesentlich größer als es die bloße Zahl von knapp über einem Drittel der Bürger vermuten lässt. ${ }^{17}$ Alan Abramowitz hat diesen Teil des Elektorats, den man als Trägergruppe der Polarisierung bezeichnen könnte, als die „Engaged Public" bezeichnet. ${ }^{18}$ Bemerkenswert ist dabei, dass nicht nur Partizipation stark mit Parteiidentifikation positiv korreliert. Amerikas ideologisch besonders motivierte Parteigänger haben auch überdurchschnittliche Bildungsabschlüsse und verfügen über ein hohes Einkommen. Amerikas Polarisierung verdankt sich vor allem dem „Extremismus“ der oberen Mittelklasse.

Stärker als die Identifikation mit der eigenen Partei ist in den USA freilich noch ein anderer Wert gestiegen: Die negative Parteiidentifikation. Gemeint ist damit die negative Einschätzung der Gegenseite, die man selbst z.B. für politisch radikal hält, während man die eigene Position weiterhin als zentristisch einstuft. Ein wenig erinnert das an das schöne Bonmot Terry Eagletons, der einmal meinte, Ideologie sei wie schlechter Atem „,immer das, was die anderen haben“ ${ }^{19}{ }^{19}$ In Zeiten, da die Bereitschaft, sich mit einer Partei zu identifizieren, keinen guten Ruf genießt, mag die Messung der negativen Parteiidentifikation womöglich ein noch besserer Indikator für scharfe Gegensätze auf der Wählerebene sein. So identifizierten sich nach einer Umfrage aus dem Jahr 2012 41\% der Anhänger der Tea Party - die bekanntermaßen voller Verachtung für das „Establishment“ der republikanischen Partei sind - als „Independents“ ${ }^{\text {“ }}{ }^{20}$ Es dürfte wohl sehr unwahrscheinlich sein, dass sich viele Obama-Wähler im Sample befanden.

Spürbar sind diese negativen Einstellungen gegenüber den Anhängern der gegnerischen Partei im Übrigen bis in Bereiche hinein, die eigentlich unpolitischer Natur sind. In den 1960er stellte man Amerikanern das erste Mal die Frage, ob sie ein Problem damit hätten, wenn ihr Sohn/ihre Tochter einen Demokraten/Republikaner heiraten würde. Gerade einmal 4\% der Republikaner und 3\% der Demokraten fanden dies seinerzeit problematisch; 2014 bekundeten $49 \%$ bzw. 33\% ihre Bedenken angesichts einer solchen Liaison. Dies verhält sich geradezu spiegelverkehrt zu vergleichbaren Umfragen in Großbritannien, in denen der Widerstand

17 Vgl. Alan Abramowitz: The Disappearing Center - Engaged Citizens, Polarization and American Democracy, Yale 2010.

18 Vgl. ebd.

19 Vgl. Terry Eagleton: Ideologie. Eine Einführung, Stuttgart 1993, S. 8.

20 Vgl. Brian Montopoli: Tea Party Supporters: Who They are and what They Believe, CBS News 12. Dezember 2012, http://www.cbsnews.com/news/tea-party-supporterswho-they-are-and-what-they-believe/ (zuletzt abgerufen am 28.09.2015). 
gegen solche ,interparty-marriages“ signifikant gesunken ist. ${ }^{21}$ In einer Umfrage des Pew Research Centers von 2014 wurde den Parteianhängern beider Seiten auch die Frage gestellt: „Do you think that [Republicans/Democrats] are a threat to the Nation's well being?" Auf diese recht dramatisch klingende Frage antworten 27\% der Demokraten und 36\% der Republikaner mit „Ja“.22 Die Antipathien gegen die Anhänger der anderen Partei sind heute stärker als die Aversionen gegen Menschen mit anderer Hautfarbe - was angesichts der noch immer tiefgehenden ethnischen Trennungslinien in den USA durchaus bemerkenswert erscheint. ${ }^{23}$

Angesichts der hohen moralischen und affektiven Aufladung des Konfliktes verblassen beinahe die Unterschiede bei konkreten Sachfragen. Dennoch: Eindeutige Unterschiede lassen sich auch auf diese Weise identifizieren. Die Frage nach der individuellen Selbsteinschätzung von Parteiidentifikation und Ideologie spielt in der amerikanischen Diskussion vor allem deshalb eine so zentrale Rolle, weil dieses die Erhebungstechnik der American National Election Study ist und sich damit für einen Zeitraum von über 60 Jahren Daten analysieren lassen, was Veränderungen im Zeitverlauf natürlich deutlicher macht. Eine andere Möglichkeit ist, anhand einer Batterie von Sachfragen zu messen wie konsistent „liberal“ oder „konservativ" ein Wähler eingestellt ist. Wendet man diese Methode an, so zeigt sich für den beschränkteren Zeitraum von 1994 bis 2014 ebenfalls eine eindeutige Stärkung des ideologischen Profils der amerikanischen Wählerschaft: Waren es nach einer Studie des Pew Research Centers 1994 noch gerade einmal 10\% der Amerikaner, die „konsistent“ liberal oder konservativ dachten, waren es 2014 bereits $21 \%{ }^{24}$ Und auch hier korreliert die ideologische Konsistenz positiv mit Partizipation und politischem Interesse.

21 Shanto Iyengar/Sood Gaurav/Yphtach Lelkes: Affect, Not Ideology: A Social Identity Perspective on Polarization, in: Public Opinion Quarterly, Vol. 76 (3) 2012: S. $405-$ 431.

22 Pew Report vom 12. Juni 2014: Political Polarization in the American Public. How Increasing Ideological Conformity and Partisan Antipathy Affects Politics, Compromise and Everyday Life.

23 Shanto Iyengar/Sean J. Westwood: Fear and Loathing Across Party Lines. New Evidence of Group Polarization, in: American Journal of Political Science, Vol. 59 (3), 2014, S. 690-707.

24 Pew stellte $\mathrm{zu}$ diesem Zweck den Befragen 10 Fragen, die die verschiedenen Politikbereiche abdeckten. Wer in mindestens 9 von 10 Fragen konsistent liberal oder konservativ antworte, galt als „Consistent Liberal“ oder „Consistent Conservative“. Vgl. den Pew Report vom 12. Juni 2014: Political Polarization in the American Public. How Increasing Ideological Conformity and Partisan Antipathy Affects Politics, Compromise and Everyday Life. 
Auch andere Indikatoren sprechen für eine gesteigerte Stabilität des Wahlverhaltens der US-Bürger. So hat etwa das „Split-Ticket-Voting“ - wenn ein Wähler bei gleichzeitig stattfindenden Präsidentschafts- und Kongresswahlen für die Kandidaten verschiedener Parteien stimmt - seit den 1970er Jahren stark abgenommen. Ende der 1970er Jahre hatten gut ein Viertel der amerikanischen Wähler von dieser Praxis Gebrauch gemacht; im Jahr 2012 waren es nur noch etwas über 10\%. ${ }^{25}$ Noch dramatischer geschrumpft ist analog hierzu die Zahl der ,split districts““. ${ }^{26}$ Eindeutig in Richtung einer Verfestigung des Wahlverhaltens weist auch, wiederum im auffälligen Kontrast zu Europa ${ }^{27}$, dass die Zahl der „late-deciders“ - in den 1970er und 1980er Jahren noch eine bedeutende Gruppe - nicht etwa zugenommen, sondern abgenommen hat. ${ }^{28}$

Dies alles sind Gründe, warum es für die große Mehrheit der Amerikaner jedenfalls in Bezug auf ihre Wahlentscheidung in der Hauptwahl - keine große Rolle mehr spielt, wer die Vorwahlen ,ihrer“ Partei gewinnt. Der konservative Publizist Michael Barone sprach daher schon vor einigen Jahren, gewiss überpointiert, von der „49 Percent Nation“: von zwei politischen Lagern, die einen Großteil der potentiellen Wähler auf sich vereinen und zwischen sich nur noch einen kleinen Teil des Elektorats lassen, das als unentschieden gelten kann. ${ }^{29}$ Im November 2011 - also ganze 12 Monate vor der Präsidentschaftswahl des folgenden Jahres und noch bevor eine einzige republikanische Vorwahl stattgefunden hatte - hatte

25 Vgl. Garry Jacobson: Polarization in American Politics: A Background Paper, in: Presidential Studies Quarterly, Vol. 34 (4) 2013: S. 688-707, hier S. 695.

26 Vgl. ebd. Unter „split districts“ wird ein Wahlkreis verstanden, der bei gleichzeitig stattfindenden Wahlen die Kandidaten unterschiedlicher Parteien präferiert.

27 Vgl. etwa für Deutschland: Rüdiger Schmitt-Beck: Better Late Than Never: Campaign Deciders at the 2005 German Parliamentary Election, paper, vorgestellt auf der 5th ECPR General Conference, Potsdam September 2009; oder allgemeiner: Russel J., Dalton/Ian McAllister/Martin P. Wattenberg: The Consequences of Partisan Dealignment, in: Russell J. Dalton/Martin P. Wattenberg (Hg.): Parties without Partisans: Political Change in Advanced Western Democracies, Oxford 2002: S. 37-63.

28 Vgl. Auch hier die Zahlen der ANES:

http://electionstudies.org/nesguide/toptable/tab9a_3.htm

Vgl. zum generellen Zusammenhang zwischen Polarisierung und dem Zeitpunkt der Wahlentscheidung Michael S. Lewis-Beck: The American Voter Revisited, Ann Arbor 2009, S. $71 \mathrm{ff}$.

29 Vgl. Michael Barone: The 49 Percent Nation, in: National Review, Vol. 33 (23) 2001:

S. 1710 . 
sich 94\% der Wähler bei der Frage ob sie Barack Obama oder Mitt Romney wählen würden, bereits festgelegt. ${ }^{30}$ Es ist daher wenig überraschend, dass amerikanische Wahlkampagnen sich mittlerweile vor allem stark auf die Mobilisierung der eigenen Basis konzentrieren und ihre Botschaften auf diese zuschneiden - was in einem sich selbst verstärkenden Prozess die Polarisierung wiederum weiter verstärkt. Nach alledem ist es auch kaum ein Zufall, dass in den meisten europäischen Demokratien die Wahlbeteiligung gesunken ist - während die Präsidentschaftswahlen 2008 und 2012 in den USA die beiden Wahlen mit der höchsten Beteiligung seit den bekanntermaßen recht partizipationsfreudigen 1960er Jahren waren. Auch dieser Zusammenhang scheint beinahe schon banal: wo die politischen Unterschiede zwischen den Parteien wirklich markant und eindeutig sind, da wird die Motivation der Stimmabgabe tendenziell steigen. ${ }^{31}$ Laut den Daten der American National Election Study (ANES) gaben 2004 und 2008 über 80\% der Amerikaner zu Protokoll, dass es ihnen wichtig sei („Cares who wins elections“), wer die Präsidentschaftswahlen gewinnt - der höchste Wert seit 1952, als man begann, Amerikanern in der ANES diese Frage zu stellen.

\section{EXPANSION UND LAGERBILDUNG: DAS COMEBACK DER AMERIKANISCHEN PARTEIEN UND PARTEILICHKEIT ALS ORDNUNGSPRINZIP}

Die intensive ideologische Polarisierung im Inneren der Gesellschaft hat auch Konsequenzen für den Status amerikanischer Parteien. Sie sind heute nicht nur ideologisch konsistenter als in der Vergangenheit, besser organisiert und gesellschaftlich stärker verwurzelt. Auch ihr institutioneller Einfluss dürfte sich eindeutig verstärkt haben. Für zeitgenössische Beobachter war auch dies zunächst nicht zu erkennen. Im Gegenteil: In den 1970er Jahren, als sich Europa noch ganz im goldenen Zeitalter der Massenpartei wähnte, begann der Abgesang auf sie, dokumentiert durch provokante Buchtitel wie „The Party is Over“ von David Broder oder William J. Crottys „American Parties in Decline““. ${ }^{32}$ Gänzlich verkehrt waren

30 Vgl. Lynn Vavreck: The A-Little-Bit-Less Undecided, in: New York Times, 20.09.2012, http://campaignstops.blogs.nytimes.com/2012/09/20/the-a-little-bit-lessundecided/?_r=0 (zuletzt abgerufen am 12.06.2015)

31 Vgl. zu diesem Zusammenhang Mark N. Franklin: Voter Turnout and the Dynamics of Electoral Competition in Established Democracies since 1945, Cambridge 2004.

32 David S. Broder: The Party's Over - The Failure of Politics in America, New York 1972; William J. Crotty: American Parties in Decline, Boston 1980. 
diese Interpretationen gleichwohl nicht. Was in dieser Zeit nämlich tatsächlich endgültig unterging, das waren die Reste jener party machines, die bis zum Beginn des 20. Jahrhunderts mit den Mitteln ungehemmter Patronage den Zugang zu allen politischen und öffentlichen Ämtern kontrolliert hatten. Diese Macht war nach und nach erodiert. Vor allem die massenhafte Ausweitung innerparteilicher Wahlen eliminierte weitgehend den Einfluss des offiziellen Parteiapparates auf die Kandidatenauswahl. Stattdessen schienen in Wahlkämpfen - seit jeher das Beobachtungsfeld und Maßstab für die Aktivität und Vitalität von Parteien in den USA - jetzt unabhängige Kandidaten und ihre Teams, die Medien, oder die Interessengruppen im Zentrum des Geschehens zu stehen. Die Partei hingegen waren nur ein Akteur unter vielen, und dabei nicht einmal Primus Inter Pares.

Die Entwicklung der Folgejahre ist ein gutes Beispiel, wie Polarisierung gesellschaftliche und politische Konstellationen prägen und verändern kann. Denn heute ist von diesen Abgesängen nichts mehr zu hören, wird eher vom erstaunlichen Comeback amerikanischer Parteien gesprochen. ${ }^{33}$ Gleichwohl bezieht sich das nur zum Teil auf Phänomene wie die Wiederbelebung von Parteiorganisationen auf lokaler Ebene oder die zwischenzeitlich gestiegene Bedeutung der nationalen Parteiorganisationen (also dem „Democratic National Committee“ und dem „Republican National Committee") beim Einsammeln von Wahlkampfspenden. Es hat vielmehr ein Perspektivwechsel stattgefunden, was überhaupt unter Partei verstanden wird. In Zeiten extremer Lagerpolarisierung alleine die offiziellen Parteistrukturen zum Maßstab zu nehmen, scheint vielen Beobachtern mittlerweile ein wenig statisch und damit wenig zielführend. Um die Wirklichkeit von Parteien und Parteilichkeit in der amerikanischen Politik zu fassen, haben daher eine Reihe amerikanische Politologen ein erweitertes Konzept von Partei entwickelt, welches hierunter nicht allein die offizielle Organisationsstruktur versteht, sondern die informellen Strukturen mit einbezieht. Was die einen als „Expanded Party ${ }^{\text {(363 }}$ bezeichnen, als „Partisan Web“35, oder als „Informal Party Organization“336, sind allesamt Versuche, Parteien als Netzwerke von Akteuren zu verstehen, die zwar formal unabhängig voneinander sind, jedoch in hohem Maße kooperieren und eine

33 Vgl. Arthur C. Paulson: Realignment and Party Revival: Understanding American Electoral Politics at the Turn of the Twenty-First Century. Westport 2000.

34 Jonathan H. Bernstein: The Expanded Party in American Politics, Dissertation, Berkeley 1999.

35 Gregory Koger/Seth Masket/Hans Noel: Partisan Webs: Information Exchange and Party Networks, in: British Journal of Political Science, Vol. 39 2009: S. 633-653.

36 Seth E. Masket: No Middle Ground. How Informal Party Organizations Control Nominations and Polarize Legislatures, Ann Arbor 2009. 
gemeinsame ,partisan identity“37 besitzen. In dieser Sichtweise bilden offizieller Parteiapparat, Interessengruppen, Wahlkampfberater, Lobbyisten, Think Tanks und „Partisan Media“ (etwa klar parteiliche Medienformate wie Fox News) kooperative Allianzen, die sich durch ein hohes Maß an Solidarität auszeichnen und so fest miteinander verbunden sind, dass es - anders als in der Vergangenheit mittlerweile keine organisatorischen oder personellen Brücken zur Gegenseite mehr gibt: Wahlkampfberater arbeiten ausschließlich für die Kandidaten einer Partei; Think Tanks schreiben Papiere, die nur auf die Resonanz in einer Partei zielen; Interessengruppen unterstützen nicht nur stets die gleiche Partei, sondern verzichten auch gleich darauf, die Politiker der Gegenseite noch mit LobbyingInitiativen überzeugen zu wollen ${ }^{38}$ - ein markanter Unterschied zur Entkopplung der Parteien-Interessengruppen-Beziehungen in Europa. ${ }^{39}$ In der Terminologie der Deutschen oder Europäischen Parteiensoziologie würde man vielleicht eher von Lagern als von Parteien sprechen, aber durch diese Perspektive wird in jedem Fall deutlich, in welch starkem Maße Polarisierung die interne Integration und Kooperation sowie Formen parteilichen Engagements fördert. Entstanden sind abgeschottete „Parteiräume ${ }^{\text {“40 }}$, „networks of ideological teammates “411 mit einer hohen inneren Geschlossenheit bei gleichzeitiger völliger Abschottung zur Gegenseite. Andere Untersuchungen haben gezeigt, dass es in Bezug auf Mitgliedschaften in anderen Vereinen oder Organisationen heute praktisch keine Schnittflächen mehr zwischen den Parteiaktivisten beider Seiten gibt. ${ }^{42}$

In der Tat scheint die Vitalität amerikanischer Parteien somit im eklatanten Gegensatz zur so häufig diagnostizierten Krise der Europäischen Parteien zu stehen. Nicht alle gehen dabei so weit wie der irische Politikwissenschaftler Peter Mair, der in seinem letzten Buch über sie kurz und bündig verkündete: „The age of party democracy has passed.“43 Aber während die Parteien in Europa in Bezug

37 Vgl. Maik Bohne: Vibrant Spaces. Dynamik und Struktur von Parteiräumen in USamerikanischen Wahlkämpfen, Opladen 2011.

38 Vgl. Barbara Sinclair: Party Wars. Polarization and the Politics of National Policy Making, Oklahoma 2006.

39 Vgl. Elin H. Allern/Tim Bale: Political Parties and Interest Groups: Disentangling Complex Relationships, in: Party Politics, Vol. 18(1) 2012: S. 7-25.

40 Bohne: Vibrant Spaces 2011, a.a.O.

41 Koger et al, Partisan Webs, a.a.O.

42 Vgl. Michael T. Heaney et. al.: Polarized Networks: The Organizational Affiliations of National Party Convention Delegates, in: American Behavioral Scientist, Vol. 56 (12) 2012: S. 1654-1676.

43 Peter Mair: Ruling the Void - The Hollowing of Western Democracy, London 2013, S. 1. 
auf ihre Regierungsfunktionen und bei der Auswahl des politischen Personals noch immer alternativlos, ja unverzichtbar erscheinen, lässt sich schwerlich behaupten, dass sie noch in der gleichen Weise wie zuvor weit in die Gesellschaft reichen. Der einfachste und zugleich klarste Indikator dafür ist der Niedergang der Parteien als Organisationen selbst: Praktisch überall in Europa ist die Zahl der Parteimitglieder gesunken, bisweilen in dramatischer Weise. ${ }^{44}$ Dadurch und aufgrund des Verlusts an gesellschaftlichen Vorfeldorganisationen verloren die Parteien ihre gesellschaftlichen Wurzelböden. ${ }^{45}$ Nun sind die Unterschiede zwischen amerikanischen und europäischen Parteien so groß, dass einfache Transfers hier schwierig sind, die funktionalen Äquivalente für einen Vergleich schon großzügig gewählt sein müssen. ${ }^{46}$ Das beitragszahlende Parteimitglied gibt es in den amerikanischen Parteien in dieser Form schließlich bekanntermaßen nicht. Und zu Mitgliederparteien, wie es die Europäischen Parteien sind (oder in manchen Fällen: waren), werden sich die amerikanischen Parteien auch in Zukunft nicht entwickeln. Andererseits existieren ja durchaus Formen der parteinahen Partizipation, die den bloßen Sympathisanten vom überzeugten Aktivisten unterscheiden. Und hier weisen alle verfügbaren Zahlen auf ein gesteigertes Engagement der Amerikaner in einer der beiden Parteien hin: Wie selten zuvor spenden sie Geld für einen Kandidaten, besuchen Wahlkampfveranstaltungen, gehen für Wahlkämpfe von Tür zu Tür, um andere von der Stimmabgabe zu überzeugen. ${ }^{47}$ Ein grandioser Höhepunkt, aber zugleich eben auch nur die Spitze des Eisbergs, war Barack Obamas Kampagne von 2008, mit ihren 13 Millionen freiwilligen Kampagnenhelfern und drei Millionen individuellen Spendern. ${ }^{48}$

Inwiefern das innerparteiliche Vorwahlsystem - bis heute die dominierende Erklärung in der amerikanischen Öffentlichkeit für den Parteienantagonismus in Washington $^{49}$ - zum ideologischen Homogenisierungsprozess in beiden Parteien

44 Vgl. Paul Whiteley: Is the Party Over? The Decline of Party Activism and Membership Across the Democratic World, in: Party Politics, Vol. 17 (1) 2001: S. 24; Ingrid Van Biezen/Peter Mair/Thomas Poguntke: Going, going, gone? The Decline of Party Membership in Contemporary Europe, in: European Journal of Political Research, Vol. 51 (1) 2012: S. 24-56.

45 Vgl. Thomas Poguntke: Parteiorganisation im Wandel, Wiesbaden 2000.

46 Vgl. Alan Ware: American Exceptionalism, in: Richard S. Katz/William J. Crotty: Handbook of Party Politics, London 2006, S. 270-277.

47 Vgl. Abramowitz: The Disappearing Center, a.a.O., S. 15-33.

48 Vgl. Maik Bohne: Vibrant Spaces, a.a.O., S.10.

49 Siehe etwa jüngst die Diagnose von Senator Charles Schumer: End Partisan Primaries, Save America, in: New York Times vom 21.07.2014. 
beigetragen hat, ist dabei weiterhin umstritten. Zwar klingt die Theorie zunächst einleuchtend, dass angesichts der sehr niedrigen Beteiligung in den Primaries eine Minderheit gut organisierter und sehr motivierter „True Believers“ ideologisch extreme Kandidaten durchzusetzen vermag. Von der Mehrheit der Politologen wird dies jedoch in Frage gestellt: entweder, weil argumentiert wurde, dass das Primary-Elektorat sich in seinen Präferenzen gar nicht so signifikant von dem unterscheide, das an Hauptwahlen teilnimmt; ${ }^{50}$ weil die zeitliche Kausalität fragwürdig erscheine, da, anders als bei den Präsidentschaftswahlen, die Mitglieder von Senat und Abgeordnetenhaus schon sehr viel länger und noch vor der Ära der Polarisierung in Vorwahlen ermittelt wurden ${ }^{51}$ und schließlich weil kein Zusammenhang existiert zwischen dem Abstimmungsverhalten eines Abgeordneten und der Art und Weise, in der er seine Vorwahlen zu bestreiten hatte. ${ }^{52}$ Auch die Erfahrungen von Experimenten mit parteiungebundenen „Open Primaries“ in Kalifornien, die nicht weniger extreme Kandidaten produzierten, geben der These vom Vorwahlsystem als Verursacher der Polarisierung keine große Nahrung.

So könnte man das Primary-System wohl lediglich als den spezifischen Mechanismus bezeichnen, mit dessen Hilfe insbesondere bei Präsidentschaftswahlen die Parteien zu ihren Polen verschoben wurden - ohne eben wissen zu können, ob die Entwicklung in Richtung ideologisch akzentuierter Parteien sich nicht auch auf anderem Wege vollzogen hätte. Ihre Einführung war eine Idee der Reformer der Progressive Era gewesen, um die Macht der korrupten Parteimaschinen zu brechen und den Prozess zu demokratisieren. Die wahren Profiteure des neuen Systems waren allerdings die politischen Interessengruppen, die in der zweiten Hälfte des 20. Jahrhunderts in Washington und anderswo im Land förmlich explodierten. ${ }^{53}$ Sie nahmen maßgeblichen Einfluss, in den meisten Fällen durch

http://www.nytimes.com/2014/07/22/opinion/charles-schumer-adopt-the-openprimary.html (zuletzt abgerufen am 14.02.2015)

50 Vgl. Alan Abramowitz: Don't Blame Primary Voters for Polarization, in: The Forum, A Journal of Applied Research in Contemporary Politics, Vol. 5. No. 4. 2008.

51 Vgl. David Karol: Charles Schumer's flawed diagnosis of polarization, in: Washington Post, 23.07.2014, abrufbar unter http://www.washingtonpost.com/blogs/monkeycage/wp/2014/07/23/charles-schumers-flawed-diagnosis-of-polarization/ (zuletzt abgerufen am 20.03.2015)

52 Shigeo Hirano/James M. Snyder Jr./Stephen Daniel Ansolabehere/John Mark Hansen: Primary Elections and Partisan Polarization in the U.S. Congress, in: Quarterly Journal of Political Science 5(2), 2010, S. 169-191.

53 Vgl. Ronald Brownstein: The Second Civil War. How Extreme Partisanship has Paralyzed Washington and Polarized America, New York 2008; Barbara Sinclair: Party Wars: Polarization and the Politics of National Policy Making, Oklahoma 2006. 
Wahlkampfspenden, die mitgliederstärkeren unter ihnen aber auch durch ihre Mobilisierungsmacht. So war etwa die christliche Rechte in den 1990er Jahren extrem erfolgreich bei ihren Versuchen, republikanische Abgeordnete, die zu moderat erschienen, durch andere Politiker herauszufordern, die, finanziell exzellent ausgestattet, die Vorwahlen gewannen. ${ }^{54}$ Diese und andere Interessengruppen wurden in der Folgezeit die wahren Hüter der ideologischen Reinheit in beiden Parteien.

Schließlich zeigen sich die Konsequenzen von Polarisierung im Zusammenhang mit Formen von Parteilichkeit auch auf allen Eben des Institutionensystems. Für den amerikanischen Kongress ist dies ohnehin offensichtlich. Aber auch der amerikanische Supreme Court - ebenso wie die obersten Gerichte in den Bundesstaaten - ist in historisch präzedenzloser Weise entlang der Parteilinien gespalten. Das Amt des Präsidenten hat sich in der Ära der Polarisierung ebenfalls verändert. In den USA konstatieren Beobachter die Entwicklung zu einer „Partisan Presidency“, in deren Folge amerikanische Präsidenten immer stärker auch als Parteiführer aufträten und, angesichts der bitteren Polarisierung auf dem Capitol Hill, kaum noch Zeit darauf verwendeten, die schwankenden Abgeordneten der Gegenseite zu überzeugen. ${ }^{55}$ Manche Politologen spekulieren angesichts der zunehmenden Geschlossenheit der Parteien im Kongress schon geraume Zeit über das Heraufdämmern eines „,responsible party systems“ oder „Party Government“" nach europäischem Vorbild, also quasi einer Parlamentarisierung des Systems. ${ }^{56}$ Angesichts der Realitäten von „Divided Government“ dürfte die zunehmend um sich greifende Fraktionsdisziplin wohl allerdings eher zur Dysfunktionalität eines stark auf Kooperation angelegten politischen Systems führen. Dennoch macht es in jedem Fall deutlich, dass der unterschiedliche Polarisierungsgrad einer Gesellschaft sogar für unverrückbar gehaltene institutionelle Unterschiede zwischen sehr verschiedenen politischen Systemen teilweise zu nivellieren vermag. In diese Richtung weist auch, dass für die weltanschaulich abgerüsteten europäischen Parteiensysteme eine in gewisser Weise ganz gegenläufige Entwicklung konstatiert wird.

54 Vgl. Kimberly Conger/John Green: Spreading out and Digging in. Christian Conservatives and State Republican Parties, in: Campaigns and Elections, Februar 2002.

55 Richard M. Skinner: George W. Bush and the Partisan Presidency, in: Political Science Quarterly, Vol. 123 (4) 2009: S. 605-622.

56 Vgl. Arthur C. Paulson: Realignment and Party Revival: Understanding American Electoral Politics at the Turn of the Twenty-First Century Westport 2000; Nicol C. Rae: Be Careful what you Wish for - The Rise of Responsible Parties in American National Politics, in: Annual Review of Political Science, Vol. 10 (2) 2007: S. 169-191. 
Das Phänomen der „Präsidentialisierung“, welches u.a. davon ausgeht, dass die gewachsene Autonomie von Regierungschefs von ihren Parteien und Parlamentsfraktionen ursächlich zusammenhängt mit der Schwächung der Parteien selbst. ${ }^{57}$ Aber möglich wird dieses letztlich natürlich nur durch ein Nachlassen des parteipolitischen Wettbewerbs und einem Schwinden der Lagerbindungen in der Wählerschaft: erst das schafft die Möglichkeit, sich als dem Parteienstreit gleichsam enthobener und unabhängiger politischer Anführer zu inszenieren. Es ist exakt jene Rolle, die Barack Obama für seine Präsidentschaft wohl gerne gewählt hätte - und die er angesichts der Zustände eines extrem polarisierten politischen Systems am Ende nie erfolgreich zur Aufführung bringen konnte.

57 Vgl. Thomas Poguntke/Paul Webb (Hg.): The Presidentialization of Politics, Oxford 2005. 
Expedition in das Herz der Echokammer:

Die Wisconsin-Feldstudie 



\section{Lebenswelten, Milieus, echo chambers: Zum Prozess gesellschaftlicher Segmentierung in historischer Perspektive}

Es geht in dieser Arbeit nicht darum, einen einzigen Erklärungsansatz für die ideologische Polarisierung der USA zu verabsolutieren. Amerikas ideologiegeschichtlicher Sonderweg - das sollte Kap. 2 gezeigt haben - bleibt ein multikausales Phänomen, das geschichtlich gewachsen ist und als Resultat individueller, nicht im Vorhinein schon determinierter Handlungen politischer Akteure zu verstehen ist. Wovon im Folgenden die Rede sein soll, ist eine komplementäre Erklärungsebene - die für das tiefere Verständnis der Natur dieses Konfliktes gleichwohl zentral ist. Diese Erklärungsebene handelt davon, in welcher Weise die Bürger des Landes in ihrer konkreten Lebenswelt die nationalen Konflikte politischkulturell verarbeitet haben - um sie dann wiederum, und zwar um einige Volt aufgeladener, in das politische System zurückzugeben.

Es geht also um die Politik der Echokammer: Wie in den USA zahlreiche soziale Räume entstanden sind, deren hervorstechendstes Merkmal ihre ideologische Homogenität ist. Es sind diese Räume und die Menschen, die in ihnen leben, die in den letzten Jahren die Polarisierung der amerikanischen Politik immer weiterbefördert haben. Denn aus diesen Räumen ging eine klare Botschaft heraus: keine Kompromisse. Es gehört zur Logik der Echokammer, dass in ihr jedes eigene Wort millionenfach widerhallt, Stimmen von außerhalb aber nicht hineindringen. So entwickelt die Mehrheitskultur aufgrund des Ausbleibens dissonanter Stimmen umso rigidere Ordnungsvorstellungen. Die Existenz der Echokammer erklärt nicht nur, wieso sich die Konflikte der 1960er derart verfestigen und ins kollektive Gedächtnis einbrennen konnten, dass Joseph Epstein diese Dekade einmal zu Recht als den kollektiven Rorschach-Test der USA bezeichnete: „,Tell me what you think of that period, and I shall tell you what your politics are."

1 Zitiert nach Daniel T. Rodgers: Age of Fracture, Cambridge 2012, S. 4. 
Sie ist auch der Grund für die stark affektive, emotional aufgeladene Polarisierung der USA, die allein mit dem Verweis auf unterschiedliche politische Anschauungen oder divergierende Interessenlagen kaum zu begreifen wäre.

Es gibt dabei eine auffällige historische Analogie zum europäischen Zeitalter der Ideologien, die im Folgenden fruchtbar gemacht werden soll für ein tieferes Verständnis der Konsequenzen des Entstehens dieser Echokammern. Auch in Europa nämlich korrespondierte die scharfe ideologische Polarisierung zwischen den Parteien lange Zeit mit einer scharfen sozio-geographischen Abgrenzung ihrer Anhänger. Konservative und Liberale, Protestanten und Katholiken, Sozialisten und Kommunisten: sie alle lebten in organisatorisch geschlossenen Eigenwelten, die ihre Angehörigen gleichsam von der Wiege bis zur Bahre umschlossen und sie von äußeren Einflüssen größtenteils abschirmten. In den Niederlanden und Belgien nannte man diese Räume „Säulen“. In Deutschland setzte sich R.M. Lepsius Begriff des ,sozio-kulturellen Milieus“ durch, in Österreich sprach man von „Lagern“. ${ }^{2}$ Ähnliche politisch-kulturelle Segmentierungsprozesse hatten sich freilich auch in den meisten anderen europäischen Gesellschaften um die Jahrhundertwende vollzogen. ${ }^{3}$ Diese Subkulturen waren organisatorisch autark durch ein enges Netz an Vorfeld- und Freizeitorganisationen. Sie alle verfügten über ihre eigenen Mediensysteme wie Zeitungen oder Rundfunkanstalten und viele über eigene Bildungseinrichtungen. Erst dieser Prozess der Entstehung von Teil-Gesellschaften und Teil-Öffentlichkeiten ebnete den Weg zum „Einfrieren“ politischer Konfliktlinien wie es im Cleavage-Konzept von Lipset und Rokkan (die von ,institutionalized segmentation" sprachen) beschrieben wurde. ${ }^{4}$

2 Vgl. z.B. Arend Lijphart: Politics of Accommodation: Pluralism and Democracy in the Netherlands, Los Angeles 1975; Rainer Maria Lepsius: Parteiensystem und Sozialstruktur. Zum Problem der Demokratisierung der Deutschen Gesellschaft, in: Gerhardt Ritter (Hg.): Deutsche Parteien vor 1918, Köln 1973, S. 56-80; Robert Kriechbaumer: Die großen Erzählungen der Politik. Politische Kultur und Parteien in Österreich von der Jahrhundertwende bis 1945, Böhlau 2001.

3 Vgl. für andere Länder aus der Gruppe der Konsens-Demokratien u.a. Val R. Lorwin: Segmented Pluralism: Ideological Cleavages and Political Cohesion in the Smaller European Democracies, in: Comparative Politics, Vol. 3 (2) 1971: S. 141-175; für Italien: Joseph LaPalombera: Italy: Fragmentation, Isolation, Alienation, in: Sidney Verba/Lucien Pye (Hg.): Political Culture and Political Development, Princeton 1965, S. 282-329.

4 Vgl. Seymour Martin Lipset/Stein Rokkan: Cleavage Structures, Party Systems and Voter Alignments, in: Seymour Martin Lipset (Hg.): Consensus and Conflict. Essays in Political Sociology, New Brunswick 1985: S.113-185, hier: S. 129. 
In diesen sozialen Räumen fand überdies auch eine Einübung gemeinsamer Lebensweisen statt, wurde eine spezifische, das Alltagsleben einschließende Sozialkultur entwickelt, die über materielle Interessenlagen weit hinausreichte - und sich gerade deswegen lange Zeit als überaus stabil erwies, oft über den eigentlichen politischen Gründungskonflikt hinaus. Über die sozio-kulturellen Milieus der deutschem Kaiserzeit und der Weimarer Republik schrieb etwa Karl Rohe: „Angehörige unterschiedlicher Milieus denken nicht nur anders und deuten nicht nur die Alltagswelt anders aus, sie leben tatsächlich anders. Ihr Tag ist anders strukturiert, und ihr Verhalten folgt einem jeweils anderen Rhythmus und anderen Mustern. ${ }^{\circ 5}$

Heute allerdings gelten diese Echokammern zu Recht als weitgehend verschwunden. Nicht nur in Deutschland gibt es keine abgegrenzten Milieus mehr von Katholiken oder Sozialdemokraten, Liberalen oder Konservativen. Die Geschichte ihres Schwindens ist so oft erzählt worden, dass einige Stichworte genügen sollten: Die Menschen wurden mobiler, gebildeter, der Wohlfahrtsstaat minderte die Notwendigkeit gemeinschaftlicher Solidaritätsstrukturen, die Ausbreitung von Massenmedien öffnete selbst den abgeschottetsten Milieus ein Fenster in die Welt. Letztlich bündeln sich diese Prozesse in einer der Schlüsselkategorien zur Beschreibung der Moderne: Individualisierung. Individualisierungsprozesse lösten die Menschen aus überkommenen Traditionen und so erodierte der Ethos dörflicher Gemeinschaften ebenso wie das proletarische Klassenbewusstsein in den Fabriken. Die neue Zeit bürdete den Menschen nun selbst die Aufgabe auf, die zersprungene Einheit der Welt wieder zusammen zu fügen und aus den Deutungssplittern konkurrierender und oft widersprüchlicher „Sinnprovinzen“ ein halbwegs stabiles Bild der Lage zu zeichnen.

Wie aber, so diese durchaus kraftvolle Erzählung vom „Ende der Erzählungen“, sollten unter diesen Umständen Ideologien, definiert als langfristige Projektentwürfe einer grundlegenden Transformation der Gesellschaft, dann noch Sinn machen? Ideologien waren historisch schließlich stets der Treibstoff für die Mobilisierung großer Kollektive - aber wo die Menschen selbst zu den Herren ihrer eigenen Schicksale würden, verlören Ideologien eben ihren Sinn. Auch die Verkünder einer solcherlei entstrukturierten Moderne behaupten deswegen noch nicht, dass dies schon das grundsätzliche Ende der Links-Rechts-Semantik des politischen Wettbewerbs bedeute; als Binärcode des Politischen bleibt diese Unterscheidung weiter überlebenswichtig.

5 Karl Rohe: Wahlen und Wählertraditionen in Deutschland. Kulturelle Grundlagen deutscher Parteien und Parteiensysteme im 19. und 20. Jahrhundert, Frankfurt a. Main 1992, S.19. 
Aber die Grenzen zwischen diesen Konzepten sind durchlässiger geworden und anders als in der Vergangenheit neigen sowohl die politischen Eliten als auch die Bürger heute stärker dazu, eklektisch und bisweilen auch erratisch miteinander zu kombinieren, was früher Ausschlusscharakter besaß. Und daher, so etwa Ulrich Beck, entstehe durch die Individualisierung politischer Konflikte und Interessen „ein widersprüchliches Vielengagement, dass die klassischen Pole des politischen Spektrums mischt, kombiniert, so dass jede $[\mathrm{r}]$ - zu Ende gedacht - zugleich rechts und links, radikal und konservativ, demokratisch und undemokratisch [...] sein kann. [...] die gängigen Politikkoordinaten - rechts und links, konservativ und sozialistisch, Rückzug und Teilhabe - stimmen und greifen nicht mehr." ${ }^{\text {“6 }}$ Nach dieser Lesart geraten in der Uneindeutigkeit der Gegenwart alle Versuche holistischer Weltdeutungen und semiotisch abgeschlossener Welterklärungssysteme in den Schmelzofen einer ,flüchtigen Moderne ${ }^{67}$, in der Politik als langfristiges Projekt kaum noch gedacht werden kann. „An ideology without a project”, schreibt jedoch Zygmunt Bauman, ,some project with by being a project and a plan for action spells out a future different from the present, is an oxymoron, a contradiction in terms."

In der Wahl- und Parteienforschung hat diese Interpretation von Individualisierungsprozessen relativ früh einen herausgehobenen Platz eingenommen und soll erklären helfen, warum die Parteien sich ideologisch angenähert haben. Max Weber und Robert Michels hatten das langsame Verblassen der ursprünglich utopisch-chiliastischen Energien der marxistischen Ideologien der Parteien der Arbeiterklasse noch mit dem unweigerlichen Rationalitätszuwachs moderner Organisationen und der „Verbonzung“ und „Verspießerung“ ihrer Funktionäre erklärt. ${ }^{9}$ Mit Otto Kirchheimers These von der „Catch-All Party“ wurde dann jedoch Individualisierung - freilich noch bevor das Wort selbst zur soziologischen Schlüsselkategorie avancierte - zum primären Deutungsinstrument des Nachlassens des ehedem harten und konfrontativen Parteienwettbewerbs. Mit ihrem Abschwören einer rigiden Parteiprogrammatik reagierten die „Catch-All Parteien“ nach Kirchheimer bereits auf die vermeintlichen Nivellierungstendenzen der Nachkriegszeit, dem Aufstieg der Konsumgesellschaft, der Säkularisierung, insgesamt somit einer Entwicklung, in der sich die „Beziehungen zu den Klassen ändern und weniger

6 Ulrich Beck: Die Erfindung des Politischen, Frankfurt a. Main 1997, S. 161.

7 Vgl. Zygmunt Bauman: Flüchtige Moderne, Frankfurt am Main, 2003.

8 Zygmunt Bauman: In Search for Politics, Stanford 1999, S. 125.

9 Vgl. Wolfgang Mommsen: Max Weber und die deutsche Politik 1890-1920, Tübingen 1974, S. 114ff; Vgl. auch Seymour Martin Lipset: A Concept and its History: The End of Ideology, in: Ders. (Hg.), Consensus and Conflict. Essays in Political Sociology, Piscataway 1985, S. 81-109. 
scharf in Erscheinung treten. "10 Dieses Interpretationsschema aus den 1960er Jahren war dann fortan dominant bis in die Gegenwart.

Auch heute noch gilt „,individual modernization“"11, so die Formulierung bei Jacques Thomassen, als Hauptgrund für das Verblassen der alten Konfliktlinien und die Erosion kollektiver Identität. Heute fehlten den Parteien, so Franz Walter und Tobias Dürr, die stabilen sozialen „Heimaten“ - eben ihre sozio-kulturellen Milieus - in denen sie früher so sicher verankert waren. ${ }^{12}$ Der pointierteste und deutungsmächtigste Interpret der europäischen Entwicklung einer weitgehenden Entideologisierung und damit Fragmentierung der europäischen Wählerschaft durch Individualisierung dürfte der irische Politikwissenschaftler Peter Mair gewesen sein, ${ }^{13}$ der immer wieder auf die hierdurch ausgelöste Abschleifung ehemals scharfer Unterschiede zwischen den etablierten Parteien verwiesen hat und dabei auch vor der pointierten Übertreibung eines vermeintlich ganz und gar entstrukturierten Wählermarktes nicht zurückgeschreckt ist. „A combination of increasing social homogenisation - the blurring of traditional identity boundaries and increasing individualization”, schreibt Mair, „has cut across differences in partisan electoral profiles, leaving most of the mainstream protagonists chasing more or less the same bodies of voters with more or less the same persuasive campaigning techniques." ${ }^{14}$ Manche Politologen halten Ideologien daher ganz einfach für ein Kennzeichen noch nicht hinreichend modernisierter - sprich: nicht ausreichend individualisierter - Gesellschaften. ${ }^{15}$

Die „Echokammern“ der USA, um die es in der Folge gehen wird, sind natürlich nicht so dicht, so undurchlässig wie die sozio-kulturellen Milieus, die Europas Gesellschaft und Politik vom Ende des 19. bis zur Mitte des 20. Jahrhunderts

10 Vgl. Otto Kirchheimer: Der Wandel des Westeuropäischen Parteiensystems, in: Politische Vierteljahresschrift, Vol. 6 (1) 1965: S. 20-41.

11 Vgl. Jacques Thomassen: The European Voter: A Comparative Study of Modern Democracies, Oxford 2005.

12 Vgl. Franz Walter/Tobias Dürr: Die Heimatlosigkeit der Macht. Wie die Politik in Deutschland ihren Boden verlor, Berlin 2000.

13 Vgl. vor allem Peter Mairs letztes, posthum veröffentlichtes Buch: Ruling the Void: The Hollowing of Western Democracy, London 2013.

14 Vgl. Peter Mair: The Challenge to Party Government, in: West European Politics, Vol. 31, 2008: S. 211-234, hier: S. 222.

15 Russell J. Dalton: Social Modernization and the End of Ideology Debate: Patterns of Ideological Polarization, in: Japanese Journal of Political Science, Vol. 7 (1) 2006, 122 . 
durchzogen und so tiefgehend prägten. Unter den Bedingungen des fluiden, individualistischen 21. Jahrhunderts lassen sich nicht die geschlossenen sozialen Räume des 19. Jahrhunderts bauen, deren „Insassen“ beinahe von der Wiege bis zur Bahre in der gleichen Lebenswelt gehalten wurden. Es geht mir nur um eine grundsätzliche Analogiebildung, mit deren Hilfe man freilich eine wichtige Erkenntnis schärfen kann: Gesellschaften, deren Bürger jeweils in zunehmend separierten Eigenwelten leben, und die dort aufgrund anderer Informationsflüsse, anderer sozialer Verkehrskreise und anderer Lebensstile im Resultat eine andere Interpretation der sozialen Wirklichkeit besitzen, neigen tendenziell auch stärker zur Ausbildung konkurrierender, sich im scharfen Wettbewerb befindlicher Ideologien. Unter diesen Voraussetzungen braucht es dann „nur“ noch politische Eliten, die diesen Differenzen politischen Ausdruck verleihen und sie zum Ziel des Machterwerbs bündeln und organisieren. Aus dieser grundsätzlichen Einsicht in die faktische soziale „Standortgebundenheit“ des Denkens, um mit dem Vater der Wissenssoziologie, Karl Mannheim, zu sprechen16, macht es Sinn, sich auch für die USA auf die Suche nach jenen Räumen zu begeben, in denen sich Ideologien mit Lebensweisen verbinden und somit besonders fest verankert sind.

Dabei geht es vor allem um eine Paradoxie, die möglicherweise auch etwas über die generelle Verfasstheit moderner Gesellschaften aussagt. Denn schließlich: Wenn es tatsächlich stimmen würde, dass Prozesse der Individualisierung zur Erosion stabiler ideologischer Gemeinschaften führen, dann müssten die USA eigentlich gerade nicht durch eine markante ideologische Lagerabgrenzung auffallen - sondern durch das genaue Gegenteil. Die Rede ist dabei weniger von individualistischen Werteinstellungen, auch wenn man diese als zentrales Element des „American Creed“ in den USA gewiss hoch veranschlagen sollte. ${ }^{17}$ Im Gegensatz zum Individualismus ist Individualisierung keine Haltung, die man einnimmt, sondern ein gesellschaftlicher Prozess, der einem wiederfährt. Doch auch aus dieser Perspektive gilt, dass die USA fraglos als hochgradig individualisierte Gesellschaft gelten können: Klassenbewusstsein spielte dort immer schon eine untergeordnete Rolle und die geographische (und lange Zeit auch die soziale) Mobilität der US-Amerikaner war historisch stets besonders hoch gewesen - und ist es bis heute. Amerikaner zu sein, das bedeutete in der Fremd- wie der Selbstwahrnehmung stets, sich selbst erfinden zu können und zu müssen; so gesehen ist die Vorstellung, erst in der Postmoderne würden die Menschen zu den vollständig eigenen

16 Vgl. Karl Mannheim, Ideologie und Utopie, Bonn 1929.

17 Samuel P. Huntington: American Politics and the Promise of Disharmony, Cambridge 1981; Robert N. Bellah et al.: Habits of the Heart: Individualism and Commitment in American Life, Los Angeles 1985; Alain Ehrenberg: Das Unbehagen in der Gesellschaft, Berlin 2011: S. 37-62. 
Autoren ihrer Biographien, für die USA kaum zutreffend. Selbst gewählt scheint dort mit der Konfession und der Kirchengemeinde (zwischen denen viele Amerikaner im Leben mehrmals hin- und herpendeln) selbst jener Aspekt des sozialen Lebens, der in Europa gemeinhin als Beispiel besonders starrer, fixierter, quasi vererbter sozialer Beziehungen gilt. Vielleicht ist das auch der Grund, warum die zeitgenössischen Individualisierungstheorien, von Ulrich Beck über Antony Giddens und Alain Ehrenberg bis Zygmunt Bauman, allesamt von Europäern stammen und in der amerikanischen Soziologie nur sehr sparsam rezipiert werden. Amerika, so ließe sich der Befund wahrscheinlich zuspitzen, war schließlich schon immer individualisiert.

Gleichwohl werden in den USA seit den 1970er Jahren Gegenwartsentwicklungen diskutiert, die letztlich auf sehr ähnliche Diagnosen einer weiter fortschreitenden Individualisierung hinauslaufen - beginnend mit Christopher Lashs Bestseller von 1979 über den ausufernden Narzissmus der Amerikaner und bis hin zu Robert Putnams großer Studie aus dem Jahr 2000 über den Verlust an Gemeinschaft und Gemeinsinn in der amerikanischen Gesellschaft. ${ }^{18}$ Bei aller Andersartigkeit der Entwicklungspfade scheinen die Gegenwartsdiagnosen so verschieden jedenfalls nicht zu sein. Die entscheidende Frage nach alledem lautet, wie es also möglich ist, dass die USA so stark polarisiert sind, wo doch die amerikanische Gesellschaft gleichzeitig als hochgradig individualisiert gelten kann?

Die Antwort auf diese Frage birgt eben jene angedeutete Paradoxie, die dazu zwingt, den gesamten Zusammenhang von (Ent-)Ideologisierung und Individualisierung zu überdenken. Denn die USA, so die zentrale These dieser Arbeit, sind nicht trotz solcher Individualisierungsprozesse so polarisiert - sondern genau wegen ihnen. Gerade die politischen Echokammern der USA sind dafür ein exzellentes Beispiel. Sie sind das Resultat freier Wahl, der Entscheidung autonomer Bürger, sich für ein Leben in Eindeutigkeit statt Ambivalenz zu entscheiden - eben im Unterschied zu den Milieus der Europäischen Sozialgeschichte, denen stets ein Element des „freiwilligen Zwanges“ beiwohnte und deren Zugehörigkeit intergenerationell vererbt wurde. ${ }^{19}$

Doch die Paradoxie reicht noch sehr viel tiefer: Es sind nämlich gerade jene vermeintlichen Katalysatoren von Individualisierung, die in den USA eine ganz entgegengesetzte Wirkung entfalten. Das amerikanische Mediensystem ist dafür

18 Vgl. Christopher Lasch: The Culture of Narcissism, New York 1979; Robert D. Putnam: Bowling Alone: The Collapse and Revival of American Community, New York 2000.

19 Vgl. Klaus Tenfelde, Historische Milieus - Erblichkeit und Konkurrenz, in: Ders. (Hg.): Arbeiter, Bürger, Städte. Zur Sozialgeschichte des 19. und 20. Jahrhunderts, Göttingen 2012, S. 343-363, hier S. 357. 
wahrscheinlich das eingängigste und geläufigste Beispiel. In der traditionellen Sichtweise hat die Expansion von Massenmedien in Europa besonders an der Auflösung weltanschaulich fest gefügter Milieus mitgewirkt, wurde so doch ein „Fenster in die Welt" geöffnet, durch welches die Menschen mit neuen, abweichenden Weltentwürfen konfrontiert wurden und die Deutungsmacht lokaler Eliten erodierte. ${ }^{20}$ Doch offenkundig führt die Ausweitung des Informationsangebotes nicht automatisch zur weltanschaulichen Entbindung. In den USA hat erst die Ausweitung des Angebotes, die Möglichkeit einer Wahl, die Sortierung in ideologisch klar akzentuierte Alternativen möglich gemacht. ${ }^{21}$ Die bewusste Konzentration auf ein bestimmtes Segment politisch interessierter Amerikaner war für den Fernsehsender Fox News beispielsweise eine sehr erfolgreiche Strategie zur Profitmaximierung. Denn in einer Zeit, in der es die Möglichkeit gibt, sich aus scheinbar unendlichen Informationsquellen zu bedienen, entscheiden sich viele Amerikaner für das immer gleiche Angebot, das in der Regel ihre bereits existierenden Meinungen über die Welt bestätigt, und sie damit nicht der Gefahr kognitiver Dissonanzen aussetzt. ${ }^{22}$ Das verstärkt noch jene durch personalisierte Algorithmen gesteuerte Tendenz zur „Filter Bubble“, deren Gefahren Eli Pariser vor einigen Jahren plastisch beschrieb. ${ }^{23}$ Und im Grunde ist es ein schwerer Schlag für alle, die einmal hofften, die Zukunft der digitalen Demokratie könnte ein „Marktplatz der Ideen“ sein. Es ist ein Prozess, der sich als Paradoxe Individualisierung bezeichnen lässt: Man wählt, nicht ständig die Wahl zu haben.

Fraglos gäbe es, neben dem Mediensystem, noch zahlreiche andere Beispiele für diesen Prozess der Profileration von Orten von Gleichgesinnten, die oft das

20 Vgl. Uwe Sander/Dorothee M. Meister: Medien und Anomie. Zum relationalen Charakter von Medien in modernen Gesellschaften, in: Wilhelm Heitmeyer (Hg.): Was treibt die Gesellschaft auseinander? Bundesrepublik Deutschland: Auf dem Wege von der Konsens- zur Konfliktgesellschaft, Band 1, Frankfurt am Main 1997, S. 196-241, hier: S. 227; Vgl. zur milieuzersetzenden Wirkung der Massenmedien im internationalen Vergleich auch Paolo Mancini/Daniel C. Hallin: Comparing Media Systems, Cambridge 2004.

21 Vgl. aus der reichen Literatur um Thema Medien und Polarisierung in den USA vor allem: Markus Prior: Post-Broadcast Democracy: How Media Choice Increases Inequality in Political Involvement and Polarizes Elections, New York 2007; Matthew Levendusky: How Partisan Media Polarize America, Chicago 2013.

22 Vgl. Shanto Iyengar/Kyu S. Hahn: Red Media, Blue Media: Evidence of Ideological Selectivity in Media Use, in: Journal of Communication, 59 (1) (2009): S. 19-39.

23 Vgl. Eli Pariser, The Filter Bubble: What the Internet Is Hiding from You, New York 2011 
Resultat stärkerer persönlicher Autonomie sind. Einige davon mögen eher anekdotischer Natur sein, wie etwa das beachtliche Wachstum von online-Dating Sites mit klarer Partei- oder Ideologie-Konnotation wie redstatedate.com oder bluestatedate.com (Was freilich aber immerhin zu dem Befund passt, dass die Zahl der inter-party-marriages tatsächlich stark zurückgegangen ist und eine wachsende Zahl von Amerikanern größere Probleme damit hätte, wenn ihre Söhne oder Töchter einen Republikaner bzw. Demokraten heiraten würden ${ }^{24}$ ). Anderes aber ist sehr viel schwerwiegender und substantieller. So sind Amerikas Kirchen seit den 1970er stetig homogener geworden, Republikaner und Demokraten beten heute an verschiedenen Orten. ${ }^{25}$ Auch andere zivilgesellschaftliche Organisationen scheinen sich zunehmend politisch homogenisiert zu haben, wenngleich die empirische Basis hierfür unsicher bleibt. ${ }^{26}$

Am Ende aber soll hier die denkbar einfachste aller Echokammern im Vordergrund stehen, nämlich jene der ,realen“ Geographie: Amerikas politische Hochburgen. Auch sie sind der Vermutung nach Orte der selbstgewählten Einseitigkeit, nämlich das Resultat eines durch Binnenmigration ausgelösten Sortierungsprozesses: Immer mehr Amerikaner entscheiden sich demnach bei der Wahl ihres Wohnortes, die Nachbarschaft von politischen Gleichgesinnten zu suchen. Es gibt gute Gründe, Amerikas wachsende Zahl politisch einseitiger Lokalitäten - ob nun ganze Bundesstaaten, Wahlbezirke, Counties, Städe, Nachbarschaften - als Phänomen paradoxer Individualisierung besonders ernst zu nehmen. Zum einen besteht Grund zu der Annahme, dass Raum und Ort als soziale Kategorien und Kontextvariablen auch im Zeitalter medialer Allgegenwart außerordentlich wichtig bleiben, die Diagnose vom „Death of Distance“ jedenfalls weit übertrieben ist. ${ }^{27}$ So wichtig etwa die simultane Fragmentierung wie Polarisierung der amerikanischen Medienlandschaft auch ist, wirklich wirkungsmächtig werden auch medial vermittelte Weltbilder erst dann, wenn sie den Nexus zur physischen und sozialen

24 Vgl. Shanto Iyengar: Affect, Not Ideology: A Social Identity Perspective on Polarization, in: Public Opinion Quarterly, Vol. 76 (3) 2012: S. 405-431.

25 Vgl. Robert D. Putnam/David E. Campbell: American Grace: How Religion Divides and Unites Us, New York 2010.

26 Vgl. Delia Baldassarri: Partisan Joiners: Associational Membership and Political Polarization in America (1974-2004), in: Social Science Quarterly, Vol. 92 (3), 2011: S. 631-655.

27 Vgl. Frances Cairncross: The Death of Distance, Boston 1997; Vgl. als grundsätzliche Verteidigungsschrift der Wichtigkeit von Raum und Ort Thomas F. Gieryn: A Space for Place in Sociology, in: Annual Review of Sociology, Vol. 26 2000: S. 463-496. 
Lebenswelt finden. ${ }^{28}$ Wer den ganzen Tag Fox News sieht, aber in seinem Umfeld ständig mit Demokraten verkehrt, auf den wird die Weltsicht des Senders zwangsläufig eine andere Wirkung haben, als auf einen Republikaner, der tagein tagaus in einem geschlossen konservativen Milieu verkehrt; erst dort, wo das eine zum anderen passt, ist das System der Echokammer perfektioniert.

Und noch ein weiterer Grund spricht dafür, sich auf die Echokammern politischer Hochburgen zu konzentrieren, und dieser ist ebenso trivial wie unwiderlegbar: Amerikas Volksvertreter, die in Washington und anderswo im Land in einem zähen Stellungskrieg verharren, verdanken ihr Mandat letzten Endes eben nicht den Online Communities des ultraliberalen „Daily Kos“ oder des erzkonservativen „Drudge Report“. Sie werden dorthin auch nicht aus konservativen oder liberalen Kirchengemeinden beordert. Entsandt werden sie auch weiterhin aus realen Orten und Regionen: z.B. New Yorks 15. Wahlbezirk, den der Demokrat Jose Serrano 2014 mit 89,6\% gewann; oder Texas 13. Kongressbezirk, in dem der Republikaner Mac Thornberry 2014 84,3\% der Stimmen abräumte. Das sind wohlgemerkt die beiden jeweils politisch einseitigsten Wahlbezirke der USA; doch angesichts der Tatsache, dass gerade einmal 10\% der Wahlkreise als überhaupt noch umkämpft gelten, sind sie andererseits auch nur die Spitze des Eisberges. In diesem Sinne bleibt der so häufig zitierte Ausspruch Tip O'Neills, des früheren Sprechers des Repräsentantenhauses, auch weiterhin wahr: „All politics is local“". Über die Auswahl der politischen Eliten in den USA entscheiden am Ende die amerikanischen Bürger zwischen Maine und New Mexico. Wenn es stimmt, dass diese Wähler in selbst konstruierten Echokammern wohnen, dass sie den Kontakt zu anderen Anschauungen, Weltsichten und Wirklichkeiten verloren haben - dann spricht sehr wenig dafür, dass der Polarisierungs-Kreislauf der amerikanischen Politik durchbrochen werden könnte.

Doch Amerikas Ultra-Hochburgen sind so etwas wie die Black Box der amerikanischen Politikwissenschaft: Mit Aggregatdaten ist ihnen bisher nicht beizukommen und sind sie nicht zu verstehen. Daher soll im Folgenden ein neuer Weg eingeschlagen werden: Anhand einer regionalen Fallstudie, die ethnographische Vor-Ort Beobachtung mit den Daten aus einer selbst durchgeführten repräsentativen Umfrage kombiniert, soll Licht ins Dunkel der politischen Hochburgen der USA gebracht werden.

28 Vgl. Russell W. Neuman/Marion R. Just/Ann N. Crigler: Common Knowledge: News and the Construction of Political Meaning, Chicago 1992; Kathrin Cramer-Walsh: Talking Politics. Informal Groups and Social Identity in American Life, Chicago 2004: S. 23-27. 


\section{Zwei aus Dreitausend: Methodische Vorüberlegungen}

\section{Amerikas Hochburgen: Die Wahltopographie der USA UND DIE THEORIE DES BIG SORT}

Doch von welchen Arten von Hochburgen reden wir eigentlich? Welche Orte oder Räume müssten dabei in den Blick genommen werden? Woran lässt sich die geographisch-ideologische Segmentierung der USA am besten erkennen? Am populärsten ist gewiss die Aufteilung der USA in demokratische und republikanische Bundesstaaten: In ein blaues, also demokratisches Amerika in den Küstenregionen des Landes und einiger weniger Bundesstaaten entlang der großen Seen; und dann schließlich in ein rotes, republikanisches Amerikas praktisch überall sonst. Tatsächlich hat sich die Zahl der noch umkämpften Bundesstaaten seit den 1970er Jahren drastisch verringert. Selbst in den 1990er Jahren galten noch rund die Hälfte aller Bundesstaaten als Battleground States, wurden also mit einer Marge von 10 Prozentpunkten oder weniger entschieden; bis 2012 hat sich diese Zahl auf gerade einmal 14 Bundesstaaten verringert. ${ }^{1}$

Freilich: ein genauerer Blick auf Amerikas Wahltopographie verdeutlicht, dass innerhalb der Bundesstaaten keineswegs flächendeckend Ein-Parteien-Dominanz vorherrscht. Allenfalls in den Staaten der Great Plains wie Oklahoma und Kansas sind Demokraten nirgendwo wirklich wettbewerbsfähig und das gleiche gilt für Republikaner in einzelnen Staaten Neu-Englands. Ansonsten jedoch existieren auch in stark republikanisch und demokratisch dominierten Bundesstaaten überall „Enklaven“ der anderen Seite. So ist Kalifornien abseits seiner Küstenregionen relativ konservativ und eine der liberalsten Großstädte der USA überhaupt, Austin, ist ausgerechnet die Hauptstadt des erzkonservativen Texas.

1 Vgl. die Analyse von Randal Olson, basierend auf den Zahlen von fairvote.org: http://www.randalolson.com/2015/01/12/the-shrinking-battleground-presidentialelections/ 
Die wahre Homogenität Amerikas verbirgt sich in sehr viel kleineren geographischen Einheiten. Oft wird dabei auf die 435 Wahlbezirke zum amerikanischen Repräsentantenhaus verwiesen, bei denen die Anzahl der umkämpften districts ebenfalls rasant abgenommen hat. Bei den Kongresswahlen 2014 waren es noch 37 districts, die mit einer Marge von 5 Prozentpunkten oder weniger gewonnen wurden; gerade einmal 79 wurden mit einer Marge zwischen 5 bis 10 Prozentpunkten gewonnen - der Rest der Sitze jedoch wurde durch sehr viel eindeutigere Mehrheiten errungen. ${ }^{2}$ Allerdings sind die Gründe für diese Entwicklung umstritten. Schließlich werden die Grenzen der Wahlbezirke alle 10 Jahre nach den neuen Zensus-Zahlen neu zugeschnitten und dabei nicht selten von den Parteien so manipuliert, dass sie von vornherein nur noch von der einen oder der anderen Partei gewonnen werden. Es handelt sich hier also um „künstliche“ Wählerhochburgen, bei denen es nicht unbedingt zu einer tatsächlichen Verschiebung der Wählerzusammensetzung gekommen sein muss. Zwar legen eine Reihe von Studien mittlerweile nahe, dass das sogenannte ,gerrymandering“ alleine kaum die zunehmende politische Einseitigkeit der districts erklären $\mathrm{kann}^{3}$, doch ganz eindeutig lässt sich dieses kaum feststellen, weswegen sie für unsere Zwecke nicht die beste Wahl sind.

Kurzum: Um wirklich belastbare, verlässliche Aussagen im historischen Längsschnitt zu generieren, braucht es geographische Einheiten, deren Grenzen sich im Zeitverlauf nicht verändert haben. Besonders geeignet erscheinen daher die über 3000 Counties in den USA, die man am ehesten mit deutschen Landkreisen vergleichen könnte. Als Verwaltungseinheiten sind ihre Grenzen statisch. Und bei ihnen zeigt sich eine elektorale Flurbereinigung von wirklich historischem Ausmaß. Diese Erkenntnis verdanken wir vor allem dem amerikanischen Publizisten Bill Bishop und dem Soziologen Robert Cushing und ihrem Buch „The Big Sort ${ }^{\star 4}$. 1976, bei der Wahl zwischen Jimmy Carter und Gerald Ford, waren es 38\%

2 Vgl. die Analyse bei Nate Silver: As Swing Districts Dwindle, Can a Divided House Stand?, in: New York Times, 27. Dezember 2012: http://fivethirtyeight.blogs.nytimes. com/2012/12/27/as-swing-districts-dwindle-can-a-divided-house-stand/ (zuletzt abgerufen am 12.06.2015).

3 Alan Abramowitz/Brad Alexander/Matthew Gunning: Don't Blame Redistricting for Uncompetitive Elections, in: PS. Political Science \& Politics, (1) 2006: S. 87-90; Thomas E. Mann: Polarizing the House of Representatives: How much does Gerrymandering matter?, in: Pietro S. Nivola/David W. Brady (Hg.): Red and Blue Nation? Characteristics and Causes of America's Polarized Politics, Washington D.C. 2006.

4 Bill Bishop/Robert Cushing: The Big Sort. Why the Clustering of like-minded Americans Is Tearing Us Apart, Boston 2008. 
der amerikanischen Counties, in denen der Unterschied zwischen beiden Kandidaten beim Wahlausgang 20 Prozentpunkte oder mehr betrug. Danach aber steigt die Anzahl dieser, wie Bishop und Cushing sie getauft haben, „landslide counties“ an. Dieser Prozess vollzieht sich nicht in einer vollständig linearen Entwicklung, und es ist dabei ratsam, nur jene Wahlen ins Blickfeld zu nehmen, die besonders knapp im nationalen Wahlausgang waren. Denn in jenen Jahren, in denen eine der beiden Parteien Erdrutschsiege feierte, (wie etwa Ronald Reagan 1980 oder Bill Clinton 1996) ist es auch weniger erstaunlich, dass die Verteilung in den einzelnen Counties teils eindeutige Majoritäten ergibt. Sie sind daher kein Maßstab. Insgesamt aber ist der Trend im Zeitverlauf klar erkennbar und bis 2004 hat sich die Anzahl der ,landslide counties“ dann annähernd verdoppelt: In über $60 \%$ der amerikanischen Counties der USA gewannen in diesem Jahr entweder Bush oder Kerry mit mindestens 20 Prozentpunkten Vorsprung, häufig genug übrigens mit deutlich größeren Margen.

\section{Abbildung 1: The Big Sort- 1976.}

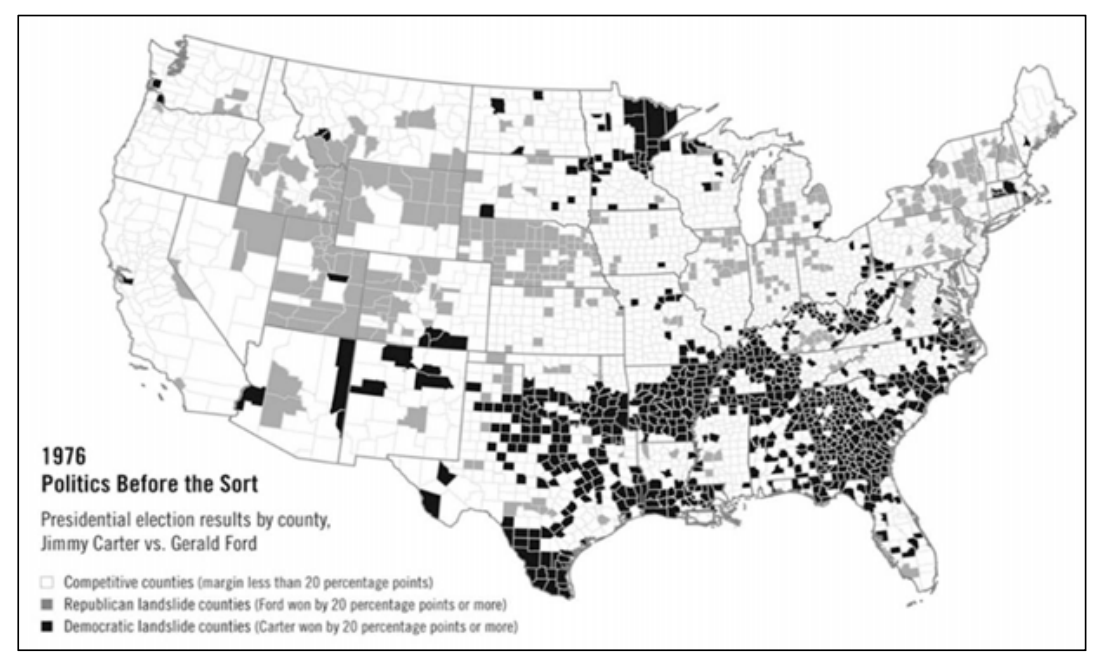

Quelle: Bill Bishop/Robert Cushing: The Big Sort, Boston 2008. 
Abbildung 2: The Big Sort-2004.

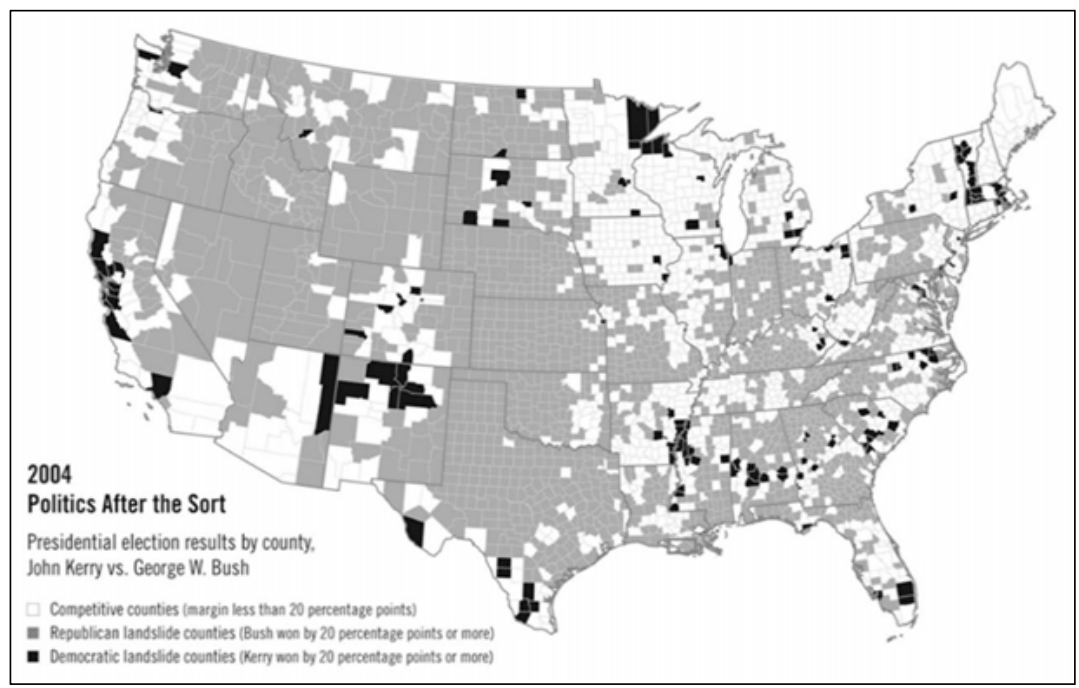

Quelle: Bill Bishop: The Big Sort, Boston 2008.

Und sowohl 2008 wie 2012 setzte sich dieser Trend ungebremst fort. ${ }^{5}$ Selbst Regionen, die heute als uneinnehmbare Bastionen einer der beiden Parteien gelten, sind 1976 noch keine eindeutigen Partei-Hochburgen: Entlang der kalifornischen Küste etwa gibt es 1976 gerade einmal ein einziges ,landslide county“; 2004 gehen, mit einer Ausnahme, alle von ihnen mit einem Vorsprung von 20 Prozentpunkten oder mehr an die Demokraten. In Kansas sind 1976 ebenfalls nur ein sehr kleiner Teil der 105 Counties des Staates „landlside counties“; 2004 sind es nur noch eine Hand voll, die nicht mit 20 Prozentpunkten oder mehr an die republikanische Partei gehen.

Gleichwohl ist die Profileration dieser „landslide counties“ in dieser Art eine leicht vereinfachte Darstellung. Denn bei zahlreichen dieser Ultra-Hochburgen handelt es sich um republikanische Counties in den strukturschwachen und schrumpfenden Regionen in der Mitte der USA, insbesondere in den Great Plains. Kurzum: was in räumlicher Hinsicht als eine gigantische Ausweitung politischer

5 Vgl. Bill Bishop: No, We Didn't: America Hasn't Changed as Much as Tuesday's Results Would Indicate, in: Slate, 4. November 2008: (zuletzt abgerufen am 27.04.2015); Thomas B. Edsall: How Fragile is the New Democatic Voter Coalition?, in: New York Times, 3. September 2012, http://opinionator.blogs.nytimes.com/ 2013/09/03/how-fragile-is-the-new-democratic-coalition/?_r=0 (zuletzt abgerufen am 14. April 2015). 
Monokulturen anmutet, stellt sich in Relation zur Bevölkerungszahl zumindest etwas moderater dar: lebten 1976 noch etwa 27\% der Amerikaner in „landslide counties", so waren es 2004 bereits 48,1\%. Ein sehr eindeutiger Trend ist gleichwohl auch dies.

Der "Big Sort" lieferte auch die Hypothese, um die seitdem in der amerikanischen Politikwissenschaft, wie in der breiteren Öffentlichkeit, intensiv gestritten wird und die im Kontext dieser Arbeit als besonders prägnantes Beispiel paradoxer Individualisierung auf ihre empirische Basis hin untersucht werden soll. Amerikas „landslide counties“, so argumentieren Bishop und Cushing, seien die Folge einer jahrzehntelangen Binnenmigration: Bei der Wahl ihrer Wohnorte entscheiden sich viele Amerikaner, tendenziell dorthin zu ziehen, wo sie auf Menschen treffen, die ihre politische Anschauung teilen. Doch wie genau läuft dieser Prozess ab? Ziehen tatsächlich Millionen von Amerikanern auf der Suche nach politisch Gleichgesinnten durch das Land? Schlagen Sie einen Wahlatlas auf, der ihnen verrät, wo sie unter ihresgleichen leben können? Einen solchen zentralen Platz dürfte die Politik wohl nur im Leben der wenigsten Amerikaner einnehmen. Es mag einige wenige Orte geben, die tatsächlich aufgrund ihrer hohen politischen Symbolkraft einen solchen direkten politischen Magnetismus ausüben, insbesondere liberale Hochburgen wie San Francisco oder Portland. Überwiegend jedoch läuft der „Big Sort" weitaus subtiler ab. Es geht um die richtigen Schulen und die passenden Freizeitmöglichkeiten, darum, ob man sich auch ohne Auto fortbewegen möchte oder aber es am einfachsten und bequemsten findet, auf breiten Straßen zu fahren und niemals ein Parkplatzproblem zu haben. Den einen ist es wichtig, in der Nähe von Theatern, Restaurants und Museen zu leben, andere verzichten auf all dieses, wenn Sie dafür in größeren Häusern leben können und mehr Platz zu ihren Nachbarn haben. Einigen ist es wichtig, in Gegenden zu leben, in denen es viele Kirchen mit einem lebendigen Gemeindeleben gibt, was anderen allerdings eher einen kalten Schauer über den Rücken jagt.

Eine Studie des Pew Research Centers fragte die Amerikaner 2014, ob sie lieber in einem größeren Haus mit reichlich Abstand zu den Nachbarn, doch dafür mehrere Meilen entfernt von Schulen, Restaurants und Geschäften leben würden, oder aber in einem kleineren Haus in enger Bebauung, doch dafür in unmittelbarer Nähe solcher urbanen Annehmlichkeiten. Dabei zeigten sich diametral unterschiedliche Präferenzen von Liberalen und Konservativen: 
Während Dreiviertel der „konsistent“6 liberalen US-Bürger lieber ein kleineres Haus in Kauf nehmen würden, sah es bei konservativen Amerikanern genau spiegelverkehrt aus: eine große Zahl von ihnen würde es bevorzugen, in größeren Häusern zu wohnen und dafür lieber weit entfernt von den „Annehmlichkeiten“ urbanen Lebens.

Abbildung 3: Abweichende Lebensstilpräferenzen von Konservativen und Liberalen

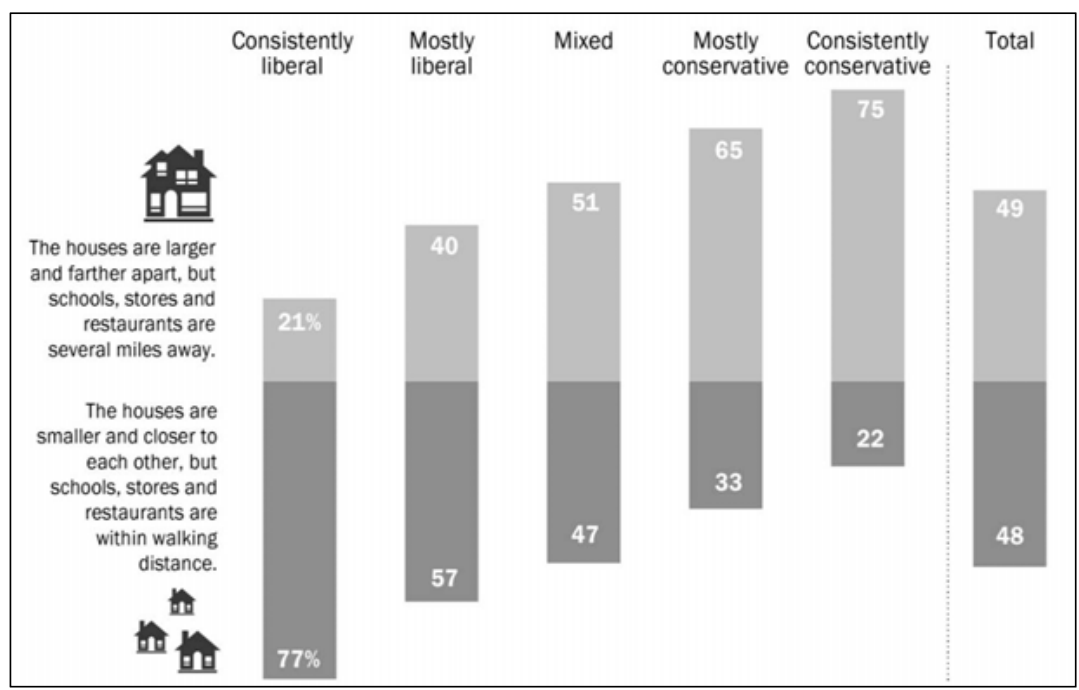

Quelle: PEW Research Center 2014 - Political Polarization in the American Public

Der geographische Sortierungsprozess Amerikas folgt also dem Modus von Lebensstildifferenzierungen. Der amerikanische Publizist Dave Berry hat das bereits

6 Pew hat hier, wie in Kap. 3. bereits kurz angedeutet, nicht die ideologische Selbsteinordnung gewählt, wie sie von amerikanischen Politologen im Rückgriff auf die National Election Study in der Regel benutzt wird, sondern ihren Liberalismus- bzw. Konservativismus-Index durch eine Batterie von Sachfragen ermittelt - je größer die Konsistenz der Antworten, desto liberaler bzw. konservativer wird der Befragte eingeschätzt. Vgl. den research report von Pew vom Juni 2014: Political Polarization in the American Public. How Increasing Ideological Uniformity and Partisan Antipathy Affects Politics, Compromise and Everyday Life: http://www.peoplepress.org/files/2014/06/6-12-2014-Political-Polarization-Release.pdf (zuletzt abgerufen am 14. April 2015) 
2004 in seiner Kolumne in der Washington Post mittels einer satirischen und seitdem häufig zitierten Gegenüberstellung auf den Punkt gebracht: „Do we truly believe that all red-state residents are ignorant, racist, fascist, knuckle-dragging, NASCAR-obsessed, cousin-marrying, roadkill-eating, tobacco juice-dribbling, gun-fondling, religious-fanatic rednecks; or that all blue-state residents are godless, unpatriotic, pierced-nosed, Volvo-driving, France-loving, left-wing communist, latte-sucking, tofu-chomping, holistic-wacko, neurotic, vegan, weenie perverts?"7 Die meisten der angeführten Attribute haben mit politischen Ansichten auf den ersten Blick nur wenig zu tun, es sind Vorlieben, Präferenzen, habituelle Stilisierungen.

Doch wissen wir wohl schon seit Georg Simmel und Max Weber (dessen zentraler Begriff hierfür freilich der der „Lebensführung“ war), aber spätestens seit Pierre Bourdieu, dass es sich beim Lebensstilkonzept letztlich natürlich um ein Konzept mit eminent politischen Folgen handelt. ${ }^{8}$ Lebensstile geben Auskunft darüber, in welcher Weise Menschen sich ein sinnerfülltes oder auch moralisch legitimiertes Leben vorstellen. Damit sind sie nicht für die eigene Identität konstitutiv, sondern auch potentielle Faktoren negativer Abgrenzung zu anderen. ${ }^{9}$ In diesem Fall lehnt man andere Lebensstile ab, obgleich es sich dabei zumindest vordergründig überhaupt gar nicht um einen Wertekonflikt handelt. Doch tatsächlich manifestieren sich in ihnen Vorstellungen über das „gute Leben“ und darüber, wie eine gerechte oder freie Gesellschaft auszusehen hat. Hinter Lebensstilen stehen natürlich Einstellungen und Werthaltungen. Identifizierbar sind sie vor allem durch wiederkehrende, alltägliche Verhaltensmuster ${ }^{10}$ : Sie sind in diesem Sinne bewusst expressiv, ausgerichtet auf die Wahrnehmung durch die soziale Umwelt. ${ }^{11}$

7 Vgl. Dave Berry: An Off-Color Rift, in: Washington Post, 19. Dezember 2004, http://www.washingtonpost.com/wp-dyn/articles/A218-2004Dec14.html (zuletzt abgerufen am 15. Juni 2015).

8 Vgl. Pierre Bourdieu: Die feinen Unterschiede, Berlin 1987; vgl. zur Lebensstilforschung insgesamt als kompakten Überblick das entsprechende Kapitel in Stefan Hradil: Sozial Ungleichheit in Deutschland, 8.Auflage, Wiesbaden 2005 S. 422-442; sowie Rudolf Richter: Die Lebensstilgesellschaft, Wiesbaden 2005.

9 Vgl. Markus Schroer: Das Individuum und die Gesellschaft. Synchrone und diachrone Theorieperspektiven, Frankfurt a. Main 2000: insbesondere S. 319ff.

10 Vgl. Hradil: Soziale Ungleichheit in Deutschland, a.a.O., S. 431.

11 Vgl. Gunnar Otte und Jörg Rössel: Lebensstile in der Soziologie, in: Dies. (Hg.): Lebensstilforschung. Sonderheft der Kölner Zeitschrift für Soziologie und Sozialpsychologie, Wiesbaden 2011, S. 7-34. 
In einigen Fällen ist diese potentielle politische Relevanz von Lebensstilpräferenzen gewiss besonders offensichtlich, etwa dort, wo Ideen von Nachhaltigkeit und Umweltschutz unmittelbar mit Formen der Lebensführung verknüpft sind. Sie gilt aber auch dort, wo Entscheidungen über den Lebensstil noch viel untrennbarer mit der Rolle des Einzelnen als Konsument und Marktteilnehmer verbunden sind. Es ist eben nicht lediglich eine Frage des Geschmacks oder eines nicht weiter zu hinterfragenden ästhetischen Empfindens, welche Automarke jemand bevorzugt, ob es ihm wichtig ist, in einem Altbauviertel zu wohnen, welche Kleidung er trägt und vieles andere mehr. Wir wissen sogar sehr genau, dass manche der vorgenannten Merkmale sehr eindeutig mit bestimmten ideologischen Orientierungen und Parteizugehörigkeiten korrelieren, besonders in den USA: Prius-Fahrer wählen häufig demokratisch; Fans der populären NASCAR-Serie sind überwiegend Republikaner; wer an Astrologie glaubt, ist - vielleicht ein schwerer Schlag für alle, die dachten, Anti-Wissenschaftlichkeit sei in den USA nur auf der politischen Rechten beheimatet - sehr viel häufiger liberal in seinen Einstellungen als jemand der dies nicht tut. ${ }^{12}$

Man könnte all das unendlich weiter durchdeklinieren, aber auch so dürfte der Punkt klar sein: in einer ideologisch stark polarisierten Gesellschaft wird das Persönliche schnell politisch. Andersherum ließe sich auch argumentieren, dass sich die Sphäre des Politischen gewaltig ausweitet, übergreift und ganz andere, vordergründig unpolitische Bereiche penetriert. Und während manche Lebensstilpräferenzen (wie etwa Online-Spiele-Communities à la „World of Warcraft“) relativ unabhängig von der physischen Lokation sind, setzt die Verfolgung anderer Lebensstile bestimmte Orte voraus. 2008 gewann Barack Obama in 89\% der Counties, in denen der Bio-Supermarkt „Whole Foods“ - für viele Liberale lange Zeit das Sinnbild nachhaltigen Konsums - eine Filiale unterhält. ${ }^{13}$ Es ist dieser Nexus von Lebensstil und Ortspräferenz, der in der Folge identifiziert werden soll.

Gleichwohl: All diesen Evidenz-Splittern zum Trotz ist die These des „Big Sort" nicht unumstritten. Dass Amerikas politische Landschaft sich homogenisiert hat, wird zwar nur selten in Abrede gestellt. ${ }^{14}$ Über die Ursachen hierfür lässt sich

12 Vgl. Michael Macy/Daniel J. DellaPosta/Yongren Shi: Why do Liberals Drink Lattes?, in: American Journal of Sociology, Vol. 120 (5) 2015: S. 1473-1511.

13 Vgl. Sheryl Gay Stolberg: You Want Compromise? Sure You Do, in: New York Times vom 13. August 2011, http://www.nytimes.com/2011/08/14/sunday-review/you-wantcompromise-sure-you-do.html (zuletzt abgerufen am 15.09.2015)

14 Vgl. zu dieser Diskussion Torben Lütjen/Robert Matschoß: Ideological Migration in Partisan Strongholds: Evidence from a Quantitative Case Study, in: The Forum. A Journal of Applied Research in Contemporary Politics, Vol. 13 (2) 2015, S. 311-346. 
hingegen streiten. Grundsätzlich existieren schließlich vier etablierte Erklärungsmodelle, warum sich die Mehrheitsverhältnisse in einem Ort ändern können: Generationswechsel; Mobilisierung neuer Wählerschichten, politischer Repräsentanzwechsel und dann schließlich Migration bzw. Mobilität. ${ }^{15}$ Die These vom „Big Sort“ konzentriert sich ganz wesentlich auf den letztgenannten Punkt. Dabei dürfte es grundsätzlich wohl wenig Zweifel daran geben, dass Mobilität für die amerikanische Gesellschaft historisch schon immer eine zentrale Rolle gespielt hat. Seit der europäischen Besiedlung des Landes ist sie Teil der kulturellen DNA Amerikas. Das galt natürlich zunächst für den Zug nach Westen. Aber auch nach dem (zumindest offiziellen) Erreichen der Western Frontier zum Ende des 19. Jahrhunderts ${ }^{16}$, blieb sie eines der Kennzeichen der USA. Amerikaner zogen grundsätzlich häufiger um als die Bürger anderer Länder, ganz so, als wollten sie ihren Ursprüngen als Nation von Siedlern treu bleiben. Und auch wenn die Mobilität in den letzten Jahren etwas nachgelassen hat: Durchschnittlich zieht jeder Amerikaner in seinem Leben noch immer 11,3-mal um. ${ }^{17}$ Im Jahr 2014, das im Vergleich eher als Jahr unterdurchschnittlicher Mobilität gilt, zogen noch immer 18,9 Millionen Amerikaner von einem County in ein anderes. ${ }^{18}$

Im Wissen um diese im internationalen Vergleich beachtliche Mobilität, scheint es zumindest plausibel, dass unterschiedliche Wohnort-Präferenzen wenngleich in einem gewiss eher langfristig, sich über mehrere Jahrzehnte erstreckenden Prozess - zu jener gewaltigen elektoralen Flurbereinigung führen, die heute die Wahltopographie der USA prägen. Zu Recht ist allerdings der Einwand erhoben worden, dass es jenseits einer eher impressionistischen Alltagssoziologie wenig belastbare Beweise dafür gibt, dass Demokraten und Republikaner wirklich verschiedene Orte bevorzugen, wenn sie entscheiden umzuziehen oder gar aus diesem Grund ihren Wohnort wechseln. Es existierte bisher schlicht kein Datensatz, der Amerikaner darüber befragt, von welchem Ort und zu welchem Zeitpunkt sie an ihren heutigen Wohnort gezogen sind, was dabei die ausschlaggebenden Kriterien gewesen wären und zusätzlich Parteiidentifikation und ideologischer Orientierung einbezieht - was aber für eine akkurate Interpretation unverzichtbar wäre. ${ }^{19}$ Was sehr wohl existiert, sind Umfragen, die nach theoretischen Präferen-

15 Vgl. James G. Gimpel/Jason E. Schuknecht: Patchwork Nation: Sectionalism and Political Change in America, Ann Arbor 2004, S. 176 ff.

16 Frederick Jackson Turner: The Frontier in American History, New York 1921.

$17 \mathrm{http}$ //fivethirtyeight.com/datalab/how-many-times-the-average-person-moves/

$18 \mathrm{http}: / /$ blogs.census.gov/2015/03/26/moving-in-the-usa-domestic-migration-beforeand-after-the-recession/

19 Vgl. Lütjen/Matschoß: Ideological Migration in Partisan Strongholds. a.a.O. 
zen fragen, danach was Demokraten und Republikanern an einem Wohnort wichtig ist. Die Studie von Pew aus dem Juni 2014 wurde bereits zitiert. Mit den Daten aus anderen Umfragen, größtenteils aus dem Fundus der „Cooperative Congressional Election Study“, konnte ebenso gezeigt werden, dass diese unterschiedlichen Präferenzen tatsächlich existieren und einige von ihnen korrespondieren auch mit durchaus stereotypen Lebensstilpräferenzen von Demokraten und Republikanern. Allerdings rangieren Themen wie Sicherheit und Bezahlbarkeit der Nachbarschaften bei allen Parteianhängern auf den ersten Plätzen. ${ }^{20}$

Das sehr viel grundsätzlichere Problem mit Präferenzen ist jedoch, dass stets fraglich bleibt, wie sie sich in konkretes Handeln übersetzen. Denn noch einmal: Es ist unwahrscheinlich, dass solche Aspekte allein direkt und unmittelbar zur Umzugsentscheidung führen. Zu Beginn einer solchen Entscheidung stehen fraglos andere Faktoren: Der Wechsel des Arbeitsplatzes, der Beginn der Ausbildung oder des Studiums, schließlich auch der Wunsch, mit dem Lebenspartner zusammen- oder mitzuziehen, oder näher an der Familie zu wohnen. Oder anders gesagt: Vielleicht stört es mich, unter lauter Republikanern zu wohnen, oder vielleicht würde ich lieber in einem hippen Großstadtquartier an der amerikanischen Ostoder Westküste wohnen - aber das heißt nicht, dass mir dieses auch in jedem Fall möglich wäre oder, dass ich dafür alle anderen Faktoren ignorieren könnte. ${ }^{21}$

Jenseits der Abfragung von Präferenzen ist es jedoch sehr schwierig, Korrelationen aufzudecken. Bishop und Cushing, und in ihrer Nachfolge dann auch andere, haben etwa mit Daten des Internal Revenue Service (IRS), der Amerikanischen Steuerbehörde, gearbeitet. Damit lässt sich relativ präzise erfassen, wie vieled Menschen von einem County in ein anderes County umgezogen sind. Bishop etwa untermauerte seine These u.a. damit, dass überproportional viele Menschen aus demokratischen Hochburgen in andere demokratische Hochburgen umzogen; oder dass Menschen, die Counties mit einem hohen Anteil evangelikaler Christen verlassen, überproportional in Counties ziehen, in denen ebenfalls viele evangelikalen Christen wohnen; oder schließlich, dass es einen regen Austausch von Amerikanern gibt, die zwischen Counties mit hohen Bildungsabschlüssen

20 Vgl. Wendy K. Tam Cho/James G. Gimpel/Iris S. Hui: Voter Migration and the Geographic Sorting of the American Electorate,in: Annals of the Association of American Geographers 2012: S. 1-16.

21 Vgl. Clayton Nall/Jonathan Mummolo: Why Partisans Don’t Sort: How Neighborhood Quality Concerns Limit Americans' Pursuit of Like-Minded Neighbors“, Working Paper, 02.10.2013. Online abrufbar unter: http://web.stanford.edu/ nall/ docs/gp2.1.pdf (zuletzt abgerufen am 20.07.2015). 
hin- und herziehen. ${ }^{22}$ Doch über die individuellen „Movers“ selbst, ihre Parteiidentifikation, ideologische Orientierung oder sonstige Merkmale, weiß man auch in diesem Fall: schlicht nichts. Hinzu kommt, dass Bishops Hauptargument - nämlich den starken Austausch zwischen Counties gleicher Parteifärbung als Belege des „Big Sort“ zu werten - im Endeffekt die These beinahe ad absurdum führt. Für die Analyse eines einzelnen Ortes mag diese Sichtweise Sinn ergeben. So lässt sich plausibel argumentieren, dass die zunehmende Stärke der Demokraten in Colorado - einst eine extreme republikanische Hochburg - vor allem auf das Konto einer expandierenden Software-Industrie und einer damit verbundenen starken Zuwanderung aus Kalifornien geht. ${ }^{23}$ Doch für die nationale Verteilung von demokratischen und republikanischen Hochburgen würden Migrationsströme dieser Art letztlich wenig bedeuten: es wäre ein Null-Summen-Spiel, bei dem die eine Hochburg an eine andere Hochburg Parteigänger verlieren würde. Um die These einer geographischen Sortierung der US-Bürger nach Parteipräferenzen empirisch zu untermauern, müsste man Bürger identifizieren, die an einen Ort ziehen, der ihren eigenen Parteineigungen stärker entspricht. Sprich: Republikaner, die von demokratischen Counties in republikanische Counties umziehen und umgekehrt. Erst der Nachweis eines solchen Musters würde nachdrücklich beweisen, dass Parteiidentifikation und Ideologie tatsächlich bestimmende Momente der amerikanischen Binnenmigration sind und insofern auch Motoren des „Big Sort.“24

Da mit bisherigen Daten und Instrumenten dieser Nachweis schwer zu erbringen ist, wird in dieser Arbeit ein anderer Weg eingeschlagen: Mit Hilfe einer regionalen Fallstudie, die ethnographische Vor-Ort Beobachtung mit Survey-Forschung kombiniert, soll zumindest für einen kleinen Ausschnitt des Landes Licht in das Dunkel des Phänomens der Herausbildung immer eindeutigerer Hochburgen geworfen werden. Die Fokussierung auf spezifische Orte bietet überdies die Möglichkeit, einen weiteren, kontrovers diskutierten Teil der Big-Sort-Hypothese intensiver auszuleuchten. Denn selbst wenn wir davon ausgehen könnten, so einige Kritiker der These von Bill Bishop und Robert Cushing, dass es zum „Clustern" von Demokraten und Republikanern gekommen ist: Ist dieses überhaupt von so großer Bedeutung? Spielt es eine Rolle, ob Demokraten und Republikaner immer weniger die gleichen Städte, Viertel, Nachbarschaften bevölkern? Ist dies im

22 Vgl. Bishop/Cushing: The Big Sort, a.a.O.

23 Vgl. Tony Robinson/Stephen Noriega: Voter Migration as a Source of Electoral Change in the Rocky Mountain West, in: Political Geography 2010 (1), S. 28-39.

24 Vgl. Lütjen/Matschoss: Ideological Migration in Partisan Strongholds, a.a.O 
Zeitalter moderner Kommunikation nicht ohne jede soziale Folge ${ }^{25}$ Es ist ein Argument, das, wenngleich unwissentlich, anschließt an all jene Überlegungen, die einen Verlust von „Örtlichkeit“ in modernen Gesellschaften diagnostizieren und von einem Bedeutungsverlust der Raum-Dimension für die Erklärung individuellen Verhaltens ausgehen. ${ }^{26}$ In der Fallstudie soll dieses Argument wiederlegt und gezeigt werden, dass die politischen Mehrheitsverhältnisse sehr wohl Einfluss auf das soziale Leben haben.

\section{BEgRÜNDUNG DER FALLAUSWAHL}

Die Orte, um die es in dieser Untersuchung gehen soll, sind zwei Counties im Bundestaat Wisconsin: Dane und Waukesha County. Dane County besteht zum größten Teil aus der Stadt Madison - einer für ihre linksliberale Kultur bekannten Universitätsstadt, in der Barack Obama 2012 71\% der Stimmen errang. Nur dreiBig Meilen in östlicher Richtung entfernt, in Waukesha County, erhielt sein Gegner Mitt Romney im gleichen Jahr 67\% der Stimmen. Waukesha County besteht aus einer Ansammlung von Suburbs westlich vor den Toren der einzigen wirklichen Großstadt des Bundesstaates Milwaukee.

Bevor es um die präzisere und ausführliche Begründung der Fallauswahl gehen soll - warum gerade diese zwei aus ca. 1700 ,landslide counties“ in den USA? - ein Wort zur allgemeinen Untersuchungsebene. Die Konzentration auf Counties ist letztlich eine forschungspragmatische Entscheidung, die nicht ohne Nachteile und daher durchaus erklärungsbedürftig ist. Denn unter dem Gesichtspunkt, jene sozialen Räume auszumachen, die Menschen tatsächlich als ihr alltägliches Interaktionsfeld betrachten und die bestimmend sind für ihre Lebenswelt, sind auch die meisten Counties gewiss keine ideale Bezugsgröße, da auch sie noch immer zu groß sind. Dane County hat über 500.000 Einwohner; Waukesha ca. 400.000. Kurzum: Wie auch viele andere Counties sind auch diese beiden Orte keineswegs vollständig homogen, differieren nicht nur von Stadt zu Stadt, sondern innerhalb der Städte natürlich auch in ihren Stadtvierteln und Nachbarschaften. Dies würde für eine Konzentration auf kleinere geographische Einheiten bei der Untersuchung

25 Morris P. Fiorina: The Big Sort that wasn't. A skeptical reexamination, in: PS: Political Science \& Politics, Vol. 45 (2) 2012, S. 203-210.

26 Vgl. Für diese Diskussion im amerikanischen Kontext und zugleich als „Verteidigungsschrift“ für die Wichtigkeit der Geographie Wilbur Zelinsky: Not Yet A Placeless Land: Tracking an Evolving American Geography, Boston 2011. 
sprechen, um die genauen Einflüsse der Lebenswelt auf die Menschen und die Einstellungen ihrer Bewohner zu ergründen.

Es gibt Untersuchungen, die für noch wesentlich kleinteiligere Einheiten einen elektoralen Homogenisierungsprozess nachzuweisen versuchen, etwa für Postleitzahlen (Zip Codes), ,precints“ oder „wards“, und dabei ähnliche Tendenzen zu Tage gefördert haben. ${ }^{27}$ Die Schwierigkeit bei der Untersuchung dieser kleineren, zweifellos überschaubareren Größen ist jedoch, dass sich ihre Grenzen im Zeitverlauf verändern. Hierdurch wird die exakte Bestimmung von Veränderungen im historischen Längsschnitt extrem erschwert. Im Gegensatz dazu verlaufen die Grenzen der Counties statisch und strukturelle Veränderungen lassen sich exakt nachvollziehen. Sie erweisen sich deshalb trotz ihrer Größe als bessere Untersuchungsebene.

Im Übrigen weisen sie eine Reihe von besonderen Vorzügen auf, die ihre Nachteile mehr als kompensieren. Da die amerikanische Zensusbehörde ihre Daten auf County-Ebene erhebt, sind diese sozio-demographisch äußerst transparent: Einkommen, Bildung, ethnische Zusammensetzung, Altersstruktur, Hausgröße, Heiratsquote - durch das Vorhandensein all dieser Informationen lassen sich bereits sehr präzise soziodemographische Profile erstellen. Hinzu kommt, dass die amerikanische Zensusbehörde Umzüge auf der Ebene der Counties erfasst. ${ }^{28}$ Es wurde bereits erwähnt, dass die Daten des Zensus allein ungenügend sind, um die Richtung der inneramerikanischen Migration zu bestimmen - denn dafür braucht man Daten auf der Individualebene. Aber erste Anhaltspunkte erhält man auf diesem Weg auf jeden Fall und das erleichtert die weitere Fallauswahl.

Und schließlich existiert ein letztes Argument, warum Counties ein so interessanter wie geeigneter Untersuchungsgegenstand sind: als Verwaltungseinheit sind sie auch eine politische Größe, in der eigene Lokalpolitik betrieben wird. Und aufgrund des starken dezentralen und föderalen Charakters der USA bietet sich

27 Vgl. für die Ebene der Zip Codes Ian McDonald: Migration and Sorting in the American Electorate: Evidence From the 2006 Cooperative Congressional Election Study, in: American Politics Research, Vol. 39 2011: S.512-533.

28 Einschränkend ist hier zu erwähnen, dass dabei natürlich nur jene Amerikaner (und ihre Familienangehörigen) erfasst werden, die Steuererklärungen ausfüllen. In den USA sind dieses jedoch immerhin $87 \%$ der Haushalte. Bedenkt man weiterhin, dass unter dieser bereits großen Gruppe Menschen, die umziehen, überrepräsentiert sein dürften (da Menschen mit geringem oder keinem Einkommen seltener umziehen), so lässt sich aus den IRS-Daten ein sehr exaktes Bild der Realität ableiten. Vgl. zu den Charakteristiken dieses Datensatzes Raven Molloy/Christopher L. Smith/Abigail K. Wozniak: Internal Migration in the United States, in: Journal of Economic Perspectives, Vol 25(3), 2011, S.173-196. 
für County Government ein durchaus beachtlicher Zuständigkeitsbereich, der von der Erhebung von Eigentumssteuern, dem öffentlichen Nahverkehr bis zum „zoning" erstreckt - allesamt Themen, wie wir noch sehen werden, bei denen sich nicht nur die Weltsichten lokaler politischer Aktivisten klar offenbaren. Es lässt sich eben auch ablesen, welche Arten von fundamental verschiedenen Politiken in diesen Ultra-Hochburgen letztlich beschlossen werden. Durch diese Entscheidungen werden die Orte wiederum möglicherweise in einer Weise geprägt, die sie (un-)attraktiv für bestimmte Arten von Migranten macht. Oder anders ausgedrückt: Republikanische super-majorities betreiben Politik für Republikaner, demokratische super-majorities betreiben Politik für Demokraten.

Das alles sind Argumente, die eine Konzentration auf Counties mehr als rechtfertigen. Gleichwohl: Angesichts der Tatsache, dass sich über die Hälfte der 3000 Counties in den USA mittlerweile als „landslide counties“ qualifizieren, blieb die Fallauswahl kompliziert und ein langwieriger Prozess. Doch stellten sich Dane und Waukesha County nach einer Kombination verschiedenster Merkmale als besonders geeignete Fallbeispiele dar. Insbesondere vier Aspekte waren dabei für die Auswahl leitend:

Erstens sollte es sich einerseits um sehr eindeutige Hochburgen handeln, die kontinuierlich und seit vielen Jahren durch ihre eindeutige politische Prägung auffielen, deren elektorale Unterschiede allerdings auch über die Jahrzehnte beständig gewachsen waren. Dane und Waukesha County waren hierfür exzellente Beispiele. Zwar wählt Dane County seit 1960 solide demokratisch und Waukesha befindet sich seit 1968 solide im republikanischen Lager bei Präsidentschaftswahlen, doch bis die Unterschiede so eklatant wurden, wie sie heute sind, vergingen mehrere Jahrzehnte. Als Referenzpunkt hierfür kann, wie auch bei Bishop und Cushing, das Jahr 1976 dienen, als die Stimmenverteilung in den US-Counties am ehesten dem nationalen Stimmenergebnis entsprach. In diesem Jahr gewann der Demokrat Jimmy Carter Dane County mit einer Marge von „nur“ 12 Prozentpunkten; 36 Jahre später wird Barack Obama Dane County mit einer Marge von 43 Prozentpunkten gewinnen. Gerald Ford gewinnt Waukesha 1976 mit 19 Prozentpunkten Vorsprung; Mitt Romneys Vorsprung wird 2012 hingegen 34 Prozentpunkte betragen. 
Abbildung 4: Ergebnisse Präsidentschaftswahlen Dane \& Waukesha 1948-2012

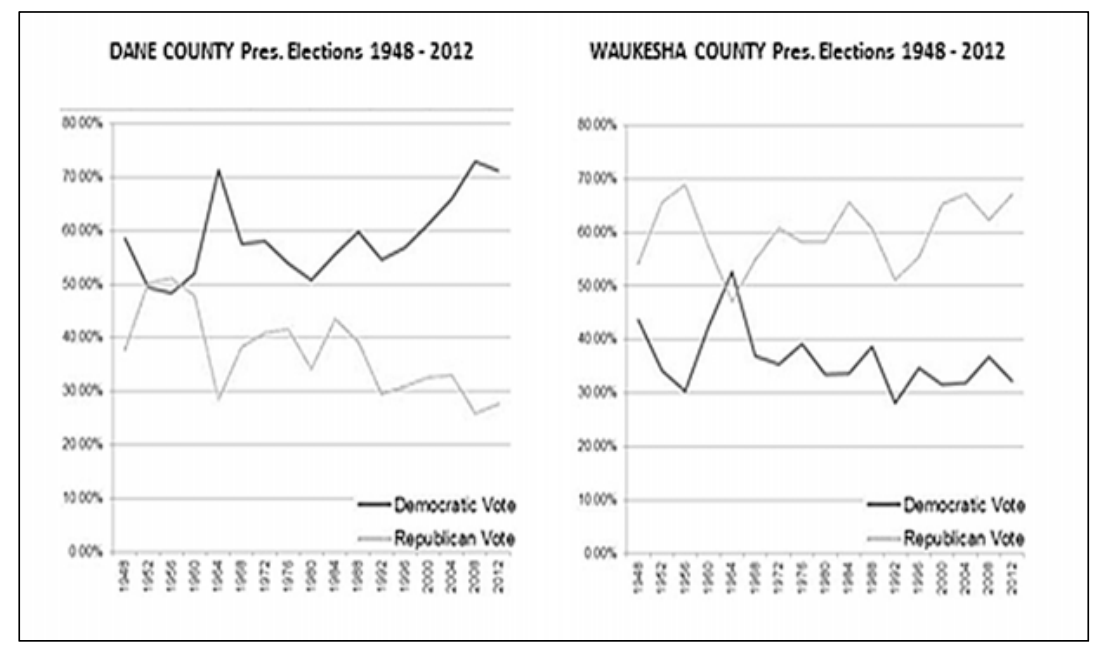

Quelle: Dave Leip - U.S. Election Atlas

Für die These von Binnenmigration als Auslöser der Hochburgenbildung sollten die Fallbeispiele zweitens eine dynamische Bevölkerungsentwicklung aufweisen. Auch das ist bei Dane und Waukesha der Fall. Von 1960 bis 2010 wuchs Dane County um $120 \%$, Waukesha County gar um beinahe 400\%. Im Vergleich zu vielen Regionen in den boomenden Staaten des Sunbelts mögen das fast noch eher durchschnittliche Zuwächse sein; für die Regionen des Mittleren Westens sind es spektakuläre Wachstumsraten, die bereits eine mögliche Magnetwirkung beider Orte andeuten.

Drittens erschien es ratsam, zwei Counties zu wählen, die räumlich nah beieinanderliegen, im besten Fall sogar benachbart. Das erleichterte nicht nur in logistischer Hinsicht den explorativen, ethnographischen Teil der Feldstudie. Es verringert außerdem auch den möglichen Einfluss regionaler Sonderfaktoren. Überdies liegen Dane und Waukesha noch so dicht beieinander, dass es möglich ist, in dem einen Ort zu wohnen und im anderen zu arbeiten - eine Möglichkeit, die von einigen auch genutzt wird. Doch am wichtigsten war dieser Aspekt, weil es bedeutete, dass die Bewohner beider Counties nicht nur einen gemeinsamen Diskursraum bewohnten, also über ähnliche Themen diskutierten und stritten, sondern dadurch auch potentiell eine Vorstellung von der anderen Seite besaßen. Wie wir noch sehen werden, ist dieses, sogar in ausgesprochen pointierter Form, auch tatsächlich der Fall bei Dane und Waukesha, deren County-Grenzen gerade einmal 
30 Meilen voneinander entfernt liegen, getrennt nur durch ein anderes, sehr spärlich besiedeltes County.

Schließlich das vierte und mit Abstand wichtigste Kriterium der Fallauswahl: Da es sich beim „Big Sort“, der Theorie nach, um ein Phänomen handelt, das sich durch eher ,weichere“, lebensstilbezogene Differenzen erklärt, sollten andere Unterschiede möglichst geringgehalten werden. Es ging also darum, zwei Counties zu finden, die sich ihrer völligen politischen Andersartigkeit zum Trotz in ihren soziodemographischen Profilen ähneln. Auch das ist bei Dane und Waukesha County fraglos der Fall. Zum einen sind beide Counties ganz überwiegend weiß (Dane County: 80\%, Waukesha County: 90\%). Das unterscheidet sie von vielen ebenfalls nebeneinanderliegenden „landslide counties“ im Süden der USA, deren Unterschiede sehr häufig eine direkte Spiegelung ethnischer Segregation sind. Beide Counties zeichnen sich auch durch eine besonders hohe Bildungsqualifikation aus. Bei Dane County mit der Universitätsstadt Madison ist das kaum erstaunlich: hier besitzen $45 \%$ der Menschen einen Bachelor-Abschluss oder einen noch höheren Bildungsabschluss. In Waukesha County sind es immerhin 39\% mit einer solchen Bildungsqualifikation und damit sind Dane und Waukesha County die beiden gebildetsten Counties im Bundesstaat Wisconsin. Etwas markanter sind die Unterschiede beim Einkommen: Im republikanischen Waukesha beträgt das durchschnittlich verfügbare Einkommen eines Haushaltes nach dem Zensus 2012 74,000 Dollar, im demokratischen Dane County sind es 60,000 Dollar p.a. Dennoch: Deutlich, sowohl über dem nationalen als auch dem Durchschnitt des Bundesstaates, liegen beide Orte, die damit an 2. und 6. Stelle von 72 Counties in Wisconsin stehen. ${ }^{29}$ Viele der üblichen sozioökonomischen Kennzahlen also, die in den USA traditionell das Wahlverhalten bestimmten, greifen hier nicht. Es muss etwas anderes sein, was Dane und Waukesha über Jahrzehnte zu Antipoden hat werden lassen; es ist die Suche nach diesem „etwas“, um die es in der Feldstudie gehen soll.

Auf jeden Fall macht gerade der letzte Punkt über das soziodemographische Profil beider Orte deutlich, dass die Geschichte von Dane und Waukesha die Geschichte eines bestimmten Segments der amerikanischen Gesellschaft ist: von weißen, gebildeten und relativ wohlhabenden Amerikanern. Sie sind besonders mobil, besitzen überhaupt erst die Ressourcen, um sich bei der Wahl ihres Wohnortes nach Lebensstilkriterien entscheiden zu können und werden so zu den „Treibern“ des „Big Sort“. Schließlich rekrutieren sich aus dieser Gruppe auch die am besten informierten, die politisch aktivsten und zugleich auch die ideologisch überzeugtesten Parteianhänger beider Seiten. Sie ist deckungsgleich mit jener

29 Sämtliche Zahlen sind zugänglich über den amerikanischen Zensus unter www. census.gov 
„Engaged Public" von der auch der Politologe Alan Abramowitz spricht, und die dafür verantwortlich ist, dass die amerikanische Politik immer tiefer in den Strudel der Polarisierung gezogen wurde. ${ }^{30}$ Überdies sind Dane und Waukesha County typische Hochburgen eines jeweils entscheidenden Teils der demokratischen bzw. republikanischen Wählerkoalition: auf der einen Seite die Verbindung aus Collegetown, High-Tech-Industrie und Angestellten des öffentlichen Dienstes; auf der anderen ein wohlhabender, weißer Vorort im Schatten einer von zahlreichen sozialen Schwierigkeiten gebeutelten Großstadt. Kurzum: Wer verstanden hat, wie diese Orte „ticken“, der ist womöglich ein Stück weiter bei der Beantwortung der Frage, warum sich die USA in zwei verfeindete ideologische Blöcke geteilt haben.

\section{Methodischer Feldzugang, Materialarten UND DATENLAGE}

Diese Arbeit verwebt sowohl sehr unterschiedliche methodische Zugänge als auch sehr disparate Quellen und Daten, um aus dieser Kombination ein plastisches und farbiges, gleichzeitig aber auch empirisch möglichst belastbares Bild über die Realität politischer Hochburgen in den USA zu erstellen. Zum einen handelt es sich um eine ethnographische Feldstudie. Von März bis Juli und von September bis Dezember 2012, und dann noch einmal von September bis Oktober 2014 verbrachte ich insgesamt 8 Monate in Wisconsin, wobei der Aufenthalt zeitlich gleich auf Dane und Waukesha County aufgeteilt wurde. In dieser Zeit interviewte ich 61 Personen beider Counties. Ein weiteres Gespräch sowie eine schriftliche Befragung ergänzten diese Umfrage. Manche meiner Interviewpartner traf ich auch zwei Mal, so dass am Ende insgesamt 68 Interviews durchgeführt wurden. 51 dieser Gespräche wurden transkribiert; in den anderen Fällen schien mir der Ertrag so gering zu sein, dass ich mich mit den Notizen begnügte, die ich unmittelbar nach jedem Gespräch aus dem Gedächtnis anfertigte. Unter den Interviewten waren Lokalpolitiker, Richter, lokale politische Aktivisten, Journalisten, Menschen mit wichtigen Positionen in der Zivilgesellschaft (wie etwa Pastoren, Unternehmer usw.), und manchmal auch einfach „normale“ Bürger, deren persönliche Erfahrungen etwas zur Beantwortung meiner Forschungsfragen beitragen konnten.

Meine Interviewtechnik war dabei flexibel und passte sich auch häufiger der Gesprächssituation an. Tendenziell wechselte ich häufiger von leitfadengestützten

30 Alan I. Abramowitz: The Disappearing Center - Engaged Citizens, Polarization, \& American Democracy, Yale 2010. 
Interviews zu stärker explorativen Interview-Designs, wie etwa narrativen Interviews und zunehmend auch zu stärker dialogischen, offenen Gesprächen. ${ }^{31}$

Den qualitativ-ethnographischen Teil meiner Studie ergänzten Erkenntnisse aus Prozessen teilnehmender und nicht-teilnehmender Beobachtung. Dies bezieht sich auf meine Teilnahme an Parteiversammlungen, Treffen von Nachbarschaftsvereinigungen, Besuch von Gottesdiensten, sowie vielen anderen, eher informellen Begegnungen. In ihrer Bedeutung waren die daraus festgehaltenen Beobachtungen im Vergleich zum Wert der Interviews weniger zentral. Doch bei der Niederschrift der Arbeit erwiesen sie sich als nützliche Eindrücke, die gleichsam den Kontext und die Hintergründe für meine übrigen Daten lieferten. Überhaupt gewinnt man Anschauungsmaterial bei Studien dieser Art auch jenseits standardisierter Erhebungen und sollte hierfür offen sein. Denn eines ist so trivial, wie es wahr ist: Um über einen bestimmten Ort und seine Bewohner zu schreiben, sollte man gewiss dort gewesen sein, um sich mit der Lebenswelt der „Forschungsobjekte" vertraut zu machen. Wer z.B. im suburbanen, zersiedelten Waukesha County für seine Interviews von einem Starbucks in der einen Mall zum Starbucks in die nächst Mall fährt, und sich auf der halbstündigen Fahrt trotz Navigationssystem fragt, ob er die ganze Zeit im Kreis fährt, da der eine Ort aussieht wie der andere, der erhält so bereits eine Vorstellung von der Struktur des sozialen Raumes und welchen Rhythmus das Leben dort wohl annehmen könnte.

Das zweite große empirische Standbein der Studie ist eine repräsentative Telefonumfrage in beiden Counties, die in Kooperation mit der Marktforschungsfirma LHK im Juli 2013 durchgeführt wurde. Aus Gründen der Vereinfachung soll diese Studie in dieser Arbeit fortan als Dane-Waukesha-Polarization-Study, oder DWPS, bezeichnet werden. Die Daten aus der DWPS stellen somit meine dritte Materialart dar. Ein Schwerpunkt dieser Erhebung war die Frage nach dem Zusammenhang zwischen Umzugsentscheidung, Parteiidentifikation und Lebensstilorientierung, um die bisher empirisch nur mangelhaft belegte These des „Big Sort" an zwei konkreten Fallbeispielen zu überprüfen. Die Umfrage widmete sich aber auch Bereichen, die stärker mit der „Soziologie der Hochburg“ im Zusammenhang stehen. So wurde etwa danach gefragt, wie ideologisch homogen oder heterogen die sozialen Netzwerke von Demokraten und Republikanern in Dane und Waukesha County waren. Und weiterhin: Wie zufrieden und sozial integriert fühlten sich beide Gruppen an ihren jeweiligen Wohnorten? Hatten die Hochburgen eine politische Prägewirkung, machten sie also diejenigen, die dorthin zogen, im Zeitverlauf tendenziell liberaler oder konservativer? Gab es Unterschiede in

31 Vgl. zur notwendigen Flexibilität und situativ bedingten Veränderungen der Interviewführung Cornelia Helfferich: Die Qualität qualitativer Daten. Manual für die Durchführung qualitativer Interviews, 3. Auflage, Wiesbaden 2009, S. 42f. 
Bezug auf Vereinszugehörigkeiten und anderen Formen sozialen Kapitals? Unterschied sich der Grad der politischen Partizipation zwischen Minderheiten und Mehrheiten in den jeweiligen Hochburgen? All dies waren Fragen, von denen ich hoffte, sie mit einer quantitativen Befragung gründlicher und präziser beantworten zu können.

So knapp wie eben möglich sollen an dieser Stelle die technischen Eckpunkte der Umfrage benannt werden. Es wurde für jedes County eine separate Zufallsstichprobe gezogen. Die computergestützte telefonische Umfrage (CATI) wurde von der Marktforschungsfirma LHK Partners durchgeführt. Sie fand vom 22. bis 28. Juli 2013 statt, durchgeführt von professionell geschulten Interviewern, mit bis zu fünf Kontaktversuchen pro Zielperson. Insgesamt wurden 1601 Personen befragt: 802 in Dane County, 799 in Waukesha County. Etwa 80\% der Befragten wurden über ihren Festanschluss erreicht, 20\% über ihr Mobilfunktelefon. Die Kooperationsrate nach AAPOR-Standard betrug 36,1\%. Das Sample für jedes County entsprach in seiner sozio-demographischen Zusammensetzung sehr genau den Daten der Amerikanischen Zensus-Behörde aus dem letzten American Community Survey, insbesondere in Bezug auf Geschlecht, Bildungsstand und Einkommen. Einzig bei der Frage des Alters sind beide Samples etwas zu alt. AfricanAmericans und Hispanics, in beiden Counties ohnehin eine sehr klare Minderheit, sind ebenfalls noch zusätzlich unterrepräsentiert. Da die Gruppe jedoch zu klein war, um sinnvollerweise eine weitestgehend verzerrungsfreie Gewichtung durchzuführen, wurde sich schließlich gegen eine Gewichtung entschieden.

Neben dem Interview-Material, den Ergebnissen der teilnehmenden Beobachtung und den Daten aus der Dane-Waukesha-Polarization-Study, existierte schließlich eine vierte Materialart bzw. Quelle: lokale Zeitungsquellen. Zwar waren diese in ihrer Bedeutung den ersten drei Materialarten klar untergeordnet, bei einigen der verfolgten Fragen aber dennoch hilfreich. Das galt zum einen für die Phase der Vorbereitung der Studie, da sich auf diese Weise noch vor den Feldaufenthalten ein guter Überblick über lokale Themen und Akteure gewinnen ließ. Wichtig aber waren Zeitungsquellen auch für die Abläufe in der Lokalpolitik, besonders im hoch politisierten Dane County, wo sich das systematische Erschließen der Berichte und Kommentare, etwa zu lokalen Wahlkämpfen, als gute Ergänzung zu meinen Interviews erwies. Für Dane County analysierte ich vor allem die Artikel zweier lokaler Tagezeitungen („Capital Times“ und „Wisconsin State Journal“) sowie einer Wochenzeitung („Isthmus“), bei Waukesha vor allem die Tageszeitung „Milwaukee Journal Sentinel“. 
In der Literatur zur Kombination qualitativer und quantitativer Forschungsansätze - etwas, was häufig gefordert, aber sehr viel seltener eingelöst wird - werden verschiedene Möglichkeiten der methodischen Verknüpfung benannt. ${ }^{32}$ Sehr grob gesagt dient der qualitative Teil entweder der Hypothesenbildung, und der quantitative Teil dann der Hypothesentestung; (,Vorstudienmodell“ bzw. „Verallgemeinerungsmodell“), oder aber auf der Grundlage der Daten einer Studie mit großer Stichprobe werden zur Vertiefung Fallstudien geleistet („Vertiefungsmodell“). Schließlich existiert die Möglichkeit der sogenannten Triangulation, in der eine Fragestellung mit verschiedenen Methoden bearbeitet wird, wie etwa in der damals bahnbrechenden Marienthal-Studie von Paul F. Lazarsfeld, Marie Jahoda und ihren Mitarbeitern. ${ }^{33}$ Die letzte Möglichkeit einer quasi vollständigen Integration kommt dem hier gewählten Ansatz wohl tatsächlich am nächsten: Verschiedene Phänomene werden sowohl mit qualitativen als auch quantitativen Daten zu erklären versucht. Freilich gilt auch hier, dass Idealtypen in der Forschungsrealität selten vorkommen: bisweilen ging es tatsächlich darum, Hypothesen aus der explorativen Feldstudie durch die DWPS zu überprüfen, was sich einfach auch durch die zeitliche Abfolge der verschiedenen Feldphasen erklärt. Schließlich erfolgte das Design des Fragebogens für die DWPS unmittelbar nach beiden längeren ethnographischen Feldphasen im Jahr 2012, stand somit unter dem unmittelbaren Eindruck meiner dort gewonnenen Erkenntnisse. Und umgekehrt diente der letzte Aufenthalt in Wisconsin 2014 zum Teil auch der Überprüfung von Zusammenhängen und Korrelationen, die sich erst aus der Datenanalyse der DWPS ergeben hatten.

Die große methodische und empirische Spannweite der Studie - von ethnographischer Vor-Ort-Beobachtung bis hin zur quantitativen Datenanalyse - wird den Stil und die Ästhetik der Arbeit bestimmen. So wechseln sich narrative Abschnitte mit solchen von eher nüchterner, berichterstattender Natur ab, in denen der Erzählfluss angehalten wird. Wo es besonders wichtig ist, werden die Daten aus der DWPS natürlich auch in Tabellen und Diagrammen graphisch dargestellt. Aller Bemühungen um methodische Integration zum Trotz steht die Arbeit jedoch letztlich in der Tradition einer interpretativen Sozialforschung, in der es primär

32 Vgl. für einen kompakten Überblick Philipp Mayring: Kombination und Integration qualitativer und quantitativer Ansätze, in: Forum Qualitative Sozialforschung (online journal), Heft 1, 2001, abrufbar unter: http://www.qualitative-research.net/index.php/ fqs/article/view/967/2111 (zuletzt abgerufen am 12. 10. 2014)

33 Vgl. Marie Jahoda, Paul Felix Lazarsfeld und Hans Zeisel: Die Arbeitslosen von Marienthal. Ein soziographischer Versuch über die Wirkungen langandauernder Arbeitslosigkeit, Leipzig 1933. 
um die subjektiven Wahrnehmungen der Akteure geht, darum, wie sich die Wirklichkeit aus ihrer Sicht darstellt. Wem es wirklich ernst ist damit, reale Menschen in den Mittelpunkt seines Erkenntnisinteresses zu stellen, der muss ihnen auch Raum geben für ihre Motivlagen und Eigenarten und sie in ihrer Individualität anerkennen - und damit allerdings auch die Singularität bestimmter sozialer Abläufe akzeptieren. Hat man diese Entscheidung einmal getroffen, dann darf man sich keinesfalls jedes Mal ängstlich fragen, wie verallgemeinerbar persönliche Erfahrungen oder „Geschichten“ sind, die einem etwa bei einem narrativen Interview mitgeteilt werden. Die selten ausgesprochene Wahrheit der qualitativen Sozialforschung ist, dass bei allen Bemühungen um Repräsentativität stets eine nicht gerade kleine „Restvarianz“ verbleibt, die sich eben durch die konkreten Handlungen konkreter Menschen ergibt, warum sich nicht alles von dem einen Ort auf einen anderen übertragen lässt. Aber an der Wirklichkeit einer von Menschen gemachten Ordnung ist diese Anerkennung der Mischung aus determinierten Strukturen einerseits und freien, individuellen Entscheidungen anderseits, sehr viel näher als die anämischen und menschenleeren Reduktionsmodelle, die insbesondere in der Politikwissenschaft zunehmend das Feld dominieren. „Good Narratives typically approach the complexities and contradictions of real life", schreibt Bent Flyvbjerg in seinem klugen Plädoyer für das Genre der Fallstudie. ${ }^{34}$ So ist das, was folgt, in der Tat nicht zuletzt eben auch eine Geschichte - die Geschichte von der Geburt, der Soziologie und der Politik zweier politischer Hochburgen, in deren Gegensätzlichkeit sich die tiefe ideologische Spaltung der USA verkörpert.

34 Vgl. Bent Flyvbjerg: Five Misunderstandings about Case-Study Research, in: Qualitative Inquiry, Vol. 12 (2) 2006: S. 219-245, hier S. 237. 



\section{Spielfeld und Akteure: Madison, Wisconsin, Februar 2011}

Feldstudien sind freilich nicht nur in räumlicher Hinsicht immer nur ein Ausschnitt der Realität. Im Grunde sind sie es ebenfalls in Bezug auf den zweiten entscheidenden Filter unserer Wirklichkeitswahrnehmung: der Zeit. Im Grunde friert man seine Eindrücke ein, drückt sozusagen auf die Pause-Taste und erstellt ein Standbild. Meine beiden längeren Aufenthalte in Wisconsin waren von März bis Juni und von September bis Dezember 2012. Während die Geschichte, die im Folgenden erzählt wird, nicht allein in diesem Zeitraum spielt, ist es doch wichtig, sich zu vergegenwärtigen, dass der Zeitpunkt einer Erhebung das Ergebnis maßgeblich beeinflusst. Möglicherweise wäre es anders ausgefallen, wenn ich zwei Jahre später in den Badger-State gekommen wäre. Ziemlich sicher bin ich mir allerdings, dass mein Ergebnis ein wenig anderes gewesen wäre, wenn ich zwei Jahre früher diese Orte besucht hätte. Oder genauer gesagt: Es wäre zumindest verborgener geblieben, was in dieser Zeit überdeutlich sichtbar wurde. Denn in den Jahren zwischen 2010 und 2012 passiert etwas mit Wisconsin und damit auch mit den Menschen in Dane und Waukesha County. Zu diesem Zeitpunkt bricht nämlich ein Konflikt aus, in dem sich ausdrückt, für was die beiden Orte paradigmatisch stehen und der den Diskurshorizont der Akteure noch lange bestimmen wird. Und da der Hauptschauplatz des Konfliktes auch noch in einem unserer beiden Fallbeispiele liegt, macht es Sinn, die Geschichte von Dane und Waukesha County zunächst im Februar 2011 beginnen zu lassen.

In diesem Monat nämlich rückt dieser kleine Bundesstaat im Mittleren Westen der USA plötzlich für viele Wochen in den Fokus der nationalen und bald sogar internationalen Berichterstattung: In Wisconsin, sonst eher für sein Bier, seine Bratwurst und seinen Käse bekannt, ist eine politische Auseinandersetzung entbrannt, die Bilder produziert, die es in westlichen Demokratien - und vor allem in den USA - seit den frühen 1980er Jahren nicht mehr gegeben hat: 
Für mehrere Wochen belagern zehntausende Demonstranten das State Capitol in der Hauptstadt Madison, dem Sitz des Gouverneurs und der State Legislature, des Parlaments des Bundestaates. Sie fordern die Rücknahme eines Gesetzes, das der erst wenige Wochen zuvor ins Amt gekommene republikanische Gouverneur Scott Walker in Rekordzeit durch das von seiner Partei ebenfalls kontrollierte Landesparlament boxen will: Die sogenannte „Budget Repair Bill“, oder auch, wie sie fortan genannt wird, den Act 10. Mit ihm will Walker, so jedenfalls lautet die offizielle Begründung, die gravierenden Haushaltsprobleme Wisconsins in den Griff bekommen. Act 10 sieht Kürzungen bei Pensionszahlungen, das Einfrieren der Gehälter der Angestellten des öffentlichen Dienstes und einige andere durchaus drakonische Sozialkürzungen vor. Nichts aber trägt so sehr zur Mobilisierung bei, wie Walkers Versuch, den öffentlich Beschäftigten das Recht zu nehmen, kollektiv um ihre Löhne und andere Angelegenheiten zu verhandeln. Für die Gewerkschaften des öffentlichen Dienstes bedeutet das einen Anschlag auf ihre Existenzgrundlage als Organisation.

Die Nachricht über Walkers Vorhaben der Abschaffung des „Collective Bargaining“, dass er am 11. Februar 2011 öffentlich macht, verbreitet sich schnell. Die ersten, die zum Widerstand aufrufen, sind noch am gleichen Tag die Lehrassistenten der Universität. Dann folgt die Lehrergewerkschaft. Da Lehrer kein Streikrecht besitzen, meldet sich in Madison die Hälfte von Ihnen am nächsten Tag einfach kollektiv krank, in der Stadt müssen die Schulen daraufhin schließen. Aus ein paar Hundert Demonstranten sind vier Tage nach Walkers Ankündigung zur Abschaffung des „Collective Bargaining“ schon mehrere Tausend geworden, nach einer Woche sind es über Zehntausend. Sie beginnen nicht nur, vor dem Capitol zu campen, sondern dringen auch in das Gebäude selbst ein, woraufhin die republikanischen Abgeordneten ihre Türen verriegeln.

In einer, im wahrsten Sinne des Wortes, Bunkermentalität beschließen sie dennoch, Nägel mit Köpfen zu machen und das geplante Gesetz so schnell wie möglich durch beide Kammern des Parlaments zu bringen. In der „State Assembly“ ist das weniger ein Problem, aber um im Senat beschlussfähig zu sein, brauchen sie die Anwesenheit von 3/5 der Mitglieder, womit ihre einfache Mehrheit dort alleine nicht reicht. Die Demokraten wollen der Abstimmung daher einfach fernbleiben, doch als Gerüchte die Runde machen, Walker beabsichtige, sie notfalls mit Hilfe des Scheriffs zur Abstimmung eskortieren zu lassen, verlassen die 14 Senatoren der demokratischen Partei in den frühen Morgenstunden des 17. Februar Wisconsin und fliehen über die Staatsgrenze nach Illinois. 
Über die Flucht ihrer gewählten Volkvertreter bricht frenetischer Jubel unter den Protestierenden aus. Erst drei Wochen später kehren die Senatoren zurück, abermals unter dem großen Beifall der Demonstranten, gefeiert wie Rockstars. ${ }^{1}$

Es ist ein veritabler Hauch von Umsturz, der in diesen Tagen durch die eiskalte Winterluft von Wisconsin flirrt, mit all den mittlerweile popkulturell eingeschmolzenen Szenen der großen Revolutionsromantik. Man campt in Zelten vor dem Capitol und natürlich kommt auch bald der unvermeidliche Bürgerrechtler und Protest-Veteran Jesse Jackson und singt mit den Demonstranten „We Shall Overcome“. Ansonsten allerdings dominiert das „Jump Around“ der Hip-HopBand „House of Pain“ die Szene, das aus riesigen Boxen über den Platz dröhnt und zu dem sonst 80000 Zuschauer bei den College-Football-Spielen der „Wisconsin Badgers“ im örtlichen „Camp Randall“ auf der Stelle hüpfen. Doch obgleich der Protest wie alle modernen Revolten auch einen Happening-Charakter hat, nehmen sich die Aktivisten in Wahrheit über alle Maßen Ernst, und die intellektuellen Stichwortgeber der Proteste werden später behaupten, dass die OccupyBewegung hier ihren Anfang nahm. ${ }^{2}$ Man tauscht gar Solidaritätsadressen mit den Protestierenden am Kairoer Tahrir-Platz aus, und verspricht sich gegenseitig, nicht zurückzuweichen. „This is what democracy looks like“ lautet der Schlachtruf der Demonstranten. Es ist natürlich eine absurde Analogie: Die einen wollen unter Einsatz des eigenen Lebens einen brutalen Diktator stürzen, die anderen einen immerhin demokratisch ins Amt gekommenen Gouverneur an der Verabschiedung eines Gesetzes hindern. Doch dieser Sinn für Perspektive ist längst allen Beteiligten abhandengekommen. Wer meint, Hitler-Vergleiche seien eine exklusive Angelegenheit der paranoiden amerikanischen Rechten, sieht sich im Winter 2011 eines Besseren belehrt: auch Walker zieren auf vielen Plakaten ein kurzer Schnurrbart und eine SS-Uniform.

Der Gouverneur, dessen Wahlsieg ein Produkt der großen Mobilisierungswelle durch die Tea Party war, die bei den Zwischenwahlen 2010 im ganzen Land sehr erfolgreich gewesen ist, bemüht sich derweil nach besten Kräften, die Stimmung weiter anzuheizen. So erhält er wenige Tage nach Beginn der Proteste einen Anruf des liberalen Bloggers Ian Murphy.

1 Die Vorgeschichte und der Ablauf der Wisconsin-Proteste ist gut und sehr detailliert dargestellt bei Jason Stein/Patrick Marley: More Than They Bargained For: Scott Walker, Unions and the Fight for Wisconsin, Madison 2013.

2 Vgl. John Nichols: Uprising. How Wisconsin Renewed the Politics of Protest from Madison to Wall Street, New York 2012. 
Der gibt sich als David Koch aus, einen erzkonservativen Multi-Milliardär und bekannten Finanzier der Tea Party Bewegung und damit für viele Demokraten der Leibhaftige selbst. Koch alias Murphy wird tatsächlich zu Walker durchgestellt und gibt ihm unter anderem ein paar gute Ratschläge mit auf den Weg: Ob es denn nicht eine gute Idee sei, ein paar gewalttätige Demonstranten einzuschleusen, um die Situation eskalieren zu lassen und danach richtig mit dem Mob aufzuräumen? Walker antwortet in seinem schnodderigen Mittlerer-Westen-Akzent nur mit: „We thought about that“, und fügt hinzu, dass seine Leute aber schließlich zu dem Ergebnis gekommen seien, dass es doch besser wäre, die Demonstrationen einfach auslaufen zu lassen.

Scott Walker, ein Mann von unscheinbarer Statur und äußerst blassem Teint, Sohn eines Baptistenpredigers, glaubt selbst zutiefst an seine historische Mission: Auf dem Höhepunkt der Proteste vergleicht er seine eigene Lage mit der Ronald Reagans beim Streik der Fluglotsen 1981. Auch Reagan sei damals unbeugsam geblieben - was schließlich, so Walker allen Ernstes, der erste Riss in der Berliner Mauer gewesen sei; danach hätten die Sowjets schließlich gewusst, dass Reagan kein „Schwächling“" sei. ${ }^{3}$

Freilich: Der Mann für die Geschichtsbücher scheint im Februar und März 2011 in der ganzen Stadt manchmal eher wie eine einsame, verlorene Figur. Demonstranten belagern auch sein Privathaus, sein Terminkalender wird zum bestgehüteten Geheimnis von Wisconsin, denn es gibt sogar Morddrohungen. Walker selbst wird aus den heftigen Anfeindungen gegen ihn und seine Familie später politisch süßen Honig saugen, es ist ein essentieller Teil der Erzählung vom unbeugsamen Reformer, den nichts von seinem Weg abbringen kann. „Unintimidated" - Uneingeschüchtert, so wird er später großspurig seine Autobiographie nennen, die in Wahrheit natürlich - wie immer bei solchen recht vorläufigen Lebensbilanzen - ein Bewerbungsschreiben für höhere Aufgaben darstellt, denn die Ereignisse dieses Winters werden ihn ein paar Jahre später kurzzeitig zu einem ernst zu nehmenden Kandidaten für die republikanische Präsidentschaftskandidatur machen. ${ }^{4}$ Davon aber ist jetzt noch nichts zu ahnen. Als Walker inmitten der Proteste ein Restaurant in der Innenstadt aufsucht, beginnen die anderen Gäste zu buhen und zu pfeifen, so lange, bis der Inhaber des Restaurants den Gouverneur auffordert, sein Etablissement wieder zu verlassen. In den meisten Geschäften der Stadt hängen Anti-Walker Plakate in den Schaufenstern, die ihre Solidarität mit den Protestierenden ausdrücken.

3 Vgl. Stein/Marley: More Than They Bargained for, a.a.O. S. 58.

4 Vgl. Scott Walker: Unintimidated. A Governor's Story and a Nation's Challenge, New York 2014. 
Etwa zwei Wochen nach Beginn der Proteste hat die Welle ihren Höhepunkt erreicht: 100.000 Menschen versammeln sich jetzt vor dem Capitol zum Widerstand. Selbst die Polizei von Madison und Dane County sympathisiert mit den Demonstranten, und das obwohl Walker - ein Schelm wer Böses dabei denkt - sie ausdrücklich von allen Kürzungen ausgenommen hat. In der Hauptstadt des von ihm regierten Bundesstaates muss der republikanische Gouverneur sich wie der verhasste Statthalter einer fremden Besatzungsmacht fühlen.

Die Sympathien der Ordnungshüter liegen vielleicht auch darin begründet, dass in den USA auch das Amt des Scheriffs durch eine demokratische Wahl vergeben wird - und in Madison, Dane County, werden dafür schon seit einiger Zeit nur noch Demokraten gewählt. Die Stadt ist eine krasse Hochburg der Demokratischen Partei und deshalb ist auch der Ort der Revolte kein Zufall. Die Universitätsstadt Madison gilt schon lange als Hochburg einer aktivistischen linken Kultur. Vermutlich hätte es nicht viele andere Städte in den USA gegeben, an denen eine solche Mobilisierung geglückt wäre. Madison war schon zu Beginn des 20. Jahrhunderts eine der Keimzellen des „Progressive Movement“, dann in den 1960er Jahren eines der Epizentren der Studentenproteste gegen den Vietnamkrieg. Einer von Walkers Vorgängern, der Republikaner Lee Dreyfuss, bezeichnete die Stadt einmal als „,30 square miles, surrounded by reality“. Er meinte das nicht unbedingt positiv, eher sollte es wohl aussagen, dass die Bewohner Madisons mit dem Rest des Landes „out of touch“ seien. Die liberale Klasse der Stadt allerdings trägt diesen Titel wie ein Ehrenabzeichen, verweist er doch auf ihren eigenen Anspruch, ganz anders zu sein als der Rest des Staates. Sie hatten Walker nicht zum Gouverneur gemacht: In Dane County, dass zum größten Teil aus Madison, seinen Vororten und einigen ländlichen Gemeinden besteht, hat Walker nicht einmal 30\% der Stimmen erhalten, in Madison selbst nicht einmal 20\%. Es gibt Nachbarschaften in der Stadt, in der die Republikaner in Präsidentschaftswahlen noch hinter dem Kandidaten der Grünen auf dem dritten Platz landen. Viele Menschen in der Stadt kennen Republikaner nur vom Hörensagen. Im 20-köpfigen Stadtrat von Madison sitzt tatsächlich kein einziger Vertreter der GOP.

Es gibt während der Anti-Walker Proteste von Madison gleichwohl auch ein paar einsame Gegendemonstranten, die Walker unterstützen. Viele sind es nicht, die es wagen, sich in dieser aufgeheizten Stimmung vor das Kapitol zu stellen. „Americans for Prosperity“, die konservative Lobby-Gruppe, die vom bereits erwähnten David Koch finanziert wird, hat einige Hundert Aktivisten in die Hauptstadt gebracht. Für viele von ihnen war die Reise allerdings nicht sehr weit: Sie kommen aus den ca. 50 Meilen von Madison entfernten Suburbs von Milwaukee, jenen wuchernden Vorstädten, die sich seit den 1950er Jahren um diese einzige echte 
Großstadt Wisconsins gelegt haben. Milwaukee selbst, mit seinem großen Anteil an afro-amerikanischen Wählern, ist ebenfalls demokratisch geprägt - die Suburbs im Umland aber sind mindestens so konservativ, wie Madison liberal ist. Diese Vororte sind Scott Walkers Heimat, hier hat er seine ersten politischen Gehversuche unternommen, sind auch seine stärksten Bataillone anzutreffen. Die meisten Stimmen bekommt er aus Waukesha County, das in just dieser Zeit in der öffentlichen Wahrnehmung zum konservativen Widerpart der liberalen Hauptstadt wird, ein Ort an dem politisch alles einmal komplett auf rechts gedreht ist - ,Walkerstan“ nennt man im liberalen Madison voller Verachtung diesen Teil des Staates. Einige der konservativsten Republikaner von Washington sind von Waukesha aus in den Kongress gewählt worden: James Sensenbrenner etwa, der Autor des „Patriot Act", kommt von dort, und auch ein Stück des Wahlkreises von Paul Ryan liegt in Waukesha.

In Waukesha denken die meisten Menschen so wie Walker selbst: dass die öffentlichen Angestellten in Wisconsin, allen voran natürlich die liberalen Professoren der Universität, mit den hart erarbeiten Steuergeldern der rechtschaffenen, hart arbeitenden Bürger von Waukesha schon zu lange eine Party gefeiert haben. Auch 2011 stecken die USA noch in der Rezession. Waukesha gehört zu den wohlhabendsten Counties des Staates, aber die Krise ist auch dort spürbar, oder jedenfalls, und dies wirkt als Katalysator von Ängsten oft stärker als die objektive Situation, die Antizipation einer nahenden Krise. Gerade in Waukesha haben Amerikaner, die „nur“ zur gehobenen Mittelklasse gehören, sich riesige Häuser geleistet, oft abfällig als „McMansions“ bezeichnet, was den Gigantismus ebenso deutlich machen soll wie die, in den Augen der Kritiker, relative Gleichförmigkeit dieser Riesenhäuser mit sechs bis acht Zimmern. Die amerikanische Immobilienkrise macht viele Leute dort äußerst nervös. Auch deswegen gibt es in Waukesha nur sehr wenige, die sich über die Kürzungen für Angestellte des öffentlichen Dienstes empören können. Dort hält man die Proteste für eine von den „Bossen“ der Gewerkschaften orchestrierte politische Veranstaltung, um die Privilegien einiger weniger zu verteidigen. Für die Republikaner von Waukesha geht es nicht um einen Konflikt zwischen Kapital und Arbeit, wie es die Linken in Madison sehen, sondern zwischen Steuerzahlern und Steuerkonsumenten, oder wie es einige von ihnen etwas drastischer formulieren: ein Konflikt zwischen den „makers“ und den ,,takers“.

Waukesha ist einer jener Orte, der für Europäer beim ersten Mal eine etwas verstörende Erfahrung sein kann, weil uns einfach jeder Vergleichsmaßstab fehlt. Es gibt keinen Stadtkern, kein Zentrum, nirgends, nur die immer gleiche Heilige Dreifaltigkeit aus Wohnsiedlung, Highway und Shopping Mall. Wer nach Waukesha kommt, der versteht, dass die USA sich mindestens mental noch immer in 
der Phase ihrer Besiedlung befinden, weshalb sich einige ihrer Bürger manchmal eben auch wie Siedler benehmen. Für die meisten Menschen in Madison hingegen ist Waukesha nur eine Transitstrecke auf dem Weg nach Milwaukee, mentales „fly-over-America“, fremdes, feindliches Territorium. Einmal schilderte ein Gastronom von Madisons State Street - einer der Orte, an denen das liberale Herz der Hauptstadt schlägt - dem Verfasser, wie er auf dem Weg nach Milwaukee eine kurze Pause machen musste und ihm plötzlich auf dem Parkplatz all die Autos mit den „Stand with Walker“-Aufklebern auf der Stoßstange auffielen - etwas, was man in Madison in dieser Zeit fast überhaupt nicht sah. „I felt dirty. When I had arrived in Milwaukee, I wanted to take a shower."5

Während der Wisconsin-Proteste versinnbildlicht sich in diesen beiden Orten die Spaltung des Bundesstaates. Hier die urbane, quirlige Universitätsstadt Madison, dort das zersiedelte, suburbane Waukesha. Die Orte sind so grundsätzlich verschieden; und sich dabei anderseits doch so ähnlich. Das gilt nicht für die schon beschriebenen soziostrukturellen Charakteristika. Beide Orte sind außerdem auch Hochburgen politischer Partizipation: Bei der Präsidentschaftswahl 2012 lag die Wahlbeteiligung in Dane County bei $81 \%$; in Waukesha County waren es sogar 84\%. Damit lagen Dane und Waukesha an sechster bzw. zweiter Stelle unter allen Counties mit mehr als 50.000 Einwohnern in den gesamten USA; und geschlagen wurde Waukesha nur von einem benachbarten County, dass ebenfalls zu den Suburbs von Milwaukee gehört. ${ }^{6}$ Niemand im amerikanischen Repräsentantenhaus hat absolut so viele Stimmen auf sich vereinigen können wie die beiden Kongressabgeordneten, die die größten Teile von Dane und Waukesha vertreten, der Demokrat Marc Pocan und der Republikaner James Sensenbrenner. ${ }^{7}$

Diese beiden Hochburgen politischer Partizipation sind die Dynamos, die die Hälften eines ehedem sehr konsensgeprägten Bundesstaates auseinandergetrieben haben.

5 In dieser Arbeit werden fortan in der Regel die Klarnamen aller Personen genannt. Ausnahmen werden natürlich dort gemacht, wo, wie bei der obigen Äußerung, Zitate nicht aus den „offiziellen“ Interviews, sondern aus eher informellen Begegnungen stammen.

6 Vgl. Craig Gilbert: Far from creating fatigue, partisan battles energize voters, in: Milwaukee Journal Sentinel, 10. Mai 2014, http://www.jsonline.com/news/state politics/far-from-creating-fatigue-partisan-battles-energize-voters-b99256305z1-2586 76961.html (zuletzt abgerufen am 15.0.2015).

7 Vgl. Craig Gilbert: Top vote-getters in US House hail from neighboring Wisconsin districts, in: Milwaukee Journal Sentinel, 13. Januar 2015, http://www.jsonline.com/ blogs/news/288475091.html (zuletzt abgerufen am 15.06.2015) 
Als die Welle der Empörung über Walkers Politik nicht verebben will, überlegt man in Madison, die Mobilisierung für ein gewagtes Manöver zu nutzen. In der Verfassung des Staates Wisconsin gibt es, wie auch in manchen anderen Bundesstaaten, einen Passus, mit dem es möglich ist, einen gewählten Gouverneur nach einem Jahr Amtszeit durch eine Sonderwahl wieder abzuwählen: den sogenannten „Recall“. In der Geschichte der USA ist dieses Instrument gegen einen regierenden Gouverneur erst zwei Mal probiert worden, 1921 in North Dakota und 2003 in Kalifornien - in beiden Fällen allerdings gelang die Abwahl. Um den Missbrauch dieses Instrumentes zu verhindern, hat man freilich die Hürden ziemlich hoch angesiedelt. Die Initiatoren des Recalls brauchen immerhin ein Viertel der Stimmen derjenigen, die bei der letzten Gouverneurs-Wahl zur Urne geschritten sind, was in diesem Fall 540.000 Stimmen bedeutet - nicht gerade wenig in einem Bundesstaat mit knapp fünf Millionen Einwohnern. Die notwendigen Unterschriften werden jedoch kein Problem sein. Im November 2011 beginnt das Stimmensammeln und nach nicht einmal acht Wochen haben die Organisatoren fast eine Million Stimmen gesammelt. Nur ein Jahr nach seiner Amtseinführung muss Scott Walker den nächsten Wahlkampf führen und die Demokraten, allen voran jene in Madison, Dane County, sind siegesgewiss.

Am 5. Juni 2012 allerdings scheitert dieser dritte Versuch eines Recalls in der amerikanischen Geschichte, denn Walker schlägt seinen Widersacher, den Demokraten Tom Barrett, mit 53\% der Stimmen. Bis zum Ende hatte das Lager der Demokraten auf einen Sieg gehofft und nach Bekanntgabe der Ergebnisse steht Madison unter Schockzustand; auf ABC laufen sogar Bilder, die weinende und fassungslose Menschen zeigen, die nicht glauben können, dass sich nach all den Protesten und der Empörung und dem unbeschreiblichen Gefühl von Solidarität am Ende - rein gar nichts ändern soll. Walker hat sogar ein paar Stimmen mehr als beim letzten Mal erhalten. Es ist wie in dem berühmt gewordenen Ausspruch der Filmkritikerin Pauline Keal, die nach Richard Nixons Wiederwahl 1972 erstaunt ausgerufen haben soll: „How can that be? No one I know voted for Nixon.“

Es ist der Schock, der Menschen befällt, wenn sie nur mit Leuten verkehren, deren Realitätswahrnehmung sich von ihrer nicht unterscheidet - eben ein plötzlicher Riss in der Echokammer. Walkers Sieg ist für sie kaum zu glauben, musste ihnen paradox erscheinen. So hatte er in Dane County keine 30\% der Stimmen bekommen, in Madison selbst keine 20\%. In Waukesha County, aber, und auch in den anderen suburbanen Counties um Milwauke herum, hatte Scott Walker 69\% der Stimmen erlangt. Und es war nicht nur die prozentuale Verteilung: dort war man, ebenso wie in Madison, in Scharen zur Urne geschritten: die Wahlbeteiligung in Waukesha lag bei über 70\%, was für amerikanische Gouverneurswahlen 
über alle Maßen ungewöhnlich ist. Ohne Waukesha und die anderen suburbanen Counties außerhalb von Milwaukee hätte Scott Walker den Recall nicht überlebt.

Es ist die Zeit, in der nicht nur die Rede von „Walkerstan“ die Runde macht. In Madison nennt man Waukesha jetzt manchmal auch „Mordor“, nach dem verbrannten Ödland in J.R.R. Tolkiens epischer Saga „Der Herr der Ringe“, aus dem alles Böse entspringt. ${ }^{8}$ Das ist ein Scherz, symbolisiert aber auch die tiefe moralische Aufladung dieses Konfliktes. Natürlich ist es auch in Waukesha, wo Scott Walker seine Siegesrede hält. Es ist vielleicht nicht originell, aber trotzdem eine kräftige Prise Salz in die offenen Wunden der Demokraten, als er noch einmal an die Proteste 2011 erinnert und kurzerhand den Slogan der Protestierenden zum Motto seiner Wiederwahl macht: „This is what Democracy looks like!““

8 Popularisiert hat den Begriff wahrscheinlich der Publizist Abe Sauer. Vgl. Abe Sauer: As Goes Wisconsin, so Goes Hell, in: The Awl, 12. April 2012, http://www.theawl.com/2012/04/as-goes-wisconsin-so-goes-hell (zuletzt abgerufen am 28.06.2015) 



\section{Die Geburt der Hochburg}

\section{Dane County: Von der Counter Culture ZUR CYBERCULTURE}

Manche meinen vielleicht, das Internet würde es erträglicher machen, an einem Ort zu leben, wo die meisten Menschen anderer Meinung sind. Vielleicht aber ist es auch einfach das probateste Mittel, um in solche Schwierigkeiten gar nicht erst zu geraten.

In einem Land, das so stark durch Mobilität geprägt ist wie die USA, ist der große Erfolg der Webseite „City-Data.com“ eigentlich nicht überraschend. Die Seite informiert nicht nur über die durchschnittlichen Mietpreise, sondern auch über die Schulen, die ethnische Zusammensetzung, die Kriminalitätsrate, die Art der Religionsgemeinschaften, das Wetter und sogar über den Grad der Luftverschmutzung in den Städten, Dörfern und Nachbarschaften Amerikas. Immerhin 18 Millionen Amerikaner besuchen nach Angaben der Betreiber der Seite pro Monat „City-Data.com“ - die meisten von ihnen, um sich zu informieren, wenn sie einen Umzug planen. ${ }^{1}$

Außerdem hat die Seite auch ein Forum, in dem die Benutzer sich untereinander über potentielle Umzugsdestinationen austauschen können. Meistens geht es dabei um die Höhe der Mieten oder die Qualität der Schulen; nicht selten aber auch um ganz andere Themen. Viele User erkundigen sich dort mittlerweile auch nach den politischen Verhältnissen potenzieller Umzugsziele. So wie z.B. ein junger Mann Anfang 20, der unter dem Alias lookoutbehindyou1992 im März 2015 der ,user-community“ seine Sorgen vorträgt: Derzeit lebe er in Portland, Oregon. Dort sei es eigentlich wunderschön; wäre da nicht das politische Klima in der Stadt, dass er als „oppressive“ bezeichnet. Er sei nämlich ein Konservativer, und könne damit im ultraliberalen Portland seine Meinung nicht mehr offen äußern.

1 So jedenfalls laut Eigendarstellung auf: www.city-data.com, (zuletzt abgerufen am 11.10.2015). 
Seine Firma habe noch andere Büros im Land - wie z.B. in Madison, Dane County, Wisconsin. Er denke über einen Umzug nach, habe allerdings gehört, dass Madison ähnlich liberal sei wie Portland. Seine Frage sei, kurzum, ob man es dort als Konservativer eigentlich überhaupt aushalten könne oder ob es ebenso schlimm sei wie in Portland?

Auf sein „Post“ erhält lookoutbehindyou1992 50 Antworten. ${ }^{2}$ Einige, wie z.B. brrabbit, halten die ganze Sache für halb so wild: „Most people in Wisconsin I knew preferred to discuss steak recipes, best places for summer sausage and favorite beer and clearly stayed away from politics, religion and any other flammable subject." Ein anderer user, $m l b$, will ihn gar animieren, das Ganze als sportliche Herausforderung zu betrachten: „I find that having my values and views challenged is a healthy thing. And I've been able to bring people over from the dark side on many an occasion. Get over yourself and find a spine. The world is a better place when we can learn to live together."

Indes, die meisten anderen raten ihm vehement ab. Selbst Megan1967, nach eigener Aussage eine Liberale, die in Madison wohnt, bekennt, dass sie dort als Konservative nicht leben wollte: „I am liberal, but even I am uncomfortable sometimes with how everyone assumes that if you have two brain cells to rub together of course you have to be liberal. The assumption is that all conservatives are knuckle dragging Neanderthals.” thefragile stimmt mit ein in diesen Chor: „Well it seems you know that Madison is liberal so I'm not sure why you would consider moving there if you are a conservative. It seems as if that is a criteria for you. Personally, politics is a thing for me so I would never move to a city that I knew was conservative." Wie kaum anders zu erwarten, wird es auch schnell persönlich. lookoutbehindyou 1992 sollte seine Entscheidung, nach Madison zu ziehen, doch bitte überdenken, schreibt ihm Enrico_Fermi: „The issues you likely will run into is you're not going to be able to spread hatred and intolerance cloaked by religion and get people to accept it without calling you out for it." Danach geht es zwischen beiden eine Weile hin und her, über sehr grundsätzliche weltanschauliche Fragen, dabei wollte lookoutbehindyou1992 eigentlich ja nur umziehen. Ein wenig ratlos und entkräftet, wünscht er von der Westküste aus allen im Forum irgendwann eine Gute Nacht. Die Diskussion aber geht auch ohne ihn noch eine Weile weiter und man streitet darüber, wie tolerant oder intolerant Madison wirklich ist, ob die Lebensqualität tatsächlich die höchste im Mittleren Westen ist, über die Politik Scott Walkers, und in welchen Nachbarschaften der Stadt wohl noch die meisten Republikaner wohnen.

2 http://www.city-data.com/forum/madison/2330513-conservative-moderate-conserva tice-considering-move-madison.html (zuletzt abgerufen am 11.10.2015). 
Diese, und viele andere Forumsdiskussionen auf City-Data.com, sind ein Ausschnitt Amerikas im Zeitalter des „Big Sort.“ Aber nicht über alle Orte lässt sich so leidenschaftlich streiten - so wie ja auch der „Big Sort“ nicht alle Orte des Landes gleichermaßen betrifft. Um ein Magnet zu werden, muss ein Ort bereits auf eine bestimmte Art und Weise geprägt sein. Bei Madison und Dane County ist dies offensichtlich, hat sich doch der expressive Liberalismus dieses Ortes bis an die Westküste der USA herumgesprochen. Wie aber wurde Dane County überhaupt ein Ort, an den umzuziehen, sich Konservative lieber zwei Mal überlegen?

Spontan ist man geneigt zu sagen: so war es immer schon. Schließlich ist Madison - das zusammen mit seinen Vororten den größten Teil von Dane County abdeckt - ein wichtiger, symbolträchtiger Ort in der Geschichte des amerikanischen Liberalismus. Zu Beginn des 20. Jahrhunderts war die Stadt, und vor allem ihre Universität, eine der Keimzellen des „Progressive Movement“, jener durchaus heterogenen Reformbewegung, die sich unter anderem für eine Zerschlagung der großen Kartelle einsetzte und generell eine stärkere und regulierende Rolle des Staates einforderte. Und doch: Was Madison heute ausmacht, die Art des Liberalismus, den die Stadt verkörpert, das entsteht in Wahrheit erst unter schwierigen Geburtswehen in einer Dekade des Aufruhrs und der Erschütterung etablierter gesellschaftlicher Ordnung. Um diese Epoche soll es hier zunächst gehen - und sie ist identisch mit der in dieser Arbeit bereits skizzierten „Sattelzeit“ der amerikanischen Polarisierung der 1960er Jahre.

Bis Mitte der 1960er Jahre nämlich ist Madison in politischer Hinsicht, ebenso wie der gesamte Bundesstaat Wisconsin, ein vergleichsweise ruhiger, politisch gemäßigter Ort. Das Parlament der Hauptstadt ist ein Feierabendparlament und noch die Domäne politischer Amateure, die in ihrem Hauptberuf ganz anderen Dingen nachgehen. Am Ende der wenigen Sitzungswochen trifft man Republikaner und Demokraten zumeist in den gleichen Cafés, Restaurants und Bars der Stadt $^{3}$; es ist ein ausgesprochener Kontrast zum Wisconsin der Gegenwart, in dem es selbst den Mitarbeitern der Abgeordneten noch untersagt ist, mit ihren Kollegen von der Gegenseite gemeinsam zu frühstücken oder ein Mittagessen einzunehmen. ${ }^{4}$

3 Vgl. John Gurda: Leaving the Middle Behind. Wisconsin's Turning Point, in: Refocus Wisconsin, Policy-Paper, herausgegeben vom Wisconsin Policy Research Institute, S. 2-18, abrufbar unter: http://www.wpri.org/WPRI-Files/Special-Reports/Reports-Docu ments/WPRI_Refocus_Digest_FNL_090710.pdf

4 Gespräch mit Joe Hasler, Mitarbeiter des republikanischen Senators Dale P. Schultz, 11. Mai 2012. 
Im Madison der 1960er Jahre geht man in der Stadtpolitik noch pfleglich miteinander um. Die Gräben zwischen den Parteien verlaufen nicht sehr tief. Republikaner sind in Madison noch keine verfemte Spezies und haben allerdings bis in die 1980er Jahre hinein auch kaum Ähnlichkeit mit der aggressiven Spielart des amerikanischen Konservativismus, wie er vor allem im Westen und Süden der USA seit Goldwaters Kampagne von 1964 beständig starken Zulauf erhalten hat. Sie können hier sogar noch bei lokalen Wahlen reüssieren. Während die Universität bereits in den 1950er Jahren als sehr liberal gilt, unter anderem dadurch auffällt, dass Studenten gegen die antikommunistische Hetzjagd des Joe McCarthy demonstrieren und eine Reihe von Professoren tatsächlich radikalen Ideen nachhängen ${ }^{5}$, bleibt das Klima der Stadt davon noch lange unbeeinflusst. Erst die Studentenproteste der 1960er Jahre werden die Bürgerschaft der Stadt tief spalten und dabei wie der bereits beschriebene kollektive Rorschach-Test funktionieren: die einen sehen darin einen Aufbruch zu neuen Ufern, die anderen den Beginn moralischer Dekadenz. Und die letzteren sind in Madison noch keineswegs in der Minderheit: 1968 wird mit Bill Dyke ein konservativer Republikaner - in Wisconsin eine wirklich seltene Spezies - zum Bürgermeister gewählt. Es ist eine Gegenreaktion auf die gewaltsamen Zusammenstöße zwischen Studenten und der Polizei. Bereits 1966 hatten Studenten gegen die Zusammenarbeit der Universitätsleitung mit der Einberufungsbehörde demonstriert. Im Oktober 1967 eskaliert die Lage, als Studenten gegen die Chemiefirma Dow Chemical protestieren, die Napalm und Agent Orange für den Krieg in Vietnam produziert und auf dem Campus Ingenieure und Naturwissenschaftler offensiv und aggressiv rekrutiert. Dieses Mal greift die Polizei hart durch, setzt Tränengas ein, mehrere Studenten werden hart geschlagen und schließlich verhaftet. ${ }^{6}$

Einer derjenigen, der damals Bekanntschaft mit dem Schlagstock der Polizei macht und danach zum Anführer der Studentenproteste aufsteigt, ist Paul Soglin. Heute, beinahe 50 Jahre später, erinnert er sich daran, wie isoliert er und die anderen sich damals noch in der Stadt gefühlt hätten. Nach den Dow-Demonstrationen hätten sie Diskussionsforen in der Stadt veranstaltet, um die Vorgänge aufzuarbeiten - mit wenig Erfolg: „That experience told me how isolated we were. [...] Getting clubbed and teargased [...] most of the people did not understand why we were concerned about US military involvement in Vietnam. If they didn't under-

5 Vgl. Matthew Levin: Cold War University. Madison and the New Left in the Sixties, Madison 2013.

6 Madisons Rolle als Hochburg der Studentenproteste wird detailliert geschildert in dem brillianten Buch von David Maraniss: They Marched into Sunlight: War and Peace, Vietnam and America, October 1967, New York 2004. 
stand that, they were certainly not gonna have any sympathy for our demonstrations [...] And this was supposedly a liberal city! That's when I realized we need to have more community engagement"?

Soglin und andere gründeten daraufhin eine eigene Campus-Partei: Die „University Community Action Party“, deren Ziel es explizit war, die Universität stärker mit der städtischen Gemeinschaft zu verschmelzen. Viele empfanden Universität und Stadt als zwei extrem getrennte Welten. Selbst Madisons Lower East Side, heute die liberalste Nachbarschaft einer ohnehin liberalen Stadt, erschien Studenten aus der radikalen Studentenszene damals noch wie fremdes Territorium, in dem die wenigen Studenten, die dort außerhalb des Campus lebten, von den Angehörigen der Arbeiterklasse misstrauisch beäugt wurden. ${ }^{8}$

Soglin tritt also den Marsch durch die lokalen Institutionen der Stadt an, um sich 1968 in den Stadtrat, den City Council, von Madison wählen zu lassen. 1973 schließlich wird er, als Nachfolger von Bill Dyke, zu einem der jüngsten Bürgermeister einer Großstadt in der amerikanischen Geschichte gewählt. Seine Freunde auf der politischen Linken hätte ihn damals für seine lokalpolitischen Aktivitäten belächelt, sagt er, denn sie hätten sich ausschließlich für „,big movement things“ interessiert: Vietnam, Race, sexuelle Befreiung usw. Aber er habe gewusst, das Graswurzel-Politik einen echten Unterschied machen könne und auch, dass es notwendig war, eine Basis zu schaffen für einen Ort, an dem Menschen sich wohlfühlten und im Kleinen bereits eine Gesellschaft verwirklichen konnten, für die man anderswo im Land vorerst noch nicht bereit war. ${ }^{9}$

Seit der Generation von Soglin werden nicht wenige der Aktivisten dieser Generation in Madison und Dane County Wurzeln schlagen, Familien gründen und sich tief mit der politischen Kultur der Stadt verweben. Der Radikalismus der 1960er Jahre flaut langsam ab und mit ihm die großen Hoffnungen, das Land radikal verändern zu können. In Madison verdichtet sich diese Umkehr symbolisch auf einen Tag, den 24. August 1970, als eine Gruppe linksradikaler Studenten, die „New Years Gang“, einen Bombenanschlag auf das von der Universität und dem amerikanischen Militär kooperativ betriebene „Army Research Center“ auf dem Campus verübt, bei dem es neben vielen Verletzten auch ein Todesopfer gibt.

Mit dem „Sterling Hall Bombing“, durch das Madison in der Wahrnehmung vieler Bewohner des Staates endgültig zum Symbol politischen Radikalismus wird, fällt die aggressive Militanz der Studentenproteste in Madison in sich zusammen.

7 Gespräch mit Paul Soglin, 8. Oktober 2014.

8 Vgl. Michael Meeropol/Gerald Markowitz: Neighborhood Politics, in: Paul Buhle (Hg.): History and the New Left. Madison 1950-1970, Philadelphia 1990, S.210-215.

9 Gespräch mit Paul Soglin, 8. Oktober 2014. 
Aber wo der große Traum geplatzt ist, da werden die Orte, in denen der Geist der 1960er Jahre aufgehoben bleibt, erst recht zu idealisierten, zäh verteidigten Rückzugsorten. Allmählich jedenfalls beginnt der linke Geist der Universität die Stadt wirklich zu verändern und zu infizieren, als Vertreter der Studentengeneration die Lokalpolitik als politische Alternative und als politisches Spielfeld entdecken. Paul Soglin war 1968 noch der einzige wirkliche Vertreter der „68er-Generation“ im 20-köpfigen Stadtrat; vier Jahre später sind es bereits fünf. ${ }^{10}$ Bei seiner Kampagne zum Bürgermeister gegen den Republikaner Dyke im Jahr 1972, also vier Jahre später, wird eine große Zahl von aktiven und ehemaligen Studenten für ihn Wahlkampf betreiben. Für zahlreiche der Aktivisten, die für diese Arbeit interviewt wurden, war es die erste politische Kampagne, an der sie mitarbeiteten. Aber etwas anderes war vielleicht noch viel wichtiger, auch wenn es vordergründig unpolitischer Natur gewesen sein mochte: Aus der „Counterculture“ der 1960er Jahre erwuchsen stabile „Counterinstitutions “. Diese griffen weit über das Campus-Leben hinaus, prägten bald (und bis heute) Teile des Stadtbildes: Lebensmittel-Kooperativen, linke Buchläden, alternative Theater, „freie“ Universitäten usw. ${ }^{11}$ Es war der Versuch der Etablierung einer autonomen Gegengesellschaft, der sich in ähnlicher Weise in den Städten vieler westlicher Gesellschaften vollzog - mit dem Unterschied freilich, dass diese Versuche in den USA als Symbol und Erkennungszeichen politischer Gesinnung bis heute ein stärkeres Differenzierungsmerkmal sind.

Als Paul Soglin schließlich 1973 zum Bürgermeister gewählt wird, erlebt die Stadt eine kleine Revolution. Das beginnt bei habituellen Kleinigkeiten: zum Polizeichef ernennt er einen Mann mit Pferdeschwanz, was auch 1973 nicht unbedingt dem üblichen Erscheinungsbild amerikanischer Ordnungshüter entspricht ${ }^{12}$; bei kleineren Mengen Marihuana schaut die Polizei künftig weg; Madison entwickelt als eine der sehr wenigen Städte im Mittleren Westen eine blühende GayCommunity und, so jedenfalls die Legende, in einem der Schwulen-Clubs der Stadt legt der Bürgermeister bisweilen selbst als DJ die Platten auf. ${ }^{13}$

Aber es gibt auch tatsächliche progressive Reformen wie die staatliche Bezuschussung bei der Kinderbetreuung. ${ }^{14}$

10 Ebd.

11 Vgl. Levin: Cold War University, a.a.O, S. 177ff.

12 Vgl. Dirk Johnson: From Firebrand to a Bit of a Grump, a 'Hippie Mayor' Evolves, in: New York Times, 10. September 2011.

13 Vgl. Paul Buhle: Introduction, in: Madison and the New Left, a.a.O.

14 Vgl. Jonathan Thompson: Progressive Innovation in the 1970s: Madison, Wisconsin, and the Conference on Alternative State and Local Public Policies, in: Progressive Planning, winter issue 2007: S. 22-25. 
Als einer der ersten amerikanischen Politiker überhaupt besucht Paul Soglin 1975 Fidel Castro auf Kuba; seitdem, witzeln einige, habe die „People‘s Republic of Madison" sogar ihre eigene Außenpolitik.

Einer der jungen Unterstützer von Soglins Kampagne 1973 ist John Hendrick, der heute im „Dane County Board“ sitzt. In den 1990er Jahren wird er zu den Gründern von „Progressiv Dane“ gehören, einer lokalen Partei, die noch ein Stück links von der örtlichen demokratischen Partei angesiedelt ist und für diese eine weitaus größere Konkurrenz darstellt bei lokalen Wahlen als die Republikaner, zeitweise sogar die Mehrheit im Madison City Council, dem Stadtrat, stellt. Hendricks kommt aus einer ländlichen Gegend Wisconsins Anfang der 1970er Jahre nach Madison, und die Art und Weise, wie er sein Verhältnis zur Stadt beschreibt, kann als durchaus repräsentativ gelten:

„So, when I came to Madison, which now was a long time ago in 1971, I came to a campus that was mobilized around the Vietnam War. And so I became an activist and a protestor and a leftist as soon as I came to Madison. And then after 7 years in school and graduating from law school I became a public interest lawyer. And moved into the east side of Madison, just east of here, which is probably the neighborhood where people moved to when they wanted to be around people who think the same as they do." 15

Wie auch viele andere Liberale Madisons findet auch Hendrick relativ schnell das Thema seines Lebens. Längst dreht sich der Aktivismus nicht mehr um den Weltfrieden oder andere große Themen. Auch Hendrick geht es vor allem darum, den Ort in dem er lebt, der ein Stück seiner eigenen Identität ist, zu beeinflussen und zu prägen. Er tritt seiner örtlichen „Neighborhood Association“ bei, einer in Madison extrem einflussreichen Organisation, die einen schier unglaublichen Einfluss auf die Stadtplanung hat: Wer in Madison etwas bauen möchte, ist verpflichtet, noch vor der Stadtverwaltung selbst eine der 120 Nachbarschaftsvereinigungen zu kontaktieren, und sie über die Pläne zu informieren. ${ }^{16}$ Nicht wenige aus dem Dane County Board und dem City Council von Madison haben ihre ersten Erfahrungen mit Lokalpolitik dort gemacht. Hendrick möchte vor allem den Sprawl, die sich überall in den USA vollziehende Zersiedelung der Landschaft, stoppen. Damit einher geht der Versuch, Wohn- und Arbeitsplätze nicht zu weit voneinander anzusiedeln und lebendige, autonome Stadtviertel zu schaffen.

15 Gespräch mit John Hendrick, 25. April 2012.

16 Vgl. Pat Schneider: Do neighborhood associations have too much voice in development decisions?, in: Captital Times, 2. August 2010, http://host.madison.com/ news/local/do-neighborhood-associations-have-too-much-voice-in-development-deci sions/article_55cb7dc6-9dc6-11df-8352-001cc4c03286.html (zuletzt abgerufen am 25.06.2015). 
Das alles natürlich fügt sich in das sich langsam entwickelnde ökologische Bewusstsein ein, da man diese Form des Zusammenlebens für nachhaltiger und ressourcenschonender hält. Aber es geht auch von Anfang an - und bis heute - um ein Stück persönliche Identität: Diese vorgestellte Form von Urbanität ist der Gegenentwurf zu Suburbia, dass viele liberale Aktivisten für einen Alptraum halten. Und wo ist dieser Alptraum am konsequentesten verkörpert? Natürlich in Waukesha. „It's a republican paradise. You can build whatever you want, until it happens next to your house", graust es etwa Scott McDonell, eine der führenden liberalen Stimmen Madisons und bis 2012 Vorsitzender des Dane County Boards. Waukesha, das sei "all Cul-de-Sac [...] Cul-de-sacs, big houses, SUVs, giant fourcar-garages." ${ }^{17}$ Dies macht deutlich, wie geradlinig dieser Konflikt der Lebensstile in einen zutiefst ideologischen Konflikt mündet. Und wie alle Konflikte dieser Art geht es nicht nur darum, in welcher Gesellschaft man leben will, sondern auch, welche Arten von Menschen von diesen Gesellschaften hervorgebracht werden. „I think it's boring living in a suburb, where everyone is the same. Nothing's ever happening", sagt Scott McDonell, der Ende der 1980er Jahre als Student mit einem Fußball-Stipendium von Maryland nach Madison ging und wie so viele andere blieb.

Die Verknüpfung von Ideologie und Lebensstil spiegelt sich noch deutlicher im Lebenslauf Steve Hinikers wieder, der der Anti-Sprawl Lobby-Gruppe „1000 Friends of Wisconsin" vorsteht. Hiniker kam schon in den 1970er Jahren aus Washington D.C. nach Madison, ganz bewusst, wie er sagt, weil es die Beschaulichkeit einer Kleinstadt mit dem kulturellen Angebot einer Großstadt verbinde. Seitdem hat er für verschiedene liberale Lobby-Organisationen und Demokratische Abgeordnete gearbeitet. Wie für viele andere Liberale in Madison ist die Stadt auch für ihn nahe am Idealbild dessen, wie eine Stadt aussehen sollte, ein Vorbild für die Entwicklung der Gesellschaft und Gemeinschaft im Ganzen. Funktionierende, dicht besiedelte Städte, sagt Hiniker, würden Vertrauen und Solidarität schaffen: Er selbst habe irgendwann in den 1990er Jahren seine Haustürschlüssel verloren und schließe seitdem seine Wohnungstür nicht mehr ab.

Im zersiedelten Waukesha wäre dies nicht möglich, meint er und zeichnet ein kleines Horrorszenario vom Leben in den amerikanischen Vororten. Surburbia, sagt Hiniker, verändere die Leute - und zwar nicht zum Guten. Vor allem Menschen in Autos seien eben andere Menschen: aggressiver, rücksichtsloser. Niemand würde schließlich auf dem Bürgersteig jemanden anbrüllen, wenn er plötzlich aufhören würde zu laufen, oder zusammenklappe. Wer jedoch ein anderes

17 Gespräch mit Scott McDonell, 28. März 2012. 
Auto auf der Straße vor sich habe, das plötzlich nicht mehr weiterfährt, der würde sofort hupen und die unflätigsten Dinge sagen. ${ }^{18}$

Und überall sehen die liberalen Meinungsführer der Stadt die Modernität auf ihrer Seite und sind zutiefst überzeugt, dass die USA der Zukunft wie Madison aussehen werden, und nicht wie Waukesha. In ein paar Jahrzehnten, davon sind sowohl Hiniker als auch McDonell überzeugt, würden Orte wie Waukesha langsam verwaisen. Wo man für die alltäglichsten Dinge wie Einkaufen ein Auto brauche, da würden sie für alte Menschen wenig attraktiv und auch die jüngere Generation der „Millennials“ wolle in Städten leben. Wer, fragt Hiniker, werde dann überhaupt noch außerhalb von Städten wohnen wollen? Vielleicht, meint er nur halb im Scherz, würden in Waukesha und in den anderen wohlhabenden Gegenden außerhalb von Milwaukee dann französische Verhältnisse einziehen: dort seien dann die neuen Ghettos, vergleichbar den französischen Banlieus außerhalb von Paris.

Nun wäre es grenzenlos übertrieben und reichlich klischeehaft, würde man Madison allein als selige Insel von Alt-68ern und steckengebliebenen Hippies beschreiben, oder zu glauben, die $72 \%$ der Obama-Wähler bestünden ausschließlich aus Menschen, die, so wie die hier zu Wort gekommenen liberalen Meinungsführer der Stadt, so ausdrücklich bewusst ihren Lebensstil oder sogar ihre moralischen Werte in der Stadt verkörpert sehen. Der Charakter Madisons als DemokratenHochburg speist sich noch aus anderen Quellen. Dabei ist weniger direkt die große Universität entscheidend. Natürlich: Die meisten Orte in den USA mit großen Forschungsuniversitäten wie Madison wählen tendenziell stark demokratisch. ${ }^{19}$ Aber abgesehen davon, dass viele amerikanische Studenten weiterhin an ihrem Heimatort ihre Stimme abgeben: Es sind keineswegs die wards und precincts am und um den Campus herum, die in Madison besonders stark demokratisch wählen; diese sind, im Gegenteil, oft am wenigsten demokratisch geprägt. ${ }^{20}$ Und ein Treibhaus des politischen Engagements ist die Univerity of Wisconsin, anders als in den 1960er und 1970er Jahren, schon lange nicht mehr. In Madison höhnen viele Demokraten der 1968-Generation über die eher unpolitische und oftmals konformistische Generation der Millennials, die für langfristige politische Ziele nur schwer zu begeistern seien. Dennoch spielt die große Präsenz der Universität eine Rolle, aber um das zu verstehen, sollten wir vielleicht noch einmal kurz zu Paul Soglin

18 Gespräch mit Steve Hiniker, 2. Oktober 2014.

19 Vgl. Blake Gumbrecht: The American College Town, Camridge 2008.

20 Vgl. Robert Booth Fowler: Wisconsin Votes: An Electoral History, Madison 2008: S. 235. 
zurückkehren und dem Gespräch mit ihm im Oktober 2014, in dem er seine Geschichte vom Anführer der Studentenproteste zum Bürgermeister Revue passieren lässt.

2014 residiert er nämlich immer noch im Rathaus von Madison. Oder man sollte wohl eher sagen: Wieder einmal. Seine erste Amtszeit dauerte von 1973 bis 1979, die zweite von 1989 bis 1997. Seit April 2011 sitzt er abermals auf dem Sessel des Bürgermeisters und vier Jahre später, mit mittlerweile 70 Jahren, in seinem Amt bestätigt. Die Bürger von Madison haben ihn schon einige Male abgewählt, aber irgendwie auch immer wieder ins Amt zurückgebracht. Es ist ein bisschen wie in einer etwas verkorksten Beziehung, wo es weder ohne, noch miteinander geht. Menschen, die ihm nicht wohlgesonnen sind, behaupten, Soglin halte sich selbst ganz einfach für unersetzlich und sein Schicksal und das der Stadt für deckungsgleich.

Auf jeden Fall spürt man an diesem Tag im Oktober 2014 wie Soglin, im roten Holzfällerhemd, die Cowboystiefel auf dem Konferenztisch gefläzt, den Raum ganz für sich einnehmend, sich mit dieser Stadt sehr fest verwachsen fühlt. Madison geht es - gerade im Vergleich zum auch 2014 von der wirtschaftlichen Krise noch nicht ganz erholten Land - prächtig. Schaut man aus dem Fenster seines Büros im 4. Stock der „City Hall“ sieht man in allen vier Himmelsrichtungen die Silhouetten von Baukränen. Madison ist heute viel mehr als nur die Universität und die Landesregierung, sondern ein Zentrum der High-Tech Industrie, viel kleiner noch als Austin und San Francisco natürlich, aber dafür mit ziemlich beeindruckenden Zuwachszahlen, regelmäßig auf den vorderen Plätzen der Forbes-Listen und anderen Rankings über Amerikas Städte mit dem größten Innovationspotenzial. Heraussticht dabei vor allem EPIC, eine Software-Firma, die sich auf den Gesundheitssektor spezialisiert hat, in den letzten Jahren rasant gewachsen ist und mittlerweile fast 10.000 Menschen beschäftigt. ${ }^{21}$ Der riesige Campus ist in Verona, einem Vorort von Madison, aber die meisten der jungen Leute, die für EPIC arbeiten, wohnen in der City; das vor allem hat den Boom neuer Appartementhochhäuser angefacht.

Und in Soglins Bild von der Geschichte der Stadt - die ja auch seine eigene Geschichte ist - gehört das alles irgendwie zusammen: Die Revolten der Vergangenheit und der Boom der Gegenwart. Für die Entwicklung von Kreativität brauche man Orte, sagt er, die nicht so stark von traditionellen Vorstellungen von Disziplin geprägt seien und wo man auch einmal fünfe gerade sein lassen könne. Die Orte wo früher die Beatniks abhingen, seien heute die Treffpunkte der digitalen

21 Vgl. Marc Eisen, EPIC Opportunity, in: Isthmus, 20. Februar 2014. http://www. isthmus.com/news/cover-story/epic-opportunity-the-software-giant-is-positioningdane-county-for-an-economic-breakthrough/ (zuletzt abgerufen am: 15.06.2015). 
Bohème. Man habe eben durch kluge Stadtpolitik dafür gesorgt, sagt Soglin ohne falsche Bescheidenheit, dass Madison ein Ort sei, an dem Menschen leben wollten. Und in einer modernen Ökonomie würden die Firmen dorthin ziehen, wo die Menschen mit den entsprechenden Qualifikationen leben wollten. Dass habe er schon gewusst, bevor der Soziologe Richard Florida den Begriff von der „,creative class“" prägte, jener Klasse von gut ausgebildeten und postmodernen Kreativarbeitern, deren Lebensstil- Präferenzen heute angeblich darüber entscheiden, wo das Wachstum stattfindet. ${ }^{22}$ Soglin weiß, dass die Unternehmer von Madison - die meisten von ihnen Demokraten - mit der Strukturpolitik der Stadt hadern. Sie halten sie für wachstumsfeindlich, da es eine Vielzahl von Sozialauflagen, Regulierungen und Umweltschutzvorschriften gäbe, die einzuhalten sind, überdies die mächtigen neighborhood associations bei allem ein gewichtiges Wort mitreden. Aber Soglin meint, das alles sei im Grunde nicht so wichtig. Die Kritiken führten am Kern der Sache vorbei. Die Unternehmen, die für Madison interessant seien, würden trotzdem kommen und all die Nörgler und Kritiker würden trotzdem bleiben und deswegen sei Madisons Strukturpolitik an den üblichen Maßstäben kaum zu messen. „Do you think they are staying here because there are other computer geeks? They are staying for the lively entertainment." Im Grunde ist das Soglins lokale Wachstumsstrategie, die beim ersten Hören noch ein wenig schrullig klingen mag: Hat man genügend Cafés, Bars und Restaurants, dann kommen auch die Unternehmer. $^{23}$

In der Tat scheint Madisons konstantes Wachstum im High-Tech Sektor ebenfalls einen beträchtlichen Teil zu seinem Status als demokratische Hochburg beizutragen. Die meisten Software-Ingenieure tendieren zur Wahl der Demokraten, wobei das eher eine extrem plausible Einschätzung, denn eine Gewissheit ist: Über das Wahlverhalten spezieller Berufsgruppen gibt es selbst in den USA, wo sonst für alles eine Statistik zu haben ist, keine verlässlichen Daten. Aber manche Fakten sprechen doch sehr für sich. Bei der Präsidentschaftswahl 2012 etwa gingen 97\% der Zuwendungen von Google-Mitarbeitern an Barack Obama; bei AppleMitarbeitern waren es $91 \%$ der Spenden, bei eBay immerhin noch $89 \%{ }^{24}$ Die gesamte San Francisco Bay Area - das globale Epi-Zentrum der Internet-Revolution - ist heute eine republikanische Diaspora, und das obwohl in den 1980er Jahren

22 Vgl. Richard Florida: The Rise of the Creative Class, New York 2002.

23 Gespräch mit Paul Soglin, 8. Oktober 2014.

24 Vgl. Nate Silver: In Silicon Valley, Technology Talent Gap Threatens G.O.P. Campaigns, in: New York Times, 28. November 2012, abrufbar unter: http://fivethirty eight.blogs.nytimes.com/2012/11/28/in-silicon-valley-technology-talent-gap-threatens -g-o-p-campaigns (zuletzt abgerufen am 23. April 2015). 
einige Counties der Region noch republikanisch wählten. Ablesbar ist diese Dominanz auch daran, dass es der Republikanischen Partei außerordentlich schwer fällt, genügend junge und talentierte Softwarentwickler zu finden, um den großen Rückstand zur medialen Kampagnenfähigkeit der Demokraten aufzuholen. ${ }^{25}$ Auch für die EPIC-Mitarbeiter gibt es eine Statistik: Nach ihr gingen $82 \%$ der Spenden der Mitarbeiter 2012 an Barack Obama und nicht an Mitt Romney. Das deckt sich in etwa mit den $84 \%$, die landesweit vom „Center for Responsive Politics" erhoben wurden. ${ }^{26}$ Nur wenige Berufsgruppen in den USA scheinen eine so einseitige politische Bindung an die Demokratische Partei aufzuweisen wie die Entwickler der IT-Industrie - geschlagen werden sie nur von der Berufsgruppe der Psychotherapeuten und der Sozialarbeiter.

Ganz rational zu erklären ist das feste Bündnis zwischen der Software-Industrie und der Demokratischen Partei eigentlich nicht. Die Menschen dieser Berufsgruppe verdienen weit überdurchschnittlich und sind keine Gewerkschaftsmitglieder. Natürlich korreliert der Bildungsgrad insgesamt mit der Wahl der demokratischen Partei, stimmt die Mehrheit der Amerikaner mit College-Abschluss für die Demokraten - doch keinesfalls in dem Umfang, wie dieses bei den Angehörigen der IT-Industrie der Fall zu sein scheint. In einigen technischen Berufen, etwa bei Ingenieuren, schlägt das Pendel auch sehr viel stärker in die konservative Richtung. Was also erklärt diese Allianz? Eine einzige Antwort darauf gibt es wohl nicht. Es könnte die Struktur der Arbeit selbst sein, die eine Rolle spielt, ihr Netzwerkcharakter, das Denken in flachen Hierarchien, die Assoziation mit Geschwindigkeit und rasantem Wandel. Wahrscheinlich ist es auch kein Zufall, dass Madison, so wie Soglin es ja auch andeutet, nicht der einzige Ort ist, der einst ein Zentrum der Revolte war und jetzt ein Zentrum der High-Tech-Industrie ist. Das gleiche gilt für San Francisco, auch für Ann Arbor, Michigan, oder Austin, Texas. Schließlich entdeckten die Angehörigen der „Counterculture“ schon früh die „Cyberculture" für sich, sahen in der Utopie des Internets einen transparenten, herrschaftsfreien Raum, den es zu besetzen galt. Das war schon damals merkwürdig genug angesichts der Ursprünge des Internets in den Vernetzungsversuchen des Pentagon und ist heute, im Zeitalter der digitalen Herrschaft einer Handvoll übermächtiger IT-Konzerne, nur noch schwer verständlich. Doch ist diese Symbiose im Bereich der kulturellen Symbolik bis heute erhalten geblieben. Der antihierarchische Netzwerkcharakter, die Vorstellung von globaler Entgrenzung, die schon

25 Vgl. ebd.

26 http://www.opensecrets.org/news/2015/05/campaign-donor-is-not-a-job-but-occupa tion-can-predict-party-preference/ 
die LSD-Konsumenten im nördlichen Kalifornien in den 1970er Jahren am Internet begeisterte ${ }^{27}$, all das mag bis heute der IT-Industrie einen progressiven, linken Anstrich geben und auch das Selbstverständnis vieler Software-Ingenieure prägen. Den stolzen Bürgern Madisons dient die Innovationsfähigkeit ihrer Stadt jedenfalls als Beleg dafür, dass Madison seiner Zeit weit voraus ist.

Man spürt diese Attitüde auch, wenn man den noch sehr jungen Mann trifft, der im Augenblick besonders stark für die Verquickung von Tech-Culture und liberaler Politik in Madison steht: Der Start-Up-Unternehmer Scott Resnick. Resnick, Jahrgang 1986, ist selbst ein liberaler Demokrat und sitzt seit 2011 im City Council. Im Mai 2015 trat er erfolglos gegen Paul Soglin als BürgermeisterKandidat an - etwa in dem Alter, in dem auch Soglin zum ersten Mal für das Amt kandidierte. In seiner Firma, „Hardin Design and Development“, sieht es an diesem Morgen des 3. Oktober 2014 aus wie in einem etwas klischeehaft geratenen Werbefilm für hippe Start Ups. Der größte Raum der Firma ist eine Art Spielplatz für Große Jungs: Basketball-Korb, eine Tischtennisplatte und ein Flipper, die Programmierer stehen in einem anderen großen Raum am Pult und tragen Kopfhörer bei der Arbeit. Mit einigem Stolz erzählt Resnick, dass viele seiner Programmierer heute erst etwas später kamen: schließlich war gestern ein Spiel der „Green Bay Packers", ein in Wisconsin beheimatetes NFL-Football-Team. Einige seiner Mitarbeiter, meint Resnick und freut sich scheinbar darüber, bauten noch den Alkohol ab.

In Resnicks durchaus romantischer Vorstellung der Tech-Culture gibt es ebenfalls Berührungspunkte zur „Counter Culture“: der nicht so selten anzutreffende Konsum weicher Drogen, der Alkohol, die Musik. Das alles, glaubt er, passe nur sehr schwer zu konservativen Weltbildern. Resnick sagt, er könnte seine Firma theoretisch innerhalb weniger Wochen überall auf der Welt hin transferieren, so lange es dort Internet gäbe, aber er plane, weiter in Madison zu bleiben: der Lebensqualität wegen, mit den vielen Bars und Musik-Festivals der Stadt, ihrer Jugendlichkeit, und weil es durch die Universität und das relativ starke InformatikDepartement einen ständigen Zuzug von talentierten jungen Menschen gäbe. Madison, sagte er, habe natürlich nicht ganz die Anziehungskraft der großen Metropolen, dafür aber seien die Lebenshaltungskosten auch nur halb so hoch. Und die Stadt sei zwar eher klein, aber mittlerweile gäbe es schon ein ernstzunehmendes Netzwerk der Tech-Culture und es sei hier einfacher, miteinander in Kontakt zu kommen, als in größeren Orten.

27 Vgl. Fred Turner: From Counterculture to Cyberculture. Stuart Brand, the Whole Earth Network, and the Rise of Digital Utopianism, Chicago 2006; Luke Dormehl: The Apple Revolution: Steve Jobs, the Counterculture and how the Crazy Ones Took Over the World, New York 2013. 
Resnick ist außerdem überzeugt, dass er nur der Anfang sei: Andere Start-UpUnternehmer hätten ebenfalls längst den Reiz der Lokalpolitik erkannt und wollten sich politisch engagieren, die Stadt und seine technologische Elite würden daher in Zukunft noch enger zusammenwachsen. ${ }^{28}$

Nicht bei allen, die nach Madison kommen und bleiben, sind Fragen des Lebensstils so unmittelbar ideologisch aufgeladen, wie bei den eingangs dieses Kapitels zu Wort gekommenen liberalen politischen Aktivisten und Lokalpolitikern. Sie könnte man als die kulturelle Kerngruppe von Dane County bezeichnen, als jene, die den Geist des Ortes besonders prägen und nach außen verkörpern. Aber auch für andere spielt das, wofür Madison steht, eine große Rolle. Was bisher durch biographische Episoden illustriert wurde, soll im Folgenden auf eine breitere empirische Basis gestellt werden: Mit Hilfe der Daten aus der DWPS lässt sich der Zusammenhang zwischen ideologischer Orientierung, Lebensstilpräferenzen und Umzugsentscheidung untersuchen. Diese Kombination macht deutlich, dass Madison tatsächlich manche Menschen stärker anzieht als andere.

In der DWPS fragten wir die Bewohner von Dane und Waukesha County, wann sie dorthin gezogen waren, von wo sie kamen, was ihre Parteiidentifikation zum Zeitpunkt des Umzuges war, und schließlich, was ihnen bei der Wahl ihres Wohnortes wichtig war. In unserem Sample für Dane County waren weit über die Hälfte der Befragten tatsächlich movers $^{29}$ : sie waren zu irgendeinem Zeitpunkt nach Dane County umgezogen. Damit war die Zahl der movers groß genug für aussagekräftige Rückschlüsse darüber, ob das County Anziehungspunkt für bestimmte Parteianhänger ist. Es erlaubte es sogar, nicht alle movers aufzunehmen, sondern nur solche, die seit 1976 - dem Startpunkt des „Big Sort“, dem Jahr, als die Wahrscheinlichkeit, dass Demokraten und Republikaner Tür an Tür wohnten, am höchsten war - nach Dane oder Waukesha County „eingewandert“ waren. Die Ursprungs-Counties wurden schließlich als republikanisch oder demokratisch codiert, um so etwas darüber zu erfahren, ob die Befragten bei ihrer Migration tendenziell in einen Ort zogen, der stärker ihren Parteipräferenzen entsprach, als der Ort, den sie verließen.

Und in der Tat scheinen die Ergebnisse eindeutig. Zwischen 1976 und 2013 wanderten beinahe doppelt so viele Demokraten wie Republikaner nach Dane County ein - ein deutliches Indiz für die Bestätigung der Big Sort Theorie. Kontrolliert man in einer multivariaten Analyse dabei für andere soziodemographische

28 Gespräch mit Scott Resnick, 3. Oktober 2014.

29 Man möge den Anglizismus an dieser Stelle verzeihen: zum einen ist der Begriff des movers in der Literatur zum „Big Sort“ relativ etabliert; und zum zweiten findet sich hierfür sprachlich auf Deutsch keine wirklich elegante Entsprechung. 
Faktoren ${ }^{30}$, so bleibt der Einfluss der Parteipräferenz weiterhin signifikant. Dane County ist ein Demokraten-Magnet: 62\% der seit 1976 Zugezogenen waren zum Zeitpunkt des Umzugs Demokraten; 27\% waren Republikaner; nur 12\% waren Independents.

Abbildung 5: Parteiidentifikation der ,,movers “ nach Dane County seit 1976

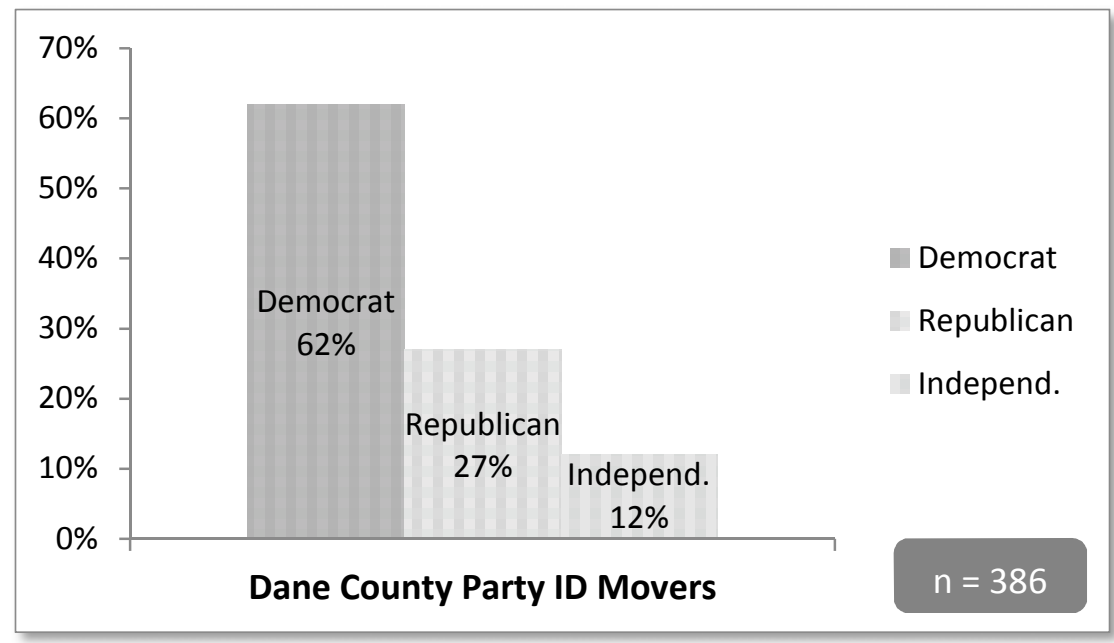

Quelle: Eigene Darstellung, Daten der DWPS

Wie bereits erwähnt, war die hauptsächliche Quelle zur Stützung der „Big Sort“ Theorie bei Bill Bishop die Daten der amerikanischen Steuerbehörde IRS. Zur Stützung seiner These verwies Bishop unter anderem darauf, dass laut der IRSDaten Menschen aus „blue Counties“ tendenziell ebenfalls stark in andere demokratische Counties umzogen. Das allerdings ist bei genauerer Betrachtung ein Argument mit sehr beschränkter Reichweite. Zwar stärkt dieses grundsätzlich die Annahme, dass es einen Zusammenhang zwischen Parteipräferenz und Migrationsverhalten gibt. Aber letztlich würde ein solcher Austausch zwischen Counties mit gleicher Parteineigung alleine kaum etwas an der nationalen Verteilung ändern. Es beweist noch einmal ausdrücklich, dass sich ohne Individual-Daten, die

30 Freilich konnte nicht für alle soziodemografischen Variablen kontrolliert werden. So kannten wir etwa nur den Bildungsstand der Befragten im Jahr 2013, nicht aber ihren Bildungsstand zum Zeitpunkt des Umzuges. Das gleiche galt für das Einkommen. Beide Faktoren haben wir daher in der Regression nicht benutzt, vgl. hierzu näher Lütjen/Matschoß, Ideological Migration in Partisan Strongholds, a.a.O. 
etwas über die Parteiidentifikation der einzelnen movers verraten, wenig Rückschlüsse ziehen lassen. Denn um ein wirkliches „Sorting“ nachzuweisen, bräuchte man Aufschluss darüber, ob die Menschen bei ihrem Umzug tendenziell einen Ort wählen, der stärker kongruent mit ihrer eigenen Parteiidentifikation ist, als der Ort, den sie verließen.

Mit den Daten der DWPS allerdings lässt sich dieser Zusammenhang beweisen: Ganz gleich, von woher die Zugezogenen stammten, ob sie also aus „blauen“ oder „roten“ Counties kamen: stets war die Wahrscheinlichkeit größer, dass es sich bei ihnen um Demokraten handelte, und das obgleich die statistische Wahrscheinlichkeit des Zuzugs von Demokraten aus republikanischen Counties theoretisch weitaus geringer ist. Zwar ist der Anteil an Demokraten aus demokratischen Counties tatsächlich höher (68\%). Doch auch bei den Zugezogenen aus republikanischen Counties besteht ein noch immer sehr deutlicher Überhang von Demokraten unter den movers (56\% Demokraten, 30\% Republikaner, 14\% Independents).

Abbildung 6: Parteiidentifikation der movers nach Dane County seit 1976 nach Herkunftscounty

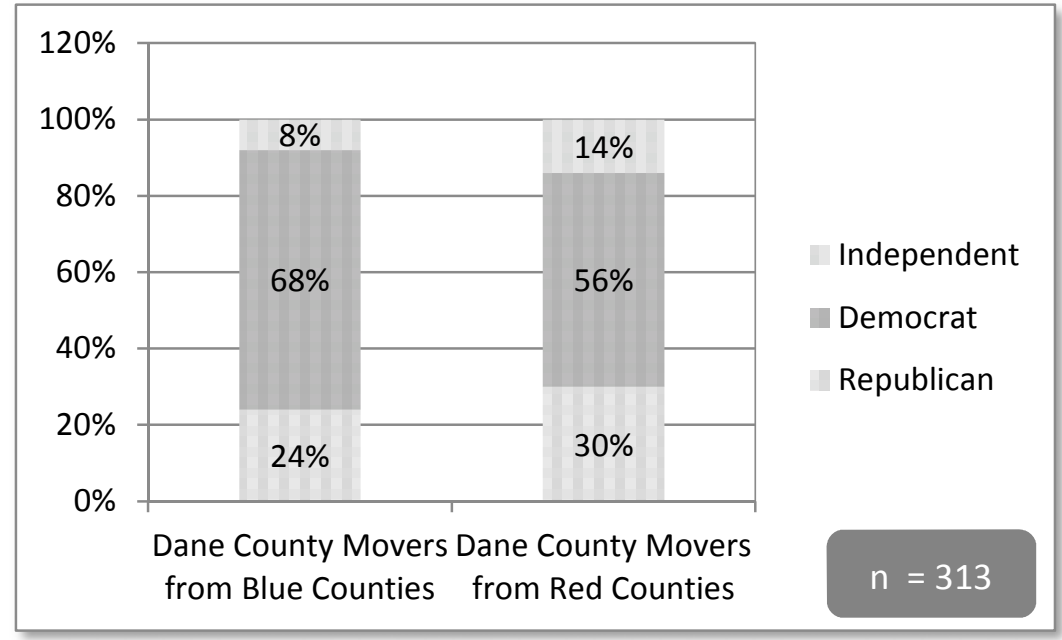

Quelle: Eigene Darstellung, Daten der DWPS 
Für die liberalen Aktivisten, die in dieser Arbeit bereits zu Wort gekommen sind, spielt Dane Countys Ultra-Liberalismus fraglos eine bedeutende Rolle: viele von ihnen könnten sich schon aus diesem Grund kaum vorstellen, an einem anderen Ort zu leben, oder jedenfalls an keinem, der nicht in ähnlicher Weise den amerikanischen Liberalismus verkörpert. Allerdings ist davon auszugehen, dass die Politik selbst nur für eine Minderheit eine solch zentrale Rolle in ihrem Leben spielt. Bei der Frage, ob es bei der Wahl eines Wohnortes wichtig gewesen sei, dass die Anwohner die eigene politische Einstellung und Weltsicht teilen, gaben nur 7\% an, dies sei ein ,sehr wichtiger" Grund ihrer Entscheidung gewesen, 25\% ordneten diesen Grund immerhin noch als „wichtig“ ein. Selbstredend handelt es sich für Dane County dabei fast ausschließlich um Demokraten.

Die zentrale Hypothese der Theorie des „Big Sort“ lautet jedoch, dass Entscheidungen für einen bestimmten Wohnort mit spezifischen Lebensstil-Präferenzen zu tun haben, die wiederum mit bestimmten Weltbildern assoziiert werden können. Nach solchen Präferenzen wurde in der DWPS vor allem gefragt. Angesichts der vielen - oftmals durchaus zutreffenden - Stereotypen über konservative und liberale Lebensstile, konzentrierte die Umfrage sich primär auf solche, die direkt etwas über das Verhältnis von Öffentlichkeit und Privatheit, Präferenzen für oder gegen urbane Dichte sowie etwas über unterschiedliche Vorstellungen von Individualität und Selbstverwirklichung aussagten. Die Unterschiede zwischen den movers nach Dane County und jenen nach Waukesha County waren dabei in der Tat signifikant. Besonders deutlich zeigen sie sich, wenn die Angehörigen der jeweiligen Mehrheitskultur miteinander verglichen werden - also die Demokraten in Dane County mit den Republikanern in Waukesha County (vgl. Abb. 7). Fragt man etwa nach der Wichtigkeit einer guten öffentlichen Infrastruktur (öffentlicher Nahverkehr, Fahrradwege, Büchereien usw.) bei der Entscheidung nach Dane County umzuziehen, dann war dieses für $46 \%$ der demokratischen movers nach Dane „sehr wichtig“, was nur für 18\% der Republikaner in Waukesha galt. Exakt 60\% der befragten Demokraten von Dane County gaben an, dass die Nähe zu einem Lebensmittelgeschäft mit Ökoprodukten aus der Region für ihre Umzugsentscheidung „,wichtig“ oder „sehr wichtig“ gewesen sei; unter Republikanern in Waukesha waren es nicht einmal die Hälfte. Ähnlich war es bei der Frage, ob es wichtig sei, nicht ständig das Auto benutzen zu müssen: 58\% der Demokraten von Dane County fanden dieses „wichtig“ oder „,sehr wichtig“; bei den Republikanern von Waukesha waren es lediglich 23\%. Im Ganzen ergibt dieses eine eindeutig differierende Präferenzstruktur bei der Frage nach Faktoren, die die Wahl des Wohnortes mitbestimmen. 
Abbildung 7: Präferenzen für ,,liberale "Lebensstilindikatoren nach Parteianhängern: Antwort ,,important " oder ,, very important"

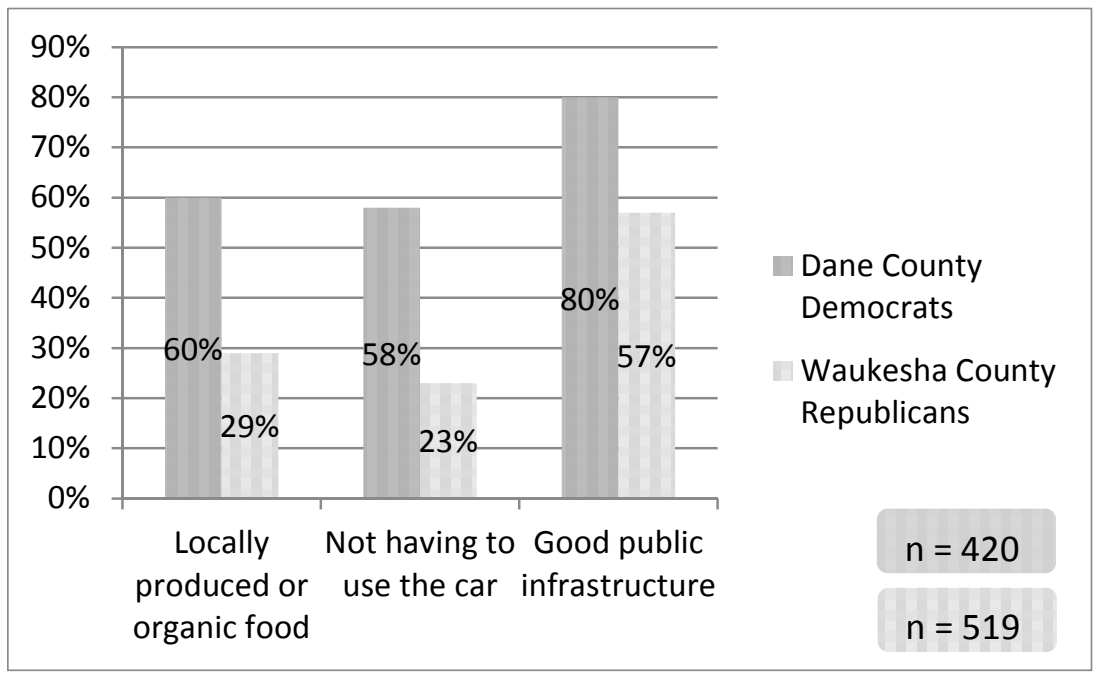

Quelle: Eigene Darstellung, Daten der DWPS

Migration spielte dementsprechend eine wichtige Rolle bei Dane Countys Entwicklung zur demokratischen Ultra-Hochburg und es konnte auch gezeigt werden, dass die nach Dane County eingewanderten Demokraten sehr eindeutige Lebensstilpräferenzen aufweisen, die mit liberalen politischen Orientierungen verknüpft sind. Freilich fehlt noch eine weitere Information, um die Frage zu beantworten, welchen Einfluss Migration an den politischen Mehrheitsverhältnissen hat. Im Grunde bräuchte man dafür auch einen Überblick über die Gruppe derjenigen, die sich entschieden haben, Dane County den Rücken zu kehren. Oder anders gesagt: Während es unbestritten erscheint, dass dieser Ort ein Magnet für Demokraten ist, stellt sich die Frage, ob er auch eine Abstoßungsfunktion auf Republikaner hat oder hatte. Statistisch ist es jedoch unmöglich durch die DWPS diese movers zu erfassen. Im Rahmen unserer eigenen Umfrage aber fragten wir zumindest a) nach der Zufriedenheit mit dem derzeitigen Wohnort und b) ob man manchmal darüber nachdenke, aus Dane County (bzw. Waukesha County) wegzuziehen.

Diejenigen, die vorhatten umzuziehen oder sich einen Umzug vorstellen könnten, fragten wir schließlich c), ob ihre Umzugsabsicht in den politischen Verhältnissen an ihrem Wohnort wurzelte. ${ }^{31}$

31 Der exakte Wortlaut in der Umfrage lautete a) „How satisfied are you with living in Dane/Waukesha County“, b) „Do you sometimes think about moving away”? c) „Is this 
Natürlich: das alles bedeutet nur eine abstrakte Absicht und bewegt sich damit auf der Präferenzebene, die im allgemeinen Teil dieses Kapitel noch kritisiert wurde. Doch abgesehen davon, dass in diesem Fall ein anderer methodischer Zugang schlicht nicht möglich ist: Die Zahlen, die sich aus diesen Daten ergeben, entschädigen für solche Unzulänglichkeiten. Es zeigt sich dabei nämlich, dass nicht nur die allgemeine Zufriedenheit mit dem Wohnort zwischen Republikanern und Demokraten beträchtlich differierte: $63 \%$ der Demokraten sagten, sie seien ,sehr zufrieden" damit, in Dane County zu leben, bei Republikanern waren es hingegen nur 31\%. Unterschiedlich, wenngleich weniger signifikant, fiel auch die Antwort auf die sehr allgemeine und zunächst ganz unpolitische Frage: „Do you sometimes think about moving away from Dane (Waukesha) County?" aus: $48 \%$ der Republikaner von Dane County sagten, dies sei der Fall, hingegen nur 37\% der Demokraten. Markant erscheint jedoch wiederum die Antwort auf die Folgefrage: „Is this because you dislike the political views of the people in Dane County (Waukesha County)?“ Immerhin antworteten fast ein Drittel (31,5\%) der „likely movers", also jener, die zuvor eine abstrakte Umzugsabsicht bekundet hatten, dies sei der Fall (insgesamt betrifft dieses also 15\% aller Republikaner im County). Unter Demokraten war die Zahl beinahe unterhalb der Wahrnehmungsschwelle.

Obwohl es hier „nur“ um theoretische Umzugsabsichten geht, lässt sich anhand der Ergebnisse plausibel argumentieren, dass Republikaner insgesamt eine sehr viel höhere Wahrscheinlichkeit des Wegzugs aufweisen als Demokraten. Kurzum: Dane Countys Status als krasse Hochburg der Demokratischen Partei verdankt sich in hohem Maße dem Zufluss von Demokraten und dem Abfluss von Republikanern.

because you dislike the political views of the people in (Dane County/Waukesha County)?" 
Abbildung 8: Zufriedenheit mit Dane County als Wohnort nach Parteianhängern: Antwort „Sehr zufrieden“

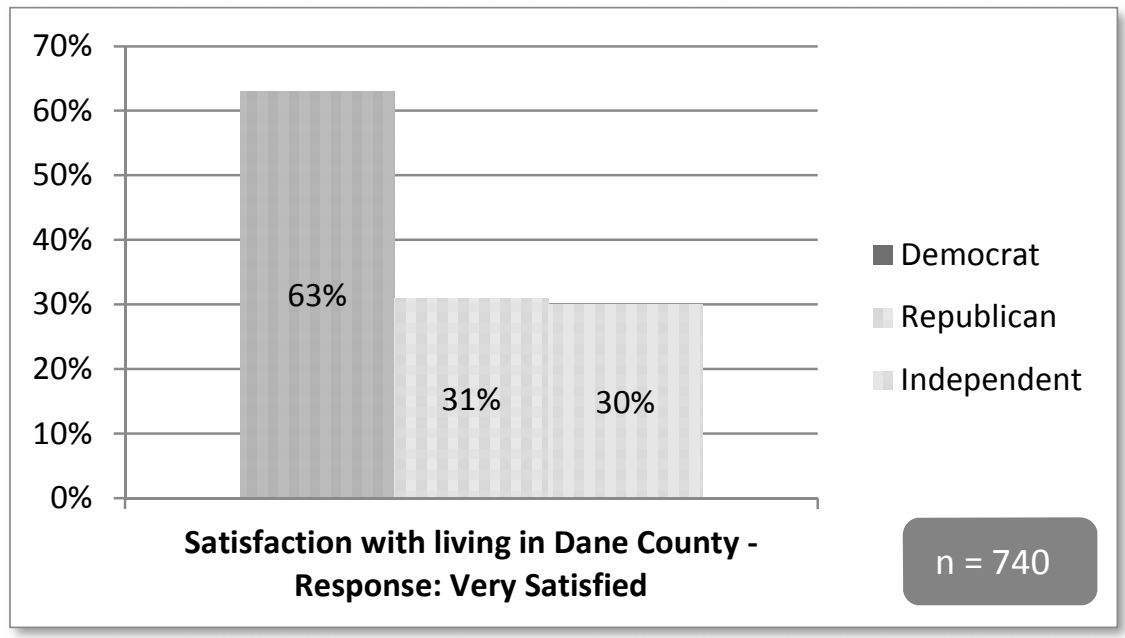

Quelle: Eigene Darstellung, Daten der DWPS

Die meisten, auf die Dane County diese Magnetwirkung ausübt, dürften fraglos die Urbanität Madisons schätzen. Gleichwohl: Wer die Stadt und seine unterschiedlichen Nachbarschaften studiert, der wird nicht umhinkommen, zuzugeben, dass das Bild von Madison als Zitadelle urbaner Dichte und städtischer Kultur leicht idealisiert ist. Es gibt Teile der Stadt, die durchaus nicht diesem Idealbild entsprechen: auch Madison hat an den Rändern seine suburbane Zersiedelung erlebt - zu einer Zeit, vor allem zwischen den 1960er und 1980er Jahren, als das Bewusstsein hierfür unter den liberalen Meinungseliten noch nicht so stark ausgeprägt war wie heute. ${ }^{32}$ Auf den ersten Blick sehen manche der Vororte Madisons wie Middleton oder Fitchburg nicht sehr viel anders aus als Waukesha. Es sind überwiegend Wohngebiete mit Einfamilienhäusern, Malls und breiten Straßen. Tatsächlich wird hier auch weniger demokratisch gewählt als in Madison.

Allerdings: Der noch immer stetige Anstieg des Stimmenanteils der Demokraten in Dane County geht nicht unbedingt auf das Konto von Madison, wo viele Nachbarschaften ohnehin seit Jahrzehnten zwischen 80-90\% für die Demokratische Partei stimmen. Es sind vielmehr einige dieser Vororte, die erst in den letzten zwei Jahrzehnten ,gekippt“ sind: Von 50:50 zu 55:45, 60:40, oder sogar noch

32 Vgl. Allen Ruff/Tracy Will: Forward! A History of Dane County, Madison 2000, S. 315340 . 
deutlicher. Madison ist gerade außerhalb seines schon immer sehr liberalen Innenstadtkerns stetig liberaler geworden. In der letzten Präsidentschaftswahl 2012 gab es in ausnahmslos allen der über 200 ,wards ${ }^{\text {“33 }}$ in Dane County eine Mehrheit für Obama; nur in einer Handvoll von ihnen war das Ergebnis überhaupt knapp. Die meisten dieser ,wards“ liegen in Sun Prairie, zehn Meilen außerhalb von Madison. Sun Prairie ist bekannt dafür, in Madison sogar berüchtigt, dass dort viele Mitarbeiter der Republikanischen Abgeordneten leben. „It's a Mini-Waukesha“ sagt Scott McDonell, der demokratische Vorsitzende des County Board bis 2012, mit unverkennbarer Abwehr, und seiner Ansicht nach ist es nur ein Zwischenstopp: wer dorthin ziehe, der sei auch bereits auf dem halben Weg nach Waukesha. ${ }^{34}$ Allerdings: nicht einmal Sun Prairie ist insgesamt republikanisch - bei der letzten Präsidentschaftswahl gewann auch hier Barack Obama.

McDonell meint, er würde gerne die Lorbeeren für die demokratischen Mehrheiten in Dane County einheimsen, dafür, dass es bis in seine Suburbs und bis in seine ländlichen Ecken überall demokratischer geworden ist. Die Wahrheit sei jedoch, dass die Einstellungen dort sich kaum noch von denen in der Stadt Madison unterscheiden würden. Verantwortlich dafür sind Migrationsströme, die sich mit der DWPS nicht messen lassen, geht es in diesem Fall doch um Umzüge innerhalb von Dane County: mehr und mehr Familien verlassen das boomende und damit immer teurer werdende Madison, um in der Umgebung bezahlbare Häuser und Wohnungen zu finden. Und dabei nehmen sie ihre liberalen Grundhaltungen mit - was diese Orte offenkundig verändert.

In vielen Orten werden City-Center neuerdings revitalisiert oder auch erst geschaffen und viele von ihnen sind Heimat sogenannter „New Urbanism“-Projekte. ${ }^{35}$ Die ältesten dieser Projekte in Madison und Umgebung, wie z.B. ,Middleton Hills", das von einem Schüler Frank Llody Wrights geplant wurde, stammen noch aus den 1980er Jahren. Beim New Urbanism geht es darum, neue Siedlungen dem Design traditioneller amerikanischer Nachbarschaften nachzuempfinden. Schmalere Straßen mit breiten Bürgersteigen und Häuser mit „Front Porches“, also den typisch amerikanischen Veranden, werden gemeinsam mit kleineren Shopping-Komplexen samt Supermarkt und, so klischeehaft dies klingen mag, Coffee-Shops angelegt. Das Ziel dabei ist, dass nicht jeder Einkauf gleich zur

33 Als wards werden die Wahlbezirke oder Wahleinheiten auf kommunaler Ebene bezeichnet.

34 Gespräch mit Scott McDonell, 28. März 2012.

35 Vgl. Mike Ivey: New Opportunities for New Urbanism, in: Capital Times, 1. Juni 2011: http://host.madison.com/business/biz_beat/new-opportunities-for-new-urban ism/article_daeb45fe-8bc8-11e0-b2dd-001cc4c03286.html (zuletzt abgerufen am 15.06.2015). 
Mall, diesem Inbegriff der Konsumgesellschaft führen muss, sondern man stattdessen seine Nachbarn beim lokalen Einkauf treffen kann. Als „self-sufficient neighborhood“ mit einem „sense of community“ preist etwa die offizielle Homepage der Siedlung die Vorzüge „Middleton Hills“ an. ${ }^{36}$ Wer durch diese oder ähnliche Siedlungen fährt, der wird registrieren, dass dieses Konzept nicht immer funktioniert und manche Projekte es dennoch nicht schaffen, ein lebendiges Nachbarschaftszentrum zu schaffen. Und für die hartnäckigsten Kritiker des „Suburban Sprawl" sollte man selbst diese Simulation urbanen Lebens lieber gleich einstellen: als „Disney Land“ etwa verspottet es Steve Hiniker. Dennoch ist die Nachfrage für solche Wohngebiete in den letzten Jahren stark angestiegen, sagt etwa Joe Alexander, einer der größten Bauunternehmer in Dane County ${ }^{37}$ Offenkundig befriedigt es das Bedürfnis nach Gemeinschaft und wenigstens einem Stück urbanen Lebensgefühls vor den Toren der Stadt.

Einer derjenigen, der seinen liberalen politischen Ansichten und auch seinen liberalen Lebensstil in die Umgebung der Stadt verpflanzt hat, ist Luke Diaz. Diaz arbeitet für EPIC, auf dem Hauptcampus des Unternehmens in Verona, etwa 10 Meilen südlich von Madison. Verona ist nach unseren Maßstäben schon fast eher ein Dorf und kein Vorort mehr, aber durch die Präsenz von EPIC eben kein Dorf wie jedes andere. Auch Diaz entschied irgendwann, dass es weder die Pendelei noch die Grundstückspreise wert waren, weiterhin in Madison wohnen zu bleiben; außerdem, sagt er, sei es aus ökologischen Gründen ohnehin besser, weniger weit zur Arbeit zu fahren. So zieht er 2005, mittlerweile Familienvater geworden, raus nach Verona, in jenen Teil, der relativ nah am kleinen, überschaubaren Zentrum der Kleinstadt liegt. Wo er wohnt, erzählt Diaz im Oktober 2014 im Fair-tradeCafé Barriques, einer wahrhaften Madison-Institution, die nun auch in Verona eine Coffee-Shop-Filiale eröffnet hat, seien viele andere Neuankömmlinge. Dort gäbe es, anders als im Rest des Ortes, auch einige Appartement-Häuser und Townhouses. Diaz ist überzeugter Anhänger eines ökologischen Lebensstils und wie manch andere in seiner Nachbarschaft hat er keinen ordinären Rollrasen verlegt, sondern wild-wucherndes "natural prairie grass“ angepflanzt. Das sei zwar wesentlich mehr Arbeit, aber besser fürs Ökosystem. In seiner Nachbarschaft sehe ihn deswegen niemand krumm an, und er ist sich nicht sicher, ob das überall in Verona so wäre. ${ }^{38}$ Man kann bei alledem kaum anders, als an einen weiteren, leicht veränderten Spitznamen Waukeshas in Madison zu denken: „Mordor with lawns“, auf Deutsch „Mordor mit Vorgarten“. In einem Land, in dem die Politik sich so

36 Vgl. http://www.middletonhills.com/ehi/mhills/ (abgerufen am 27.03.2015).

37 Gespräch mit Joe Alexander, 2. Oktober 2014.

38 Gespräch mit Luke Diaz, 3. Oktober 2014. 
tief in das Alltagsleben eingefressen hat wie in den USA, wird selbst die Gartenarbeit zum Politikum.

Jedenfalls hat der Umzug Diaz nicht in einen konservativen Vorstadtbewohner verwandelt. Erst in Verona angekommen, wird Diaz politisch wirklich aktiv. Zusammen mit drei anderen Neuankömmlingen und Neulingen in der Lokalpolitik kandidiert er 2013 für den City Council von Verona. Alle vier gewinnen ihre Wahlen und erringen damit sofort die Mehrheit. In der Folge führt das zu einigen Spannungen und Friktionen im Council, einer der altgedienten Mitglieder tritt gar zurück, da er die „Politisierung“ des Councils nicht länger aushält. ${ }^{39}$ Dabei geht es Diaz und den anderen - unter denen sich noch zwei andere EPIC-Mitarbeiter befinden - durchaus um Verona und die Lokalpolitik. Ihr größtes politisches Anliegen ist es, dass man das in der Tat winzige und in den letzten Jahrzehnten extrem vernachlässigte Zentrum von Verona revitalisiert und neue Geschäfte und Restaurants anlockt, überdies mehr Bürgersteige einrichtet, damit Verona besser für Fußgänger geeignet ist. Wie wir gesehen haben, sind das Themen, die sehr wohl für Dissens sorgen können, da sie Lebensstilneigungen ausdrücken, die in den USA zwischen Parteianhängern stark differieren. Daher muss man das Ende der Geschichte auch erwähnen. Denn nur ein Jahr später kommt es zu einer Art konservativem „,backlash“: Bei Nachwahlen geht die liberale Mehrheit im City Council wieder verloren. Auch die Abwahl des eher moderat-konservativen Bürgermeisters scheitert. Offenkundig ging es manchen Bewohnern von Verona doch etwas zu schnell mit der Veränderung.

Von solch kleineren Rückschlägen abgesehen, ist unverkennbar, dass Madisons Liberalismus quasi „,ansteckend“ wirkt und die angrenzenden Communities in Dane County infiziert und damit verändert hat. Fast alle Vororte wählen heute stärker demokratisch als noch vor dreißig Jahren. ${ }^{40}$ Verona selbst ist dafür ein gutes Beispiel. Bei der Präsidentschaftswahl 1976 wurden in Verona 2254 Stimmen abgegeben und Gerald Ford und Jimmy Carter lagen bis auf exakt drei Stimmen gleichauf. Danach aber wuchs Verona kontinuierlich - und wurde dabei beständig demokratischer. 1984 gewann mit Ronald Reagan noch ein letztes Mal ein Republikaner die Mehrheit der Stimmen in Verona. George W. Bush konnte im Jahr 2000 - mittlerweile wurden in Verona 6631 Stimmen abgegeben - immerhin noch 43\% der Stimmen gewinnen. Danach schritt die Veränderung des Ortes, auch durch das Wachstum von EPIC, immer weiter voran: 2008 und 2012 erhielt

39 Vgl. Jim Ferolie: Alder Resigns Over „Political Climate“, in: Verona Press, 26. April 2013, abrufbar unter: http://connectverona.com/articles/2013/04/26/alder-resigns-overpolitical-climate (zuletzt abgerufen: 24.04.2015).

40 Vgl. Fowler, Wisconsin Votes, S. $235 \mathrm{ff}$. 
Obama $62 \%$ bzw. $65 \%$ der Stimmen. Verona ist jetzt, in der Terminologie des „Big Sort“, eine „landslide town“. 2012 wurden 8165 Stimmen in Verona gezählt - beinahe eine Vervierfachung der Stimmen seit $1976 .{ }^{41}$ Das spricht stark dafür, dass die Veränderungen der politischen Kräfteverhältnisse auch hier migrationsbzw. mobilitätsgetrieben sind. Kein Wunder vielleicht, dass nicht gerade wenige Republikaner darüber nachdenken, gleich das ganze County zu verlassen - wo sich doch selbst in Dane County langsam alles tiefblau einfärbt und auch außerhalb Madisons die Rückzugsorte langsam nur noch spärlich gesät sind.

Wer das Pendeln nicht scheut, kann vielleicht an einen Ort ziehen, der nur eine Stunde mit dem Auto entfernt ist, und dabei doch in einer anderen Welt liegt: nach Waukesha.

\section{„A LITTLE PIECE OF LAND": WAUKESHA UND DER REPUBLICAN FLIGHT}

Die Geschichte von Waukesha County ist auch die Geschichte der Taylor-Familie. Wer ermessen will, wie groß der Wandel Waukeshas von einem spärlich besiedelten und politisch ganz und gar unauffälligen Ort zum national bewunderten, republikanischen Vorzeigecounty ist, der sollte zuerst mit Don Taylor sprechen. Er hat bis 2013 über dreißig Jahre lang als Vorsitzender die Geschicke der Republican Party of Waukesha County bestimmt. Anders als die meisten anderen Bewohner von Waukesha County war Taylor, Jahrgang 1932, schon da, bevor die große Welle der Suburbanisierung begann. Sein Vater Carl war bereits Ende der 1930er Jahre mit der Familie aus Milwaukee hinausgezogen, mit der festen Absicht, in der City of Waukesha, der einzigen, wenngleich sehr überschaubaren Stadt des Counties, eine Bank zu eröffnen. Carl Taylor, bis dahin ein Rhetorik-Professor an der University of Wisconsin in Milwaukee und bar jeder Erfahrung im Geldgeschäft, muss ein geduldiger Mann gewesen sein. Seit 1936, als das Land tief in der wirtschaftlichen Depression feststeckte, beginnt er bei Zwangsversteigerungen Bank-Equipment aufzukaufen und lagert alles in einem Warenhaus ein. Er knüpft Kontakte in der Stadt Waukesha, tritt der örtlichen Presbyterianischen Kirche bei, weil dort viele der wichtigsten Honoratioren der Stadt den Gottesdienst besuchen. Einer von ihnen, ein Zigarrenfabrikant, leiht ihm das nötige Startkapital und im Juni 1944, ,just a week after D-Day“, wie sein Sohn Don Taylor mit einigem Stolz

41 Alle Zahlen stammen aus dem State of Wisconsin Blue Book, online abrufbar unter: http://digicoll.library.wisc.edu/cgi-bin/WI/WI-idx?type=browse\&scope=WI.WIBlue Bks 
bemerkt, eröffnet die Waukesha State Bank. ${ }^{42}$ Es gibt ein paar kleinere Fabriken in der Stadt, ansonsten vergibt die Bank zunächst vor allem Kleinkredite für die Farmer im Umland. Carl Taylor hat sich für seine Gründung indes einen guten Zeitpunkt ausgesucht. Bald schon wird Waukesha rasant wachsen und mit dem Boom auch seine Bank. Taylor und seine Nachkommen wird das zu einer sehr reichen Familie machen.

Aber Carl Taylor ist nicht einfach nur ein erfolgreicher self-made Millionär. Er ist außerdem auch: Ultrakonservativ. Er gehört zu jenem Flügel des amerikanischen Konservativismus, der von den 1930er bis zu den 1950er Jahren ein Sektiererdasein fristet und in den Jahren des New Deal auch parteipolitisch heimatlos ist, im Grunde als Ansammlung exzentrischer Esoteriker gilt. Taylor reist häufig durchs Land, hält bezahlte Vorträge zu Themen wie: „Why America is great“ und geißelt die Politik Franklin D. Roosevelts, dessen New Deal das Ende der Freiheit in Amerika bedeute. Auf seinen Reisen begleitet ihn manchmal auch sein Sohn Don, der so von Kindesbeinen an mit dieser spezifischen, radikalen Variante des amerikanischen Konservativismus in Berührung kommt und die Reden des bewunderten Vaters wie ein Schwamm aufsaugt: „As a teenager then, sometimes during his speech I would just feel the hair is going up in the back of my neck."

Nach der High-School beginnt Taylor sein Wirtschaftsstudium - ausgerechnet an der University of Wisconsin in Madison. Es ist eine eher unglückliche Zeit in seinem Leben, ein regelrechtes Martyrium. Die Universität gilt schon Anfang der 1950er Jahre als sehr links, und das ist einer der Gründe, warum er sich dort nicht wohl fühlt. Ein anderer Grund ist die „G.I. Bill“: Durch das Gesetz werden die amerikanischen Colleges mit jungen Ex-Soldaten geflutet, und dass zu einer Zeit, als ohnehin noch viel mehr Männer als Frauen eine Universität besuchen. Die Männer-Frauen-Ratio ist 8:1, und das, sagt Taylor, machte das Leben nicht gerade leichter für einen „farmboy“ wie ihn: „I couldn't get a date!“

Als die Leidenszeit in Madison vorbei ist, kann Taylor Mitte der 1950er Jahre nach Waukesha zurückkehren, wo sein Vater ihn bald in der Bank anlernen wird. Taylor erinnert sich an eine Art Initiationsritus in die noch überschaubare Business-Welt der Stadt, bei einem Treffen des örtlichen Rotary-Clubs. Es ist die Zeit der „Red Scare“, die McCarthy-Ära, als Amerikas Konservative hinter jedem Busch einen Agenten Moskaus vermuten und so stellt sich der Rückkehrer mit den Worten vor: „I just got my four years out of University of Wisconsin in Madison, but I want to assure you gentlemen: I did not become a communist.“

42 Sofern nicht kenntlich gemacht, basieren die folgenden zwei Seiten auf dem Gespräch mit Don Taylor, 26. September 2012. 
Seine eigentliche Leidenschaft ist die Politik, aber zunächst bleibt er ebenso wie sein Vater ein Außenseiter. 1964 ist er immerhin in San Francisco auf dem legendären Nominierungsparteitag der Republikanischen Partei eingeladen und stimmt als Mitglied der Wisconsin-Delegation für die Kandidatur Barry Goldwaters. Doch den Zeitgenossen erscheint Goldwater als Ausrutscher der Geschichte, und die Republikanische Partei wird weiterhin vom liberalen Ostküsten-Flügel der Partei beherrscht. Taylor hat schon 1964 Ronald Reagan als sein Idol entdeckt, nach dessen legendärer „A Time for Choosing“-Rede. 1968 schreibt er ihm mehrere Briefe und drängt ihn, in der Vorwahl der Partei gegen Richard Nixon anzutreten. Ohne Erfolg. In den Folgejahren gerät Taylor mit den Republikanern in seinem Staat und jenen in seinem County immer mehr in Streit. Zu den folgenden Conventions wird er nicht einmal mehr als Delegierter zugelassen. Er gilt einfach als zu radikal. Auch 1976, als Reagan dann tatsächlich antritt und gegen Gerald Ford verliert, ist er nur Zuschauer, weil Fords Gefolgsleute in Wisconsin ihm den Zugang verwehren.

Doch Fords Nominierungssieg sollte das letzte Hurra der moderaten Republikaner in der Partei sein - der Wind dreht sich. Die Anhänger Ronald Reagans bekommen in den krisengeplagten 1970er Jahren beständig Zulauf. Speziell in Waukesha, in den wachsenden, wohlhabenden Suburbs, verfangen Reagans Attacken gegen den Wohlfahrtsstaat und die zu hohen Steuern. Suburbia ist jetzt Reagan-Land. 1979 entscheidet sich Taylor, dass die Zeit reif ist: er tritt in einer Kampfabstimmung um den Vorsitz der County-Partei an, mobilisiert beinahe 500 Leute für den Caucus und gewinnt deutlich. Wenig später bitten ihn Reagans Wahlkampfleute, in Wisconsin Reagans Kampagne zu organisieren. Als Reagan 1980 gewinnt, fühlt sich Don Taylor am Ziel. Als nächsten Schritt modelt er die County-Partei um und macht sie zu einer effizienten Spendensammelmaschine. Seine Vorgänger hätten die Partei wohl eher als einen „Social Club“ gesehen, erinnert sich Taylor. Doch sein Ziel war eindeutig: Aus Waukesha County sollten nur noch konservative Republikaner in die Parlamente nach Madison und Washington D.C. entsandt werden. Und so wird es kommen: 1979, als Taylor sein Amt antritt, sind einige der Volksvertreter von Waukesha sogar noch Demokraten. Mitte der 1990er Jahre aber ist von dieser Spezies keiner mehr übrig: Waukesha wählt auf nationaler und bundesstaatlicher Ebene nur noch sehr konservative Republikaner in politische Ämter.

Wahrscheinlich hat Waukeshas Aufstieg zum republikanischen VorzeigeCounty tatsächlich etwas mit Don Taylor zu tun, vor allem mit den nicht unbeträchtlichen finanziellen Ressourcen seiner Bank, die, so sagen es selbst die Demokraten von Waukesha, jeden wohltätigen Zweck im County schon unterstützt 
hat. ${ }^{43}$ Doch auch Don Taylor würde nicht bestreiten, dass die Zeit auch für ihn gearbeitet hat und dass Waukeshas Wachstum einen Ort hervorgebracht hat, der prädestiniert ist für genau die Art von konservativer Ideologie, die die republikanische Partei seit nun mehr als drei Jahrzehnten zu ihrem Programm gemacht hat. Waukesha, sagte Taylor einmal, sei ein „Conservative Garden of Eden“. ${ }^{44}$ Darum also soll es also gehen: Wie wurde Waukesha, was es heute ist: stolze Bastion der Konservativen und gleichzeitig ein verachtetes „Mordor“ für die Liberalen des Staates?

Waukeshas Geschichte erzählt sich anders als jene von Madison und Dane County. Im letzten Fall geht es um einen autonomen Mikrokosmos des amerikanischen Liberalismus. Es ist die Geschichte von Menschen, denen die Stadt ein Mittelpunkt ihrer Identität ist, die einen Teil ihrer Selbstgewissheit daraus ziehen, in ihr zu leben und zu arbeiten. Bei Waukesha, dieser großen, politischen Antipode zu Dane County, verhält es sich ein wenig anders. Als Madison in den 1960er Jahren schon auf eine stolze Geschichte als liberale Hochburg zurückschauen kann, fliegt Waukesha eben noch ganz unter dem Radar. Denn dieser heutige Garten Eden des amerikanischen Konservativismus ist zu dieser Zeit erst im Entstehen.

Man könnte es gar noch weiter zuspitzen: Im Grunde ist die Geschichte Waukeshas - und zwar bis zum heutigen Tage - nicht wirklich eine eigene Geschichte, sondern der Seitenarm einer anderen Erzählung: jener des Verfalls Milwaukees, dieser einst stolzen Industriestadt am Lake Michigan, in deren Niedergang Waukesha (und andere Counties im Umkreis der Stadt) wie ein Nachtschattengewächs blüht. Bis in die 1950er Jahre trägt Waukesha den Spitznamen „Cow County USA“, weil dort noch wesentlich mehr Kühe als Menschen wohnen. Etwa in der geographischen Mitte von Waukesha und circa 15 Meilen entfernt von Milwaukee liegt die einzige wirkliche Stadt des Countys, die beschauliche City of Waukesha - der Ort, von dem aus die Taylor-Familie bald schon ein kleines Imperium aufbauen sollte. Zwischen dieser Kleinstadt und Milwaukee aber liegt noch 1950 fast

43 Vgl. Bill Glauber: Waukesha County's Republican Party's Longtime Leader is Stepping Down, in: Milwaukee Journal Sentinel, 27. Februar 2013, abrufbar unter: http://www.jsonline.com/news/waukesha/waukesha-countys-republican-partys-long time-leader-stepping-down-o48v0vb-193707341.html (zuletzt abgerufen am 29.04. 2015).

44 Vgl. Scott Wittkopf: Blame Waukesha: The GOP's Answer to Liberal Dane County Swings Elections to the Right, in: Isthmus, 3.1.2011. abrufbar unter: http://www. isthmus.com/news/news/blame-waukesha-the-gops-answer-to-liberal-dane-countyswings-elections-to-the-right/ (zuletzt abgerufen am 29.04.2015). 
nichts, nur ein paar hingekleckste Orte auf der Landkarte mit Namen wie Brookfield, Menomonee Falls oder New Berlin, die oft nur aus ein paar Farmen bestehen.

Was dann passiert, dafür liefert eine einfache Statistik die ersten Indizien: 1950 hat die Stadt Milwaukee 637,000 und Waukesha County 85,000 Einwohner. 2010 leben in der Stadt Milwaukee (die zwischenzeitlich beinahe 800,000 Einwohner hatte) nur noch 590,000 Menschen, während es in Waukesha County jetzt 390,000 Menschen sind - eine Steigerung von 400\%. Und die Bevölkerung im Innenstadtkern von Milwaukee schrumpft in Wahrheit sehr viel drastischer als es diese Zahlen aussagen, da sich die Stadt durch Annexionen anderer Körperschaften in der Zeit zwischen 1950 und 1990 in der Fläche fast verdoppelt. ${ }^{45}$ Waukesha wächst, wie auch andere Suburbs in den USA, auf Kosten der benachbarten Großstadt.

Beinahe schon reflexhaft fällt angesichts dieser drastischen Bevölkerungsverschiebung der Begriff des „White Flight“: der Wegzug der weißen Mittelklasse aus den zunehmend von Afro-Amerikanern dominierten Innenstadtvierteln der amerikanischen Großstädte. In Wahrheit überlappen sich hier jedoch mehrere Prozesse, und der Exodus beginnt noch vor der dann in der Tat gewaltigen afro-amerikanischen Einwanderungswelle. Home-Ownership - der Besitz eines eigenen Familienhauses, dieser heute essentielle Bestandteil des amerikanischen Traums - wird in den Jahren nach 1930, und verstärkt in den Boom-Jahren der Nachkriegszeit, erklärtes Ziel einer Reihe von Bundesprogrammen, die mit großzügigen Subventionen diese Entwicklung fördern. Und da der Erwerb eines Eigenheims angesichts eines in den USA auch weiterhin rasant verlaufenden Bevölkerungswachstums in den Grenzen der amerikanischen Innenstädte schwierig oder jedenfalls für die wenigsten erschwinglich ist, bleibt nur das Ausgreifen über die Grenzen der Stadt hinaus. Dieser Prozess wird durch die Motorisierung des Landes unterstützt, vor allem durch die Dominanz des Automobils (alleine zwischen 1945 und 1955 nimmt die Zahl der Autos in Milwaukee um $79 \% \mathrm{zu}^{46}$ ), ohne die das Leben in Suburbia schwer vorstellbar wäre. Auch dahinter verbirgt sich ein Prozess, der politisch gewollt ist und gefördert wird. Für den Auszug aus Milwaukee ist der eigentliche Startschuss daher der „Federal Aid Highway Act“ von 1956, der vor allem das Werk des damaligen Präsidenten Dwight D. Eisenhower ist. Es ist von einiger Ironie, dass ausgerechnet Eisenhower - der für die Konservativen seiner Zeit eine große Enttäuschung war, da er an kaum einer Stelle die Sozialprogramme

45 Vgl. David Rusk: Sprawl, Race, and Concentrated Poverty in Southeast Wisconsin, Paper der Federal Reserve Bank Chicago, 2001.

46 Vgl. John Gurda: The Making of Milwaukee, Milwaukee 2004 (3. Auflage) S. 328. 
des New Deal in Frage stellte - damit die Expansion jenes sozialen Raumes beförderte, aus dem sich bis heute eine der treusten Klientelen der republikanischen Partei rekrutiert. Anfang der 1960er Jahre beginnt man damit, Wisconsin an die Interstate 94 anzuschließen, die nun von Milwaukee Richtung Westen durch Waukesha führt, und deren Bau 1964 abgeschlossen ist. Die bessere verkehrstechnische Erschließung wird den Prozess der Suburbanisierung noch einmal bedeutend verstärken. $^{47}$

Es war also ganz zu Beginn nicht alles nur eine Frage des „White Flight“ - im Laufe der 1960er Jahre wird der Rassenkonflikt dann aber in der Tat eine große Rolle spielen. Milwaukee hatte seit den Nachkriegsjahren, ganz so wie viele andere Wirtschaftszentren der USA, einen starken Zustrom von Afro-Amerikanern vor allem aus dem Süden der USA erfahren, die auf der Suche nach besser bezahlten Industriejobs ihren Heimatort verließen. Die Tragik besteht darin, dass bereits in den 1960er Jahren viele dieser Jobs beginnen wegzubrechen: die in den USA früh einsetzende Deindustrialisierung trifft Milwaukee, diese Hauptstadt aus der Ära des „,schweren Kapitalismus“, besonders hart. Die Autofirma American Motors, die Maschinenbauer von Allis-Chalmers, der Motorradhersteller Harley-Davidson, die Brauereien von Papst und Schlitz (einst die Größten in den USA), sie alle beschäftigen bald zunehmend weniger Leute oder verschwinden einfach ganz vom Markt. Milwaukee wird Teil des berüchtigten „Rust Belts“ des Mittleren Westen, in dem - von Ausnahmen wie Chicago abgesehen - der Strukturwandel nur schlecht gelingt und die wegbrechenden Industriearbeitsplätze nicht durch eine neue Service-Industrie ersetzt werden können. Die Krise trifft Milwaukee schwer, doch am härtesten die häufig unwillkommenen Neuankömmlinge aus dem Süden, von denen viele erst gar keine Arbeit finden und die sich vor allem in einigen wenigen Vierteln nahe und nördlich von Downtown, dem sogenannten „,inner core“, ansiedeln. Gleichzeitig kommt es in Milwaukee 1967 und 1968 mehrmals zu aggressiven Unruhen, als die Polizei gewaltsam gegen Demonstrationen der schwarzen Bürgerrechtsbewegung vorgeht. Im Juli 1967 verhängt der Bürgermeister der Stadt, Henry Maier, für 24 Stunden sogar den Ausnahmezustand. Als Milwaukee, im wahrsten Sinne des Wortes, zu brennen beginnt, wird es für viele endgültig zu einem Ort, den man lieber heute als morgen verlassen möchte - sofern man überhaupt die Möglichkeit dazu hat. ${ }^{48}$

47 Vgl. mit dezidiertem Verweis auf Waukesha County Clayton Nall: The Road to Division: How Interstate Highways Caused Geographic Polarization, Paper, 24. März 2013, abrufbar unter: http://web.stanford.edu/ nall/docs/gp2.1.pdf (zuletzt abgerufen am 29.04.2015).

48 Vgl. Gurda: The Making of Milwaukee, a.a.O. S. 365-388. 
So beginnt eine Abwärtsspirale dramatischen Ausmaßes, in der sich alle Prozesse bald gegenseitig verstärken. Durch den Auszug großer Teile der weißen Mittelund Oberschicht brechen der Stadt wichtige Steuereinnahmen weg, die so in eine desolate finanzielle Situation gerät. Seit den 1980er Jahren schließlich kehren nicht nur Privatpersonen der Stadt den Rücken; ganze Firmen siedeln sich jetzt direkt in Waukesha und Umgebung an. Der Teufelskreis wirkt sich besonders gravierend auf den zunehmend maroden Zustand der öffentlichen Schulen in der Stadt aus. Dieser Umstand verleiht dem „White Flight“ fortan die größte Dynamik, denn auch wer sonst ohne Ressentiments sein mag: die Zukunft der eigenen Kinder zu sichern, schlägt einfach alle anderen Erwägungen aus dem Feld. So ist der „amerikanische Traum“, den sich viele in Waukesha erfüllen wollen, eben auch die Flucht vor einem Alptraum. So klingt es auch bei Janel Brandtjen, einer lokalen Tea Party Aktivistin aus Menomonee Falls, einem der besonders konservativen Flecken von Waukesha County: „And we wanted like a yard and expecting our first child. And wanted the American Dream of a little piece of land. [...] And besides good schools. My husband and I were products of Milwaukee public schools. We don't want our children to have to be in that. It was bad. Yeah, so we were trying to move up. “49

Das Wachstum der Suburbs ist rasant und verläuft so unkoordiniert und mit so wenigen Regulierungen, dass sich die neuen Wohngebiete wie ein Flickenteppich über das ehemalige Farmland legen. Und weil es in den frühen Jahren noch Teil der Verlockung von Suburbia ist, die Nähe zur Großstadt mit dem Leben in echter Natur zu verbinden, werden die Siedlungen weit auseinander gebaut und fressen sich immer tiefer in das frühere Farmland hinein. Es ist ein typisches Beispiel für einen Prozess der Pfadanhängigkeit: einmal zersiedelt, wird die Fortbewegung per Auto auf diese Art und Weise unverzichtbar, öffentlicher Nahverkehr dafür umso weniger praktikabel, weil die Entfernungen einfach zu groß sind. So entsteht American Suburbia, das aus vielen Gründen schwer mit den Maßstäben deutscher Raum- oder Siedlungsstruktur zu fassen ist. Denn in vielen Fällen wachsen diese Vororte nicht in bestehende Dörfer oder Kleinstädte hinein, sondern entstehen buchstäblich aus dem Nichts. Es gibt keine wirklichen Zentren oder Stadtkerne, jedenfalls nicht wie wir sie kennen. Stattdessen dominieren Wohnsiedlungen und Shopping-Malls, durchtrennt von vierspurigen Freeways. Die größte Abwechslung stellen noch die „Mega-Churches“ da, große, meist evangelikal-protestantische Freikirchen, die selbst in vielerlei Hinsicht an Einkaufszentren erinnern: die brachiale architektonische Einfallslosigkeit der Kirchengebäude, die Größe des Parkplatzes vor der Tür, vor allem aber die Tatsache, dass im Inneren der Kirchen

49 Gespräch mit Janel Brandtjen, Mitglied des Waukesha County Boards, 2. November 2012. 
ebenfalls vor allem der Konsument angesprochen wird mit christlichen Buchläden und Cafés. Obgleich weit entfernt vom tief religiösen Bible Belt, dem „Bibel-Gürtel" im Süden der USA, befindet sich in Waukesha eine der lange Zeit am schnellsten wachsenden Mega-Kirchen der USA: Elmbrook Church. 1970 hatte Elmbrook noch 300 Gemeindemitglieder. Dann kam ein junger und begabter evangelikaler Prediger aus Manchester, Stuart Briscoe, während einer USA-Reise nach Wisconsin und entschied zu bleiben. An Sonntagen predigt er in Jeans und T-Shirt in den Kinos der Region und bald wächst seine Kirche rasant auf mehrere tausend Mitglieder an, die meisten von ihnen vom Glauben abgefallene Katholiken. ${ }^{50}$

Heute besuchen bis zu 7.000 Menschen den Gottesdienst der evangelikalen Kirche - jede Woche. Einer von ihnen war viele Jahrzehnte lang Don Taylor, der legendäre Vorsitzende der Republikanischen Partei von Waukesha County. In Suburbia, wo sonst alles auf Individualismus und Privatheit ausgerichtet ist, sind die Kirchen eine der wenigen Räume öffentlicher Begegnung, was sie als mentalitätsprägende Institutionen eminent wichtig macht. ${ }^{51}$ Und von den 100 größten Kirchen der USA befinden sich 69 in suburbanen Gebieten. ${ }^{52}$

Suburbia mag für viele ein Traum sein, ist aber in Südost-Wisconsin beileibe nicht für alle bezahlbar. Zwar sind die Grundstückspreise zunächst noch erschwinglich, aber eine Reihe anderer Faktoren verhindert die Ansiedlung von Menschen mit unterdurchschnittlichem Einkommen. Zum einen hält die öffentliche Infrastruktur nicht mit dem Wachstum der Wohngebiete Schritt. Daher sind diese zunächst (und viele bis heute) nicht an das öffentliche Kanalisationssystem angeschlossen, sondern verfügen über ihre eigene Abwasserentsorgung, meistens in großen, unter dem Grundstück liegenden Tanks, die dann regelmäßig ausgepumpt werden müssen. Das alleine schon erfordert grundsätzlich größere und damit teurere Grundstücke. ${ }^{53}$ Daneben existieren eine Reihe anderer Verordnungen,

50 Gespräch mit Stuart Briscoe, 29. November 2012. Vgl. für die Geschichte von Elmbrook Church auch die Autobiographie von Stuart Briscoe: Flowing Streams. Journeys of a Life Well Lived, Grand Rapids 2008.

51 Vgl. besonders in Bezug auf konservative Mobilisierungs-Strategien Eileen Luhr: Witnessing Suburbia: Conservatives and Christian Youth Culture, Los Angeles 2009; Lisa McGirr: Suburban Warriors. The Origins of the New American Right, Princeton 2001.

52 Vgl. Justin Wilford: Sacred Subdivisions. The Postsuburban Transformation of American Evangelicalism, New York 2012, S. 53.

53 Vgl. Mark Edward Braun: Suburban Sprawl in Southeast Wisconsin: Planning, Politics, and the Lack of Affordable Housing, in: Matthew J. Lindstrom/Hugh Bartling (Hg.): Suburban Sprawl. Culture, Theory and Politics, Lanham 2003, S. 257-272. 
die eine bestimmte Mindest-Grundstücksgröße vorschreiben, etwa, dass die Häuser extrem weit zurückgesetzt sein müssen von der Straße - wie viele meinen eine bewusste Politik, um Nicht-Mittelklasse-Amerikanern, vor allem solche mit einer anderen Hautfarbe, von den Suburbs fernzuhalten. ${ }^{54}$ Bis heute gilt in Waukesha County das Einfamilienhaus als die „normale“ und akzeptierte Form des Zusammenlebens, während alles andere mit größtem Misstrauen beäugt wird, bisweilen auch schlicht als ,unamerikanisch“ " gilt. ${ }^{55}$ Nüchtern betrachtet bräuchte Waukesha längst andere Wohnsiedlungen, denn dort ist man in der Service-Industrie auf niedrig qualifizierte Arbeitskräfte angewiesen, die aufgrund der fehlenden Infrastruktur aber aus Milwaukee ohne eigenes Auto nur schwer anreisen können. Die Förderung solcher Projekte scheitert oft nicht nur am mangelnden Willen örtlicher Bau- oder Immobilienfirmen, die sich mehr Profit vom nächsten Neubaugebiet mit Einfamilienhäusern versprechen. Problematisch ist auch staatlich subventionierter Wohnungsbau, der in den USA als „Affordable Housing“ deklariert wird. Doch allein es so zu nennen, wäre bereits politischer Selbstmord, erzählt etwa Norm Cummings, der Verwaltungsdirektor von Waukesha County. Deswegen habe man sich entschlossen, solche Projekte als „workforce housing“ zu bezeichnen, da dieses die Assoziation schaffe, dass die Menschen die dort wohnten, immerhin einem Beruf nachgingen. ${ }^{56}$

Gleichwohl helfen auch solche semantischen Tricksereien nicht immer. Ein extremes Beispiel ereignet sich im Jahr 2011 in der Stadt New Berlin, am östlichsten Rand des Counties und direkt an der Grenze zu Milwaukee gelegen. Dort hat die Verwaltung zunächst den Bau eines großen Appartement-Blocks mit 100 Einheiten genehmigt. In der Bevölkerung formiert sich nach Bekanntwerden der Pläne schnell ein massiver und über alle Maßen erregter Protest: inwiefern dieser Plan zum „Lifestyle“ in New Berlin passe oder kompatibel sei mit der „Kultur“ des Ortes, schließlich, dass man sich nicht „Milwaukees Probleme“ in das idyllische New Berlin holen wolle. ${ }^{57}$ Das alles sind nur mäßig verschlüsselte Signalwör-

54 Vgl. David Ray Papke: Keeping the Underclass In Its Place: Zoning, the Poor, and Residential Segregation, in: The Urban Lawyer, Vol. 41 (4) 2009.

55 Waukesha County hat eine Homeownership Rate von über 76\%. Diese Zahlen beruhen auf den Zensus-Daten 2010: http:/quickfacts.census.gov/qfd/states/55/55 133.html (zuletzt abgerufen am 6.12.2014).

56 Gespräch mit Norm Cummings, Director of Administrations, Waukesha County, am 5. Oktober 2012.

57 Vgl. Bill Glauber/Mike Johnson: New Berlin residents divided on racism's role in city's housing decision, in: Milwaukee Journal Sentinel, 10. Juli 2011: http:/www. jsonline.com/news/waukesha/125323453.html (zuletzt abgerufen am 27.11.2014.) 
ter für eine eindeutig rassistische Motivation. Unter dem geballten Druck der Bürger der Stadt knickt zuerst der City Council, dann der Bürgermeister von New Berlin ein. Wenig später nimmt sich sogar das amerikanische Justizministerium in Washington des Falles an und prüft, ob die Rücknahme der Baugenehmigung einen rassistischen Hintergrund hatte. ${ }^{58}$ Fraglos sind das die extremsten Auswüchse, die meisten Abgrenzungen gegenüber Milwaukee und seiner großen afroamerikanischen Minderheit sind sehr viel subtilerer Natur.

Dennoch wäre es verkürzt, die großen Spannungen zwischen Milwaukee und Waukesha alleine auf den Faktor der Hautfarbe zurückzuführen, so wichtig dieser auch ist. Auch Milwaukee ist „nur“ zu 40\% schwarz, und es gibt auch in der City einige Viertel, die ganz überwiegend von Weißen bewohnt werden. Diese Stadteile allerdings, zumeist erst seit kurzem ,gentrifizierte“ Nachbarschaften, in denen eine oft gut situierte Mittelschicht fast so stark demokratisch wählt wie in Dane County, sind den meisten Menschen in Waukesha ebenfalls kulturell sehr fremd. Ein prägnantes Beispiel für einen solchen eher kulturell bedingten Abstoßungsprozess und Motive für den Wegzug aus der City liefert der konservative Blogger James Wigderson: „I remember the first time when I went to the laundry man as a college student, in there, on the window of the laundry shop was a poster for [...] some sort of lesbian art festival and it showed [...] a large lesbian woman, naked from the back, holding the hand of her daughter.[...] And I was saying: I'm really not living in the right neighborhood." 59

In der Tat: Die meisten die der Stadt Rücken gekehrt haben, vermissen urbanes Leben nicht. Es gibt nur noch wenig, was Waukeshas Bürger nach Downtown Milwaukee zieht, meistens sind es begrenzte Events oder Veranstaltungen. Natürlich, da ist das großartige und über die Grenzen der Stadt gerühmte Milwaukee Art Museum, das jährliche „Summerfest“, in dem mit viel Bier und Bratwurst die deutschen Wurzeln Milwaukees gefeiert werden, oder auch die Spiele in der Bradley-Arena, der Heimat des NBA-Basketballteams der Milwaukee Bucks. Aber zum Einkaufen? Für einen Restaurant-Besuch oder für einen Kaffee? Oder um einfach einmal an der Uferpromenade des Lake Michigan im Veteran's Park entlang zu flanieren? Das wären kaum die spontanen Einfälle der „Suburbanites“ bezüglich ihrer Freizeitgestaltung. Milwaukee ist für viele in Waukesha einfach nur eine „failed city“, in der rein gar nichts zusammenläuft, und das die Stadt seit ewigen Zeiten von demokratischen Bürgermeistern regiert wird, passt in das Weltbild ihrer Kritiker.

58 Vgl. ebd.

59 Gespräch mit James Wigderson, 29. September 2012. 
Nichts erscheint daher dringlicher, als sich von der Stadt abzugrenzen, was in der Lokalpolitik bisweilen schon groteske Züge annehmen kann. Da ist etwa Waukeshas permanentes Problem, die Bewohner mit sauberem Trinkwasser zu versorgen. Das klingt ein wenig merkwürdig angesichts der Tatsache, dass das County nur wenige Meilen vom Lake Michigan entfernt liegt, immerhin dem fünftgrößten See der Welt. Diese paar Meilen sind allerdings genau das Problem, denn über Jahre konnten sich Waukesha und Milwaukee nicht über die Modalitäten der Lieferung einigen - und das obgleich die Bewohner von Waukesha über Jahre gezwungen waren, das eigene radiumverseuchte Grundwasser zu nutzen. Die Details sind hier weniger interessant, signifikant freilich ist, in welcher Weise Lokalpolitiker in Waukesha den Widerstand gegen einen Wasser-Deal mit Milwaukee begründeten. Der Bürgermeister der City of Waukesha von 2010-2014, Jeff Scrimma, hatte in seinem Wahlkampf gezielt die Animositäten mit Milwaukee ausgeschlachtet, und auch danach nichts unversucht gelassen, um den Konflikt politisch aufzuladen. Seine Begründung, warum man das Wasser lieber von einem anderen Ort am Lake Michigan holen sollte, hatte dann auch offenkundig wenig pragmatische Gründe: „Do the citizens of Waukesha want a railroaded approach to a water solution, which will abdicate their future to the City of Milwaukee? Or do they want a comprehensive solution that allows us to live within our means, protect our environment and pocketbooks and keep our identity and independence?" 60

„Unabhängigkeit" - das ist hier, wie in vielen anderen Stellungnahmen der lokalpolitischen Eliten von Waukesha, ein wesentliches Leitmotiv, das das Verhältnis zu Milwaukee bestimmt. Zu der Geschichte gehört allerdings auch die gewaltige Häme, mit der viele in Milwaukee auf die Versorgungsprobleme der sonst so auf ihre Unabhängigkeit und Autarkie pochenden Suburbs blickten. Spätestens nachdem Waukesha in liberalen Kreisen als „Homebase“ des aufstrebenden Gouverneurs Scott Walker berüchtigt wurde, begann die Geschichte vom radiumverseuchten Wasser auch nationale Aufmerksamkeit zu erlangen. Vielen galt sie als Symbol der rücksichtslosen suburbanen Expansion, die alle natürlichen Ressourcen vernichte. „Let the loyal Republicans of Waukesha drink radium and salt water, go thirsty or move", heißt es etwa im Oktober 2013 in einem Beitrag auf einer

60 Vgl. Jeff Scrimma: Let's trust Waukesha citizens, in: Milwaukee Journal Sentinel, 10. Juli 2010, http://www.jsonline.com/news/opinion/98142654.html (zuletzt abgerufen am 09.12.2014); Vgl. auch mit explizitem Bezug auf das Verhältnis Milwaukees zu seinen Suburbs: Katherine Levine Einstein: Divided Regions: Race, Political Segregation, and the Polarization of Metropolitan America, Paper, Presented at the Annual Meeting of the American Political Science Association, September 1-4, 2011. 
der größten liberalen Blogger-Plattformen, dem „Daily Kos“. „Don't let them have Lake Michigan water. More Republicans can only be bad for the environment." ${ }^{\prime \prime}$

Diese und andere Konflikte zwischen City und Suburbs existieren in vielen Regionen der USA. In ihnen spiegelt sich auch häufig der Gegensatz zwischen liberalen und konservativen Werthaltungen. Gleichzeitig sticht Waukesha wahlempirisch doch noch ein Stück hervor. Die politischen Demarkationslinien zwischen City und Suburb verlaufen in der „Milwaukee Metropolitan Area“ jedenfalls extrem, zumindest für die Verhältnisse des Mittleren Westens. Gewiss sind auch Chicago, Detroit oder Cleveland in den Innenstädten stärker demokratisch, in den Suburbs tendenziell republikanisch. Doch gibt es dort auch außerhalb der Innenstädte demokratisch dominierte Wohnviertel, während die Demarkationslinien in der Milwaukee-Region wie mit dem Lineal gezogen erscheinen und dabei eher an die Metropolregionen des Südens und Südwestens der USA wie Atlanta oder Charlotte erinnern. ${ }^{62}$

Viele Suburbs im Osten und auch im Mittleren Westen der USA sind sogar im Zeitverlauf weniger republikanisch geworden, während Waukeshas „Zug nach rechts" weiter ungebremst scheint. Teilweise lässt sich dies durch die noch etwas schärferen ethnischen Segregationslinien erklären. In vielen Statistiken gilt die Milwaukee-Region als eine der ethnisch segregiertesten in den gesamten USA. ${ }^{63}$ In Waukesha hat so gut wie keine Surbanisierung durch Afro-Amerikaner stattgefunden, die weiterhin in den Innenstadtvierteln nahe Downtown konzentriert bleiben.

61 Wisconsin Republican Hotbed Running Out of Water, in: Daily Kos, 19. Oktober 2013, abrufbar unter: http://www.dailykos.com/story/2013/10/19/1248963/-Wiscon sin-Republican-Hotbed-Out-of-Water (zuletzt abgerufen am 09.12.2014).

62 Vgl. die Analyse von Craig Gilbert: Democratic, Republican Voters Worlds Apart in Divided Wisconsin, in: Milwaukee Journal Sentinel vom 3. Mai 2014: http://www. jsonline.com/news/statepolitics/democratic-republican-voters-worlds-apart-in-divided -wisconsin-b99249564z1-255883361.html (zuletzt abgerufen am 05. Juni 2015).

63 Tatsächlich gibt es hierzu eine verwirrende Vielfalt von Statistiken, die je nach Messmenthode zu unterschiedlichen Ergebnissen kommen; Milwaukee jedoch rangiert in allen Statistiken weit vorne. Vgl. für einen zugänglichen Überblick Nate Silver: The Most Diverse Cities are often the most Segregated, http://fivethirtyeight. com/features/the-most-diverse-cities-are-often-the-most-segregated/ (zuletzt abgerufen am 15.07.2015). 
Noch etwas Anderes mag schließlich eine Rolle spielen: Waukeshas ökonomische Erfolgsgeschichte, die dazu führte, dass der Ort einem anderen Rhythmus folgt als dieses bei typischen Schlafstädten, oder, wie es in den USA heißt, ,bedroom communities“ der Fall ist. Ursprünglich hatte man die I-94 gebaut, damit die Menschen, die in Waukesha wohnten, schneller und einfacher nach Milwaukee pendeln konnten. Doch wer heute die Interstate befährt, der wird feststellen, dass der Verkehr in beide Richtungen fließt: mittlerweile fahren ebenso viele Menschen von Milwaukee nach Waukesha zur Arbeit wie andersherum und in diesem Fall wird solche Alltagsempirie offenkundig von der Statistik bestätigt. ${ }^{64}$ Es lässt sich annehmen, dass auch dieser Grund ursächlich für die besonders scharfen Gegensätze zwischen beiden Orten ist. Denn zum einen verstärkt es die Anschauung in Waukesha, von der Stadt eigentlich nicht nur autark zu sein, sondern sie ganz im Gegenteil auch noch zu subventionieren. Schließlich, so etwa der „County Executive“" (vergleichbar mit einem deutschen Landrat) von Waukesha, der Republikaner Dan Vrakas, erhalte man für jeden erwirtschafteten Dollar, den man der Landesregierung nach Madison schicke, gerade einmal 30 Cent zurück, während Milwaukee für jeden Dollar 1,21 Dollar zurückbekomme. Würden die Politiker in Milwaukee begreifen, wer hier wen finanziere, dann müsste das leidige WasserProblem eigentlich sofort gelöst sein: „The reality is, if they really understood those numbers, they'd be running out here with a water source and say: ,Here you go. And thank you by the way for sending all your tax money into our school system! "“65 Und noch eine Konsequenz hat die Tatsache, dass viele Bewohner Waukeshas im County selbst ihren Arbeitsplatz haben: Es verstärkt die Entfremdung der Stadt gegenüber, die man jetzt nicht einmal auf dem Weg zum Arbeitsplatz anzusteuern hat. Die Erfahrung mit den Realitäten urbanen Lebens gehen auf diese Weise immer weiter verloren - was wiederum erklärt, dass unter vielen in Waukesha wahre Horrorgeschichten über Milwaukee kursieren, die die wahren Verhältnisse in der Stadt bisweilen grotesk übertreiben.

Waukeshas Geschichte ist ohne Milwaukee eben nicht zu verstehen. Schon die Zahlen des Internal Revenue Service zeigen, dass über die Hälfte derjenigen, die in den letzten Jahrzehnten nach Waukesha einwanderten, tatsächlich aus Milwaukee County kamen. Eine Überraschung ist das nicht gerade.

Doch bei aller unbestreitbaren Erklärungskraft des „White Flight“", bleibt da eine interpretatorische Leerstelle. Denn ja: große Teile der weißen Mittelschicht zieht es aus Milwaukee in die anliegenden Suburbs von Waukesha County - aber

64 Gespräch mit dem Verwaltungsdirektor von Waukesha County, Norm Cummmings, 5. Oktober 2012.

65 Gespräch mit dem County Executive von Waukesha County, Dan Vrakas, am 17. Mai 2012. 
eben nicht alle und schon gar nicht, ohne dass dabei nicht ein Muster erkennbar wäre. Die Gleichung ist schon deswegen nicht so einfach, weil Milwaukee zum Zeitpunkt des Beginns des Exodus ja alles andere als ein Hort des Konservativismus ist. Im Gegenteil: Kaum eine andere Stadt in den USA kann sich einer so dezidiert progressiven Geschichte rühmen wie Milwaukee. Von 1916 bis 1940 und dann noch einmal von 1948 bis 1960 wird die Stadt von einem sozialistischen Bürgermeister regiert, gilt überdies als die Stadt mit dem höchsten gewerkschaftlichen Organisationsgrad in den gesamten USA. Das letzte Mal, dass ein Republikaner die Stadt regierte, war hingegen 1908 - als innerhalb der Partei in Wisconsin freilich noch der progressive Flügel tonangebend war.

Als daher der Prozess der Suburbanisierung in den 1950er Jahren Fahrt aufnahm, waren keineswegs alle davon überzeugt, dass Waukesha hierdurch zwangsläufig stärker republikanisch werden würde. Anfangs spekulieren die Demokraten im Ort auf eine ganz andere Entwicklung. Denn schließlich: Waren nicht viele aus der weißen Mittelschicht, zumindest noch in den 1960er und 1970er Jahren, Gewerkschaftsmitglieder? Musste der Zuzug aus der linken Hochburg Milwaukee das County nicht im Gegenteil „blau“ einfärben? Richard Congdon, der viele Jahre dem versprengten Haufen von Demokraten in Waukesha als Vorsitzender vorstand, erinnert sich jedenfalls, dass diese Hoffnung lange überwog. Das es anders kam, dafür hat Congdon einen nicht ganz ernst gemeinten Erklärungsvorschlag: „And then they breath the air and all of a sudden they became Republicans!

Wie wir im weiteren Verlauf noch sehen werden, ist Congdons Mutmaßung gar nicht so abwegig, auch wenn das mit dem Sauerstoffgehalt der Luft wohl nichts zu tun hat: tatsächlich veränderten sowohl Dane als auch Waukesha County all jene die dort hinzogen. Doch entscheidender war zunächst einmal, wer überhaupt kam. Und auch hier liefern die Daten aus der Dane-Waukesha-PolarizationStudy (DWP) entscheidende Hinweise. Wie auch im Fall von Dane County lässt sich in den Einwanderungsprofilen ein klares Muster der Parteiidentifizierung erkennen, wenngleich etwas abgeschwächter.

66 Gespräch mit Richard Congdon, in den 1990er Jahren Vorsitzender der Demokraten in Waukesha County, 21. September 2012. 
Abbildung 9: Parteiidentifikation der movers nach Waukesha County seit 1976

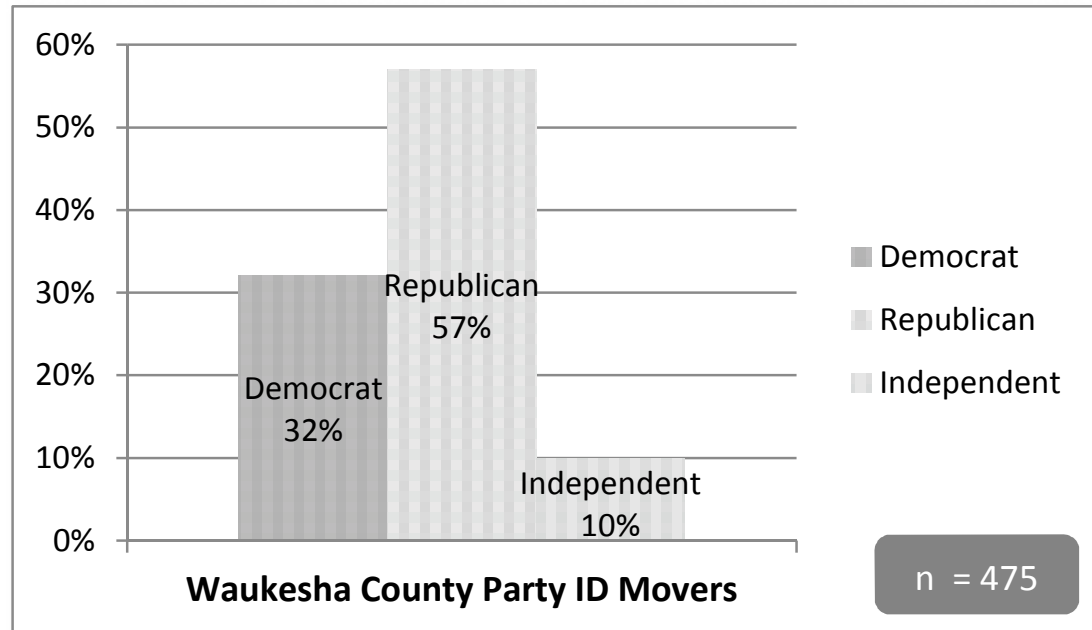

Quelle: Eigene Darstellung, Daten der DWPS

Abbildung 10: Parteiidentifikation der movers nach Waukesha County nach Herkunftscounty

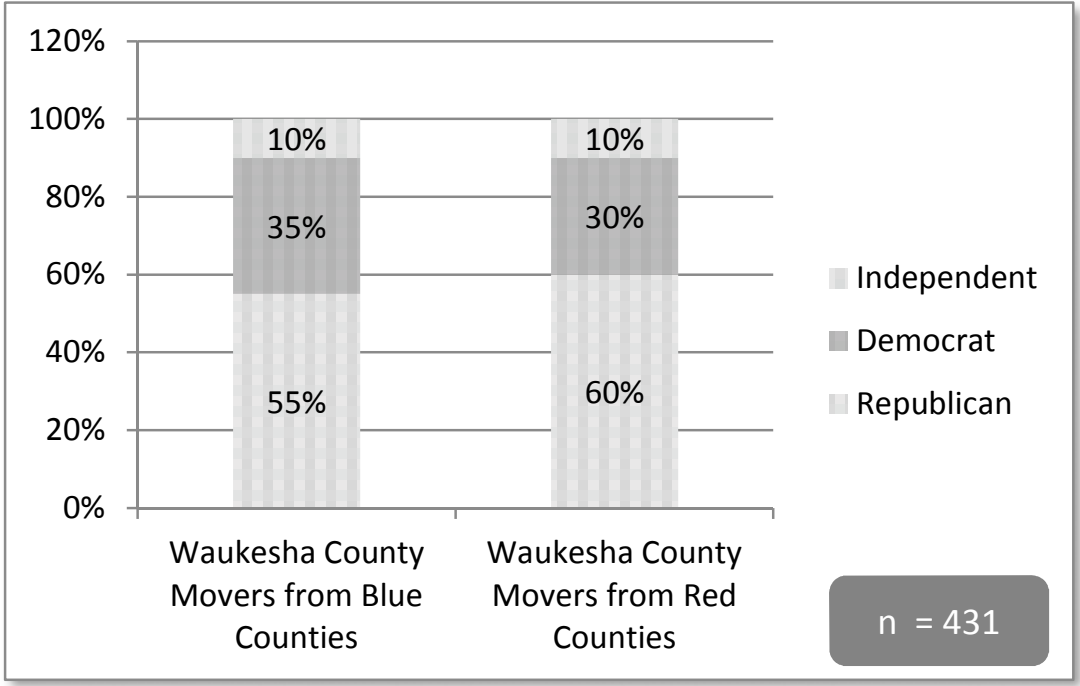

Quelle: Eigene Darstellung, Daten der DWPS 
Zwischen 1976 und 2013 waren 57\% der Zugezogenen Republikaner, 32\% Demokraten und nur 10\% „Independents ${ }^{\text {“ }}{ }^{67}$ Auch im DWPS-Sample kam die Hälfte der Zugezogenen nach Waukesha aus Milwaukee County. Auch von ihnen waren die meisten Republikaner. Freilich zeigt sich auch bei Waukesha ein Muster, dass zuvor schon bei Dane County zutage getreten war: Letzten Endes spielte es keine große Rolle, woher die Zugezogenen kamen: immer ist der Anteil der Republikaner unter ihnen größer. Um es präzise zusammenzufassen: der „White Flight“ nach Waukesha ist vor allem ein „Republican Flight“.

Auch hier gilt: Es dürfte wohl eher eine Minderheit sein, die bei der Wahl des Wohnortes direkt nach politischen Erwägungen vorgeht - obwohl es zweifelsohne auch das gibt. Insbesondere unter den politischen Aktivisten in Waukesha, denen diese Frage in der Studie stets gestellt wurde, gilt es als geradezu unvorstellbar, in der Demokraten-Hochburg Madison zu leben. Für einen Besuch am Capitol sei die Stadt vielleicht einen kurzen Familienausflug wert, sagt etwa die Tea-Party Republikanerin Janel Brandtjen. Aber aufgrund des politischen Klimas würde sie dort kaum leben können, die Stadt ist praktisch feindliches Territorium. „You got to be guarded in what you say. If you go for dinner, we all kind of huddle in. Because the last thing I need is somebody to go nuts on me." ${ }^{" 68}$

Dennoch ist auch hier davon auszugehen, dass die meisten Menschen keinen so expliziten Wert auf Politik legen. In Waukesha antworteten in der DWPS ebenfalls nur $22 \%$ der Befragten, dass es ihnen ,wichtig“ oder ,sehr wichtig“ sei, in einer Nachbarschaft zu wohnen, in der andere ihre politischen Ansichten teilten, die Werte waren damit geringer als bei Bürgern, die nach Dane County gezogen waren. Davon abgesehen allerdings sind andere Ergebnisse aus der DWPS für die Frage nach wichtigen Faktoren bei der Wahl des Wohnortes in Waukesha beinahe spiegelverkehrt. Hier war es z.B. für 49\% der Republikaner ein „wichtiger“ oder „sehr wichtiger" Faktor der Umzugsentscheidung, dass in ihrer Nachbarschaft an Feiertagen, wie dem 4. Juli, die Flaggen gehisst werden und Patriotismus offen gezeigt wird - in Madison fand das nur ein Bruchteil der Demokraten wichtig. Auf die Möglichkeit hingegen, fußläufig in der Nähe von Geschäften oder Restaurants zu leben, verzichtet man in Waukesha liebend gern: gerade einmal 24\% der Befragten legte darauf Wert und auch eine gute öffentliche Infrastruktur mit Fahrradwegen, öffentlichem Nahverkehr oder öffentlichen Bibliotheken war deutlicher weniger Leuten wichtig als in Dane County. Dafür gaben im Vergleich mit

67 Auch hier blieb bei einer multivariaten Analyse der Einfluss der Parteiidentifikation auf das Umzugsverhalten sehr signifikant, vgl. näher Lütjen/Matschoß, Ideological Migration in Partisan Strongholds, a.a.O.

68 Gespräch mit Janel Brandtjen, 2. November 2012. 
den Demokraten in Dane County deutlich mehr Republikaner in Waukesha an, dass ihnen eine Kirche in der Nachbarschaft wichtig sei, nämlich annährend $60 \%$, ( $28 \%$ von ihnen fanden dieses sogar ,sehr wichtig“). In Dane County waren es unter Demokraten nur 22\%.

Hier übrigens stößt man auf eine interessante Tatsache: Demokraten in Dane County und Demokraten in Waukesha County antworteten auf die gleichen Fragen bisweilen sehr unterschiedlich. Bei der Frage nach der Wichtigkeit einer Kirche in der Nachbarschaft war das sehr deutlich: Immerhin 26\% der Demokraten in Waukesha fand dieses „sehr wichtig“, aber nur 7\% der Demokraten in Dane County. Das weist, wie im nächsten Kapitel noch genauer beleuchtet wird, auf bestimmte Anpassungseffekte der Minderheiten hin, aber auch darauf, dass verschiedene Arten von Demokraten an beide Orte zogen.

Abbildung 11: Präferenzen für „,konservative“ Lebensstilindikatoren nach Parteianhängern: Antwort , important" oder ,very important“.

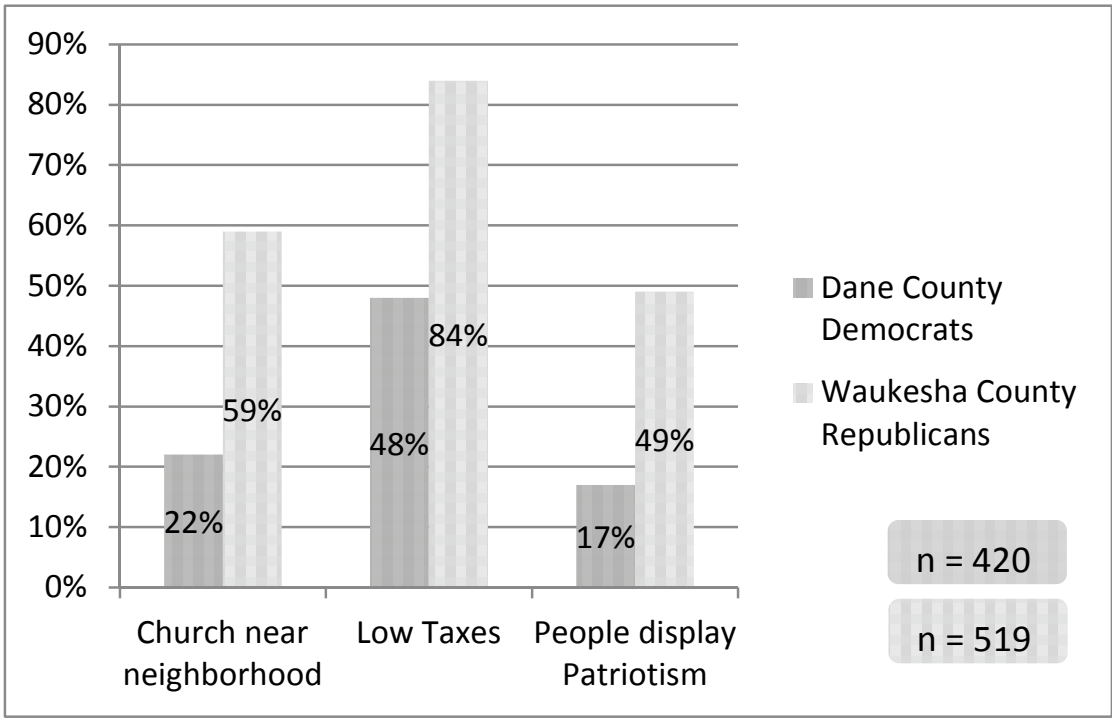

Quelle: Eigene Darstellung, Daten der DPWS.

In Bezug auf ihre Magnetwirkung auf Angehörige der Mehrheitskultur ähneln sich Dane und Waukesha also. Dabei kristallisiert sich deutlich heraus, welche unterschiedlichen Attribute Demokraten und Republikanern an ihren jeweiligen Wohnorten wichtig sind. Bei der Frage nach der Abstoßungswirkung, also der Frage danach, inwiefern die Wahrscheinlichkeit eines Wegzugs bei der Minderheitskul- 
tur größer ist, unterscheiden sich die beiden Counties jedoch markant. Zwar differiert auch die Zufriedenheit mit dem Wohnort zwischen den Anhängern beider Parteien recht deutlich: 71\% der Republikaner sagen, sie seien „sehr zufrieden“ damit, in Waukesha zu leben, während es bei den Demokraten „nur“ 51\%. sind. Bei der Frage nach der Wegzugsabsicht unterscheiden sich beide Gruppen hingegen kaum. Erst bei der Folgefrage - aber das überrascht wenig - treten wieder Differenzen zu Tage: immerhin 27\% der Demokraten, die eine abstrakte Wegzugsabsicht ausgedrückt hatten, sagten, dieser Wunsch habe mit politischen Gründen zu tun. Insgesamt zeigen sich die Abstoßungseffekte in Waukesha dennoch viel schwächer als in Dane County. Oder um es ein wenig plastischer auszudrücken: Offenkundig empfinden Republikaner in Dane County einen größeren Leidensdruck als Demokraten in Waukesha.

Diese Ergebnisse sind kein Zufall und werden sich später, wenn es um die „Soziologie der Hochburg“ geht, noch in vielen anderen Daten spiegeln: im urbanen, dichteren und politisch hoch aktivierten Madison ein Republikaner zu sein, sorgt für eine andere Wahrnehmung und auch Sichtbarkeit von Fremdheit, als ein Demokrat im suburbanen, viel anonymeren und extrem privatistischen Waukesha zu sein.

Abbildung 12: Zufriedenheit mit Waukesha County als Wohnort nach Parteianhängern: Antwort ,, Sehr zufrieden “

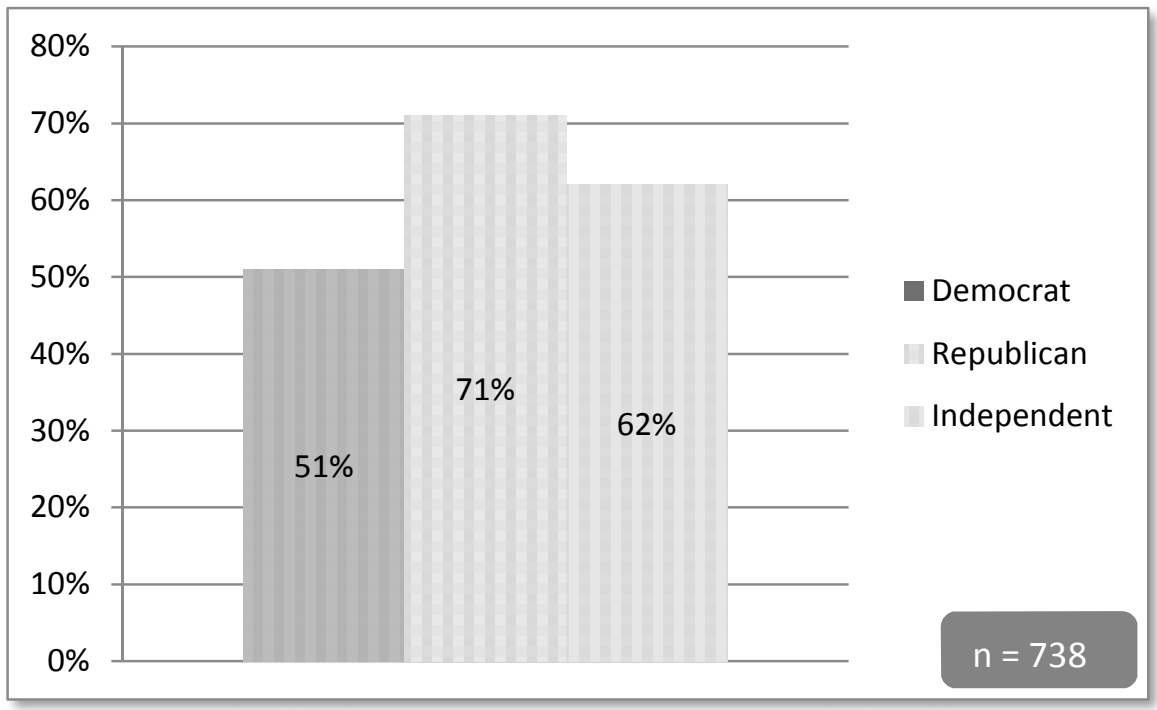

Quelle: Eigene Darstellung, Daten der DWPS 
Aus diesem Zusammenspiel von Siedlungsstruktur und den Politik- und Lebensstilpräferenzen der Neuankömmlinge, entsteht ein sozialer Raum sehr spezifischer Art, dessen Struktur nur bedingt mit europäischen Vorstellungen zu begreifen ist. Es sind exakt Orte wie Waukesha, die die extreme Staatsfeindschaft der republikanischen Parteibasis erklärbar machen: American Suburbia ist ein Raum radikaler Privatheit, der darauf ausgerichtet erscheint, spontane Begegnungen so weit wie möglich zu vermeiden: Man sieht dort so gut wie keine Fußgänger, kaum Fahrradfahrer, die Herrschaft des Automobils ist tatsächlich total. Insbesondere die neueren Häuser haben praktisch durchgängig eine Garage, in der Platz für mindestens zwei Autos ist und außerdem einen direkten Durchgang von dort ins Haus: wer will, der braucht seine Nachbarn im Grunde niemals zu sehen. Daraus entsteht ein Rhythmus des Lebens, der nicht unbedingt die Einsicht fördert, dass die Interessen von Fremden miteinander verbunden sein könnten oder es Sinn machen würde, für diese auch noch finanzielle Transfers zu leisten. ${ }^{69}$

Waukesha County ist auch deswegen ein so überaus erhellendes Beispiel für den Zusammenhang zwischen Siedlungsstruktur und Weltanschauung, weil es, anders als Dane County, in seiner Struktur etwas heterogener ist. Inmitten dieses tiefroten Counties gibt es nämlich einen zumindest leichtblauen Fleck: Die „City of Waukesha“, in der bei Präsidentschaftswahlen Demokraten und Republikaner in den letzten Jahren beinahe gleich stark waren. Von 2006 bis 2010 hatte Waukesha, eine Stadt von rund 70.000 Einwohnern, gar einen Bürgermeister, der überall als Demokrat bekannt war: Larry Nelson. Einerseits war das gewiss eine Kuriosität. Selbst das „Milwaukee Magazine“, für das die Suburbs ansonsten eine dunkle terra incognita sind, schickte damals einen Reporter nach Waukesha, um herauszufinden, was es mit einem demokratischen Bürgermeister in diesem Treibhaus konservativer Ideologie auf sich hatte. Nelson, so stand es später im Text, wirke in Waukesha wie ein „ham sandwich at a bar-mitzvah." ${ }^{\text {“70 }}$ Es ist ein lustiger Vergleich, aber ganz richtig ist er eigentlich nicht: Die City of Waukesha unterscheidet sich vom Rest des Countys, und um das zu erkennen, braucht man eigentlich keine Wahltabelle. Selbst die Tatsache, dass es in Waukesha eine kleine LatinoGemeinde gibt, ist nicht so erhellend wie ein einfacher Besuch des Ortes selbst. Waukesha ist zwar eine beschauliche Stadt und verströmt den Charme von Small-

69 Vgl. sehr kritisch, für die mentalitätsprägende Kraft von Suburbia: Thad Williamson: Sprawl, Justice, and Citizenship. The Civic Costs of the American Way of Life, New York 2009.

70 Vgl. Eric Gunn: The Happy Warrior, in: Milwaukee Magazine, 28. September 2007, http://www.milwaukeemag.com/2007/09/28/TheHappyWarrior/ (zuletzt abgerufen am 16.06.2015). 
Town-America, erinnert fast ein wenig an „Main Street“ in Disneyland, die Verkörperung eines heilen 1950er-Jahre Amerikas. Aber ein Stück Urbanität ist doch vorhanden, wenn auch nur für vier Straßenzüge, mit einigen Cafés, Restaurants, einer Kunstgalerie und einem Tattoo-Studio.

Damals, im Frühjahr 2012 (während meines ersten Aufenthalts in Wisconsin vom März bis Juni 2012 war ich eigentlich in Madison ,stationiert“"), hatte mich mein erster Besuch in die City of Waukesha geführt. Es war ein kleiner Schock, gefolgt von einer mittelschweren Panik, ob die Fallauswahl vielleicht verkehrt gewesen war: so hatte ich mir diese Hochburg des amerikanischen Konservativismus wahrlich nicht vorgestellt. Als ich ein paar Monate später Don Taylor, dessen „Waukesha State Bank“ immerhin im Zentrum der Stadt ihren Sitz hat, darauf ansprach, dass die Stadt Waukesha, wenn auch nur vier Straßenzüge lang, fast ein wenig wie Madison aussehe, da entgegnete er mir: „Ouch! Thank God I live outside the City. ${ }^{\text {"71 }}$ Aber das eben ist der Punkt: Die Stadt Waukesha ist kein Magnet für die Menschen in der Umgebung, ein Ort, zu dem es sie zum Einkaufen oder für Veranstaltungen ziehen würde. Selbst der konservative Blogger James Wigderson, der in der Stadt wohnt, erzählt, dass viele seiner Bekannten ihn nicht gerne besuchen kämen: aus Angst sich dort zu verfahren, denn immerhin gibt es zwei Einbahnstraßen und dann und wann eine echte Kurve. ${ }^{72}$ Die City of Waukesha ist so etwas wie eine Enklave in der Enklave.

So ist selbst innerhalb des Counties offensichtlich, dass unterschiedliche soziale Räume unterschiedliche Vorstellungen gesellschaftlichen Zusammenlebens hervorbringen. Um die eifernde Staatsfeindschaft vieler Bewohner Waukeshas zu ergründen, braucht man nicht einmal nach den Einstellungen zu den in der Regel aus Bundesmitteln finanzierten Sozialprogrammen zu fragen, für die es in Orten wie Waukesha nur wenige Sympathien gibt. Erhellend sind hier vor allem die Diskussionen um ein klassisches Thema der Lokalpolitik: der öffentliche Nahverkehr. Kaum ein anderes Thema ist in der Lage, größere Emotionen in Waukesha hervorzurufen. Hinter vorgehaltener Hand geben auch viele Republikaner in Waukesha zu, dass die mangelnden Transportmöglichkeiten zwischen Milwaukee und Waukesha ein sehr großes Problem für weiteres Wachstum sind. Viele niedrig qualifizierte Arbeitskräfte aus Milwaukee haben oft keine Möglichkeit, mit einem eigenen Auto zur Arbeitsstelle zu fahren. Allein: offensiv einsetzen darf sich kein Republikaner für den Bau einer Straßenbahn oder einer Metro, die von Milwaukee Downtown wenigstens in die City of Waukesha führt - politisch könnte er gleich

71 Gespräch mit Don Taylor, 26. September 2012.

72 Gespräch mit James Wigderson, 29. September 2012. 
alle weiteren Ambitionen begraben, das Thema gilt als „toxisch““ ${ }^{73}$ Öffentliche Investitionen, also „taxpayer's money“, in ein System zu stecken, das man selber niemals nutzen würde - schon das leuchtet vielen nicht so recht ein. Überdies spielt auch hier wieder die Sorge eine Rolle, dass die Stadt Milwaukee samt ihrer sozialen Probleme plötzlich näher an Waukesha heranrücken könnte.

Doch da ist noch mehr, es gibt eine noch tieferliegende Schicht von Ängsten. Jede Diskussion zum Thema wird sofort ideologisch aufgeladen. „Public Transportation", das sei, so der konservative Sound des Widerstandes, ein weiterer Trick der liberalen Elite, durch „social engineering“ die Menschen zusammenzuhorden, um sie sodann ihrer Individualität zu berauben. Menschen in Zügen sind, so geht diese Erzählung weiter, leichter zu kontrollieren und zu manipulieren als Menschen in ihren eigenen Autos - und damit entspreche der Ausbau des öffentlichen Nahverkehrs eben genau der Strategie liberaler Bevormundung und des „Kollektivismus“ ${ }^{74}$ Wisconsins Gouverneur, Scott Walker, diesen kongenialen Sohn der Suburbs, trogen seine Instinkte daher nicht, als er Anfang 2011 als eine seiner ersten Amtshandlungen den fast schon beschlossenen Bau einer Zugstrecke von Chicago über Milwaukee und Madison bis nach Minneapolis in letzter Sekunde stoppte - und das obgleich das gesamte Geld für den Bau der Strecke aus Bundesmitteln gekommen wäre. Wer Züge generell für die falsche Form der Fortbewegung hält, wer glaubt, dass sie den Charakter der Menschen korrumpieren und letztlich dem „American Way of Life“ widersprechen, der bleibt auch unter solchen Voraussetzungen seinen Prinzipien treu.

Darin steckt eine tiefe Ironie: Während die Liberalen von Dane County Suburbia für einen Ausbund an gleichförmiger Monotonie halten, wo ein Tag wie der andere ist, zelebrieren die Konservativen von Waukesha den gleichen Raum als Hort individueller Selbstentfaltung. Denn was könnte größere individuelle Freiheit bedeuten, als die rasche und reibungslose Fortbewegung mit dem Auto? Und was bietet mehr Wahl als die riesigen Einkaufstempel der Malls, in denen man alles was man braucht, und das in jeder nur denkbaren Variante, an einem Ort kriegen kann? Und wie kann man es vorziehen, mit anderen Tür an Tür zu leben, wenn man selbst mehr als genügend „ellbow space“ hat?

73 Gespräch mit Norm Cummings, 5. Oktober 2012.

74 Vgl. z.B. geradezu paradigmatisch die Kritik an öffentlichen Verkehrsmitteln bei George Will: Why Liberals Love Trains, in: Newsweek, 27.02.2011, http://www.newsweek.com/will-why-liberals-love-trains-68597 (abgerufen am 21.03.2011). 
Warum solle er wohl in der Stadt leben wollen, lachte der Vorsitzende der Republikanischen Partei von Waukesha, John P. Macy, den Verfasser bei einer entsprechenden Frage einmal kopfschüttelnd aus. „I have 15 acres on a lake!‘775

Individualität, dieser essentielle Bestandteil des „American Creed“ - das ist tatsächlich ein Wert an sich an beiden Orten, nur, dass diese Individualität von den jeweiligen kulturellen Kerngruppen ganz anders mit Leben gefüllt wird. In Dane County bedeutet sie, jeden Tag - theoretisch - eine andere Erfahrung machen zu können, offen zu sein für andere kulturelle Kontexte oder - theoretisch die Begegnung mit „Fremden“ zu erleben. In Waukesha bedeutet Individualität vor allem Freiheit, Unabhängigkeit, ein autarkes Leben mit so wenigen Einschränkungen wie möglich zu führen. Es ist oft gesagt worden, dass Suburbia vor allem eine Versinnbildlichung der Konsumgesellschaft sei, aber diese zumeist von den Kritikern suburbaner Lebensstile vorgebrachte Kritik verkennt, dass auch der prototypische Lebensstil von Madison oft genug durch Konsum ausgedrückt wird. Die Liberalen von Dane County sind in der Regel gewaltige Verächter von FastFood-Ketten, natürlich, weil die dahinterstehenden Firmen nicht nachhaltig produzieren und für ihre Weiderinder der Regenwald abgeholzt wird oder ganz generell, weil es sich bei ihnen um multinationale Großunternehmen handelt. Aber Fast-Food-Restaurants sind für sie auch der Inbegriff des Gipfels der kulinarischen Monotonie, Symbol eines Lebens in uninspirierter Langeweile. Indes: Die Bewohner Waukeshas verstehen gar nicht, was daran eintönig sein soll, zwischen Dutzenden solcher Ketten wählen zu können. Ist das nicht mehr Auswahl, mehr Optionen als ein Mensch überhaupt in kurzer Zeit durchtesten kann?

Auch wenn Suburbia eigentlich eine Erfindung des 20. Jahrhunderts ist: die Weltsicht vieler Bürger von Suburbia speist sich aus viel älteren Mentalitäten, aus den Ur-Mythen Amerikas, die durch die Suburbanisierung der USA - und fraglos auch durch die politische Instrumentalisierung seitens des amerikanischen Konservativismus - reaktualisiert und perpetuiert wurden. Zwar ist die Abscheu gegen die vermeintliche Hässlichkeit, den Schmutz und den Lärm der Großstadt noch kein speziell amerikanisches Phänomen, sondern Teil einer auch andernorts anzutreffenden Kritik an der Moderne. Doch schon bei Thomas Jefferson war die Glorifizierung des Landlebens und die Huldigung des amerikanischen „Yeoman“ zugleich eine Absage an die soziale Kontrolle der europäischen Städte, die sich mit Amerikas Freiheitsversprechen eben nicht vertrug, diente also von Anfang an als Mechanismus der Abgrenzung. ${ }^{76}$

75 Gespräch mit John P. Macy, seit 2014 Chairman der Republikanischen Partei von Waukesha County, 24. September 2014.

76 Vgl. Tom Martinson: American Dreamscape. The Pursuit of Happiness in Postwar Suburbia, New York 2000. Vgl. für die Verwurzelung dieses Denkens im „Frontier- 
Am pointiertesten verdichtet sich diese Art des amerikanischen Exzeptionalismus im Frontier-Mythos: die Begründung des amerikanischen Exzeptionalismus durch die Existenz einer bis ins Ende des 19. Jahrhunderts vorhandenen und stets weiter gen Westen verschobenen Besiedlungsgrenze. Vor allem der Historiker Frederick Jackson Turner hat diese Mythenbildung Ende des 19. Jahrhunderts vorangetrieben: erst im tagtäglichen Zusammenstoß von westlicher Zivilisation und einer wilden, ungezähmten Natur entstünde der Amerikanische Nationalcharakter, jene Mischung aus Wagemut, Unerschrockenheit, Freiheitsliebe und rauem Individualismus, die seine Landsleute von den Europäern unterscheide. ${ }^{77}$ Als Turner 1893 seinen Aufsatz schrieb, hatte die amerikanische Zensus-Behörde gerade erst offiziell erklärt, dass die Frontier aufgehört habe zu existieren: die Besiedlung der USA war damit offiziell an ihr Ende gekommen, der offene Raum war verschwunden. Turner ließ das sorgenvoll in die Zukunft blicken: Was würde mit den USA geschehen, nachdem das Land seinen Exzeptionalismus verloren hatte? In gewisser Weise sollte sich die Sorge als unbegründet erweisen, da Amerikas Wertehaushalt auch in der Zukunft stark differieren würde. Als Idee lebte die Frontier weiter, nicht nur in der Populärkultur wie im Genre des Westerns. Amerika suchte sich neue physische Grenzen - etwa das Ausgreifen in den Weltall, von John F. Kennedy als „New Frontier“ bezeichnet. Vor allem aber verlagerte sich die Frontier nach innen: als imaginäre und immer neu zu überschreitende Grenze des Menschenmöglichen. Ansonsten wird in Ermangelung anderer Grenzerfahrungen vor allem der amerikanische Unternehmer zum neuen Helden des Frontier-Mythos. Mit den unter amerikanischen Rechten vergötterten Romanen Ayn Rands und ihren heroischen, unbeugsamen Unternehmer-Charakteren ist dieser Frontier-Mythos dann schließlich vor allem vom amerikanischen Konservativismus für seine Zwecke vereinnahmt worden, wie wir bereits am Beispiel Barry Goldwaters gesehen haben.

Diese Frontier-Mythologie ist in Waukesha sehr lebendig: der generelle Stolz darauf, wie die Landschaft stets weiter besiedelt wird und die völlige Abwesenheit jeden Zweifels an der Nachhaltigkeit dieser Entwicklung. Mehr noch: die Überzeugung, dass es eine Verpflichtung sei, diese Entwicklung weiter fortzuführen, weil sie davon zeugt, dass die Zukunft weiter ein offener Horizont ist. Als europäischer Beobachter mag man sich wundern, wenn man sieht, dass eine 1980er-

Mythos" auch Paul Nolte: Was ist Demokratie? Geschichte und Gegenwart, München 2012, S. $201 \mathrm{ff}$.

77 Frederick Jackson Turner: The Frontier in American History, a.a.O.; Vgl. auch die Darstellung der amerikanischen Frontier, hier besonders im Vergleich zu anderen Siedlergesellschaften, bei Jürgen Osterhammel: Die Verwandlung der Welt. Eine Geschichte des 20. Jahrhunderts, München 2011 (Sonderausgabe), S. 465-501. 
Jahre Mall wie eine traurige Ruine zwischen zwei Kreuzungen steht - und zwar ganz einfach, weil eine Meile weiter ein besseres, schöneres Einkaufszentrum aufgemacht hat und man fragt sich, wer hier - wenn überhaupt - eigentlich die Baugenehmigungen erteilt. Aber den typischen Bewohner von Suburbia ficht das alles nicht an: der Treck zieht eben weiter und die alten Siedlungen werden dabei einfach zurückgelassen.

Dabei geht es, man braucht es kaum zu erwähnen, um eine Simulation des Frontier-Lebens. Waukesha ist nicht mehr wirklich ländlich und schon gar nicht mehr bedeutet es wilde Natur - anders noch als in den 1830er Jahren, als Tocqueville seine Reise bis in das heutige Wisconsin führte, wo damals tatsächlich die Besiedlungsgrenze endete. Inszeniert wird das suburbane Leben aber doch häufig genug so, als ginge es darum, in einer rauen Umwelt zu überleben. Da ist nicht nur der festungsartige Baustil mancher Häuser, vor allem der gewaltigen „McMansions“. Interessant ist auch, in welcher Art viele dieser Wohngebiete auf dem Immobilienmarkt vermarktet werden, tragen sie doch Namen wie „Deer Creek“, „Prairie Meadow“ oder „Fox Chase“. Und obgleich Wisconsins harte Winter fraglos robuste Fortbewegungsmittel verlangen: ein Zufall ist es natürlich nicht, dass in Waukesha wie anderswo in Suburbia SUVs und Pick-Up Trucks das Straßenbild so vollkommen dominieren: kleine, rollende Festungen mit bisweilen grotesk großen Offroadreifen, ganz so, als würden sie nicht etwa auf Asphalt fahren, sondern als müssten sie auf unbefestigten Wegen den Siedlertrecks der Pioniere noch den Weg frei fahren. Es ist diese Mentalität, auf die republikanische Politiker stets zuverlässig zählen können bei ihren Attacken gegen eine vermeintlich bevormundende „liberale Elite“, die meint, sie könne anderen vorschreiben, wie sie zu leben haben.

So trifft sich in Waukesha das alte Versprechen der Frontier auf eine autoritätsfreie Ordnung mit dem von der konservativen Bewegung orchestrierten Widerstand gegen Washington, den Steuer-Zwangs-Staat und die Zumutungen des „Big Government“. 



\section{Die Soziologie der Hochburg}

\section{„NO ONE I KNOW VOTED FOR SCOTT WALKER“ - SoZIALE HOMOPHILIE UND NETZWERKHOMOgENITÄT}

Würden die Konservativen von Waukesha eine Karikatur des typischen Madison Liberal zeichnen - es kämen wohl Ron Dole und Katie Songer aus Madison dabei heraus. Das kinderlose Ehepaar in den Mitdreißigern hat sich 2002 bei der Freiwilligen-Arbeit für den Friedenschor in einem kleinen Dorf im Hochland Tansanias kennengelernt. Bald darauf ziehen sie nach Madison, wo sie ihr Studium beginnen. Die Stadt wird für das Paar schnell zur Heimat. Nach dem Studium beginnen die beiden, für das „Wisconsin Natural Resource Department“ zu arbeiten und auch in ihrer Freizeit sind sie als engagierte Umweltschützer tätig. Sie sind wohl das, was Amerikas Konservative despektierlich als „,tree hugger“ bezeichnen. Katie wird kurz darauf beginnen, als freie Schriftstellerin zu arbeiten, um in einem autobiographischen Roman das Verhältnis zu ihrem Vater aufzuarbeiten. Im Sommer 2014 ziehen sie weiter nach Portland, Oregon, einem anderen Fluchtpunkt liberaler Sehnsüchte des Landes. Keine Frage: Ron und Katie sind Teil des „Big Sort."

Und doch: In manchem unterscheiden sie sich vom liberalen Mainstream der Stadt. Sie wohnen in Madisons Lower East Side, in einer Seitenstraße entlang der ebenso belebten wie beliebten Williamson Street mit ihren Öko-Bäckereien, Cafés und Tatoostudios. In diesem liberalen Epizentrum der Stadt hat Barack Obama 2012 mit über 90\% der Stimmen gewonnen. Sie haben sich diesen Ort so ausgesucht, aber irgendwann wird es ihnen in der eigenen Echo-Kammer zu viel: Es gibt in ihrem Bekanntenkreis schlicht keinen einzigen Republikaner, selbst Independents sind rar gesät. 
Niemand den sie kennen, hat 2008 John McCain gewählt oder 2010 für Scott Walker gestimmt. Um das zu ändern, schreiben sie am 8. November 2010, sechs Tage nach Walkers Wahlsieg, einen Brief an die lokale Sektion der Republikanischen Partei von Dane County. ${ }^{1}$

Sie fragen an, ob es nicht Republikaner gäbe, mit denen sie in einen informellen Austausch treten könnten. Es ist ein merkwürdig gekünsteltes und gestelztes Vorhaben, aber in dem liberalen Mikrokosmos in dem Ron und Katie wohnen, ist es womöglich tatsächlich der einzige Weg, die seltene Spezies konservativer Amerikaner von Angesicht zu Angesicht zu treffen.

Wenig später kommt tatsächlich eine Antwort, die „Partnervermittlung“ war erfolgreich. Ein anderes Ehepaar hat Interesse an einem solchen Austausch: Scott und Carol Grabins, beide eingeschworene Republikaner. Scott ist in gewisser Weise eine kleine Anomalie: Er arbeitet als Softwareentwickler für EPIC in Verona, wo es außer ihm nicht sehr viele Republikaner gibt. Zum Wohnen allerdings sind die Grabins noch ein Stück weiter rausgezogen: nach Mount Horeb, einer ländlichen Gegend etwa 20 Meilen von Madison entfernt. Als man dort im Mai 2012 auf der Terrasse ihres riesigen Grundstücks sitzt, streift ein Reh durch den Garten; die Grabins sind der Stadt wirklich entkommen. Dennoch, ginge es nach Carol, würde die Familie noch weiterziehen: bis nach Waukesha, ein Ort, bei dessen Nennung sie ins Schwärmen gerät, und den sie so ausspricht, als würden dort Milch und Honig fließen. Mit Madison hingegen haben die Grabins nicht besonders viel am Hut, die Stadt ist ihnen zu grell, zu laut, zu unübersichtlich. Während Ron und Katie darüber klagen, dass sie stets nur mit Leuten verkehren, die ihrer Meinung sind, geht es den Grabins, so sagen sie, genau andersherum: sie treffen Liberale ständig und überall. ${ }^{2}$

Die beiden Paare treffen sich fortan ein paar Mal zum Abendessen und man findet allen Unterschieden zum Trotz eine Basis: Es soll nicht darum gehen, den anderen zu überzeugen (was in der Tat ein hoffnungsloses Unterfangen wäre), sondern darum, überhaupt erstmal den Standpunkt des anderen nachzuvollziehen und zu lernen zuzuhören. Ein paar Monate nach dem ersten Treffen entscheiden die Vier, ihrem Austausch einen größeren Rahmen zu geben. Sie gründen ein öffentliches Forum und nennen es „Reach Out Wisconsin.“ Beide Paare mobilisieren ihre liberalen und konservativen Netzwerke und zum ersten Treffen in einer Bar in Madison kommen bereits 30 Leute. Sie haben einen speziellen Zeitpunkt für die Gründung von „Reach Out“ gewählt: Es ist die Zeit der Proteste gegen Scott Walker und den Act 10. Ausgerechnet also im vergifteten politischen Klima des Winters 2010/2011, als liberale Aktivisten einen Belagerungsring um das

1 Gespräch mit Katie Songer und Ron Dolen, 2. April 2012.

2 Gespäch mit Scott und Carol Grabins, 10. Mai 2012. 
State Capitol gelegt haben, beschließen sie, die ideologischen Grenzen zu überwinden. In der hasserfüllten Atmosphäre dieser Monate ist das eine ungewöhnliche Geschichte, für die sich die lokale Presse schnell zu interessieren beginnt, und wenig später berichten landesweit sogar Medien wie National Public Radio über die Treffen. ${ }^{3}$ Bald gibt es jeden Monat ein Treffen, jeweils zu einem vorher ausgewählten Thema mit Gastrednern und in den besten Zeiten kommen über 60 Teilnehmer.

Zögern wir an dieser Stelle den Fortgang der Geschichte um „Reach Out Wisconsin“ noch einen Augenblick hinaus. Interessant ist diese Geschichte zunächst ihrer bloßen Existenz wegen: Sie ist Ausdruck der extremen ideologischen Abschottung zwischen den politischen Lagern in zumindest einer der beiden Hochburgen. Wenn der Austausch mit politisch Andersdenkenden in einer solchen Weise quasi-offiziell organisiert werden muss, dann findet er auf natürlichem Wege offensichtlich kaum noch statt. „Soziale Homophilie“ - so der soziologische Terminus für die alte Volksweisheit von „Gleich und Gleich gesellt sich gern“ ist im Grunde ein natürlicher sozialer Zug des Menschen. Katie und Ron und Scott und Carol sind eher die Ausnahmen, die die Regel bestätigen. Die meisten von uns bringen ihre Zeit damit zu, Gleichgesinnte zu finden und nicht nach jenen Ausschau zu halten, mit denen wir uns streiten können. ${ }^{4}$ Das gilt auch für die Politik, und offenkundig gerade in den USA, wo die Wahrscheinlichkeit einer Unterhaltung über Politik zwischen Menschen unterschiedlicher Parteiidentifikation geringer ist als anderen Ländern. ${ }^{5}$

Doch auch wenn die Vermeidung von Meinungsverschiedenheiten ein Grundcharakteristikum sozialen Verhaltens sein mag: ein Mindestmaß an Dissens sollten Gesellschaften schon auszuhalten bereit sein. Eine der Annahmen über die Konsequenzen des „Big Sort“ lautet daher auch, dass die Herausbildung von ausgeprägten politischen Hochburgen zu einem Prozess der Gruppenpolarisierung führen kann. Gemeint ist damit die Tendenz politisch homogener Gruppen, sich in Richtung ihrer radikaleren Elemente zu entwickeln. Grundsätzlich kann dieser Prozess als gut erforscht gelten: Unzählige Experimente in der Sozialpsychologie haben bestätigt, dass innerhalb von Gruppen, deren Mitglieder bereits alle in eine

3 Vgl. David Shaper: Wisconsinites 'Reach Out' To Heal Partisan Divide, Sendung auf NPR vom 4.Juni 2012, http://www.npr.org/2012/06/04/154305938/wisconsinitesreach-out-to-heal-partisan-divide (zuletzt abgerufen am 14. April 2014)

4 Vgl. hier grundlegend Miller McPherson/Lynn Smith-Lovin/James M. Cook: Birds of a Feather - Homophily in Social Networks, in: Annual Review of Sociology, Vol. 27 2001, S. 415-444.

5 Vgl. Diana C. Mutz: Hearing the Other Side. Deliberative versus Participatory Democracy, Cambridge 2006: S. 49-54. 
bestimmte Richtung argumentieren, im Laufe eines Diskussionsprozesses die Ansichten ,radikalisiert" werden. ${ }^{6}$ Würde man also aus einer politischen Versammlung all jene herausfiltern, die tendenziell für die Todesstrafe plädieren und sie dann einige Stunden getrennt vom Rest und unter sich diskutieren lassen, dann ließe sich relativ sicher voraussagen, dass die einzelnen Teilnehmer hinterher ihre bereits bestehenden Dispositionen verstärkt haben werden. Es gibt verschiedene Erklärungen für dieses Phänomen. Eine lautet, dass die Akkumulation von Argumenten, die allesamt eine bereits vorgefasste Meinung unterstützen, zur Stärkung bzw. Verhärtung dieser Position führen. Eine andere Möglichkeit ist, dass es in solchen homogenen Gruppen keine soziale Prämie mehr gibt für Moderation oder Mäßigung. Die Zuspitzung, Radikalisierung der Gruppenposition hingegen sichert die Akzeptanz anderer Gruppenmitglieder und verleiht soziales Prestige. ${ }^{7}$

Letztlich bleibt es fraglich, inwiefern diese Erkenntnisse aus der Sozialpsychologie in die reale Welt übertragbar sind. Denn jenseits der kontrollierten, geschlossenen Bedingungen von Laborexperimenten ist es faktisch unmöglich, dissonante Informationen einfach vollständig auszuschließen: Vielleicht höre ich im Zugabteil ein Gespräch mit, in dem politische Ansichten geäußert werden, die mit meinen nicht konform gehen; oder vielleicht macht mein Arbeitskollege (tatsächlich findet sich am Arbeitsplatz die höchste Wahrscheinlichkeit, auf konträre politische Meinungen zu stoßen ${ }^{8}$ ) eine abfällige Bemerkung über „meine“ Partei oder „,meinen“ politischen Kandidaten. Lange Zeit hielt man auch die Massenmedien für Einfallstore dissonanter Informationen, da durch sie ja schließlich ein jeder selbst in die Lage versetzt würde, sich Informationen mit geringer Anstrengung und unabhängig von der physischen Lokation zu besorgen ${ }^{9}$ - eine Vorstellung, die allerdings mit der offenkundigen Wende zur Parteilichkeit von Medien-

6 Vgl. ursprünglich zum Konzept der Gruppenpolarisierung: Serge Moscovi/Marisa Zavalloni: The Group as a Polarizer of Attitudes, in: Journal of Personality and Social Psychology, Vol. 12 (2) 1969: S. 125-135; in jüngerer Zeit und mit Blick auf die gegenwärtigen USA: Cass S. Sunstein: Going to Extremes. How Like Minds Divide and Unite, Oxford 2009.

7 Vgl. Lyn M.Van Swol: Extreme Members and Group Polarization, in: Social Influence 4 (3), 2009, S. 185-199.

8 Vgl. Diana C. Mutz/Jeffrey J. Mondak: The Workplace as a Context for Cross-Cutting Political Discourse, in: The Journal of Politics, Vol. 1, Feb. 2006: S. 140-155.

9 Diese Auffassung war auch in den Nullerjahren, also zu Beginn des digitalen Zeitalters, noch vorherrschend. Vgl. auch hier die Arbeit von Diana C. Mutz: Facilitating Communication across Lines of Political Difference: The Role of Mass Media, in: American Political Science Review, Vol. 1 2001: S. 97-114. 
formaten und der beobachteten Tendenz von Medienkonsumenten, kognitive Dissonanzen bei der Informationsbeschaffung möglichst zu vermeiden, äußerst fraglich geworden sein dürfte.

Das sind gewiss gewichtige Argumente und einige der Kritiker der These vom „Big Sort“ haben sie auch gegen Bishop und Cushing ins Feld geführt. Morris P. Fiorina und Samuel J. Abrams argumentieren z.B., dass es auf der individuellen Einstellungsebene keinen wirklichen Unterschied mache, ob Nachbarschaften zunehmend von Demokraten oder Republikanern bevölkert würden. Denn schließlich, so ihr Argument, spielten diese Nachbarschaften in der Lebensrealität vieler Amerikaner eine immer geringere Rolle: die meisten Amerikaner, so zeigten es Studien, würden in ihren Nachbarschaften nur noch wenig miteinander interagieren und wenn Nachbarn überhaupt miteinander redeten, dann höchst selten über Politik. Stattdessen seien die Massenmedien heute sehr viel stärkere Faktoren der Meinungsbildung. ${ }^{10}$

Die Wahrheit ist, dass wir letztlich zu wenig darüber wissen, wie ein Phänomen wie Gruppenpolarisierung in der realen Welt funktioniert. Bisher ließ sich nur spekulieren, in welcher Weise das Leben in politischen Hochburgen die Parteianhänger beider Seiten unterschiedlich prägt, ob es also für die Entwicklung meiner Weltanschauung eine Rolle spielt, ob ich als eingeschworener Republikaner in einer republikanischen Hochburg oder der republikanischen Diaspora lebe. Relativ unumstritten ist zwar, dass soziale Informationsflüsse selbstverständlich entscheidend sind für politische Einstellungen: Ein politischer „Independent“, der (hypothetisch) nur von Demokraten umgeben ist, wird wahrscheinlich tendenziell eher nicht republikanisch wählen. Selten jedoch wurden diese Überlegungen anhand konkreter räumlicher Gegebenheiten untersucht. Es ist schließlich zumindest theoretisch denkbar, dass auch Demokraten in Waukesha oder Republikaner in Dane County in der Lage sind, sich ebenso abzuschotten wie die Angehörigen der Mehrheitskultur. Die These vom „,ansteckenden Charakter“ einer lokalen PolitikKultur durch sogenannte „Nachbarschaftseffekte“, wie sie etwa von Kevin Cox im Kontext Großbritanniens aufgestellt wurde, gilt daher insgesamt als durchaus umstritten. ${ }^{11}$ Relativ eindeutig scheint hingegen zu sein, dass politische Minderheiten grundsätzlich stärker zur Wahlenthaltung neigen als die Angehörigen der

10 Morris P. Fiorina: The „Big Sort” That Wasn't: A Skeptical Reexamination, in: PS: Political Science \& Politics, Vol. 45 (2) 2012: S. 203-210. Vgl. als ähnliche Kritik auch Bruce E. Cain: Sorting It Out. Review of the Big Sort, in: The California Journal of Politics and Policy, Vol. 1, 2009: S. 1-4.

11 Vgl. Kevin Cox: The Spatial Structuring of Information Flows and Partisan Attitudes, in: Mattei Dogan und Stein Rokkan (Hg.): Quantitative Ecological Analysis in the Social Sciences, Cambridge 1969, S. 343-370; als kompakte Zusammenfassung zu 
Mehrheitskultur. ${ }^{12}$ Die These des „Big Sort“ jedoch - dass sich die Angehörigen dieser Mehrheitskultur durch das Ausbleiben von Dissens in Richtung ihres ideologischen Pols bewegen - ist durch diese Arbeiten nicht bewiesen worden. Auch in dieser Hinsicht sind Amerikas neue Partei-Hochburgen, ihrem rasanten Wachstum zum Trotz, hinsichtlich ihrer politischen und soziokulturellen Erforschung bisher eine Art Black Box geblieben.

Genau diese Leerstelle soll im Folgenden ins Auge genommen werden, und zwar mit Hilfe der Daten aus der DWPS. In einem ersten Schritt soll ergründet werden, inwiefern es auch anderen Bürgern in den Hochburgen Dane und Waukesha County so ergeht wie Ron Dolen und Katie Songer: Wie ideologisch homogen sind die persönlichen Netzwerke der Bewohner dieser Orte und wie unterscheiden sich diese zwischen Demokraten und Republikanern? Gibt es einen Zusammenhang zwischen politischer Netzwerkhomogenität und den politischen Ansichten? Neigen besonders überzeugte Demokraten/Republikaner stärker zur sozialen Homophilie als Demokraten/Republikaner die weniger ideologisch gefestigt erscheinen? In einem weiteren Schritt soll dann die Frage beantwortet werden, inwiefern es einen politischen Angleichungseffekt gibt und ob sich diejenigen, die an einen der beiden Orte umgezogen sind, in ihrer Einstellung der Ideologie der Mehrheitskultur angepasst haben.

An dieser Stelle sind eine Reihe methodischer Bemerkungen unvermeidbar. Die politische Homogenität (bzw. im Umkehrschluss Heterogenität) persönlicher Netzwerke zu erfragen, ist methodisch eine komplizierte und aufwendige Aufgabe. Die wenigsten geben gerne zu, dass ihr Umfeld ausschließlich aus Gleichgesinnten besteht, denn das erweckt nicht gerade den Eindruck von Offenheit und Aufgeklärtheit. Daher macht es nur begrenzt Sinn, die Frage zu stellen: „Wie viele ihrer Freunde/Bekannten haben politisch andere Ansichten als Sie?" Eine der gängigsten Methoden in der Erforschung politischer Netzwerke ist daher die Erstellung eines Name oder Discussant Generators: ${ }^{13}$ Es wird nach den (maximal) drei

möglichen „Nachbarschaftseffekten“ und ihrer Kritik auch Jürgen W. Falter/Jürgen R. Winkler: Wahlgeographie und Politische Ökologe, in: Jürgen W. Falter/Harald Schoen: Handbuch Wahlforschung, Wiesbaden 2014, S. 135-168, hier S. 149-152.

12 Vgl. bereits sehr früh Warren E. Miller: One-Party Politics and the Voter, in: American Political Science Review, Vol. 50 (3) 1956: S. 707-725; für die jüngere Zeit im Kontext der USA David E. Campbell: Why We Vote. How Schools and Communities Shape Our Civic Life, Princeton 2006.

13 Im Bereich der politikwissenschaftlichen Netzwerkforschung und ihrer Verbindung zur Wahlforschung haben vor allem die Arbeiten von Robert Huckfeldt und John Sprague den Einsatz von Discussant Generators bekannt gemacht, inbesondere ihre „South Bend“"-Studie über die Präsidentschaftswahl 1984. Vgl. Robert Huckfeld/John Sprague: 
Personen gefragt, mit denen der Befragte am häufigsten und wahrscheinlichsten über Politik spricht und dann anhand einer Reihe von Fragen versucht zu ermitteln, wie stark der Grad politischer Übereinstimmung ist. ${ }^{14}$ Auch das ist keine Methode ohne Fehler, schließlich misst sich auch auf diese Weise nur die wahrgenommene Übereinstimmung zwischen dem Befragten und seinen Diskutanten. Allerdings haben insbesondere die Studien von Robert Huckfeldt und John Sprague gezeigt, dass die meisten Menschen die politische Einstellung ihrer Gesprächspartner relativ korrekt einschätzen. Auch deswegen wurde in der DWPS dieser Methode vertraut. In Bezug auf alle genannten Diskutanten des Befragten wurden in unserer Umfrage drei Folgefragen gestellt, die jeweils auf den Grad der politischen Übereinstimmung zielten. ${ }^{15}$ Aus diesen maximal drei Diskutanten und drei Folgefragen wurde dann ein additiver Index gebildet, der von 0 (perfekte Heterogenität=alle Diskutanten des Befragten sind zu 100\% anderer politischer Auffassung) bis 3 (perfekte Homogenität= alle Diskutanten sind zu 100\% der gleichen politischen Auffassung) reichte. ${ }^{16}$

Citizens, Politics and Social Communication. Information and Influence in an Election Campaign, Cambridge 1995.

14 Abweichend wird oft auch nicht direkt nach der Politik, sondern nach ,important matters" gefragt. Die Ergebnisse freilich weichen dabei nur wenig voneinander ab. Vgl. Casey A. Klofstadt/Scott D. McClur/Meredith Rolfe: Measurement of Political Discussion Networks. A Comparison of Two Name Generator Procedures, in: Public Opinion Quarterly, Vol. 73 (3) 2009: S. 462-483.

15 Die drei Fragen lauteten: a) Compared with [Discussant \#1], would you say that your political views are much the same, somewhat different, or very different; b) Do you think [Discussant \#1] normally favors Republicans or Democrats, or both, or neither?; c) Which presidential candidate, if any, did [Discussant \#1] prefer? Romney, Obama or some other candidate?

16 Die konkrete Frage hierbei lautete: „From time to time, people discuss government, elections, and politics with other people. We'd like to know the first names or just the initials of people you talk with about these matters. These people might be from your family, from work, from the neighborhood, from some other organization you belong to, or they might be from somewhere else." Für den Fall, dass der Befragte keine Personen nennen konnten, fragten wir nach "the person you were most likely to have informal conversations with“. Diese Frage wurde auch denjenigen gestellt, die nur einen oder zwei Diskutanten nennen konnten, um auf diese Weise die Fallzahl zu erhöhen. 
Sowohl in Dane als auch in Waukesha County war die Homogenität der persönlichen Netzwerke zunächst sehr groß. Unterschiede zwischen den Counties waren dabei größtenteils zu vernachlässigen. In der Tat zeigte sich, dass die jeweiligen Minderheiten zu einem höheren Grad anderen politischen Meinungen ausgesetzt waren als Angehörige der Mehrheitskultur.

In beiden Counties stieg vor allem aber der Grad der Netzwerkhomogenität stets mit der Stärke der Parteizugehörigkeit an: „Strong Republicans“ hatten homogenere Netzwerke als „Weak Republicans“ - die allerdings wiederum noch weniger mit Demokraten über Politik sprachen als die „Independent Leaning Republicans." Auch mit anderen Faktoren, die teilweise in dieser Arbeit schon angeführt wurden, war die Netzwerkhomogenität bemerkenswert eng verknüpft: $\mathrm{Zu}$ mindest in Dane County führte ein homogenes Netzwerk zu einem deutlich geringeren Wunsch wegzuziehen als ein heterogenes Netzwerk. Auch der Faktor der Zufriedenheit war - in diesem Fall in beiden Counties - hiermit eng verknüpft: Je homogener das Netzwerk, desto größer die Zufriedenheit mit dem Wohnort. Offenkundig macht es tatsächlich glücklicher, unter seinesgleichen zu bleiben. Und noch in einer letzten Hinsicht spielte Netzwerkhomogenität eine Rolle: sie korrelierte positiv mit politischer Partizipation, was im Einklang mit anderen Studien steht, ${ }^{17}$ und erklärt, warum Hochburgen wie Dane und Waukesha häufig durch hohe Wahlbeteiligung gekennzeichnet sind. ${ }^{18}$

17 Diana Mutz: Hearing the Other Side, Cambridge 2006.

18 Vgl. David E. Campbell: Why We Vote. How Schools and Communities Shape Our Civic Life, Princeton 2006. 
Tabelle 1: Zusammenhang Netzwerkhomogenität und Parteiidentifikation Waukesha County

\begin{tabular}{|l|r|r|}
\hline $\begin{array}{l}\text { partylD7 Party identifica- } \\
\text { tion on 7-point-scale }\end{array}$ & Mittelwert & $\begin{array}{r}\text { Standardabwei- } \\
\text { chung }\end{array}$ \\
\hline 1,00 Strong Republican & 2,6429 &, 47924 \\
2,00 Weak Republican & 2,5370 &, 48432 \\
3,00 Independent Republi- & 2,3030 &, 75529 \\
can & 1,2778 & \\
4,00 True Independent & 1,8333 &, 69389 \\
5,00 Independent De- &, 76497 \\
mocrat & 1,7778 &, 19245 \\
6,00 Weak Democrat & 2,1833 &, 78519 \\
7,00 Strong Democrat & 2,3997 &, 68096 \\
Insgesamt & & \multicolumn{1}{c|}{} \\
\hline
\end{tabular}

Tabelle 2: Zusammenhang Netzwerkhomogenität und Parteiidentifikation Dane County

\begin{tabular}{|l|r|r|}
\hline $\begin{array}{l}\text { partyID7 Party identifica- } \\
\text { tion on 7-point-scale }\end{array}$ & Mittelwert & $\begin{array}{r}\text { Standardabwei- } \\
\text { chung }\end{array}$ \\
\hline 1,00 Strong Republican & 2,3086 &, 77446 \\
2,00 Weak Republican & 2,1364 &, 52078 \\
3,00 Independent Republi- & 1,8750 &, 82975 \\
can & 1,4000 & \\
4,00 True Independent & 1,8951 &, 51039 \\
5,00 Independent De- &, 73110 \\
mocrat & 2,3889 &, 54857 \\
6,00 Weak Democrat & 2,5967 &, 59211 \\
7,00 Strong Democrat & 2,3054 &, 71852 \\
Insgesamt & & \\
\hline
\end{tabular}

Quelle: Eigene Darstellung, Daten der DWPS. 
Die höhere Netzwerkhomogenität der Angehörigen der Mehrheitskultur hat natürlich einen banalen Grund: schließlich ist für sie schon allein die statistische Wahrscheinlichkeit geringer, mit Menschen anderer politischer Anschauung - ob nun am Arbeitsplatz oder tatsächlich mit dem Nachbarn nebenan - Kontakt zu haben. Aber das alleine ist es wahrscheinlich nicht. Wer als Demokrat in Waukesha County lebt oder als Republikaner in Dane County, dürfte sich ohnehin der Tatsache bewusst sein, sich in jedem Fall mit der Mehrheitskultur arrangieren zu müssen. Wahrscheinlich ist in dieser Gruppe die Politik auch seltener ein zentraler Bezugspunkt des Lebens, divergierende politische Anschauungen daher leichter zu ertragen. Ganz anders jedoch ist der Fall gelagert bei vielen Angehörigen der Mehrheitskultur, und dabei vor allem bei jenen, die in dieser Arbeit als kulturelle Kerngruppe identifiziert wurden: einmal angekommen an einem Ort, der ihren politischen und kulturellen Neigungen entspricht, gibt es nur noch wenig Grund, sich noch weiterhin auf die Argumente der Gegenseite einzulassen - was auch erklärt, warum besonders treue oder ideologisch motivierte Parteianhänger die homogensten Netzwerke haben. „Geez, why should I go talk to them? I came here to get away from those people", rügte eine junge Frau, die aus dem Norden des Bundesstaates Wisconsin nach Madison gezogen war, einmal den Verfasser, als er fragte, ob es in ihrer Bekanntschaft Republikaner gäbe.

Dieses Kapitel wurde mit den Bemühungen von „Reach Out Wisconsin“ begonnen, weil sich die empirischen Ergebnisse der DWPS auch im Geschehen rund um die Gruppe spiegeln. Das Forum litt von Anfang an unter einem Umstand, der sich mit der Zeit zu einem veritablen Problem entwickelte: die Partizipation war nie ganz ausgeglichen. Ausgerechnet in Dane County, wo auf drei Demokraten gerade einmal ein Republikaner kommt und wo es ständig irgendwo in der Stadt gut besuchte politische Veranstaltungen gibt, wurde es mit der Zeit immer schwerer, genügend Demokraten für einen zivilgesellschaftlichen Dialog zu gewinnen. ${ }^{19}$ Diejenigen, die kamen, waren in der Regel Freunde und Bekannte der Initiatoren, darüber hinaus wurde es extrem schwer, genügend Menschen zu mobilisieren. Die örtliche Parteiführung der Demokraten betrachtete „Reach Out“ von Beginn an sogar mit großem Argwohn. Dabei versuchten Katie Songer und Ron Dolen wiederholt, dort für ihr Vorhaben zu werben und luden den Vorsitzenden der Demokratischen Partei mehrmals zu den Treffen ein - ohne Erfolg. In einer E-Mail, so

19 Vgl. auch Chris Rickert: Reach out Wisconsin not Reaching Many Liberal These Days, in: Wisconsin State Journal, 19. Oktober 2014, http://host.madison.com/news/ local/columnists/chris-rickert/chris-rickert-reach-out-wisconsin-not-reaching-many-lib erals-these/article_321093f5-cfc4-5e0b-8d4a-af07eba4169e.html (zuletzt abgerufen am 29.06.2015). 
Katie Songer, wies er sie gar brüsk ab: Er habe wohl kaum Nachholbedarf darin, Republikaner zu ,verstehen“, er ,verstehe“ sie nämlich bereits jetzt ziemlich gut und sei sich über deren Motive völlig im Klaren. Danach listete er noch alle Verfehlungen der Republikanischen Partei der letzten Monate auf. ${ }^{20}$ Unter vielen Demokraten in Madison gelten die Initiatoren von „Reach Out“ mindestens als Nervensägen, ein wenig aber sogar als Verräter, die nicht verstünden, mit welcher Art von „Feind“ man es zu tun habe. Warum sollte man Republikanern auf diese Weise „Legitimität“ verleihen, fragt etwa der in einem vorangegangenen Kapitel bereits vorgestellte Luke Diaz, der liberale Aktivist aus Verona. Menschen wie Ron und Katie nennt er „Apologetic Liberals“, die offenkundig aus irgendeinem falsch verstandenen Schuldgefühl handelten. ${ }^{21}$

Die Republikaner von Dane County hingegen lieben „Reach Out Wisconsin“. Konservative Blogger berichten darüber, auf den Parteiveranstaltungen wird „Reach Out“ regelmäßig beworben und die Vorsitzenden der Partei - ansonsten in Madison und Dane County so gut wie unsichtbar - sind häufige Teilnehmer. Mittlerweile hat einer der Gründer von „Reach Out“, Scott Grabins, selbst den Vorsitz der Partei übernommen. Eine Sache, die Republikaner an „Reach Out“ lieben, ist schon ganz einfach, dass viele Demokraten „Reach Out“" hassen. Für sie ist das der ultimative Beweis, dass die angebliche Weltoffenheit des amerikanischen Liberalismus geheuchelt ist und in Wahrheit alles vermieden wird, was die Gewissheiten der Menschen in der „Madison Bubble“ irritieren könnte. Gänzlich falsch ist der Vorwurf mangelnder Toleranz nicht, aber dieser Mangel hat weniger mit grundsätzlichen Unterschieden zwischen Demokraten und Republikanern in Bezug auf Offenheit gegenüber anderen Anschauungen zu tun - in dieser Hinsicht tun sich beide Seiten nicht sehr viel. Es ist vielmehr in der unterschiedlichen Status-Position beider Gruppen begründet, mit dem Minderheiten- bzw. MehrheitenStatus von Demokraten und Republikanern. Madisons Konservative haben vor allem deswegen eine positive Einstellung zu „Reach Out“, weil sie in der Stadt sonst kaum eine Stimme haben und buchstäblich überhaupt nicht vorkommen. Allein die Medienberichterstattung über das Forum verschafft ihnen mehr Aufmerksamkeit als die monatlichen Parteitreffen. Es ist eine Chance, die eigene Position zu erklären, die sonst - so ihre Ansicht - nur als verzerrte Karikatur wiedergegeben wird.

Es gibt in Waukesha kein Gegenstück zu „Reach Out Wisconsin“, aber wäre das der Fall, dann wären die Verhältnisse gewiss spiegelverkehrt, denn dort interessiert sich kaum ein Republikaner für diese merkwürdige, exotische Spezies namens Demokraten.

20 Gespräch mit Katie Songer und Ron Dolen, 2. April 2012.

21 Gespräch mit Luke Diaz, 3. Oktober 2014. 
Bei allen gewiss gut gemeinten Vorsätzen auf beiden Seiten ist die Erwartungshaltung letztlich auch eine andere: Für die Republikaner in Dane County - gestählt im Aushalten anderer Meinungen - ist „Reach Out“ vor allem ein Testgelände für ihre politischen Ideen. Sie mögen den Wettstreit darüber, und den üblichen Ablauf eines Treffens mit zwei Rednern, die jeweils konträre Standpunkte zu einem Thema vorstellen, genießen sie wie einen guten Boxkampf. Die Konservativen im Forum stärken ihre eigenen Überzeugungen an denen der Gegenseite - was vielleicht nicht unbedingt dem eigentlichen Zweck von „Reach Out“ dient. Den Demokraten von „Reach Out“ geht es um etwas Anderes. Es ist eine Sehnsucht nach Versöhnung, die bei ihnen durchklingt, nach Heilung fast, der Versuch, auch innerlich Frieden zu machen mit der anderen Seite, deren Denken und Handeln man einfach nicht verstehen kann. Als Katie Songer und Ron Dolen vorschlugen, die Treffen um vertrauensbildende Gruppenübungen zu erweitern - ein Teilnehmer lässt sich nach hinten fallen, die anderen fangen ihn auf usw. - hielten die Republikaner solcherlei für ziemlichen Kokolores und lehnten den Vorschlag brüsk ab.

Im Grunde handelt „Reach Out Wisconsin“ von einem liberalen Paradox, einem Widerspruch, der nicht aufzulösen ist: Schließlich gehört zu den Grundpfeilern der eigenen Weltanschauung, dass Konflikte durch Deliberation zu lösen sind, dass Toleranz gegenüber anderen Anschauungen geübt werden muss. In seiner postmodernen Form zugespitzt bedeutet es eigentlich auch, zu akzeptieren, dass man selbst vielleicht auch nur einen Ausschnitt der Realität erkennt, weil alle Betrachtung letztlich vom subjektiven Standpunkt abhängt. Gleichzeitig aber beschleicht viele Liberale - bei „Reach Out“ und anderswo - der Gedanke, dass all das Verständnis vielleicht von der Gegenseite nicht geteilt wird, man also letztlich einem Gegner gegenübersteht, der nach anderen Regeln spielt. Was aber soll man dann tun? Soll man alle politischen Streitfragen einfach nur als unterschiedliche aber ebenbürtig legitime Standpunkte interpretieren, oder übertreibt man es dann nicht vielleicht doch ein wenig mit der postmodernen Offenheit?

Selbst Ron und Katies Toleranz, die lange so unerschöpflich erscheint, wird am Ende teilweise verbraucht sein. Im Frühjahr 2014 ziehen sie sich aus der Organisationsleitung von „Reach Out“ zurück, zum Teil, weil andere Verpflichtungen sie sehr in Anspruch nehmen, aber auch, weil sie manche Aspekte ihrer Arbeit mit dem Forum mental belasten und ermüden. Kurz zuvor wäre es fast zum Bruch gekommen, als man die Agenda für eines der nächsten Treffen besprach: Es sollte um den Klimawandel gehen. Als Scott Grabins eine Liste von möglichen Diskutanten vorschlug und es sich dabei ausschließlich um Personen handelte, die die bloße Realität des Klimawandels - das wichtigste Thema für Ron und Katie und Quelle ihrer politischen Identität - schlichtweg leugneten, war für sie eine Grenze überschritten und die Idee dieses Forums platzte. 
Heute leben sie in Portland und schauen auf „Reach Out“ positiv zurück, weil sie sagen, es habe ihnen durchaus manche konservativen Standpunkte leichter verständlich gemacht. Vor allem aber, weil es ihnen gelang, trotz allem Freundschaften $\mathrm{zu}$ Menschen aufzubauen, die fundamental andere Meinungen vertreten. So sind sie rühmliche Beispiele für die positiven Effekte interpersonalen Kontaktes, aber anderseits auch Zeugnisse, wie schwer es fallen kann, diese Differenzen auszuhalten, denn stets klingt es bei Katie Songer und Ron Dolen wie eine anstrengende Übung, eine Art Bürde, die man im Dienste der politischen Friedensstiftung auf sich zu nehmen hat. Ein anderer Liberaler der ersten Stunde, Rick Nelson, hatte schon ein Jahr zuvor die Segel gestrichen, da es ihn zunehmend mit Angst erfüllte, dass einer der regelmäßigen republikanischen Teilnehmer zu jedem Treffen seine Waffen mitbrachte und zudem davon sprach, dass er jedenfalls vorbereitet sei, wenn es im Land bald einen Bürgerkrieg gäbe. ${ }^{22}$

\section{DER EFFEKT DER ECHOKAMMER: GRUPPENPOLARISIERUNG UND DIE „RADIKALISIERUNG“ DER MEHRHEITSKULTUR}

Rekapitulieren wir also: Sowohl die Daten unserer Umfrage als auch die Erfahrungen von „Reach Out Wisconsin“ zeigen, dass es in der wachsenden Zahl von krassen politischen Hochburgen nur höchst selten zum Austausch divergierender Meinungen kommt und dass vor allem der Mehrheitskultur kaum daran gelegen ist, ,cross-cutting exposure“ zuzulassen. Orte wie Dane und Waukesha County können also in der Tat als Echo-Kammern bezeichnet werden, in denen die Stimmen der Mehrheit um ein Vielfaches verstärkt werden. Die Daten zeigen überdies, dass mit der Stärke der Parteiidentifikation auch die Homogenität des Netzwerkes zunimmt.

Somit drängt sich eine Frage auf: Sind die persönlichen Netzwerke so homogen, weil die Person eine hohe Parteiidentifikation besitzt, oder ist die Parteiidentifikation, jedenfalls auch zum Teil, Resultat der homogenen Netzwerke? Die Frage ist aus den Daten als solches nicht zu beantworten. Allerdings haben wir generell versucht zu ermitteln, inwiefern der Ort als Kontextvariable die politische Einstellung bestimmt. Anders gefragt: Wie beeinflusst das Leben in einer liberalen/konservativen Hochburg im Zeitverlauf die ideologische Einstellung der Menschen?

22 Schriftliche Auskunft des „Reach Out“ Teilnehmers Rick Nelson vom 13.01.2015. 
Diese Fragen führen zur Kategorie der movers zurück, also jene Menschen, die in den letzten Jahrzehnten nach Dane und Waukesha umgezogen sind, und die uns im letzten Kapitel näher beschäftigt haben. Denn in ihrem Fall lässt sich die frühere Parteiidentifikation mit der heutigen abgleichen - was allerdings sehr eindeutige Ergebnisse produziert. ${ }^{23}$ Dabei wurde zunächst davon ausgegangen, dass komplette Wechsel in der Parteiidentifikation eher selten sind, da Parteienzugehörigkeit im Allgemeinen als relativ stabile, meist in den frühen Jahren der Sozialisation gewonnene Eigenschaft nicht so leicht zu erschüttern ist. ${ }^{24}$ In dieser Hinsicht waren die Ergebnisse bereits überraschend, denn die Anzahl der „Parteiwechsler“ war weitaus höher als vermutet: Etwa 15\% derjenigen, die zum Zeitpunkt ihres Umzuges nach Waukesha Demokraten waren, identifizierten sich nun, im Jahr 2013, als Republikaner. In Dane County war die Zahl der „Konvertiten“ sogar noch etwas höher (22\%). Umgekehrt jedoch - also Republikaner in Waukesha, die Demokraten wurden oder Demokraten in Dane, die Republikaner wurden - kam eine solche Konversion beinahe gar nicht vor. ${ }^{25}$

Dabei war die eigentliche Hypothese grundsätzlich bescheidener. Sie lautet, dass die Prägewirkung dieser Hochburgen sich vor allem darin zeigt, dass Parteianhänger, die bereits zum Zeitpunkt des Umzuges zur Mehrheitskultur gehören, ihre Parteiidentifikation stärken werden - das wäre schließlich ein entscheidender Hinweis darauf, dass die Mechanismen der Gruppenpolarisierung tatsächlich greifen. Umgekehrt wäre zu erwarten, dass die Angehörigen der Minderheitskultur ihrerseits ihrer Parteiidentifikation abschwächen.

23 In diesem Fall schien es, auch um die Fallzahl leicht zu erhöhen, sinnvoll, alle movers nach Dane und Waukesha County einzubeziehen, und nicht nur jene, die ab 1976 einwanderten. Für die Frage der generellen Prägewirkung der Counties war das für den „Big Sort“ so wichtige Signaljahr 1976 nicht entscheidend.

24 So schon Angus Campbell: The American Voter, Chicago 1960.

25 An dieser Stelle ist selbstverständlich anzumerken, dass die Validität von Rückerinnerungsfragen in der Wahlforschung umstritten ist, da es hier bei den Befragten aus verschiedenen Gründen zu Verzerrungen kommen kann. Zum einen jedoch weisen alle der folgenden Ergebnisse in die gleiche Richtung. Und zum anderen ist wahrscheinlich, dass das Ausmaß der Veränderungen bei Rückerinnerungsfragen eher noch kleiner ausfällt bzw. die tatsächlichen ideologischen Anpassungseffekte tatsächlich noch größer sein könnten, da das Bemühen nach kognitiver Konsonanz dazu verleitet, die derzeitige Parteiidentifikation in die Vergangenheit zurück zu projizieren. Vgl. für die Thematik von Rückerinnerungsfragen in der Wahlforschung Harald Schoen: Wenn ich mich recht erinnere... Zur Validität von Rückerinnerungsfragen, in: Harald Schoen/Gabriel, Oscar W. (Hg.): Vom Interview zur Analyse. Methodische Aspekte der Einstellungs- und Wahlforschung, Baden-Baden 2009, S. 259-279. 
Und schließlich müsste sich im Sinne dieser Annahme auch die Gruppe der „Independents“ in Richtung der Ideologie der Mehrheitskultur bewegen.

Alle drei Hypothesen bestätigen sich, für beide Counties. In diesem Fall macht es Sinn, auf die die 7-gliedrige Einteilung der Parteiidentifikation zurückzugreifen: „Strong Republican“ - ,Weak Republican“ - „Independent Leaning Republican“ - „True Independent“ - „Independent Leaning Democrat“ - „Weak Democrat“ - „Strong Democrat. Auf den ersten Blick ist die Stabilität der politischen Einstellungen dabei relativ hoch, dem Phänomen des oben demonstrierten ,totalen“ Lagerwechsels zum Trotz. In Waukesha County etwa verortet sich über die Hälfte der Befragten noch an der exakt gleichen ideologischen Position wie zum Zeitpunkt des Umzuges. Allerdings: Es ist dort vor allem die Gruppe der „strong republicans“, die sich in diesem Sinne treu geblieben sind: $83 \%$ von ihnen sind heute (bzw. zum Zeitpunkt der Erhebung 2013) wie zum Zeitpunkt des Umzugs „strong republicans.“ Allerdings: da eine stärkere Parteiidentifikation als Option in der Umfrage nicht zur Verfügung stand, könnte man provokant fragen: wohin hätten sie sich auch bewegen sollen? Viel aufschlussreicher sind daher die Veränderungen etwa bei den „Weak Republicans“. Während sich hier etwa ein Viertel „treu“ blieb, wechselte beinahe die Hälfte $(48,4 \%)$ ins Lager der „Strong Republicans", nur ein weiteres Viertel bewegte sich in eine weniger konservative Richtung.

Von der Zahl derjenigen, die ihre Parteiidentifikation komplett änderten, war bereits die Rede. Wenig überraschend ist dabei wohl, dass die Gruppe der „Strong Democrats“ in ihrer Parteiloyalität wesentlich schwererer zu erschüttern ist als die „Weak Democrats“ oder auch die „Independent Leaning Democrats“. Auch bei den „Independents“ fällt zunächst auf, dass die Hälfte von ihnen ihre Parteiidentifikation nicht änderte. Wenn doch, dann entwickelte sich auch bei ihnen die politische Gesinnung jedoch sehr viel stärker in die konservative Richtung. Aus Gründen der Vereinfachung sind in Abbildung 13 drei Gruppen aufgeführt: Erstens jene, bei denen es überhaupt keine Veränderungen der Parteiidentifikation gab; zweitens die Gruppe derjenigen, die republikanischer (bzw. weniger demokratisch) wurden; drittens jene, die demokratischer (bzw. weniger republikanisch) wurden.

Und die Ergebnisse sind eindeutig: die Zahl derjenigen, die sich stärker in Richtung der Ideologie der Mehrheitskultur bewegt, ist bedeutend größer. Einfacher ausgedrückt: Das republikanische, konservative Waukesha County hat die Menschen, die dorthin zogen, im Zeitverlauf tendenziell ,konservativer“" gemacht: 
Abbildung 13: Veränderung der Parteiidentifikation seit dem Umzug: movers nach Waukesha County

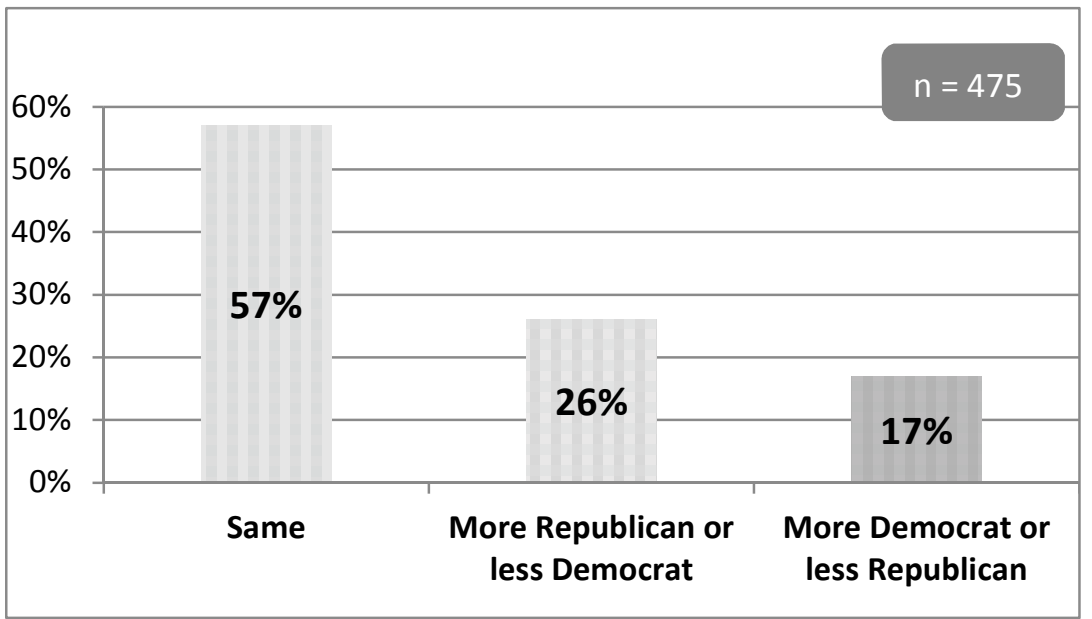

Quelle: Eigene Darstellung, Daten der DWPS.

In Dane County zeigt sich ein beinahe spiegelverkehrtes Bild: Hier ist wiederum die liberale Prägewirkung auf die movers überdeutlich. Die Effekte sind noch etwas stärker, besonders gilt das für die Gruppe der „Independents“, bei denen es zu einer massiven Bewegung in Richtung der Demokraten gekommen ist: Über die Hälfte änderte die Party ID zwar gar nicht (55,8\%). Aber während weniger als $10 \%$ heute zu den Republikanern tendieren, ordnet sich über ein Drittel der Befragten $(34,6 \%)$ heute als Demokraten ein.

In Abbildung 14 sind die gleichen drei Gruppen wie für Waukesha aufgeführt: abermals jene, deren Parteiidentifikation unverändert blieb; movers die sich im Zeitverlauf in Richtung der Mehrheitsideologie bewegt haben: und schließlich solche, die sich in die gegensätzliche Richtung bewegt haben. Die Veränderungen sind noch deutlicher als in Waukesha. 
Abbildung 14: Veränderung der Parteiidentifikation seit dem Umzug: movers nach Dane County

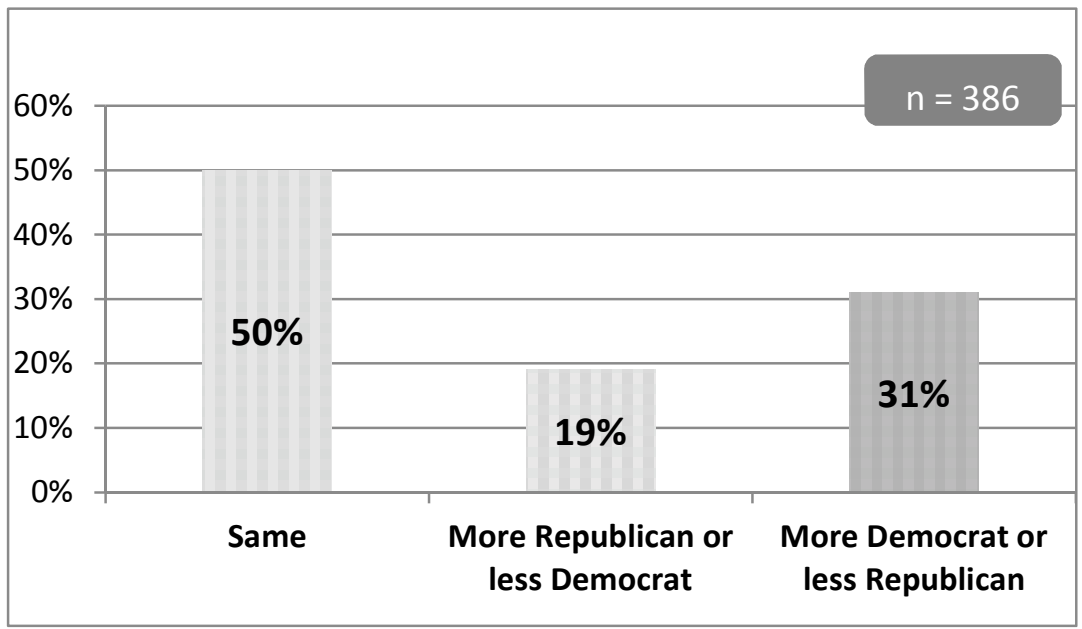

Quelle: Eigene Darstellung, Daten der DPWS.

Aus dieser Kombination - der ideologischen Magnetwirkung von Dane und Waukesha County sowie der nachfolgenden weltanschaulichen Prägewirkung beider Orte - entstehen soziale Räume, die nicht nur stark von Demokraten oder Republikanern bevölkert sind. Es sind auch andere Demokraten, andere Republikaner, die wir dort jeweils finden: Republikaner in Waukesha sind konservativer als der nationale Durchschnitt, und Demokraten in Dane County sind liberaler als Demokraten anderswo.

Politisch hat das wenig überraschende Folgen: Es kommt zu einem permanenten ideologischen Überbietungsversuch. Nichts kann nämlich in Dane oder Waukesha County eine politische Karriere schneller beenden als der Vorwurf, nicht liberal bzw. nicht konservativ genug zu sein. Auf die Lokalpolitik im engeren Sinne werden wir dabei noch in einem späteren Kapitel zu sprechen kommen. Aber auch die Abgeordneten, die aus diesen beiden Counties in die Parlamente nach Washington oder Madison entsandt werden, haben sich diesen Realitäten zu stellen. Bis 2012 vertrat Tammy Baldwin die Interessen Dane Countys im Repräsentantenhaus in Washington. Baldwin war nicht nur die erste offen lesbische Abgeordnete im amerikanischen Kongress, sondern war laut ihres Abstimmungsverhaltens auch eine der liberalsten Demokraten in der Hauptstadt überhaupt. Mittlerweile ist sie zur Senatorin aufgestiegen und wetteifert dort mit Elisabeth Warren aus Massachusetts um die Position der liberalsten Senatorin. Waukeshas Repräsentanten in Washington, vor allem James Sensenbrenner, aber auch Paul Ryan, 
dessen Wahlkreis ebenfalls ein kleines Stück von Waukesha abdeckt, gehören zum konservativeren Flügel eines ohnehin bereits sehr konservativen GOP Caucus. Da die ideologischen Unterschiede in der Regel mit der Lupe zu suchen sind, führt das zu bisweilen sehr merkwürdigen Wettbewerben - etwa wenn sich zwei Kandidaten für den Sitz Madisons in der State Legislature in der demokratischen Vorwahl darum streiten, wer denn nun die schlechteren Beziehungen zur Business Community habe. ${ }^{26}$ Es ist ein wenig der Freudsche „Narzissmus der kleinen Differenzen“" auf die Politik übertragen.

Wenn einer weiß, wie man als Demokrat in Madison politisch überlebt, dann ist es Fred Risser. Risser ist derzeit der am längsten dienende Parlamentarier der USA: Er sitzt als State Senator seit sage und schreibe 1962 in der State Legislature. Als der Autor ihn im Mai 2012 in seinem Abgeordneten-Büro besucht, zeigt er stolz seinen politischen Stammbaum. Risser kommt aus einer Familie, der die Politik immer schon im Blut lag: schon sein Vater saß im Parlament in Madison. Die Geschichte der Rissers - und vor allem ihrer Parteiwechsel - ist ein kleines Kompendium der amerikanischen Parteiengeschichte. Denn während die Parteien ihren Standort in den letzten einhundert Jahren mehrmals verschoben, blieben sich die Risser stets treu - und dabei so links, wie es in diesem Land möglich ist, ohne wirklich Sozialist zu sein. Rissers Vater war in der kurzlebigen „Progressive Party", sein Großvater ein Republikaner in der Tradition des Sozialreformers Robert LaFollette. Risser ist der erste Demokrat der Familie. In über 50 Jahren als State Senator hat Risser noch nicht eine einzige wirklich ernsthafte Hauptwahl erlebt. Bisweilen haben die Republikaner erst gar keinen eigenen Kandidaten gegen ihn aufgestellt. Auch Risser muss sich einzig auf die Primary konzentrieren und das Schema ist dabei stets das Gleiche, sagt er: „In my party, the only way you can get at me, is try to prove I am not left enough.“ Allein: An Risser haben sich noch alle Herausforderer die Zähne ausgebissen: „They try to move to my left, but they are having a hard time doing it!"27

26 So geschehen im demokratischen Vorwahlkampf 2014 zwischen Mark Clear und Lisa Subeck um Wisconsins 78. Assembly Seat. Vgl. Joe Tarr: Mark Clear and Lisa Subeck battle for liberal cred in west-side Assembly race: Will the real progressive please stand up?, in: Isthmus, 17. Juli 2014, abrufbar unter: http://www.isthmus.com/ news/news/mark-clear-and-lisa-subeck-battle-for-liberal-cred-in-west-side-assemblyrace/ (zuletzt abgerufen am 28.04.2015).

27 Gespräch mit Fred Risser, 7. Mai 2012. 
Denn Risser hat sich über all die Jahrzehnte als äußerst geschmeidiger Politiker erwiesen, und alle Linkswendungen seiner Partei mitgenommen. Als Risser das erste Mal in die State Legislature gewählt wird, gab es noch keine „New Left“, spielten „Gay Rights“ keine Rolle, selbst Abtreibung war noch kein politisch extrem aufgeladenes Thema. Aber Risser folgte dem amerikanischen Liberalismus forthin auf all seinen Wegen. Seine Rolle als Repräsentant nimmt er sehr wörtlich: Er habe sich stets bemüht, sagt Risser, die Positionen seines Wahlkreises zu übernehmen und den Leuten zu geben, was sie wollten; und sein Wahlkreis sei nun einmal wahrscheinlich einer der liberalsten in den gesamten USA. Risser ist ein Glücksfall für alle, denen vor allem die Responsivität von Politik am Herzen liegt aber ein Alptraum für andere, die an die Unabhängigkeit der politischen Auffassungen von Repräsentanten glauben. Risser hat nach der Devise: „I am their leader, I must follow them" gehandelt und damit hat er in Dane County, den sieben Leben einer Katze gleich, noch stets jeden Widersacher überlebt.

Diese Dynamik ist in Waukesha die Gleiche. Waukeshas Republikaner, und jene aus anderen Counties, die die Suburbs von Milwaukee umfassen, gelten als besonders konservativ. Auch ihnen droht Gefahr nur noch in den Vorwahlen, auch sie müssen in Permanenz beweisen, dass zwischen den Bedürfnissen ihrer Wählerbasis und ihrer Politik kein Blatt Papier mehr passt. Seitdem Scott Walker in Wisconsin ein konservatives Gesetzesvorhaben nach dem anderen durchgesetzt hat, ist es allerdings nicht mehr leicht, noch die Rolle der ideologischen Avantgarde zu spielen. Manche Abgeordnete der State Legislature hat auf das auf schon fürwahr abenteuerliche Wege geführt. Als im November 2012 acht Republikaner den Antrag stellten, alle Bundesbeamten, die in Wisconsin an der Umsetzung von Obamacare arbeiteten - in den Augen vieler extrem konservativer Aktivisten nicht einfach ein schlechtes Gesetz, sondern schlicht ein Verfassungsbruch - zu verhaften, da befanden sich in dieser Gruppe fast nur Abgeordnete aus Waukesha oder aus anderen Suburbs bei Milwaukee. Es war eine Aktion, die selbst unter anderen konservativen Republikanern in Wisconsin nur noch Kopfschütteln verursachte. ${ }^{28}$ Verbabschiedet wurde ein solches Gesetz dann natürlich nicht. Doch darum war es natürlich auch nie gegangen - sondern nur darum, die größtmögliche Opposition gegen den gerade wiedergewählten und so sehr verhassten Präsidenten im fernen Washington auszudrücken.

28 Vgl. Patrick Marley: 9 lawmakers want to arrest U.S. officials who implement Obamacare, in: Milwaukee Journal Sentinel, 13. November 2012, http://www.json line.com/news/statepolitics/nine-lawmakers-back-charging-federal-officials-who-im plement-obamacare-here-n47k110-179180251.html (zuletzt abgerufen am 17.06. 2015). 


\section{SozIALE KONTROLLE UND DIE IDEOLOGISCHE DURCHDRINGUNG DER ZIVILGESELLSCHAFT - ODER: WARUM ES REPUBLIKANER IN DANE COUNTY SCHWERER HABEN}

Das alles sollte deutlich gemacht haben, dass die durch Binnenmigration ausgelöste Entstehung politischer Hochburgen nicht einfach nur ein Symptom der ideologischen Spaltung des Landes ist, sondern in der Konsequenz soziale Räume entstehen, die den perfekten Nährboden für eine weitere Entfremdung zwischen dem liberalen und konservativen Amerika bieten, was die Polarisierung des Landes, einem Teufelskreis gleich, weiter befördert. Der „Big Sort“ ist also nicht nur Symptom, sondern auch eine wesentliche Ursache des ideologischen Grabens, der die modernen USA durchzieht.

Auffällig ist allerdings, dass viele der angesprochenen, messbaren Effekte in Dane County jedoch deutlich größer sind: Hier drückt die Minderheit, also die Republikaner, eine größere Unzufriedenheit mit ihrem Wohnort aus, zeigt ein sehr viel stärkeres Bedürfnis umzuziehen, viele direkt aus politischen Gründen. Die Republikaner von Dane County, auch diese Frage stellten wir in der DWPS, haben von allen Befragten auch am wenigsten das Gefühl, dass die Menschen in ihrer Umgebung ihre Werte teilen. Und wie das vorangegangene Kapitel gezeigt hat, übt Dane County auch eine stärkere ideologische Prägewirkung (oder auch Konversionseffekt) auf die Parteianhänger beider Seiten aus.

Kurz gesagt: Bei allen Ähnlichkeiten in Bezug auf die Soziologie dieser Hochburgen bleibt es wichtig festzuhalten, dass manches sich dennoch markant unterscheidet. Liberale und Konservative, Demokraten und Republikaner - sie alle mögen die gleiche Tendenz haben, untereinander zu bleiben, die gleiche Neigung, Rückzugsorte zu finden, die nach dem Prinzip der Echokammer funktionieren. Und doch spielt die Ideologie der Mehrheitskultur in Dane County eine weitaus größere Rolle: sie hat dort viel sichtbarer den öffentlichen Raum eingenommen und sorgt für sehr viel spürbarere Trennlinien zwischen beiden Lagern, die bis tief in den Lebensalltag spürbar sind.

Das hat verschiedene Gründe. Da ist einmal die physische Struktur beider Räume und damit die Art und Weise in der Privatheit und Öffentlichkeit miteinander verzahnt sind. Suburbia, das wurde bereits gezeigt, ist generell ein Ort größerer Privatheit und in diesem spezifischen Sinne weniger politisch. Das bedeutet nicht, dass Waukesha nicht ebenso konservativ wäre wie Dane County County liberal ist - aber es ist einfach weniger sichtbar. Während es in Madisons Innenstadt ständig Veranstaltungen mit einer liberalen politischen Agenda gibt, ist diese Art von politischem Aktivismus - zumindest außerhalb von Wahlkampfzeiten - 
in Waukesha schlicht abwesend. Ein Republikaner wird in Madison schnell merken, dass er in der Minderheit ist, ein Demokrat in Waukesha vielleicht erst dann, wenn seine Nachbarn in der Wahlkampfsaison ihre „yard signs“ aufstellen. In Madison gibt es zwei Tageszeitungen und eine Wochenzeitung, die täglich über Lokalpolitik berichten und dabei jede Kabale zwischen und innerhalb der Parteien genüsslich ausschlachten. In Waukesha County gibt es allenfalls die Regionalseiten des Milwaukee Journal Sentinels, der jenseits seiner Chronistenpflicht bezüglich der Ergebnisse lokaler Wahlen kaum über Politik in Suburbia berichtet. Man könnte auch sagen: In Madison kann man eine Gesellschaft dabei beobachten wie sich selbst permanent beobachtet, wie verschiedene Gruppen auf offener Bühne ihre Konflikte austragen. Im Vergleich dazu ist Waukesha ein gigantischer Backstage-Bereich, zu dem der Zugang stark eingeschränkt ist - selbst für einen Feldforscher, der dort über drei Monate gelebt hat.

Doch nur die unterschiedliche Sichtbarkeit gewisser Phänomene ist es nicht. Es gibt noch einen weiteren Punkt und dieser ist nicht ganz leicht zu versöhnen mit der Ansicht, der amerikanische Liberalismus sei vor allem geprägt von Toleranz gegenüber anderen Anschauungen. Denn zur Ideologie des amerikanischen Liberalismus gehört ganz einfach eine größere Spannweite von ,richtigen“ Verhaltensweisen, die in den Lebensalltag von Menschen potentiell eingreifen können und deren Nicht-Einhaltung gesellschaftlich sanktioniert wird. Ein Bio-Supermarkt in Waukesha hätte es vielleicht schwer, sich ökonomisch zu behaupten wirkliches Aufsehen hingegen würde er kaum erregen. Doch sobald die Supermarktkette Wal-Mart, für viele Liberale der Hauptverursacher der Verödung amerikanischer Innenstädte und außerdem als Lohndumper gefürchtet, sich in Dane County ansiedeln will, ist eine Protestveranstaltung sicher. Wer in Waukesha ein Hybrid-Auto fährt, dürfte unbehelligt bleiben; wer aber in einigen der besonders liberalen Nachbarschaften von Madison einen der typisch überdimensionierten SUVs fährt, dürfte irgendwann auf seine Meinung zum Klimaschutz angesprochen werden. Es mag solche Formen sozialer Kontrolle durch die Mehrheitsgesellschaft auch in Waukesha geben, aber sie sind seltener, subtiler, individueller. Wer in Waukesha nicht willkommen ist, wird auch das schnell spüren, aber die Ablehnung wird normaler Weise nicht in Form von Boykotten, Demonstrationen oder Petitionen erfolgen - und damit für den Forscher sehr viel schwerer zu erkennen und auch zu beschreiben sein. Kurz gesagt: wenn es im Folgenden darum geht, die Durchdringung der Zivilgesellschaft durch die Mehrheitsideologie darzustellen - wie sehr also liberale und konservative Weltanschauungen Einfluss auf das soziale Leben der Menschen haben - dann wird diese Darstellung sich ganz überwiegend auf das liberale Dane County fokussieren. 
Wer erfahren will, wie tief sich eine Ideologie in die Struktur eines Ortes eingegraben hat, wie hegemonial sie herrscht, der sollte dort nach ihr suchen, wo die Wahrscheinlichkeit sie zu finden zunächst am geringsten erscheint: in jenen Institutionen, die eigentlich die Bastionen der Gegenseite sind. In einer Hochburg der Demokratischen Partei lenkt das die Aufmerksamkeit fast schon automatisch auf die örtlichen Pressure- und Lobbygroups aus dem Arbeitgeber-Lager. Sympathien für die Demokratische Partei sind diese in der Regel eher unverdächtig. Wisconsins einflussreichste Lobby-Gruppe ist eine Organisation mit dem Namen „Wisconsin Manufacturers and Commerce“(WMC). Früher unterhielt WMC exzellente Verbindungen in beide politische Parteien - heute aber ist die Organisation ein stramm republikanischer Unterstützungsverein. Eng verbunden ist WMC auch mit den örtlichen Handelskammern, den „Chambers of Commerce“. Auch diese unterstützen in der Regel die Politik der Republikanischen Partei.

Indes: In Dane County liegen die Dinge tatsächlich anders. Hier hat die „Greater Madison Chamber of Commerce" in den letzten Jahren wiederholt Stellung gegen republikanische Gesetzesvorhaben bezogen. Von Scott Walkers Act 10, von WMC als entscheidender Durchbruch gefeiert, distanzierte sich die Chamber im Februar 2011 vehement. ${ }^{29}$ Deutlich wurde die unorthodoxe Haltung aber bereits 2006, als die Chamber im Rahmen eines Referendums gegen das Verbot der Homoehe kämpfte und damit an der Seite zahlreicher liberaler Interessenverbände stand. Die Chamber verteilte eine Zeit lang auch die in den USA gängigen „endorsements " - Wahlaufrufe für einen bestimmten Kandidaten - und unterstützte dabei in der Vergangenheit sowohl liberale als auch konservative Kandidaten (Rennen zum City Council und zum County Board sind offiziell non-partisan, es stehen also keine Parteizugehörigkeiten hinter den Namen auf dem Wahlzettel). Freilich: Bei den meisten Wahlen, wie etwa zum City Council, stehen Konservative gar nicht zur Wahl. „Liberal, more liberal and really, really liberal“, so beschreibt Jennifer Alexander, die Vorsitzende der Chamber von 2004 bis 2012, die Wahlmöglichkeiten im City Council von Madison. ${ }^{30}$

Wahrscheinlich ist die Chamber eine der wenigen Institutionen in Dane County (abgesehen vom privat organisierten „Reach Out Wisconsin“), in der Demokraten und Republikaner tatsächlich noch aufeinandertreffen und miteinander sprechen. Der derzeitige Vorsitzende der Chamber ist ein moderater Demokrat, wovon es in Dane County nicht gerade viele gibt. Seine Vorgängerin von 2004 bis

29 Vgl. Dan Kaufman: Note on the Cheddar Revolution, in: The New Yorker, 22. Februar 2011, http://www.newyorker.com/news/news-desk/notes-on-the-cheddar-revolution (zuletzt abgerufen am 18.Juni 2015).

30 Gespräch mit Jennifer Alexander, Vorsitzende der Greater Madison Chamber of Commerce 2004-2012, 28. November 2012. 
2012, Alexander, war wiederum eine moderate Republikanerin, die unter anderem das Recht auf Abtreibung befürwortet - wovon es tatsächlich im ganzen Land nicht mehr besonders viele gibt. Wahrscheinlich kommen andere Persönlichkeiten kaum für einen Job in Frage, bei dem es ständig gilt, die Balance zu halten. Denn einerseits sind große Teile der Business Community - wir sahen es bereits - nicht unbedingt glücklich mit der Wirtschaftspolitik der Stadt und des Counties und stöhnen über die in der Tat vielen Regulierungen, die hohen ,property taxes“ und „sales taxes “ und vor allem den großen Einfluss der mächtigen Nachbarschaftsvereinigungen. Ihrer Meinung nach ist Madison Heimstatt des Nimbyism, der notin-my-backyard-Ideologie: So sprächen sich theoretisch alle für urbane Dichte aus - solange eben nichts unmittelbar neben dem eigenen Hause gebaut würde und dann im Sommer vielleicht etwas weniger Licht ins Wohnzimmer scheinen könnte. ${ }^{31}$ Dane County floriert - aber, so empfindet es die Mehrzahl der Unternehmer, eher trotz und nicht wegen der Politik der Stadt und des Counties.

Man könnte meinen, all dieses würde zumindest den überwiegenden Teil der Wirtschaftselite von Madison zu erklärten Gegnern der Stadt-Politik machen, sie überhaupt ins Lager der Konservativen ziehen. Doch all der Beschwernisse zum Trotz: eine solche geschlossene Opposition stellt Madisons Wirtschaftselite beileibe nicht dar und die Politik der Chamber spiegelt das wider. Die Organisation vermeidet als Kollektiv alles, was sie zu sehr in die Nähe der Republikanischen Partei rücken könnte. Für die versprengten Konservativen von Madison ist das ein konstanter Quell der Frustration: sie verstehen nicht, warum selbst der natürlichste Bündnispartner der Republikanischen Partei in Madison die Gefolgschaft verweigert. Ihrer Ansicht nach kann es dafür nur eine Erklärung geben: Es muss an der Politik der liberalen Einschüchterung liegen, und dem Konformitätsdruck, dem sich selbst Madisons Unternehmer nicht entziehen können. Für David Blaska, einen konservativen Blogger in Madison, und damit eine ziemlich einsame Stimme in der Stadt, liegt der Fall klar: „Too many of Madison's businesspeople have Stockholm Syndrome, an identification with their captors, a willingness to take orders rather than give them. ${ }^{\text {"32 }}$

Liberale hingegen halten die These von der „Unterdrückung“ konservativer Ideen und der Verfemung von Republikanern in der Stadt für einen Anflug von mittlelschwerer Paranoia. Als „Culture of Victimization“ etwa bezeichnet Bill Lueders, ein dezidiert liberaler Publizist, die Geisteshaltung vieler Republikaner, die

31 Gespräch mit dem Bauunternehmer Joe Alexander, 2. November 2014.

32 Vgl. David Blaska: Madison Chamber Lands High Draft Pick in Zach Brandon, in: Blaska's Bring It!, 12. November 2012. http://www.ibmadison.com/Blogger/BringIt/November-2012/Madison-Chamber-lands-high-draft-pick-in-Zach-Brandon (zuletzt abgerufen am 27.01.2015). 
sich gerne zu den Opfern eines angeblich liberalen Mainstreams stilisieren. ${ }^{33}$ Und John Hendrick, der bis 2014 Vorsitzender des Dane County Boards war, versucht die Klagen der Republikaner in Madison, die man dort schließlich für die Partei der Privilegierten hält, in eine historische Perspektive zu rücken: „Are they oppressed? I don't see it. I don't think they are oppressed in the same sense that different classes and groups have been oppressed through history." ${ }^{34}$

In der Tat erinnern die Klagen der Republikaner von Madison an die rhetorischen Versatzstücke, mit denen auch „Fox News“ das Ressentiment gegen die Dominanz und gleichzeitige Ignoranz der „liberalen Elite“ schürt. Andererseits: Gänzlich abwegig ist die Vorstellung nicht, dass es vielleicht schwieriger sein könnte, Geschäfte in Dane County zu tätigen, wenn man als Freund der Republikanischen Partei gilt. Da sind einmal die direkten Interventionen von politischer Seite. 2013 plante Bürgermeister Soglin eine Verordnung, die bei öffentlichen Ausschreibungen alle Firmen gezwungen hätte, sämtliche Zuwendungen an politische Parteien, Kandidaten, Interessengruppen oder Super-Pacs offen zu legen. Soglins Begründung: Die Stadt könne schließlich nicht Aufträge an Firmen vergeben, die ihrerseits an Gruppen spendeten, die den „Staat hassten.“35 Allerdings fanden selbst einige von Soglins Parteifreunden, dass dieser Vorschlag zu weit gehe und gegen den Grundsatz der freien Meinungsäußerung verstoße und auch die vorsichtige Chamber bezog Stellung dagegen. Am Ende stimmte der City Council in Madison knapp gegen den Vorschlag des Bürgermeisters. ${ }^{36}$

Andere, subtilere Methoden verhindert das nicht. So gehört es etwa für Madisons liberale Tageszeitungen zu den liebsten Beschäftigungen, Unternehmen, die für republikanische Kandidaten gespendet haben, öffentlich zu machen - was bei vielen Betroffenen zu bisweilen würdelosen öffentlichen Verrenkungen und Unterwerfungsgesten führt.

33 Gespräch mit Bill Lueders, Wisconsin Center for Investigative Journalism, 19. März 2012.

34 Gespräch mit John Hendrick, Dane County Board Chair 2012-2014, 25. April 2012.

35 Vgl. Pat Schneider: Mayor Paul Soglin Wants City Contractors to Disclose Lobbying Contributions, in: Capital Times, 08. Mai 2013: http://host.madison.com/news/local/ writers/pat_schneider/mayor-paul-soglin-wants-city-contractors-to-disclose-lobbyingcontributions/article_5e72743e-b772-11e2-9130-0019bb2963f4.html (zuletzt abgerufen am 26.01.2015).

36 Vgl. Ed Treleven: City Council Rejects Mayor's Plan to Require Contractors to Disclose Certain Contributions, in: Wisconsin State Journal, 19. Juni 2013: http://host. madison.com/news/local/govt-and-politics/city-council-rejects-mayor-s-plan-to-re quire-contractors-to/article_e2714918-ba90-587f-bd48-17b33b425a7c.html\#ixzz3Q17 NFggS (zuletzt abgerufen am 27.02.2015). 
Ein solcher Fall spielte sich z.B. 2014 ab, als die „Capital Times“ den Inhaber einer Druckerei als Spender republikanischer Wahlkämpfe der letzten Jahre „,enttarnte.“ Der Unternehmer David K. Reinke sah sich daraufhin gezwungen, öffentlich Abbitte zu leisten und seine Spenden an Romney und andere im Nachhinein in der Zeitung als „Fehler“" zu bezeichnen. ${ }^{37}$

Der mit Abstand skurrilste Fall politischer Selbstverleugnung hatte sich freilich schon 2011 zugetragen, als der frisch gewählte Vorsitzende der Republikanischen Partei von Dane County, der Bauunternehmer Mike Herl, etwa ein gutes halbes Jahr bemüht war, seinen Namen geheim zu halten - aus Angst, seine Firma könnte sonst einen lukrativen Auftrag verlieren. Für einen Mann, dessen Aufgabe vor allem darin besteht, eine Organisation nach außen zu vertreten, war das eine gewiss ungewöhnliche Idee und für die liberale Presse der Stadt, die sich ohnehin gerne lustig macht über die Minderwertigkeitskomplexe von Konservativen in Madison, ein gefundenes Fressen: fortan titulierten sie Herl nur noch als den „Secret G.O.P. Chair. " ${ }^{38}$ Über den Grad empfundener Einschüchterung entscheiden am Ende auch jene, die die Bedrohung wahrnehmen. Ob also eingebildet oder nicht: Für viele Republikaner ist das Klima in Madison und Dane County feindlich und bedrohlich. Natürlich gibt es Geschäftsleute, von denen bekannt ist, dass sie der Republikanischen Partei angehören und die das nicht daran hindert, gute Geschäfte in der Stadt zu machen. Die Liberalen etwa verweisen gerne auf Terence Wall, einen Immobilien-Magnaten aus Madison, der sich 2010 sogar erfolglos um das Amt des Senators bewarb. Aber es sind in der Tat sehr, sehr wenige, die sich „outen“ und in der Regel sind es solche Unternehmer, deren Position ökonomisch sehr gesichert scheint.

Dennoch gibt es weitaus wichtigere Gründe, warum die Wirtschaftselite von Madison politisch so offenkundig anders strukturiert ist als im Rest des Bundesstaates Wisconsin. Zum Teil sind die Interessenlagen einfach andere: Wenn die Chamber sich für das Thema Stammzellenforschung engagiert - ein Thema, dass WMC aufgrund der engen Beziehung zur Republikanischen Partei und den dortigen Befindlichkeiten auf Seiten der religiösen Rechten meidet - dann eben ganz

37 Vgl. Jack Craver: The Madison company that contributed to Romney's Super PAC, in: Capital Times, 12. März 2014: http://host.madison.com/news/local/writ ers/jack_craver/the-madison-company-that-contributed-to-romney-s-super-pac/article _c2bad788-a95c-11e3-91b1-0019bb2963f4.html\#ixzz3Q1AAkRv8 (zuletzt abgerufen am 20.06.2015).

38 Vgl. Bill Lueders: Dane County's Secrtet GOP Chair, in: Isthmus 13. November 2008, abrufbar unter: http://www.isthmus.com/news/news/dane-countys-secret-gop-chair/ (zuletzt abgerufen am 20.06.2015). 
einfach deswegen, weil nur in Madison aufgrund einer forschungsstarken Universität Biotechnologie als Wirtschaftsfaktor überhaupt eine nennenswerte Rolle spielt. Und dass die Chamber 2006 das Thema Homoehe unterstützte, erklärt sich durch die schlichte Tatsache, dass viele Unternehmen im Raum Madison ganz einfach eine andere Interessenlage haben: Für viele der High-Tech Unternehmen in der Region ist Diversität ein Wettbewerbsfaktor im Kampf um die besten Köpfe. ${ }^{39}$ Auch die Chamber ist in ihrer Lobbyarbeit deswegen vor allem darum bemüht, die richtigen atmosphärischen Rahmenbedingungen für die Angehörigen der Creative Class zu fördern. Die starke Beachtung von Life-Style Faktoren lässt sie daher häufiger eine liberale linke Agenda unterstützen. Obgleich sie die strengen Umweltauflagen in Madison und Dane County beklagen, tragen sie die restriktive Raumordnungspolitik der Stadt (oder wie es der „Secret G.O.P. Chair“" Mike Herl im Interview überaus plastisch ausdrückt: „You can't even build a damn Dunkin Donuts without putting 16 appartments on top of it. For Christ's sake! ${ }^{\text {(440) }}$ ) zumindest im Grundsätzlichen oft mit. Denn auch ihnen ist es ein Anliegen, dass die beiden Seen, die Madison umschließen, sauber und für die Öffentlichkeit zugänglich bleiben, und dass die schlimmsten Auswüchse suburbaner Zersiedelung ausbleiben: denn beides ist auch ihrer Ansicht nach wichtig, um die Stadt lebenswert zu halten und jüngere Generationen nach Madison zu locken. ${ }^{41}$

So leben der öffentliche Sektor - in Dane County sind immerhin rund 20\% der Beschäftigen Angestellte des öffentlichen Dienstes - und der private Sektor in Madison und Dane County in einer Art friedlicher Symbiose, bei der die AntiGovernment-Rhetorik der Republikanischen Partei kaum verfangen kann. Denn schließlich: geht es der öffentlich finanzierten University of Wisconsin gut, dann wirkt sich in jedem Fall positiv auf die Innovationsfähigkeit der Ökonomie Madisons aus. Wenig verwunderlich, dass manche in Madison schon lange spekuliert hatten, Walkers nächster Schlag nach seinem Angriff auf die Gewerkschaften des öffentlichen Dienstes könnte nun der Universität gelten - alleine schon deswegen, weil durch sie der Nachschub an „Out-of-State-Liberals“ in die verhasste Demokraten-Hochburg Madison gestoppt werden könnte. Bei der nächsten Runde von Budgetkürzungen 2015 strich Walker der Universität dann tatsächlich 13\% ihres Budgets. ${ }^{42}$ Scott McDonell, demokratischer County Board Chair bis 2012, sieht

39 Gespräch mit Jennifer Alexander, 28. November 2012

40 Gespräch mit Mike Herl, Vorsitzender der Republikanischen Partei von Dane County von 2008-2014, 31. Mai 2012

41 Gespräch mit Jennifer Alexander, 28. November 2012.

42 Vgl. Julie Bosman: 2016 Ambitions Seen in Walker's Push for University Cuts in Wisconsin, in: New York Times, 16. Februar 2015: http://www.nytimes.com/2015/ 
die Solidarität vieler Firmen und Inhaber von Geschäften in Madison mit den Gewerkschaften während der Anti-Walker-Proteste 2011 ebenfalls in ähnlichen Interessenlagen begründet, denn unter ihren Kunden seien schließlich ebenfalls viele Angestellte des öffentlichen Dienstes, die durch die Kürzungen weniger für den Konsum übrig hätten. ${ }^{43}$

Konformität mag also der eine Grund sein, warum in Madison selbst die Wirtschaftselite keine Zitadelle konservativer Ideologie darstellt. Der zweite Grund ist eine sehr spezifische, abweichende Interessenlage, durch die der private Sektor in einer Symbiose mit liberalen politischen Eliten steht. Und schließlich gibt es noch einen dritten Grund, und dieser wiegt am schwersten: Viele Unternehmer in Madison sind tatsächlich überzeugte Liberale, teilweise sogar besonders engagierte Parteigänger der Demokraten. Die Stadt hat, wie erwähnt, eine andere ökonomische Struktur, die andere Arten von Unternehmen und Universitätsabsolventen anzieht als der Rest des Staates. Niemand verkörpert das stärker als Madisons wichtigster privater Arbeitgeber: EPIC Systems.

EPIC, das ist vor allem die Firmengründerin und Chefin Judy Faulkner. Faulkner ist so etwa die Sphinx von Madison: sie selbst gibt praktisch keine Interviews und auch die Firmenpolitik von EPIC ist äußerst verschwiegen. Wie in vielen Software-Firmen herrscht im Innern des Unternehmens anscheinend eine Art von esoterischem Kult, der sich unter anderem in einem Kodex für die Mitarbeiter niederschlägt und Punkt 1 der 12 „EPIC-Principles“ lautet: „,Do not go public. “44 Man weiß daher wenig über die Firma aus Verona, einem Vorort von Madison. Aber zwei Dinge sind unbestritten: Zum einen, dass Madisons High-Tech Boom bei genauerer Betrachtung vor allem ein „EPIC-Boom“ ist: In den letzten 10 Jahren hat sich die Mitarbeiterzahl mehr als verdoppelt und mittlerweile beschäftigt EPIC fast 10.000 Mitarbeiter. Viele der neuen Start-up Unternehmen in Madison sind Gründungen ehemaliger EPIC-Mitarbeiter. Und schließlich ist auch dies kein Geheimnis: Judy Faulkner gilt als eine der größten Spenderinnen der Demokratischen Partei in Wisconsin.

02/17/us/politics/scott-walker-university-wisconsin (zuletzt abgerufen am 01.05. 2015).

43 Gespräch mit Scott McDonell, 28. März 2012.

44 Vgl. Jeff Buchanan: My Epic journey: An insider's look at what makes Dane County's biggest company tick, in: Capital Times, 7. Mai 2014, http://host. madison.com/news/local/my-epic-journey-an-insider-s-look-at-what-makes/article 06e96295-13ed-51ef-9821-be0da8fc31dd.html\#ixzz3Q1IRnYZw (zuletzt abgerufen am 27.01.2015). 
Vor allem aber hat EPIC unter ihrer Führung entschieden, jede Kooperation mit Firmen zu beenden, die Mitglied im republikanisch dominierten WMC sind ${ }^{45} \mathrm{Un}$ ter diesem Druck entschlossen sich tatsächlich mehrere Firmen, WMC zu verlassen. Die vielen kleinen Tech-Firmen in Madison sind dort ohnehin kein Mitglied und fühlen sich von der Agenda von Wisconsins größtem Lobby-Verband nicht vertreten. Verantwortlich dafür sind nicht nur die möglicherweise divergierenden Interessen oder WMCs klare parteipolitische Positionierung. Da ist außerdem auch eine kulturelle Fremdheit, die dafür sorgt, dass Madisons Start-Up Community sich wenig heimisch fühlt in einem noch von klassischen Industriebetrieben dominierten Wirtschaftsverband. ${ }^{46}$

Das alles sind die Gründe, warum der amerikanische Konservativismus in Dane County selbst innerhalb der Business-Community keine Heimat findet. Und gleichzeitig belegt es, wie tiefgreifend die Mehrheitsideologie den gesellschaftlichen Takt der Stadt Madison bestimmt. Im Fall von Dane und Waukesha County scheint es in der Tat nicht übertrieben zu sein, wenn man feststellt, dass die Prägung durch den Ort viele der normalerweise üblichen Gruppenloyalitäten oder sozio-demographischen Korrelationen eindeutig überlagert oder sogar vollständig verdrängt. So gehört es etwa zu den jeweiligen Zerrbildern in Dane und Waukesha vom jeweils anderen Ort, dass die hohen Stimmenanteile der Demokraten in Dane County sich ausschließlich den vielen Angestellten des öffentlichen Dienstes verdanken, die so ihre eigenen Pfründe sicherten. Umgekehrt hält man in Dane County Waukeshas Konservativismus für das Produkt reicher, weißer Amerikaner, die sich mit ihrer Stimme die Steuersenkung für Wohlhabende erkauften.

Wie bei so vielen Klischees ist auch an diesen etwas dran, aber die Wahrheit ist zugleich auch weitaus komplexer. Mit Hilfe der DWPS lässt sich vergleichen, wie die verschiedenen demographischen Gruppen in Dane und Waukesha bei der Präsidentschaftswahl 2012 wählten und inwiefern diese Ergebnisse vom nationalen Wahlergebnis abwichen. Tatsächlich lagen die beiden Parteien in ihren Hochburgen in fast allen demographischen Gruppen vorne - sie sind, wenn man so will, veritable Volksparteien. In Dane County erhielt Obama z.B. bei jenen, die mehr als 100.000 Dollar im Jahr verdienen (was die allerwenigsten Angestellten des

45 Vgl. Mike Ivey: Businesses are turning backs on WMC, in: BIZTIMES. com, 07.07.2008: http://www.biztimes.com/article/20080707/BLOGS/307079990/ (zuletzt abgerufen am 20.06.2015)

46 Vgl. Marc Eisen: What the hell do they do? Tech Leaders Get Little Help From Wisconsin Manufacture \& Commerce, in: Isthmus, 18. September 2014, http://www. isthmus.com/news/cover-story/tech-leaders-get-little-help-from-wisconsin-manufactur ers-and-commerce/ (zuletzt abgerufen am 20.06.2015). 
öffentlichen Dienstes verdienen dürften), 66\% der Stimmen - auf nationaler Ebene waren es 2012 nur 44\%. Andersherum konnte Mitt Romney in Waukesha County selbst in der Gruppe derjenigen, die unter 50.000 Dollar verdienen, die Mehrheit der Stimmen erreichen, wenngleich weniger eindeutig mit $55 \%$.

Abbildung 15: Vergleich Wahlverhalten Dane und Waukesha County bei Präsidentschaftswahl 2016 mit nationalem Wahlverhalten - Einkommen.

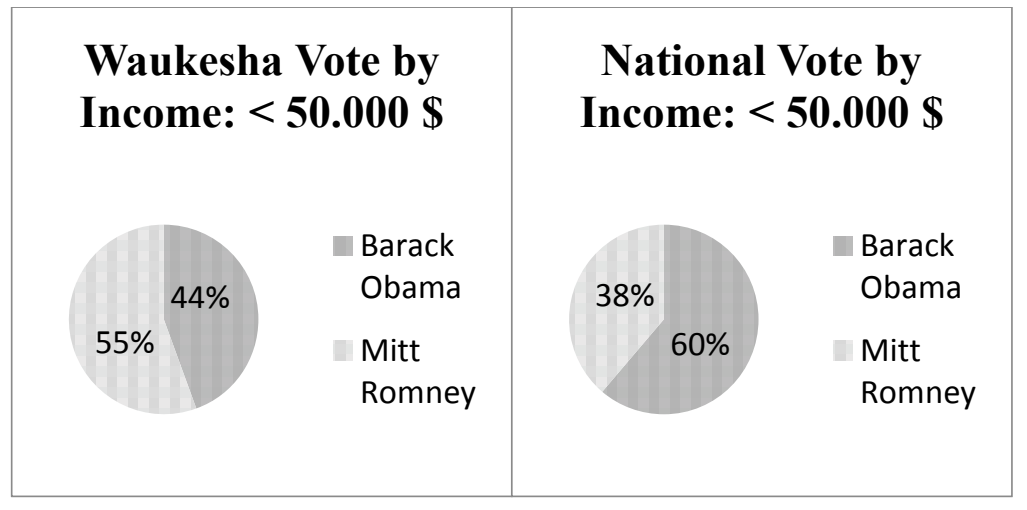

\begin{tabular}{|c|c|}
\hline $\begin{array}{c}\text { Dane County Vote } \\
\text { by Income: } \\
\text { 100.000\$ or more }\end{array}$ & $\begin{array}{c}\text { National Vote by } \\
\text { Income: } 100.000 \$ \\
\text { or more }\end{array}$ \\
\hline $\begin{array}{l}\text { Barack } \\
\text { Obama } \\
\text { Mitt } \\
\text { Romney }\end{array}$ & $\begin{array}{l}\text { Barack } \\
\text { Obama } \\
\text { Mitt } \\
\text { Romney }\end{array}$ \\
\hline
\end{tabular}

Quelle: Dane/Waukesha: Eigene Darstellung, Daten der DWPS; National: CNN Exit Polls 2012 (http://edition.cnn.com/election/2012/results/race/president/)

Der gleiche Überlagerungseffekt zeigte sich bei den verschiedenen Alterskohorten. Bekanntlich gibt es hier bei den letzten beiden Präsidentschaftswahlen eine eklatante Generationenlücke: die Republikaner sind bei jüngeren Wählern stark unterrepräsentiert. In Waukesha jedoch erhielt Romney selbst bei den 18-29-jäh- 
rigen eine überwältigende Mehrheit, die sogar noch über seinem Ergebnis in älteren Altersgruppen liegt. Umgekehrt gewann Obama in Dane County auch die Stimmen der über 65-jährigen. Auch bei der Frage des Bildungsgrades zeigt sich dieser Überlagerungseffekt, wenngleich weniger drastisch. Allein bei der Frage der Hautfarbe erwies sich der Ort überhaupt nicht als Durchbrecher sonstiger soziodemographischer Charakteristika: Hispanics und African-Americans wählten auch in Waukesha demokratisch, wenngleich diese Gruppen zahlenmäßig dort kaum ins Gewicht fallen.

Abbildung 16: Vergleich Wahlverhalten Dane und Waukesha County bei Präsidentschaftswahl 2016 mit nationalem Wahlverhalten - Alter.

\begin{tabular}{|c|c|c|c|}
\hline \multicolumn{2}{|c|}{$\begin{array}{l}\text { Waukesha County } \\
\text { Vote by age } 18-29\end{array}$} & \multicolumn{2}{|c|}{$\begin{array}{l}\text { National Vote } \\
\text { by age } 18-29\end{array}$} \\
\hline $23 \%$ & $\begin{array}{l}\text { Barack } \\
\text { Obama }\end{array}$ & $37 \%$ & $\begin{array}{l}\text { Barack } \\
\text { Obama }\end{array}$ \\
\hline $73 \%$ & $\begin{array}{l}\text { Mitt } \\
\text { Romney }\end{array}$ & $60 \%$ & $\begin{array}{l}\text { Mitt } \\
\text { Romney }\end{array}$ \\
\hline
\end{tabular}

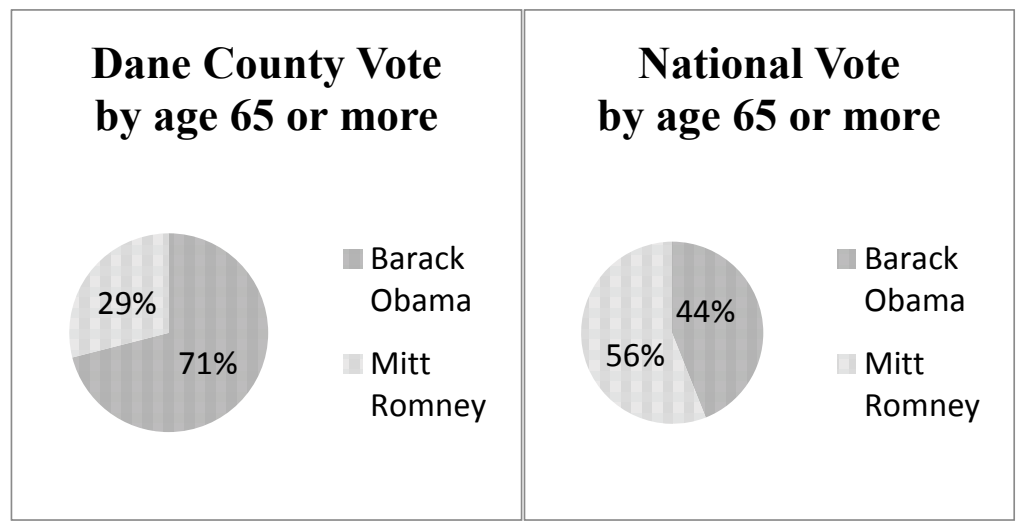

Quelle: Dane/Waukesha: Eigene Darstellung, Daten der DWPS;

National: http://edition.cnn.com/election/2012/results/race/president/ 
Und schließlich zeigt sich der Volkspartei-Charakter beider Parteien sogar beim von der Hautfarbe abgesehen - heute wohl größten Differenzierungsmerkmal der politischen Wahlentscheidung: der Religiosität. Bei der Wahl 2012 hatte Obama unter Amerikanern, die mindestens einmal pro Woche in die Kirche gehen, lediglich $39 \%$ der Stimmen geholt. ${ }^{47}$ In Dane County aber erhielt er von der gleichen Gruppe über $60 \%$ der Stimmen, bei jenen, die öfter als einmal die Woche gehen, sogar 65\%. In Waukesha hingegen gewinnt Romney selbst eine Mehrheit unter säkularen Wählern, die angeben, nie in die Kirche zu gehen - eine Gruppe, die auf nationaler Ebene bekanntlich sehr stark demokratisch wählt.

Abbildung 17: Vergleich Wahlverhalten Dane und Waukesha County bei

Präsidentschaftswahl 2016 mit nationalem Wahlverhalten - Religiosität.
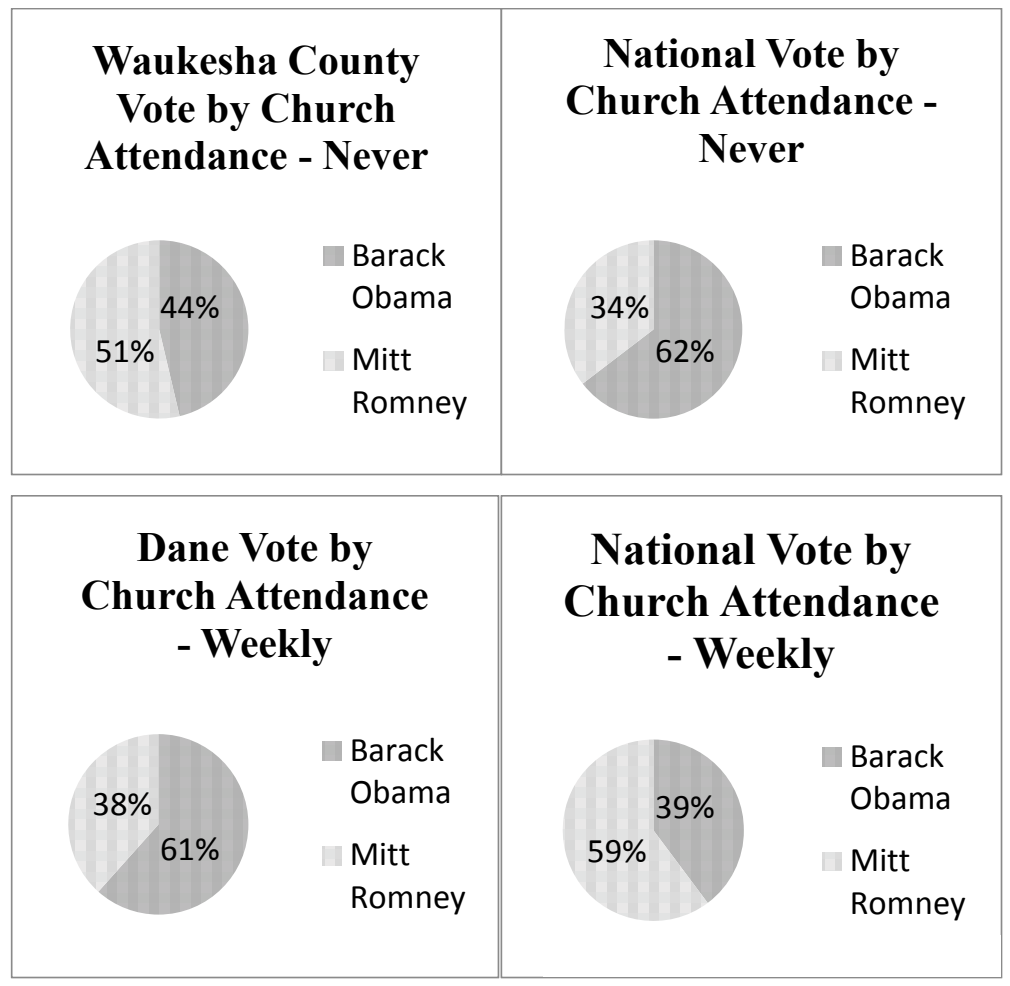

Quelle: DWPS / http://edition.cnn.com/election/2012/results/race/president/

47 http://www.pewforum.org/2012/11/07/how-the-faithful-voted-2012-preliminary-exitpoll-analysis/ 
Von allen überraschenden Befunden ist dieser dann vielleicht der verblüffendste. Wahrscheinlich zeigt sich die zivilgesellschaftliche Dominanz der Mehrheitskultur nirgendwo plastischer als in der religiösen Landschaft Dane Countys. Natürlich bleibt es dabei, dass das „blaue“ Amerika weitaus säkularer ist als das „rote“ Amerika, auch in Wisconsin: Im liberalen Dane County gehen nur 30\% der Befragten einmal pro Woche oder häufiger in die Kirche, während es in Waukesha County über $42 \%$ sind. Aber die wahre Differenz verbirgt sich eher in der Art der Kirchen und Kirchgänger beider Orte. In Madison gehören viele Kirchen der liberalen „Mainline“-Tradition an und einige von ihnen sind dezidierte Träger der liberalen Kultur der Stadt. Sie sind stark verankert in der „Social-Justice“-Bewegung und halfen 2011 auch bei der Mobilisierung der Anti-Walter-Proteste. 2006 unterstützten viele von ihnen in einem Referendum des Bundesstaates die HomoEhe.

Besonders hervor stechen hier die „Unitarian Universalists“, der, wenn man so will, liberale Flügel des liberalen Protestantismus. „Churches of Liberal Guilt“, nennt sie der konservative Blogger David Blaska und was er noch zu diesen Kirchen zu sagen hat, ist zwar voller Zynismus, anderseits aber auch von jener klaren Pointiertheit, die gesellschaftlichen Underdogs ebenso wie den Verlierern der Geschichte manchmal zu eigen ist: „What they say is: When we pray it's to whom it may concern. Cause we are not sure if there is someone [...] I mean homosexuality is fine, but for them it's a sacrament. I got no problem for me, but [...] they're like: Oh my god, we love you. Come in to our church [...] Well. And that's fine. I mean, they advertise being non-judgemental. That is [...] If you think of a church being non-judgemental. You know? What did Jesus say? Whatever! You know? It doesn't matter [...] Comme si, comme ça!"48 In der Tat sind die Unitarian Universalists eine Kirche, die man eher als spirituell denn als christlich bezeichnen würde. Zu ihren Grundaussagen gehört etwa die „free and responsible search for truth and meaning ${ }^{\prime 49}$, nicht die Fixierung auf schriftlich überlieferte Dogmen.

Nicht alle Kirchen in Madison sind so stark mit dem liberalen Lebensgefühl der Stadt verbunden. Aber selbst viele der gemäßigt moderateren protestantischen Kirchen sind in Madison noch ein wenig liberaler als ihre nationalen Dachverbände. So hat sich die Presbyterian Church in Madison früh und eindeutig für die Homo-Ehe ausgesprochen, schon zu einem Zeitpunkt, als die Kirche auf nationaler Ebene mit dem Thema noch schwer gerungen hat. Als 2006 das Verbot der

48 Gespräch mit David Blaska, 21. März 2012.

$49 \mathrm{http}: / /$ madisoncountyuu.org/what-we-believe/ 
Homo-Ehe in Wisconsin per Referendum zur Debatte stand, da taten sich viele Kirchen in Madison mit dem Thema schwerer als ihre nationalen Dachverbände. ${ }^{50}$ Am aussagekräftigsten in Bezug auf die Prägewirkung des Ortes und die Anpassungseffekte, die diese nach sich zieht, ist freilich die komplexe Haltung der größten und lange Zeit am schnellsten wachsenden Kirche von Dane County: Blackhawk Church. Blackhawk Church ist eine evangelikale Megachurch in Middelton, einem der Vororte von Madison. An Sonntagen strömen bis zu 4000 Gläubige in einen hochmodernen Kirchenkomplex, der 2007 gebaut werden musste, weil die Kirche bis dahin rasant und stürmisch gewachsen war. Der Gottesdienst ähnelt der Dramaturgie vieler anderer ähnlicher Megachurches: Moderne christliche Popmusik, Texte aus der Bibel an die Wand gebeamt, Video-Einspielungen, freie Predigten. Der Senior Pastor ist heute, an diesem Abend des 5. Oktober 2014, als der Autor den Gottesdienst von Blackhawk besucht, leider verhindert, seine Ansprache ist eine Aufzeichnung der Morgenpredigt per Stream. Aber die Dame am Infoschalter hat einem immerhin bereits mitgeteilt, dass man dennoch einen guten Tag gewählt habe. Das Thema lautet nämlich „Why is Sex Such a Big Deal?“ Das Publikum ist relativ jung und wohl auch deshalb verkehren Busse zwischen dem fast 10 Meilen entfernten Campus in Madison und der Kirche.

Diese größte Kirchengemeine in Dane County, gelegen in einem der liberalsten Flecken der USA, ist in theologischer Hinsicht extrem konservativ. Geglaubt wird auch hier, wie in allen evangelikalen Kirchen, an die wörtliche Überlieferung der Bibel - die das „unfehlbare“ Wort Gottes darstelle. ${ }^{51}$ Und auch an diesem Abend, wo man also endlich erfährt was der „Big Deal about Sex“ ist, lässt der Senior Pastor Chris Dolson bei aller Konzilianz, dass Gott natürlich jeden liebe, an entscheidenden Dingen keinen Zweifel: Die Ehe sei nur etwas zwischen Mann und Frau, wer Sex außerhalb der Ehe, oder jedenfalls einer festen Partnerschaft praktiziere, sündige und riskiere, seiner Seele schweren Schaden zuzufügen.

Eigentlich sollte man daher davon ausgehen, dass Blackhawk - wie die meisten anderen evangelikalen Freikirchen Amerikas - damit auch politisch konservative Botschaften aussendet. Blackhawk ist immerhin Mitglied der „Evangelical Free Churches of America“" (EFCA), einem der größten Dachverbände evangelikaler Kirchen in den USA. Nach einer Studie aus dem Jahr 2001 über die politischen Ansichten der Pastoren dieser Vereinigung sind beinahe 100\% von ihnen

50 Vgl. Kenneth Burns: Rallying the Faithful - Advocates for and against the proposed gay marriage ban tap into the wellspring of religious conviction, in: Isthmus, 5. Oktober 2006: http://www.isthmus.com/news/cover-story/rallying-the-faithful/ (abgerufen am 1. Mai 2015).

51 Vgl. das „Mission Statement“ von Blackhawk: http://www.blackhawkchurch.org/ discover/about/what-we-believe/ 
Republikaner. Bei der Wahl 2000 votierten 97\% der Pastoren für George W. Bush. ${ }^{52}$ Allerdings: In Madison ist auch dies anders. In politischer Hinsicht ist die Haltung von Blackhawk nämlich extrem ambivalent - und das hat vor allem mit der Tatsache zu tun, dass die Kirche in Dane County liegt. In einem internen Positionspapier der Kirche heißt es: „we will not have [...] Christian campaigns against various moral issues of the day. We will not march against same-sex marriage, abortion, or other cultural practices we find to be in conflict with biblical truth. The reason for this refusal is not because truth is not important, but because such polarizing activities tend to divide and separate us from the very culture we are trying to reach." Madison, heißt es in dem Papier, sei natürlich fremdes Territorium, „We are aliens in a different Culture.“ Aber man wolle keine separierte Subkultur sein, die verbittert auf die Mehrheitskultur schaue..$^{53}$

Im Grunde, sagt etwa Matt Rusten, einer der Junior Pastors von Blackhawk, gäbe es drei konventionelle Möglichkeiten, wie konservative Glaubenskongregationen mit der modernen Welt umgehen könnten: „Purity“, also der Rückzug aus der modernen Gesellschaft um den eigenen Glauben nicht zu beschädigen; „Conflict“, also der Kampf gegen die moderne Gesellschaft; oder „Adaption“, also die teilweise Preisgabe der eigenen Überzeugungen und die Anpassung an die Mehrheitsgesellschaft. Und dann schließlich gäbe es eine vierte Möglichkeit, die Rusten als „faithful presence“ bezeichnet und das Verhalten seiner Kirche bestimme: Man setzte ein Beispiel, was es heißt, ein guter Christ in einer sündhaften Welt zu sein, versuche aber nicht, aggressiv andere von einem besseren Weg zu überzeugen.

Das alles ist natürlich ein schwieriger Balanceakt voller unlösbarer Widersprüche, erzeugt eine Spannung, die die Verantwortlichen von Blackhawk auch gar nicht leugnen. In der Vergangenheit hat es offenkundig immer wieder Versuche von kleinen Gruppen gegeben, die Kirche über die verschiedenen Themengruppen, die die Kirche anbietet, stärker politisch zu mobilisieren. Aber die Laienführer in Blackhawk seien geübt darin, solche Diskussion zu neutralisieren, sagt Rusten. ${ }^{54}$ Es gibt zwar in Madison und Dane County auch einige wirklich konservative Kirchen, die sich auch in ihrer politischen Rhetorik Sonntag für Sonntag am Liberalismus und der Kultur der Stadt abarbeiten. Nur: die mit weitem Abstand

52 Vgl. Kedron Bardwell: Evangelical Free Church of America, in: Corwin E. Smidt (Hg.): Pulpit and Politics: Clergy in American Politics at the Advent of the Millenium, Waco 2004, S.195-206. Die Zahlen basieren auf einer schriftlichen Befragung von 676 Pastoren, von den 261 (39\%) den Survey beantworteten.

53 Internes Positionspapier der Blackhawk Church: „Blackhawk Church and Our Culture“ (Fall 2014).

54 Gespräch mit Matt Rusten, 7. Oktober 2014. 
größte konservative Kirche unter ihnen hat entschieden, die Politik außen vor zu lassen. Oder wie es in einem anderen Positionspapier der Kirche heißt: „Politics Divides; the Gosple Unites. ${ }^{\text {"55 }}$

Tief also reicht die zivilgesellschaftliche Durchdringung durch die Mehrheitskultur und ihre Ideologie in Dane County. Bisher ging es dabei um Institutionen, deren politische Bedeutung offenkundig ist. In Dane County agieren zwei der verlässlichsten gesellschaftlichen Bündnispartner der Republikanischen Partei, die Wirtschaftslobby und konservative protestantische Kirchen, mit Blick auf die Mehrheitsverhältnisse sehr vorsichtig, bzw. teilen sogar von vornherein nicht die weltanschaulichen Prämissen des amerikanischen Konservativismus. Doch der Liberalismus von Dane County und Madison ist mehr als nur ein Konglomerat von politischen Anschauungen. Er ist auch und gerade ein Lebensgefühl, ein „Way of Life“. Und dieser „Way of Life“ manifestiert sich auch dort, wo die Politik eigentlich abwesend sein sollte. Politisch kann in Dane County nämlich alles werden. Selbst das Freizeitvergnügen ist davor nicht gefeit, auch nicht Institutionen, die lange Zeit gerade Bürger ganz unterschiedlicher Schichten und politischer Ansichten zusammengebracht haben. So wurde Madisons „Bratfest“ - ein dreitägiges Musikfestival mit Bier und Bratwurst, das an die starken deutschen Wurzeln des Bundesstaates anknüpft und dessen Einnahmen einem guten Zweck zukommen - in den letzten Jahren zum Schauplatz der Auseinandersetzungen um Madisons Selbstverständnis. Schon 2011 gab es die erste Aufregung, als Aktivisten die Würstchen-Sponsoren des Festes, „Johnsonville Sausages“, ins Visier nahmen, weil Angestellte aus dem Management der Firma für Scott Walker gespendet hatten. Daraufhin wurde ein alternatives Bratfest organsiert: „The People's Bratfest.“

Nun war es zwar nicht so, dass Konservative und Liberale fortan nur noch getrennt ihre Würstchen aßen - auf dem Niveau europäischer Milieubildungen mit ihren streng separierten Freizeitorganisationen sind wir schließlich hier noch nicht angelangt. Die meisten Menschen in Madison gingen auch weiterhin zum alteingesessenen „Bratfest“, andere besuchten einfach beide Festivitäten. Gleichwohl hatte das Fest danach seine politische Unschuld verloren und wurde fortan zum Schauplatz von Debatten darüber, inwiefern das Kultur- und Unterhaltungsprogramm der Stadt im Einklang mit den Werten Madisons stehen solle. 2014 kam es beispielsweise zu Kontroversen, als auf einer der fünf Bühnen Bob Lenz auftreten sollte, ein bekannter Pastor und christlich inspirierter „Motivationsredner“, der über die Suizidgefahren von Teenagern sprechen sollte. Allerdings wurde schnell bekannt, dass Lenz als Anti-Abtreibungs-Aktivist bei verschiedenen Gruppen mitgearbeitet hatte, unter anderem bei „Save the Storks“, die mit Bussen vor

55 Internes Positionspapier der Blackhawk Church: „The Elders of Blackhawk Chuch Statement Regarding „Politics and Blackhawk“, Oktober 2008. 
Abtreibungsklinken parken um dort auf schwangere Frauen einzuwirken. Mitglieder des City Councils und des County Boards machten mobil gegen seine Teilnahme: Lenz stünde wohl kaum für die Werte Madisons. ${ }^{56}$ Der Organisator des Bratfests, Tim Metcalf, Inhaber einer Reihe von Supermärkten in der Stadt, entschied sich daher schnell, Lenz wieder auszuladen.

Wie gesagt: Es ist schwer, für Waukesha ähnliche Vorgänge zu finden. Madison versteht sich eben selbst als Community, in der Tag für Tag die Identität der Stadt und ihrer Bürger verhandelt wird und in der dieser Identität auch tagtäglich Ausdruck verliehen wird. In Waukesha aber wird wenig verhandelt. Es gibt dort auch nicht den politischen Bekenntnisdruck, den es in Dane County gibt. Die Vorsitzende der „Waukesha Business Alliance“ - das Gegenstück zur „Chamber of Commerce" in Madison - Suzanne Kelley, möchte ihre parteipolitischen Neigungen auf Nachfrage lieber für sich behalten, obgleich es extrem unwahrscheinlich ist, dass sie sie irgendetwas anderes als Republikanerin sein könnte. Unter den Mitgliedern der Business Alliance, erzählt sie, würde insgesamt wenig über Politik geredet. Wenn doch, dann höre man eher beiläufige Bekundungen der Sympathie für die Politik Scott Walkers. Es könne schon sein, sagt sie, dass es einige Demokraten unter ihren Mitgliedern gäbe; zu erkennen gegeben habe sich allerdings noch keiner. $^{57}$

Noch einmal: Das bedeutet nicht, dass es nicht auch in Waukesha schwierig sein kann, ein Demokrat zu sein oder besonders liberale Ansichten zu vertreten. Es gibt auch dort Menschen, die sich ihres Minderheitenstatus ähnlich bewusst sind wie viele Republikaner in Dane County. Ein Beispiel dafür ist die liberale Bloggerin Lisa Mux - die in Wirklichkeit anders heißt und nicht unter ihrem richtigen Namen bloggt. Mux organisiert seit 2011 die lokale Variante von „Drinking Liberally" - ein monatlich stattfindender Kneipenabend der Liberalen in Waukesha. Dabei es geht, wie Mux sagt, um eine Art „Coming Out“, bei dem die Menschen feststellen sollten, dass in der Nachbarschaft vielleicht ein paar Leute wohnten, die ähnlich dachten wie sie. Es sind Veranstaltungen für die liberale Diaspora - in Madison, Berkeley oder Brooklyn würde solche Veranstaltungen vermutlich wenig Sinn machen. Als Mux begann, die Organisation von „Drinking Liberally“ für Waukesha zu übernehmen, habe sie bei Bars und Restaurants, die sie für die erste Veranstaltung angefragt habe, Missbilligung und Abwehr erfahren: „You

56 Vgl. Joe Tarr: Antiabortion Activist Bob Lenz Uninvited from Brat Fest After Pushback from Public Officials, in: Isthmus, 19. Mai 2014, http://www.isthmus.com/ news/news/antiabortion-activist-bob-lenz-uninvited-from-brat-fest-after-pushbackfrom-public-officials/ (zuletzt abgerufen am 27.02.2015)

57 Gespräch mit Suzanne Kelley, 22. September 2014. 
could tell by talking to people whether you are welcome. You could tell. You would think that the color of money is green, not red or blue." ${ }^{, 58}$

Noch sehr viel prägnanter und drastischer fallen diese Schilderungen bei denen aus, die in Waukesha sozusagen an der vordersten Front der Culture Wars stehen: z. B. die „United Unitarian Universalist Congregation“ in der City of Waukesha. Es ist eine jener bereits erwähnten Glaubensgemeinschaften, die sich als „non-creedal“ beschreiben und verschiedene Glaubensrichtungen willkommen heißen, und dabei politisch sehr aktiv für liberale Anliegen einstehen. Das gilt auch für die Unitarier von Waukesha. Anders als bei der evangelikalen Blackhawk Church in Madison - die allerdings beinahe hundertmal so viele Mitglieder hat kann man keine ideologischen Anpassungseffekte feststellen: die Kirche ist nicht weniger liberal als Unitarier anderswo im Land. Leicht ist das Leben trotzdem nicht als ultraliberale Kirchengemeinde in einem der konservativsten Counties der USA. Schuyler Vogel, der Pastor der Kirche, der selbst allerdings in Milwaukee wohnt, erzählt recht plastisch von den Beschwernissen der Gemeindearbeit: Wie aggressive Abtreibungsgegner vor der Kirche protestierten, oder wie die „Black Lives Matter"-Solidaritäts-Plakate vom Kirchengebäude abgerissen wurden. Vogel beschreibt seine kleine Gemeinde - zu den sonntäglichen Gottesdiensten finden sich um die 50 Leute ein - als liberale Insel in einem tosenden Meer der Intoleranz, ein Ort der ,sicher“ sei für Homosexuelle und andere Minderheiten. Wohin auch sonst in Waukesha solle man gehen, wenn man liberale Ansichten verträte? Auffällig aber ist auch, dass Vogel von „Drinking Liberally“ noch nie etwas gehört hat. Auch sonst sind seine Kooperationspartner eher in Milwaukee. In der Diaspora scheint am Ende jeder für sich selbst zu kämpfen. ${ }^{59}$

Diesen wichtigen Beispielen zum Trotz: Der Leidensdruck der Demokraten in Waukesha scheint geringer zu sein als der der Republikaner in Dane County. Die meisten Liberalen drückten zwar eine gewisse ironische Distanz zu Waukesha aus, und nur sehr wenige hätten es als den Ort beschrieben, an dem sie immer schon leben wollten oder den sie niemals verlassen würden. Es fehlte dabei auch der Enthusiasmus, mit dem viele Konservative Waukesha beschreiben. Aber das Gefühl von Entfremdung, das bei vielen Konservativen in Dane County so überaus präsent ist, ist dort viel weniger greifbar und gegenwärtig - was sich ja auch in den Daten der DWPS spiegelt. Wahrscheinlich hat das auch damit zu tun, dass wer in Waukesha wohnt, dort nicht auch automatisch seinen Lebensmittelpunkt haben muss - dafür liegt Milwaukee immerhin noch jederzeit in Reichweite. Leider fragten wir in der DWPS nicht nach den Orten der Freizeitgestaltung. Aber

58 Gespräch mit Lisa Mux, 15. Mai 2012.

59 Gespräch mit Schuyler Vogel, 16. September 2015 (Skype-Gespräch) 
nach den Eindrücken aus den Interviews spielte die Stadt als Bezugspunkt für Liberale und Demokraten tatsächlich eine weitaus größere Rolle als für viele Angehörige der konservativen Mehrheitskultur. Demokraten/Liberale in Waukesha haben insofern einen „Fluchtpunkt“, über den Republikaner/Konservative in Dane County in dieser Form nicht verfügen.

Das alles erklärt wohl auch die unterschiedlichen Partizipationsquoten von Demokraten und Republikanern in Dane und Waukesha. Abermals sind die Unterschiede in Dane County hier wesentlich größer. Dort, in dieser Hochburg des politischen Aktivismus, berichten etwa laut der DWPS über 37\% der Demokraten, bei der Präsidentschaftswahl 2012 öffentliche Unterstützung für ihren Kandidaten gezeigt zu haben, etwa durch das Aufstellen eines Yard Signs, durch einen Autoaufkleber oder einem Button auf ihrer Kleidung. Bei den Republikanern in Dane County aber waren es lediglich $22 \%$. Dies passt jedenfalls zu den vielen Geschichten von Republikanern, die erzählen, ihr Auto sei wegen eines Romney- oder Walker-Aufklebers zerkratzt oder ihrer Yard Signs zertrampelt worden - oder die sagten, auf eine solche Idee der Meinungsäußerung würden sie ohnehin nie kommen, da das politische Klima in Madison dafür zu aggressiv sei. Selbst der konservative Blogger David Blaska, der sich sonst gerne als unnachgiebige Stimme des Widerstandes inszeniert, beugt sich in dieser Hinsicht angeblich dem Klima der „Einschüchterung“: „I have a pro-Walker bumper sticker on my truck. It's magnetic - I can take it off. .60

In Waukesha hingegen sind die Unterschiede für diese Form politischer Partizipation und Unterstützung marginal. Sowohl bei Demokraten als auch bei Republikanern sind es etwa 30\%, die in dieser Form ihre Unterstützung während des Wahlkampfes 2012 bekundet haben. Dies bestätigt noch einmal nachdrücklich, was sich wie ein roter Faden durch diese Studie zieht: die Konsequenzen der politischen Dominanz des einen politischen Lagers sind in Waukesha insgesamt weniger spürbar als in Dane County und üben somit weniger Einfluss auf das konkrete Verhalten der Parteianhänger beider Seiten aus.

60 Gespräch mit David Blaska, 21. März 2012. 


\section{Die (Lokal-)Politik der Hochburg}

Die Lokalpolitik soll am Ende dieser Expedition in die politischen Hochburgen von Dane und Waukesha County stehen. Am Ende steht sie zum einen, weil sie letztlich Widerspiegelung und Resultat der zunehmenden Homogenität dieser Orte ist, das letzte Glied in einer Kette von Entwicklungen: Wenn in einer Stadt wie Madison kein einziger Republikaner mehr im City Council sitzt, dann ist das Minderheitsbewusstsein eines Konservativen kein Gefühl mehr, sondern eine Tatsache. Nirgendwo zeigt sich die politische Einseitigkeit von Orten wie Dane und Waukesha County daher deutlicher als hier. Aber Lokalpolitik ist zugleich mehr als nur das Endresultat der hier bereits beschriebenen Prozesse. Sie kann auch Ausgangspunkt einer weiteren Verstärkung dieser Effekte sein. Entscheidungen, die auf dieser Ebene getroffen werden, bestimmen sehr maßgeblich die Struktur eines Ortes, gerade in den in ihrem staatlichen Aufbau extrem dezentralen USA: ob es Fahrradwege gibt oder nicht, wie weit die Häuser voneinander entfernt stehen oder für was überhaupt eine Baugenehmigung erteilt wird, wie hoch die Eigentums- und Umsatzsteuern sind, schließlich sogar, wo und wann man welche Getränke und Speisen konsumieren kann - über all das entscheidet in den USA ausschließlich oder in Teilen local government.

Und dass es hier tatsächlich unterschiedliche Präferenzen von Republikanern und Demokraten gibt, das ist bereits in Kapitel 7 über die Magnetwirkung (bzw. Abstoßungswirkung) dieser Hochburgen dargelegt worden. In der Konsequenz bedeutet dies, dass die lokalen Mehrheitsverhältnisse potentiell großen Einfluss auf die Struktur eines Ortes haben können, was in der Folge die Prozesslogik des „Big Sort“ noch weiter verstärken dürfte: Demokratische super-majorities machen unter diesen Umständen also Politik für andere Demokraten, republikanische super-majorities machen Politik für andere Republikaner. Der Kreis ist dann geschlossen - und diese Idee taucht bereits bei einem der Klassiker der Public Choice-Theorie, Charles Tiebout, und seiner Idee des „Foot Voting“ auf ${ }^{1}$ - wenn

1 Vgl. Charles Tiebout: A Pure Theory of Local Expenditures, in: Journal of Political Economy, Vol. 64 (5) 1956: S. 416-424. 
diese Entscheidungen wiederum Auswirkungen auf das potentielle Migrationsverhalten der Einwohner eines Ortes haben. So bietet Dane County zwar eine weitaus bessere öffentliche Infrastruktur als Waukesha County, hat aber im Vergleich dafür eine der höchsten ,property tax“ in Wisconsin, Waukesha eine der niedrigsten.

Interessant wäre es dabei gewiss zu erfahren, inwiefern die Lokalpolitik von Dane und Waukesha anderen Gesetzen folgt als dies bei politisch weniger einseitigen Orten der Fall ist. Allerdings ist das ein schwieriges, wahrscheinlich sogar unmögliches Unterfangen, denn die Lokalpolitik ist eine der großen Leerstellen der ansonsten wahrlich nicht gerade sparsam ausdifferenzierten amerikanischen Politikwissenschaft. Das ist schon deswegen erstaunlich, da bereits Alexis de Tocqueville in der Idee und Praxis der lokalen Selbstregierung die Ursache für Amerikas demokratische Entwicklung und Vitalität sah. Überdies wird so ein wesentlicher Teil der Realität von Politik in den USA überhaupt ignoriert. Etwa ein Viertel des Bruttosozialproduktes des Landes verdankt sich den Ausgaben der über 90.000 verschieden lokalen Gebietskörperschaften - „school boards“, „,city councils“, , ,county boards“, „town boards“, und viele andere Institutionen, die teilweise von Staat zu Staat und von County zu County auch sehr verschieden sein können. ${ }^{2}$ Und wie bereits angedeutet, sind die USA ein sehr dezentral angelegtes politisches System, in dem viele Entscheidungen nicht in Washington (oder in Madison und anderen Hauptstädten der Bundesstaaten), sondern auf sehr viel niedrigerer lokaler Ebene getroffen werden. Und doch wissen wir wirklich erstaunlich wenig darüber, wer in den USA zu lokalen Wahlen als Kandidat antritt, wer überhaupt wählen geht und inwiefern das Resultat dieser Wahlen den „output“ lokaler Politik tangiert. Dabei dürfte das Wahlverhalten auf lokaler Ebene sogar vergleichsweise noch am besten erforscht $\operatorname{sein}^{3}$ - und das obgleich sich in der Wahlforschung nach einer Auswertung weniger als 1\% der Aufsätze in wissenschaftlichen Zeitschriften mit Wahlen auf dieser Ebene beschäftigen. ${ }^{4}$ Im Vergleich dazu sind jedoch lokale Wahlkämpfe oder die Strategien und das Verhalten von lokalen Mandatsträgern nachgerade ein blinder Fleck. Allenfalls in Bezug auf den politischen Prozess in den großen amerikanischen Städten ist die Lage eine andere. Doch was hier unter dem Label der „Urban Politics“ für Chicago, New York, Los Angeles, Atlanta und ein halbes Dutzend weiterer amerikanischer Großstädte erforscht wird, dürfte mit

2 Vgl. J. Eric Oliver/Shang E. Ha/Zachary Callen: Local Elections and the Politics of Small-Scale Democracy, Princeton 2012: S. 1.

3 Vgl. für einen aktuellen Überblick Brady Baybeck: Local Political Participation, in: Donald P. Haider-Markel (Hg.): The Oxford Handbook of State and Local Government, Oxford 2014, S. 95-111; Timothy B. Krebs: Local Campaigns and Local election, in: ebd., S. 189-211.

4 Vgl. Oliver/Shang/Callen, Local Elections a.a.O, S. 2 (FN 4). 
den Realitäten in sehr viel kleineren Einheiten (wo allerdings noch immer die Mehrzahl der Amerikaner lebt) nur sehr wenig zu tun haben. Aus vielerlei Gründen ist anzunehmen, dass die Politik jenseits dieser Millionenstädte, historisch oft geprägt durch die extrem an Patronage orientierten ,party machines“ und in ihrer Bevölkerungszusammensetzung ethnisch sehr heterogen, völlig anders funktioniert. Es käme noch einem Euphemismus gleich, zu behaupten, das Feld amerikanischer Lokalpolitik jenseits dieser Beispiele sei bisher stiefmütterlich behandelt worden; es handelt sich wohl eher um ein Waisenkind.

Über die Funktionsweise lokaler Politik in den USA herrschen gleichwohl einige Annahmen. Sie sei, so wird oft behauptet, weniger ideologisch durchsetzt als die Politik auf der nationalen oder bundesstaatlichen Ebene. Parteiidentifikation spiele eine geringere Rolle bei der Wahlentscheidung, die Streitfragen lokaler Politik ließen sich auch selten anhand des auf nationaler Ebene so überaus präsenten „liberal vs. konservativ“ - Kontinuum verstehen. Stattdessen dominierten temporäre und klar eingrenzbare Themen die Agenda der Lokalpolitik. Wo Konflikte aufbrächen, bildeten sich daher ad-hoc-Koalitionen, die nicht von Dauer seien. Die meisten Entscheidungen auf lokaler Ebene hätten ohnehin einen „managerial character", einen Verwaltungscharakter. Theodore Lowi formulierte in seiner kritischen Würdigung der ,party machines“ in den großen amerikanischen Städten schon in den 1960er Jahren einen Satz, der nach Ansicht vieler Autoren auch heute noch die Essenz lokaler Politik ausdrückt: „There is no Republican or Democratic way to clean a street". 5 Pointiert formulieren daher Eric Oliver und seine Co-Autoren: „Unlike national offices, the politics of local governments are rarely fought along ideological lines. Whereas debates among 'liberal' and 'conservative' elites dominate national and state politics, most local governments are not amenable venues for contesting [...] ideological visions of social organization." ${ }^{6}$ Grundsätzlich wird die amerikanische Lokalpolitik also nicht anders interpretiert als ihr Pendant in Deutschland: Als Hort einer relativ ,,ideologiefreien“ Sachpolitik, wo persönliche Netzwerke und die Persönlichkeit des Kandidaten weltanschauliche Motive eindeutig überlagern. ${ }^{7}$ Wie gesagt: An empirischen Untersuchungen, die diese Behauptungen untermauen würden, besteht ein eklatanter Mangel. Einleuchtend

5 Zitiert nach Christopher R. Berry: Imperfect Union: Representation and Taxation in Multilevel Governments, Cambridge 2009: S. 191.

6 Vgl. Oliver/Shang /Callen, Local Elections a.a.O, S. 7.

7 Vgl. Torben Lütjen: Jenseits der Parteilichkeit? Zum Anspruch der Freien Wähler auf Ideologiefreiheit, in: Martin Morlok/Thomas Poguntke/Jens Walther (Hg.): Politik an den Parteien vorbei. Freie Wähler und kommunale Wählergemeinschaften als Alternative, Baden-Baden 2012. 
dürfte sie den meisten jedoch schon deswegen erscheinen, weil Schätzungen zufolge über ca. 75\% der Wahlen auf lokaler Ebene eine non-partisan ballot darstellen: Hinter dem Namen der Kandidaten steht keine Parteizugehörigkeit. ${ }^{8}$

Jedenfalls soll diese weithin geteilte und grundsätzlich plausible Beschreibung, die die historische Wirklichkeit vermutlich relativ akkurat wiederspiegelt, als Referenzpunkt dienen und danach gefragt werden, ob sie auch weiterhin die Realität amerikanischer Lokalpolitik im Zeitalter der scharfen ideologischen Polarisierung beschreibt. Wie also wirkt sich der nationale Konflikt, weltanschaulich in extremer Weise aufgeladen, in Gremien aus, die, salopp ausgedrückt, darüber zu entscheiden haben, ob eine Umgehungsstraße nun links oder rechts am Ort vorbeiführt?

\section{DANe County: Polarisierung als ERfolgsstrategie}

Beginnen wir abermals mit Dane County. Es ist fraglos der einfachere, klarere Fall. Nach allem was bisher geschrieben wurde, dürfte wohl kaum noch überraschen, dass sich Dane Countys expressiver, täglicher gelebter Liberalismus auch in der Lokalpolitik manifestiert. Um die Kräfteverhältnisse zu erahnen, lohnt sich ein Gespräch mit Mike Herl. Dem Vorsitzenden der Republikanischen Partei von Dane County - als „Secret G.O.P. Chair“, der seine Identität zunächst der Presse nicht verraten wollte, sind wir ihm in diesem Buch schon kurz begegnet - hat eine sehr präzise Vorstellung von Madison und Dane County. Und positiv ist diese nicht gerade. Herl arbeitete früher als Tourmanager von Rock Bands wie Cheap Trick und Mötley Crue. Wer 60 zugedröhnte Musiker und Roadies auf Tour aushalte, der sei für jede Herausforderung gewappnet, sagt er. Und doch: Madison, sagt Herl, ein Mann von hünenhafter und ein wenig furchteinflößender Gestalt, sei schon eine Klasse für sich, nämlich: eine „Freakshow“, bevölkert von „Sozialisten" und anderen Verrückten, die in den 1960er Jahren offensichtlich zu viel geraucht hätten. Ob er überhaupt Hoffnung habe, dass sich die Dinge in Dane County jemals zum Besseren ändern könnten? Und Herl sagt darauf: „When the baby boomers start dying off, sure [...] But here in Madison you have a lot of the

8 Vgl. Brian F. Schaffner/Matthew Streb/Gerald Wright: Teams without Uniforms. The Nonpartisan Ballot in State and Local Elections, in: Political Research Quarterly, Vol. 54 (1) 2001: S. 1-30, hier S. 7. 
freakin hippies that never left campus. That are still here. But they have to die off. They are not going to hand this over. No, they have to die off."

An diesen Aussagen verblüffen vielleicht nicht einmal so sehr die heftigen Ressentiments gegen den politischen Gegner - dies teilt Herl mittlerweile mit vielen anderen in den USA, und zwar durchaus auf beiden Seiten der Barrikade. Atemberaubend aber bleibt, mit welcher Heftigkeit Herl hier mit jener Stadt abrechnet, die er, wohl oder übel, dennoch sein Zuhause nennt und in der er und seine Partei in irgendeiner Weise ja politisch zu operieren haben. Doch Herl ist das scheinbar alles egal: er selbst, sagt er, würde ohnehin niemals für ein öffentliches Amt kandidieren; ihm fehle diese „,bullshit attitude“, die Wahrheit ständig so zu verdrehen, wie es einem gerade passt.

Die eigentliche Wahrheit aber ist: Mike Herl hat leicht reden, denn er muss sich ernstlich auch keine Gedanken machen über politische Ämter. Er wird so schnell nämlich keins bekleiden. Madison hat seit 1968 keinen republikanischen Bürgermeister mehr gehabt. Seit den 1990er Jahren repräsentiert auch kein Republikaner mehr einen Wahlkreis in Washington oder im Parlament des Bundesstaates Wisconsin in Madison, der sich mit den Grenzen Dane Countys überschneiden würde. Im Stadtrat von Madison, dem „City Council“", befindet sich unter den 20 „Aldermen“ kein einziger Republikaner. In der „Mad City“ ist selbst der Sheriff ein Demokrat. Einzig im 37-köpfigen County Board sind noch einige wenige „Konservative“ zu finden - die freilich in der Regel ebenfalls bemüht sind, nicht zu sehr mit der Republikanischen Partei in Verbindung gebracht zu werden. Während die demokratische Partei in Madison eine gut geölte Wahlkampfmaschine ist, die im Zusammenspiel mit Gewerkschaften und Interessengruppen die Wahlkämpfe für lokale Ämter sehr ernst nimmt, verteilen die Republikaner in Dane County erst gar keine ,endorsements“, die in den USA so etablierten Wahlempfehlungen für einen Kandidaten. Herl sagt, dies geschehe aus Anstand, schließlich seien das Wahlen, bei denen Personen und nicht Parteien auf dem Wahlzettel stünden. Aber jeder kennt den eigentlichen Grund der Zurückhaltung: Die Republikanische Partei empfiehlt keine Kandidaten zur Wahl, weil es diesen schaden anstatt nutzen würde. Niemand ist in Dane County darauf erpicht, von Herl und seinen Leuten unterstützt zu werden.

Man muss sich das „endorsement“ durch die County GOP in etwa als sizilianischen Todeskuss vorstellen.

9 Gespräch mit Mike Herl, 31. Mai 2012. 
Es ist diese Asymmetrie, die die lokale Politik in Dane County mehr als alles andere prägt: Die einen versuchen alles, den Parteicharakter und alles Ideologische herauszuhalten, während die anderen nach Kräften bestrebt sind, das Gegenteil zu erreichen. Es lässt sich denken, wer dabei die Oberhand behält. Unparteilichkeit oder Ideologiefreiheit - diese oben genannten angeblichen Charakteristika lokaler Politik in den USA - scheinen allenfalls an der Oberfläche die Atmosphäre zu bestimmen. Der größte Teil der Abstimmungen im County Board wird zwar mit Einstimmigkeit getroffen. Vieles von dem, was dort entschieden wird, eignet sich in der Tat schlecht zur Politisierung: wenn zusätzliche finanzielle Mittel bereitgestellt werden müssen, weil ein besonders harter Winter die Straßen im County mehr als sonst noch ruiniert hat und die Schlaglöcher beseitigt werden müssen, dann hat dieses mit liberalen und konservativen Positionen wenig zu tun. Und dennoch muss man sich das 37-köpfige Dane County Board - eine Ansammlung von ehrenamtlichen Politikern, die dafür lediglich eine bescheidene Aufwandsentschädigung erhalten - ansonsten wie ein kleines Parlament vorstellen, mit markanten ideologischen Trennungslinien, und einer Atmosphäre der Parteilichkeit, die bis ins Persönliche geht. Insbesondere die Verabschiedung des County-Budgets schaffte in den letzten Jahren Dynamiken wie in der nationalen Politik. Bis 2012 etwa besaßen die Konservativen im Board noch immer eine Art Sperrminorität, um ein Veto einzulegen, sobald das County sich für neue Projekte verschulden wollte. Exakt 10 konservative „Supervisor“ - so der Name für die Mitglieder des County Boards - blockierten auf diese Weise von 2010 bis 2012 zahlreiche Vorhaben des County Boards, vor allem Umweltschutzprojekte, die den Erwerb von Land an den Ufern der beiden großen Seen, die Madison umschließen, vorsahen. Es war eine Konstellation, die nicht wenigen Beobachtern wie eine Kopie des Washingtoner Budget-Streits erschien, durch welche die USA mehrfach knapp am Staatsbankrott vorbeischrammten, mitsamt der exakt gleichen Rhetorik auf beiden Seiten. ${ }^{10}$

Die konservativen und progressiven Mitglieder des County Boards (eine Unterscheidung, die hier eher gebräuchlich ist als die Unterteilung in Demokraten und Republikaner) treffen sich vor den Sitzungen der County Boards und verabreden ihre Strategien und ihr Abstimmungsverhalten, obgleich es, wie gesagt, nur eine Minderheit von Fällen sind, in denen wirkliche ideologische Standpunkte

10 Vgl. Steven Verburg: Dane County Board conservatives seek influence by threatening borrowing resolution, in: Wisconsin State Journal, 18. September 2011, http://host. madison.com/news/local/govt-and-politics/dane-county-board-conservatives-seek-in fluence-by-threatening-borrowing-resolution/article_e8ceaaa6-e22d-11e0-aa4c-001cc 4c002e0.html (zuletzt abgerufen am 4. Juni 2015). 
ernsthaft eine Rolle spielen. Wobei die Liberalen diese Art von Koordination eigentlich sowieso kaum nötig hätten: Denn seit 2014 zählen von den 37 Mitgliedern das Board gerade einmal noch 6 zum Block der Konservativen - zu wenig, um eigene Initiativen zu entwickeln oder solche der Gegenseite zu blockieren.

Interessanterweise ist diese erdrückende Dominanz des liberalen Lagers gleichwohl jüngeren Datums, als es Madisons Status als bereits jahrzehntelanger Hochburg des amerikanischen Liberalismus vermuten ließe. Obgleich gewiss schon immer politisierter als anderswo, entsprach die lokale Politik bis vor etwa 10 Jahren noch sehr viel stärker dem eingangs dieses Kapitels zitierten Credo der Über- bzw. Unparteilichkeit lokaler Politik. Das County Board war auch nicht unbedingt eine Institution, auf der das große Interesse der Demokratischen Partei oder liberaler Interessengruppen lag. In den 1990er Jahren war es auch deshalb zu einer ungewöhnlichen Konstellation gekommen: Für ein paar Jahre, zwischen 1992 und 1996, existierte im Board eine konservativ-moderate Mehrheit. Eine republikanische Mehrheit war dies deswegen noch nicht, denn schon damals hielt sich die republikanische Partei aus der Lokalpolitik weitgehend heraus. Die Bruchlinien im County Board verliefen ziemlich genau zwischen den Wahlbezirken, die zur Stadt Madison gehören und den eher ländlichen Gegenden in Dane County. Heute wie damals ging es vor allem um ,zoning regulations“, die sehr restriktiven Bau- und Umweltauflagen, die insbesondere vielen Farmern in der Umgebung ein Dorn im Auge waren. Der County Board Chair dieser Jahre, Michael Blaska (der Bruder des hier schon zitierten konservativen Bloggers David Blaska) hatte sich selbst lange Zeit als Demokrat verstanden, und sich erst in seiner Zeit im County Board kontinuierlich nach rechts entwickelt. Damals, so Blaska, sei es noch möglich gewesen, mit lokalpolitischen Themen jenseits ideologischer Zuordnungen zu punkten. Bei einigen Supervisors sei auch gar nicht so eindeutig gewesen, auf welcher Seite sie eigentlich standen. Er selbst etwa, obgleich Teil der kurzfristigen konservativen Mehrheit, unterstützte damals die Idee, in Dane County auf „Light Rail“ zu setzen, eine Art von S-Bahn-System, das Madison mit seinen Vororten verbunden hätte. Die Meinungen dazu seien damals im County Board nicht strikt entlang der ideologischen Linien verlaufen. ${ }^{11}$ Blaska zitiert gerade dieses Beispiel, weil er weiß, dass es heute zum politischen Lackmusstest geworden ist: Während ein auf Schienen basierendes Nahverkehrssystem heute zu den großen, unerfüllten Sehnsüchten der liberalen Meinungsführer gehört, weil nichts für sie stärker das Ideal von urbaner Dichte verkörpert, lehnen Konservative in Dane County dieses Projekt unisono ab.

11 Gespräch mit Michael Blaska, 25. Mai 2012. 
Irgendwann in den 2000er-Jahren aber begann sich Madisons und Dane Countys Liberalismus stärker in den lokalen Mehrheitsverhältnissen niederzuschlagen. Ein Grund war gewiss, dass das County in dieser Zeit begann, auch im Umland demokratischer zu werden. Es war jedoch auch dem Erfolg einer bewussten Strategie des liberalen Lagers geschuldet. Und diese Strategie ist eigentlich denkbar einfach in einem County, in dem Barack Obama 2008 und 2012 deutlich über 70\% der Stimmen auf sich vereinigen konnte: Unter der Voraussetzung einer solchen politischen Hegemonie haben die politischen Eliten der Mehrheitskultur stets ein Interesse an einer möglichst extremen Polarisierung und Parteipolitisierung der lokalen Wahlen. Sie versuchen, den politischen Diskurs möglichst nah an nationale Themen und damit an die Konfliktmuster nationaler Politik heranzuführen. Die Wahlen zum County Board finden alle zwei Jahre im Frühjahr statt, also nicht zeitgleich zu den nationalen Wahlen, was die Mobilisierung dezidiert ideologisch ausgerichteter Wähler erheblich erschwert. Stattdessen dominieren dann in der Tat die Themen der Lokalpolitik, die sich bisweilen nur schwer in ein „liberal vs. konservativ"-Schema pressen lassen. Zwar gibt es in der Stadt Madison nicht wenige liberale Aktivisten mit großem Interesse an Lokalpolitik. Viele verfolgen gerade auf diesem Feld ihre Kernanliegen, zum Beispiel den Kampf gegen suburbane Zersiedelung. Doch das bleibt eine Minderheit und so dürften diese Wahlen selbst im vergleichsweise hochpolitisierten Dane County von einem Typus dominiert werden, für den William Fischel den Begriff des „homevoters“ geprägt hat: die Besitzer von Eigenheimen, die seit langem an einem Ort wohnen, dort sozial sehr verankert sind und die Kandidaten für lokale Ämter oft sogar persönlich kennen. Nicht selten sind ihre unmittelbaren Interessen stärker berührt, nicht nur aufgrund ihrer Sorge über die Wertentwicklung ihres Hauses, sondern vielleicht auch weil sie als Klein-Unternehmer und Geschäftsleute von Entscheidungen auf lokaler Ebene stärker betroffen sind. ${ }^{12}$ Insgesamt kann die Kombination dieser Faktoren fraglos für einen konservativeren Zuschnitt des Wählerprofils sorgen, als es sich bei nationalen Wahlen herausbildet. Diese These passt auch exzellent zu Analysen, die herausgefunden haben, dass „,non-partisan ballots“ die Wahlbeteiligung sinken lassen und dadurch konservative Kandidaten tendenziell bevorteilt werden. $^{13}$

12 Vgl. William A. Fischel: The Homevoter Hypothesis: How Home Values Influence Local Government Taxation, School Finance and Land-Use Policies, Cambridge 2004.

13 Vgl. Schaffner et al: Teams without Uniforms, a.a.O; Brian Schaffner/Matthew J. Streb/Gerald C. Wright: A New Look at the Republican Advantage in Non-Partisan Elections, in: Political Research Quarterly, Vol. 60 (2) 2007: S. 240-249. 
Folglich gilt es also, das Elektorat stärker an das der nationalen Wahlen anzupassen. Doch wie erreicht man, dass die ideologischen Konflikte von Washington auch den politischen Diskurs in Dane County bestimmen? Schließlich macht es wenig Sinn, bei Wahlen zum Dane County Board eine Reform des nationalen Gesundheitssystems anzukündigen - das würde auch der eigenen potentiellen Anhängerschaft wenig glaubwürdig erscheinen.

Dane Countys Liberale erreichen diese Polarisierung vor allem durch eine Art von deklamatorischer Politikinszenierung, die zwar auf den ersten Blick nur symbolische Bedeutung zu haben scheint - tatsächlich aber in effizienter Weise die Fronten klärt. In erster Linie sind das die Resolutionen, die das Board mindestens einmal im Jahr, oft aber auch häufiger, verabschiedet, und die mit „County Government“ in der Tat rein gar nichts zu tun haben. Diese Resolutionen fordern etwa den Rückzug der amerikanischen Truppen aus dem Irak, sprechen sich für die Einführung der Homo-Ehe aus oder für die Legalisierung von Marihuana und viele andere Lieblingsthemen der amerikanischen Linken. 2011 verabschiedet das Board, selbstverständlich, eine Resolution, die sich gegen den Act 10 Scott Walkers aussprach. Die politischen Anführer der liberalen Mehrheit räumen offen ein, dass dieses vor allem geschieht, um die Integration nach innen zu stärken und für eine gewisse Gruppenkohäsion zu sorgen. „It keeps our people happy“, wie eine der führenden Stimmen im Board verrät. Doch die viel wichtigere Konsequenz dieser Resolutionen ist, dass sie die Mitglieder des Boards dazu zwingen, Stellung zu beziehen: eben für oder gegen den Irak-Krieg, für oder gegen die Home-Ehe, für oder gegen eine Amnestie für illegale Einwanderer usw. Damit unterlaufen die Resolutionen die Intention der Minderheitskultur - in diesem Fall der Republikaner von Dane County - den politischen Diskurs auf lokale Themen zu beschränken und unterstützen die Intention der ideologischen Mehrheitskultur, lokale Politik zu einer Frage der politischen Identität zu machen.

Oft hat das sehr praktische und plastische Konsequenzen: Viele Mandatsträger des Boards, die nicht zur liberalen Mehrheit gehören, werden in den Wahlkämpfen aufgrund ihres Widerstandes gegen diese Resolution attackiert. Es heißt dann, das Kandidat A, der gegen die Annahme der Resolution gegen den Irak-Krieg gestimmt hat, ja ganz offenkundig ein Unterstützer des Krieges sei; oder Kandidat B das Recht auf Abtreibung bestreitet; oder, der schlimmste aller Fälle, Kandidat C nicht für die Resolution gestimmt hat, die sich vom Act 10 Scott Walkers distanziert. Es gibt ein paar Supervisor, die in der Vergangenheit schlau genug waren, nicht in diese Falle zu tappen. Da ist z.B. Ronn Ferrell, einer der wenigen „Überlebenden" der liberalen Mobilisierungswellen der letzten Jahre. Ferrell sitzt seit 2008 im Board, und das obgleich er bei fast jeder Wahl einen Herausforderer gegen sich hatte, stets unterstützt von der Demokratischen Partei. 
Ferell sagt von sich selbst, er sei zwar kein Mitglied irgendeiner Partei, ideologisch jedoch ein „fiscal conservative“ und ein „social moderate.“ Er sagt allerdings auch, dass Wisconsins Gouverneur Scott Walker alles fehle, um Präsident zu werden. Vor die Wahl gestellt, würde er für jeden anderen Demokraten im Kampf ums Weiße Haus stimmen - einschließlich der ultraliberalen Senatorin von Massachusetts, Elisabeth Warren. Ferrell ist wohl tatsächlich kein eingeschworener Republikaner und Konservativer, aber weil er eben auch nicht zur liberalen community von Dane County gehört, ist er für die Gegenseite de facto ein Konservativer. Dass er sich behaupten konnte, liegt zum einen daran, dass sein Wahlbezirk im Vorort Middelton nicht ultraliberal ist, er viel Zeit und Energie in seine Arbeit steckt - aber eben auch daran, dass er zwar „,bekennt“, konservativ zu sein, aber es ansonsten so wie gut wie möglich vermeidet, mit der Republikanischen Partei assoziiert zu werden. Ferrell hat es deswegen auch schlichtweg abgelehnt, bei diesen Resolutionen eine Position einzunehmen: er wählt nicht dagegen, er wählt nicht dafür, er enthält sich nicht einmal offiziell - sondern gibt zu Protokoll, dass es sich nicht um eine Angelegenheit handelt, die County Government betrifft, und er daher gar keine Kompetenz zum Thema besäße. Im Protokoll wird dies unter „did not vote“ gewertet. Damit, erzählt Ronn Ferrell im September 2012, sei er besser gefahren als andere Supervisor, die bei der nächsten Wahl aufgrund ihres Votums gegen diese Resolutionen damit attackiert wurden, offensichtlich nicht die Werte der Gemeinschaft in Dane County zu teilen. Gleichwohl sagt auch Ferrell, dass es letztlich langfristig unmöglich sei, sich als unabhängige Stimme zu profilieren in Dane County: „There is no neutral. You are not allowed to be neutral. " 14

Nach Scott Walkers Act 10 bieten sich im Übrigen noch ganz neue Möglichkeiten, die politischen Unterschiede hervorzuheben. Da die Namen der fast eine Millionen Menschen, die die Petition für den Recall unterzeichnet haben, online in einem Register einsehbar sind, weiß nun jedermann wer den Recall unterstützt hat und wer nicht. Und in Madison ist die Sache ganz einfach: Bei allen, die die Petition nicht unterzeichnet haben, muss es sich wohl folglich um Scott WalkerUnterstützer handeln. Wer in irgendeiner Weise mit dem Gouverneur in Verbindung gebracht werden kann, ist danach in Dane County politisch praktisch erledigt. Das gilt nicht nur für das County Board, sondern z.B. auch für die Richterämter. 2012 traf es etwa Roger Allen, ein von allen Seiten respektierten „County Judge“. Allen, der strikt darauf bestand, ,non-partisan“ zu sein, also keiner Partei und keinem Lager anzugehören, hatte breite Unterstützung sogar von einigen führenden Liberalen der Stadt wie Paul Soglin erhalten. Nichts in seiner Biographie wies ihn als Republikaner oder Konservativen aus. Sein einziges Problem war,

14 Gespräch mit Ronn Ferrell, 18. April 2012. 
dass er wenige Monate zuvor aufgrund einer Vakanz von der republikanischen Landesregierung eingesetzt worden war. Seiner Widersacherin fiel es deshalb leicht, ihn als „Scott Walker Appointee“ zu verunglimpfen. Der Vorwurf verfing und Allen verlor die Wahl. ${ }^{15}$ Da dieses in der Folge noch häufiger passierte, ließ Walker schließlich verlautbaren, dass es wohl keinen Sinn mehr mache, in Dane County bei vakanten Richter-Stellen eine Ernennung durch den Gouverneur vorzunehmen - da diese danach ohnehin abgewählt würden. ${ }^{16}$

Eine weitere Strategie der Politisierung besteht darin, am Tag der County Board Elections gleichzeitig Referenden abzuhalten, natürlich ebenfalls zu Themen, bei denen man sich im ultraliberalen Dane County sehr sicher sein kann, ein positives Echo zu finden. 2014, die Zahl der konservativen Supervisors war mittlerweile bereits auf acht gesunken, gelang es auf diese Weise den Dienstältesten von ihnen, Dave Wiganowsky, aus dem Amt zu hebeln: Gleichzeitig mit den Wahlen zum County Board wurde ein Referendum über die Legalisierung von Marihuana angestrengt. Die Befugnis dafür liegt natürlich beim Bundesstaat Wisconsin, insofern hatte das Referendum praktisch überhaupt keine Bedeutung. Aber noch einmal: um reale Entscheidungen geht es dabei ja auch gar nicht, sondern darum, ein Zeichen zu setzen. Jedenfalls ging auch in diesem Fall das Kalkül auf: Wiganowsky verlor die Wahl und gleichzeitig gab es auch für das Referendum eine klare Mehrheit. ${ }^{17}$

Auch der Fortschritt im Mikro-Targeting - der effizienten und sehr genauen Erfassung potentieller Wähler - spielt diesen Strategien zusätzlich in die Hände. Seit geraumer Zeit besitzen die Untergliederungen der Demokratischen Partei Zugang zum „Voter Activation Network“ (VAN), dem Datenschatz des Democratic

15 Vgl. Nayantara Mukherji: Ellen Berz bests Walker-appointed judge, Roger Allen, in Dane County Circuit Court Primary, in: Isthmus, 22. Februar 2012. http://www. isthmus.com/news/news/ellen-berz-bests-walker-appointed-judge-roger-allen-in-danecounty-circuit-court-primary/ (zuletzt abgerufen am 4. Juni 2015).

16 Vgl. Mary Spicuzza: Scott Walker may stop filling Dane County judge vacancies after 2nd appointee loses, in: Wisconsin State Journal, 4. April 2013. http://host. madison.com/news/local/govt-and-politics/scott-walker-may-stop-filling-dane-countyjudge-vacancies-after/article_f182e392-9cad-11e2-8a3c-001a4bcf887a.html (zuletzt abgerufen am 4. Juni 2015).

17 Vgl. Nathan J. Comp: Andrew Schauer crushes 10-term incumbent David Wiganowsky as liberals increase Dane County Board majority, in: Isthmus, 2. April 2014. http://www.isthmus.com/news/news/andrew-schauer-crushes-10-term-incum bent-david-wiganowsky-as-liberals-increase-dane-county-board-majority (zuletzt abgerufen am 4. Juni 2015). 
National Committee. Durch die Zusammenführung von Spenderlisten, Umfragedaten und Parteiregistrierungsdaten ist damit seit Obamas Kampagne 2008 ein extrem exaktes Bild der Wählerschaft möglich. Das macht es leicht, ideologisch besonders motivierte Wähler sehr gezielt für diese Wahlen anzusprechen, Menschen, denen die Erderwärmung wichtiger ist als der Bau einer neuen Ortsumgehung oder wie viele Spielplätze gebaut werden. Um sie zu mobilisieren braucht man Botschaften, die über die lokale Ebene hinausreichen - und mit genau diesen Botschaften nationaler Politik werden sie auch in Dane County angesprochen. ${ }^{18}$ Auch das trägt dazu bei, dass sich das Elektorat, das an diesen Wahlen überhaupt teilnimmt, verändert, es sich jenem angleicht, das auch bei nationalen Wahlen zur Urne schreitet, wenngleich die Unterschiede in der Beteiligung natürlich eklatant bleiben. ${ }^{19}$

Überhaupt ist die politische Führung der liberalen Mehrheit in Dane County erstaunlich hochprofessionell organisiert. Die Demokratische Partei spricht in der Regel auch dann „endorsements“ aus, wenn zwei Demokraten in der Hauptwahl gegeneinander antreten. Zuvor werden Interviews durchgeführt, in denen die politischen Ansichten der Kandidaten durchleuchtet werden. ${ }^{20}$ Allerdings muss man sich, das wurde schon erwähnt, die Lokalpolitik in Dane County nicht nach Parteien, sondern nach ideologischen Lagern organisiert vorstellen, da ja neben den Demokraten mit „Progressive Dane“ noch eine weitere linke Partei existiert. Beide Gruppen sind allerdings eng miteinander verzahnt. In seiner Zeit als County Board Chair (bis 2012) kontrollierte Scott McDonell (ein Demokrat) auch ein „Political Action Committee“(PAC): „Citizens for Dane County's Future“. Die Spenden für das PAC kamen auch von der Demokratischen Partei, größtenteils jedoch von den Gewerkschaften. McDonell wiederum entschied, an welche Kandidaten das Geld verteilt wurde, und natürlich flossen die Ressourcen an Kandidaten in stärker kompetitiven Wahlkreisen, die wirklich konservative Gegen-Kandidaten hatten. Das PAC unterstützt dabei nicht allein Kandidaten der Demokratischen Partei, sondern auch solche, die zu Progressive Dane gehörten. ${ }^{21}$

18 Gespräch mit Scott McDonell, 28. März 2012.

19 Erstaunlicher Weise blieben alle Nachforschungen und alle offziellen Anfragen erfolglos: die exakte Wahlbeteiligung bei Wahlen zum County Board konnte weder für Dane noch für Waukesha ermittelt werden. Nach den Schätzungen der jeweiligen Funktionäre der lokalen Parteiorganisationen dürfte sie zwischen 15-20\% liegen.

20 Gespräch mit dem Vorsitzenden der Demokratischen Partei von Dane County, Michael Basford, 30.März 2012.

21 Gespräch mit Scott McDonell, 28. März 2012. 
Generell ist der finanzielle Vorsprung des liberalen Lagers enorm, was auch und gerade in Wahlkämpfen zum County Board einen Unterschied macht, wo Kandidaten im Schnitt ca. 8000 Dollar für eine Kampagne ausgeben. ${ }^{22}$

Das sogenannte „redistricting“ ist das letzte Instrument, dass zur Absicherung der eigenen Mehrheit eingesetzt wird, eine Praktik, die ebenfalls aus höheren Ebenen der USA nicht unbekannt, ist und in der sich die selbstverstärkende, perpetuierende Kraft der politisch hegemonialen Verhältnisse am deutlichsten zeigt. 2011 wurden von der liberalen Mehrheit im County Board die Grenzen der einzelnen Wahlkreise neu zugeschnitten. Viele Bezirke, die bis dahin rein ländlich waren, bekamen durch die Einverleibung der Außenbezirke der Stadt Madison einen sehr viel urbaneren Charakter - mit absehbaren Konsequenzen. Andere wurden so verändert, dass konservative Supervisor gegeneinander hätten antreten müssen. Auf Seiten der Konservativen sorgte das für Wut und Verärgerung. Aber selbst eher liberale Kolumnisten kritisierten, dass die liberale Mehrheit des County Board ganz offenkundig ein ähnliches Demokratieverständnis offenbare wie die republikanische Mehrheit in der State Legislature. ${ }^{23}$ Die Liberalen im Board gaben ungerührt zu, dass die Neueinteilung zu ihrem Vorteil ausgefallen sei - allerdings habe das nur die ungerechtfertige Bevorzugung der ländlichen Wahlkreise zuvor ausgeglichen. ${ }^{24}$

Im Resultat führt das bei Konservativen und Republikanern zu einem Zustand, der mit Resignation noch unzureichend beschrieben ist. Schon 2012 - der Tiefpunkt stand erst noch bevor, der konservative Block hatte immerhin noch acht anstatt wie heute sechs Mitglieder - meinte Ronn Ferrell, dass er und seine Kollegen entschieden hätten, einfach nur interessierte Zuschauer zu sein: „We have all decided basically just to have fun the next two years. Because there is nothing else to do." ${ }^{\text {25 }}$

22 Ebd.

23 Vgl. Chris Rickert: Dane County Rediscricting not that different from State, in: Wisconsin State Journal, 25. Februar 2012, http://host.madison.com/news/local/ chris_rickert/chris-rickert-dane-county-redistricting-not-that-different-from-state/arti cle_1dbe2386-5f3d-11e1-be4b-0019bb2963f4.html (zuletzt abgerufen am 4. Juni 2015).

24 Vgl. Jack Craver: Progressives County Board Majority Likeley to Grow, in: The Capital Times, 4. Februar 2012, http://host.madison.com/news/local/govt-and-poli tics/politiscope/madison-politiscope-progressives-county-board-majority-likely-togrow/article_88d97036-4eac-11e1-ab01-001871e3ce6c.html (zuletzt abgerufen am 4. Juni 2015).

25 Gespräch mit Ronn Ferrell, 18. April 2012. 
In einem Zeitungsinterview verriet er später, dass er am besten erst gar keine Vorschläge machen würde - denn schließlich sei dies der sicherste Weg, um ein Vorhaben sofort zu Fall zu bringen. ${ }^{26}$ Alle konservativen Supervisor beschreiben auch recht plastisch, wie sich ihrer Ansicht nach die sozialen Umgangsformen im Board verändert hätten. „We used to be able to just like each other. And disagree. And it's not that way anymore. It has become very personal ${ }^{\text {“27 }}$, sagt etwa Eileen Bruskewitz, ein konservatives Mitglied des County-Boards, die bis 2012 im County Board saß, und dann der Neueinteilung der Wahlkreise zum Opfer fiel. Früher, erzählt Bruskewitz, sei man nach den County Board Treffen noch häufiger ein Bier trinken gegangen, quer durch die politischen Blöcke. Heute ist das Geschichte. Alle zwei Jahre, bei dem ersten Zusammentreffen eines neuen County Boards mit dem Einschwören der neuen Supervisors, gibt es weiterhin einen gemeinsamen Kneipenabend. Dabei allerdings bleiben beide Gruppen zunehmend unter sich. Ronn Ferrell beschreibt das Phänomen so: „And you don't feel welcome in that group. Particularly it was interesting watching the body language of the new supervisors and particular if they would [...] They obviously were standing out. You could see them kind of looking at me and almost like [...] 'Go away, evil person!' or whatever... And again I am probably reading something into their gestures and expressions that isn't there." 28

Das mag banal klingen. Doch darf man davon ausgehen, dass bei einer ehrenamtlichen Tätigkeit, die wenig soziales Prestige und noch weniger Geld einbringt, das soziale Miteinander eine entscheidende Rolle für die Motivation spielt. So ist nicht verwunderlich, dass sich immer weniger Nicht-Liberale Kandidaten finden, die zur Wahl antreten wollen. 2014 etwa waren bei den Wahlen zum County Board nur noch sehr wenige Wahlen (7 von 37; 2010 wären es hingegen noch 20 und 2012 noch 14 Wahlen gewesen, bei denen es Gegenkandidaten gab) überhaupt noch kompetitiv - in den meisten Fällen also trat überhaupt kein Gegenkandidat mehr an. Auch das ist ein Zeichen für die zunehmende Resignation der konservativen Minderheit im County.

26 Vgl. Jack Craver: Conservatives are nearly extinct in Dane County Government, in: Capital Times, 5. Juni 2013, http://host.madison.com/news/local/writers/jack_craver/ conservatives-are-nearly-extinct-in-dane-county-government/article_7bc00739-e3875cf1-9c2b-0163f07c8dd9.html (zuletzt abgerufen am 15. Juni 2015).

27 Gespräch mit Eileen Bruskewitz, 22. März 2012.

28 Gespräch mit Ronn Ferrell, 18. April 2012. 
Mit einer gewissen Verzögerung, doch dafür nach den Protesten rund um das Capitol 2011 umso vehementer, spiegelt sich Dane Countys Status als demokratische Hochburg, und die große Präsenz des amerikanischen Liberalismus auch als prägende Alltagsideologie, jetzt auch in der Lokalpolitik wider.

\section{Waukesha County: Die Tea PARTy in DER LOKALPOLITIK}

Wer sich nach seinem Besuch in Dane County in die Ebenen der Lokalpolitik von Waukesha begibt, der kann zunächst ein wenig erstaunt sein - oder, je nach Perspektive, womöglich sogar enttäuscht. Denn hier, in diesem „Garten Eden des Konservativismus“, der von Hardlinern wie Paul Ryan und James Sensenbrenner in Washington repräsentiert wird, und dessen Abgeordnete in der State Legislature in Madison als besonders loyale Prätorianer-Garde Scott Walkers gelten - in diesem durch und durch konservativen Ort, erscheint die Lokalpolitik auf den ersten Blick keineswegs als Hort konservativer Ideologie.

Gewiss sollte man dabei zwar die Selbstbeschreibung von Akteuren hierbei nicht unkritisch übernehmen: das Versprechen einer ideologiefreien, sachlichen Lokalpolitik, die im Kontrast stehe zum Parteienstreit auf nationaler Ebene, gehört wahrscheinlich nicht nur in den USA fest in das Arsenal dieser Gruppe von Politikern. Vorsicht ist also geboten, wenn der County Executive von Waukesha County, Dan Vrakas, behauptet, alle seine Entscheidungen seien rein ,data-driven“" und das Wunderbare in der Lokalpolitik sei, dass es stets nur um die Sache gehe ${ }^{29}$; oder wenn der County Board Chair, Paul Decker, sagt, er lehne politische Labels generell ab und versuche, Probleme stets von ihrer „objektiven“ Seite zu betrachten. ${ }^{30}$ Nicht selten schließlich verbirgt sich hinter vermeintlichen Sachzwängen eine besonders doktrinäre Politik.

Doch auch jenseits solcher Selbst-Etikettierungen vermeintlicher Unparteilichkeit: Abermals ist in Waukesha viel schwerer zu entdecken, was in Dane County so überdeutlich zu Tage tritt. Während die nationale Politik mit ihren Streitigkeiten und ihren ideologischen Reflexen in der liberalen Hochburg stets präsent ist, scheinen die Uhren in Waukesha tatsächlich anders zu gehen. Das Waukesha County Board verabschiedet keine Resolutionen für Anliegen, die in Wahrheit die nationale Ebene betreffen und mit Lokalpolitik nichts zu tun haben - so wie es in Dane County ständig passiert.

29 Gespräch mit Dan Vrakas, 20.November 2012.

30 Gespräch mit Paul Decker, 27. September 2012. 
Wer die lokalen Wahlkämpfe in Waukesha studiert, trifft nur höchst selten auf Konflikte, die man in das liberal-konservativ-Kontinuum pressen könnte. Überhaupt finden sich hier, in diesem Treibhaus politischer Partizipation auf der nationalen und bundesstaatlichen Ebene, kaum echte Wahlkämpfe: lange Zeit jedenfalls traten viele Kandidaten für das County Board ohne Gegenkandidaten an. Auch das Board selber scheint auf den ersten Blick keine ideologischen Spaltungslinien zu kennen. Es gibt, wiederum im Gegensatz zu Dane County, keine quasiFraktionsbildungen, keine liberalen oder konservativen „Caucuses“, die sich vor den Sitzungen des County Boards treffen und koordinieren würden. Im 25-köpfigen County Board sitzen neben einigen Republikanern und Manchen, die politisch tatsächlich nur schwer einzuordnen sind, auch zwei Demokraten. Aber wirklich isoliert oder vereinsamt fühlen diese sich nicht, sondern eher gut integriert.

Die örtlichen Parteiorganisationen halten sich aus lokalen Angelegenheiten beinahe komplett heraus, verteilen keine „endorsements“, geben keine finanzielle Unterstützung, scheren sich insgesamt recht wenig um den Ausgang der Wahlen. Ganz besonders gilt dies für die Demokratische Partei, die in Waukesha noch weniger involviert ist als die Republikaner in Dane County. Letztere kritisieren wenigstens in ihrer Hilflosigkeit und Handlungsunfähigkeit die Lokalpolitik der „Mad City“; den Demokraten in Waukesha entlocken die politischen Verhältnisse vor Ort jedoch nicht mehr als ein stummes Achselzucken. Liberale Aktivisten vor Ort, ausgestattet mit intimen Kenntnissen über die Folgen der Globalisierung in weit entfernten Erdteilen, wissen über die Themen lokaler Politik erstaunlich wenig, oft sogar einfach gar nichts.

Kurz gesagt: In Waukesha scheint Lokalpolitik noch immer Lokalpolitik zu sein. Der konservative Blogger James Wigderson, der von Waukesha aus bloggt und dabei viel über die örtliche Politik schreibt, hat ebenfalls seine Schwierigkeiten, diese nach parteipolitischen Konfliktlinien zu sortieren: „I couldn't tell you what party any of them belong to", sagt er etwas ratlos über die Mitglieder des County Boards oder auch der Mitglieder des City Councils von Waukesha City. "I don't think they see themselves as part of a broader movement. Most of the people get involved like, say, Waukesha County government are just happy of wearing the title of Waukesha County Supervisor and going to their church picknicks." 31

Doch womöglich befindet sich die Lokalpolitik von Waukesha auch einfach in einer anderen, und zwar früheren Phase der ideologischen Aufladung. Vieles spricht dafür, dass dort noch in den Kinderschuhen steckt, was in Dane County längst zur vollen Reife gelangt ist. Auch in Waukesha wird es zunehmend schwieriger, als Lokalpolitiker den Anspruch von Unparteilichkeit aufrecht zu erhalten

31 Gespräch mit James Wigderson, 29. September 2012. 
und sich nicht auf jene ideologischen Diskurse einzulassen, die auch die nationale Politik dominieren. Um diese Zeichen des Wandels zu erkennen, lohnt es, die Geschichte von Jim Dwyer gründlich zu studieren. Er war einerseits Jahre lang das beste Beispiel dafür, dass die toxische ideologische Polarisierung von Washington die Lokalpolitik von Waukesha scheinbar nie erreicht hatte - und ist heute Beleg dafür, dass es mit der Ruhe bald vorbei sein könnte.

Bis genau 2012 war Dwyer beinahe zwei Jahrzehnte Vorsitzender des County Boards in Waukesha. Damit bekleidete er nach dem County Executive die zweithöchste Position in diesem tiefroten County. Und dennoch: Spricht man mit jenen, die sich mit der örtlichen Politik wirklich gut auskennen, so vermag selbst niemand von ihnen mit Sicherheit zu sagen, wo Dwyer politisch eigentlich stand und steht, ob er Republikaner war, oder Demokrat oder tatsächlich keines von beiden. ${ }^{32}$ Nichts dokumentiert wohl besser, wie offenkundig depolitisiert die Lokalpolitik in Waukesha einmal war. Jim Dwyer selbst sagt, dass er wohl entweder ein sehr konservativer Demokrat oder aber ein sehr liberaler Republikaner sein müsse, denn für ihn bestünde da kein Unterschied.

An diesem Tag im Oktober 2012, als man ihn in seinem Haus in Menomonee Falls besucht, inmitten des Präsidentschaftswahlkampfes 2012, lässt er durchblicken, dass er seine Wahl-Entscheidung noch nicht ganz fest getroffen hat, aber offensichtlich neigt er eher zur Wahl Barack Obamas. Dass er sich von anderen in Waukesha politisch unterscheidt, erschließt sich im Gespräch schnell. Man merkt es vor allem daran, dass er anders über Milwaukee spricht. Er kommt wie viele andere aus der „Brew City“, aber Dwyer erinnert sich eher wehmütig an das Aufwachsen in der Großstadt, und dass seine Eltern damals noch kein Auto besaßen und mit öffentlichen Verkehrsmitteln fuhren. Ein „europäischer" Lebensstil sei das gewesen, sagt Dwyer melancholisch, denn er meint das keinesfalls negativ. Dass Milwaukee viele Probleme hat, bestreit auch er nicht, aber den Kontext sieht er doch etwas anders: „We are one freeway exit away from reality. Because that's what reality is. We can live here. But if we don't help take care of the problems that they have, it will be here." ${ }^{33}$

Dwyer scheint in vielerlei Hinsicht einem Lehrbuch für die Tugend lokaler Politik entlaufen, Sinnbild eines Ideals, in der es tatsächlich um die Sache, nicht um das Parteiinteresse geht, und auch darum, so pathetisch es klingen mag, für das öffentliche Wohl persönliche Opfer in Kauf zu nehmen. Dwyer, Vater von acht und

32 So etwa im Gespräch mit der Journalistin Laurel Walker, die über drei Jahrzehnte für den Milwaukee Journal Sentinel über die Politik in den Suburbs von Milwaukee berichtet hat. Gespräch mit Laurel Walker, 18. Mai 2012.

33 Gespräch mit Jim Dwyer, 11. Oktober 2012. 
Großvater von 24 Kindern, diente zunächst im Village Board von Menomonee Falls, dann seit 1992 zusätzlich noch im Waukesha County Board.

In seinem Hauptberuf arbeitete er als Maschinist, zwei künstliche Kniegelenke und eine künstliche Hüfte sind heute sein Andenken. Nach der Arbeit sei er meistens nur kurz zu Hause gewesen, danach habe es immer irgendeine Sitzung eines Ausschusses gegeben oder andere Veranstaltungen. Nach seiner Parteizugehörigkeit habe ihn eigentlich nie jemand gefragt, meint er, und dass obwohl sein Wahlbezirk gemessen an den Ergebnissen bei Präsidentschaftswahlen schon damals extrem konservativ gewesen sein muss. In den 20 Jahren im County Board habe er dennoch kein einziges Mal einen Gegenkandidaten gehabt. Wahlkampf hätte er ohnehin nicht betreiben müssen, sagt er, die Dwyers waren bekannt genug in der Gegend, hatten viele Freunde aus der Kirchengemeinde und vom wöchentlichen Softball-Spielen, die Söhne erfolgreiche Sportler in der High-School, weswegen der Name Dwyer regelmäßig in der Zeitung stand. Es sind Erfolgskriterien, die in den USA, wo die Parteien in der Kandidatenauswahl auf dieser Ebene kaum eine Rolle spielen, in normalen Zeiten über die Schicksale lokaler Politikerkarrieren entscheiden.

Einige Jahre nach seinem Einstieg in die Lokalpolitik, im Jahr 1994, wählen ihn seine Kollegen zum County Board Chair, eine Position, die bereits ein voll bezahlter Full-Time-Job ist. Den Knochen-Job als Maschinisten kann er nun an den Nagel hängen. Und noch einmal: Dass Dwyer als parteiloser, moderater Politiker in Waukesha so schnell so viel Akzeptanz gewann, kann man als sicheres Zeichen werten, das ideologische Zuordnungen ganz offenkundig keine große Rolle spielten.

Erst im Jahr 2005 merkt er, dass es doch nicht ganz so egal ist, wie man politisch verortet wird, und vor allem, wie man politisch vernetzt ist: Dwyer will County Executive werden, das höchste politische Amt im County. Sein Gegenkandidat ist Dan Vrakas, der bis dahin republikanischer Abgeordneter der State Legislature in Madison ist. Er lässt die gesamte Prominenz der republikanischen Partei von Wisconsin im Wahlkampf in Waukesha auflaufen, und sein Wahlkampfteam porträtiert Dwyer als „Big Spender“, der eine liberale ,shadow-campaign“ führe. Dwyer selbst erzählt, dass er erfahren haben will, dass am Ende sogar das „Republican National Committee“ in Washington aktiv geworden sei: dort habe man verhindern wollen, dass eines der Vorzeige-Countys im Mittleeren Westen einen nicht-republikanischen County Executive bekommt. ${ }^{34}$ Jedenfalls gelingt Vrakas zumindest teilweise die Mobilisierung konservativer Wähler: Dwyer verliert die Wahl sehr deutlich. Er versucht es kein zweites Mal und bleibt County Board Chair.

34 Gespräch mit Jim Dwyer, 11. Oktober 2012. 
Vielleicht war das ein Vorzeichen. Denn in der Folge, und verstärkt dann seit 2009, als nach Barack Obamas Amtsantritt die konservative Mobilisierung durch die Tea Party Bewegung beginnt, verändert sich das politische Klima in Waukesha. Es beginnt damit, dass eine lokale „Waukesha Taxpayers League“ schon 2006 das erste Mal eine Kampagne für die Reduzierung der Mitglieder des County Boards unternimmt. Waukesha hat bereits zu diesem Zeitpunkt die wenigsten Mitglieder im County Board per Einwohner und Dwyer hält die Reduzierung, wie nicht wenige andere Board-Mitglieder, für keine besonders kluge Idee, weil es die Arbeitsbelastung der einzelnen Supervisors erhöht, die Einsparungen angesichts der wenigen tausend Dollar, die als Aufwandsentschädigung gezahlt werden, dafür eher minimal ausfallen. Aber die „Taxpayers League“ hat in einer Petition genügend Stimmen gesammelt, um Druck auszuüben und einige Supervisor machen sich die Forderung zu Eigen und bringen eine entsprechende Resolution ein. Dahinter steckt schließlich die Idee von „Small Governement“", und diese ist in Waukesha so populär, dass auch jene Supervisors einknicken, die von der ganzen Idee herzlich wenig halten. Allerdings ist das erst der Anfang: Von jetzt an werden im Zwei-Jahre-Rhythmus neue Unterschriften gesammelt, um das Board weiter zu verkleinern. ${ }^{35}$

Mit Scott Walkers Amtsantritt 2011 erreicht die Polarisierung der amerikanischen Politik endgültig die lokale Ebene. Da es in Waukesha überhaupt keine Stimme der Demokratischen Partei in der Lokalpolitik gibt, äußert sich dies vor allem in der Politisierung ehedem eher unpolitischer Institutionen und in dem vermehrten Aufkommen von Forderungen, die lokale Politik nun endlich den Maßstäben der konservativen Werte seiner Bewohner anzupassen. Der Versuch der Politisierung zeigt sich unter anderem darin, dass jetzt auch in Waukesha probiert wird, was in Dane County schon lange Usus ist: Es werden Resolutionen verabschiedet.

Es beginnt gleich nach dem Act 10. Einige der konservativen Supervisors im County Board wollen Scott Walker symbolisch den Rücken stärken, indem sie eine Resolution verabschieden, die ausdrücklich die Maßnahmen des Governeurs unterstützt. Wieder leisten Dwyer und andere zunächst Widerstand: Man sei nicht in Madison oder Milwaukee, und die Lokalpolitik mit solchen nicht-lokalen Themen aufzuladen, entspreche nicht der Kultur des Ortes. ${ }^{36}$

Tatsächlich tauchen vor dem Courthouse, wo die Sitzungen des County Boards stattfinden, am Abend der Entscheidung ca. 100 Bürger auf - und die meisten von

35 Vgl. Laurel Walker: Waukesha County Supervisors spar over Board Size, in: The Milwaukee Journal Sentinel, 14. Februar 2011, http://www.jsonline.com/news/ waukesha/116192734.html (zuletzt abgerufen am 2. Juni 2015).

36 Gespräch mit Jim Dwyer, 11. Oktober 2012. 
ihnen protestieren sogar gegen Walkers Politik. Dessen ungeachtet jedoch spüren die meisten Supervisor den Druck, Walkers Maßnahmen zuzustimmen. Auch Dwyer knickt ein: er selbst sagt, ihm sei die Einheit des County Boards wichtiger gewesen, als die Tatsache, dass er das ganze Vorgehen für wenig klug hält. ${ }^{37} \mathrm{Au}-$ ßerdem hofft er, dass es eine einmalige Sache bleibt, erklärbar nur durch die besonderen Emotionen, die Walkers Politik ausgelöst hat. Die Resolution wird mit einigen Gegenstimmen (die noch eine Rolle spielen werden) verabschiedet. ${ }^{38}$

2012 schließlich trifft die beginnende stärkere Polarisierung der Lokalpolitik Dwyer persönlich. In Waukesha County - das würde den Liberalen in Dane County in der Tat niemals passieren - wird das alle paar Jahre notwendig werdende Neuziehen von Wahlkreisgrenzen tatsächlich von einer unabhängigen Kommission geleistet. Nach der letzten Neueinteilung überschneidet sich Dwyers neuer Wahlkreis jetzt mit dem eines anderen County Board Mitgliedes: Janel Brandtjen, die bereits in dieser Arbeit zu Wort gekommene Tea Party Aktivistin, die ebenso wie Dwyer aus Menomonee Falls stammt. Brandtjen ist schon seit 2008 im County Board und bisher dahin eher ein unauffälliger Supervisor gewesen. 2012 aber ist ihre Kampagne ziemlich auffällig, denn sie arbeitet mit den klassischen Versatzstücken konservativer Ideologie, die bis zu diesem Zeitpunkt in der Lokalpolitik von Waukesha selten eine Rolle spielten: In den Flyern, die auch bei Dwyers Nachbarn im Briefkasten landen, heißt es, Dwyer sei ein „Big Spender“, ein „Verschwender“ von Steuermitteln und überhaupt eigentlich ein spärlich getarnter Liberaler. Sie, Brandtjen, hingegen, wolle fortan die konservative Stimme im County Board sein. Sogar der konservative Talk-Radio-Star Mark Belling, vermutlich die wichtigste Stimme des Konservativismus in diesem Teil Wisconsins, hat sich in diesen Wahlkampf eingeschaltet und unterstützt sie.

Dwyer trifft diese Art von Wahlkampf völlig unvorbereitet. Die Wahl verliert er haushoch und für ihn, den von allen hoch respektierten Vorsitzenden des Waukesha County Boards, der vom Sheriff bis zu den Bezirksrichtern auch von vielen moderaten Republikanern im County ,endorsements“ erhalten hatte, kommt nach 20 Jahren in der Lokalpolitik ein plötzliches und jähes politisches Ende.

Für die in dieser Hinsicht ansonsten eher unspektakuläre Lokalpolitik von Waukesha ist das ein kleines Erdbeben. Brandtjen, die mittlerweile politische Karriere gemacht hat und seit 2014 auch in der State Legislature in Madison sitzt, hatte außer Mark Belling noch andere Unterstützer: lokale Tea Party Gruppen, die zu

37 Nachträgliche schriftlichte Auskunft von Jim Dwyer vom 24. Juni 2015.

38 Vgl. Laurel Walker: Waukesha County Board Endorses Walker's Budget Action, in: Milwaukee Journal Sentinel, 23. März 2011: http://www.jsonline.com/news/ waukesha/118508684.html (zuletzt abgerufen am 5. Mai 2015). 
der Meinung gekommen sind, dass Waukesha zwar in Madison und Washington durch hinreichend konservative Republikaner repräsentiert wird, die Lokalpolitik aber nicht in gleicher Weise geprägt sei. Der Organisator und „Präsident“ einer dieser Gruppen, der „Waukesha Taxpayers Association“, ist Steve Welcenbach. Welcenbach, ein diplomierter Chemiker und Inhaber einer Müllentsorgungsfirma, hat allerlei Interessantes zu sagen. Als man ihn etwa mit Waukeshas Bild als Hort konservativer Ideale konfrontiert und erwähnt, dass die Liberalen in Madison stets von „Mordor“ sprechen, da kann Welcenbach darüber nur ungläubig den Kopf schütteln: „If they only knew how much they have penetrated this county [...]. If they only knew how much engrained liberal ideology is here. “39

Für Welcenbach sind die moderaten Republikaner in der Lokalpolitik von Waukesha nicht besser als die Demokraten von Madison. In seinem Weltbild macht das alles keinen wirklichen Unterschied. Die meisten Republikaner von Waukesha hält er bestenfalls für Opportunisten. Der County Executive Dan Vrakas etwa sei in Wahrheit ein Liberaler, der sich hinter seinem republikanischen Partei-Label verstecke. Und dann, einmal in Schwung gekommen, gewährt Welcenbach dem Autor einen kurzen aber dafür umso intensiveren Einblick in die Gedankenwelt der paranoiden amerikanischen Rechten: Er erzählt, dass der Faschismus in den USA putzmunter sei und seine Gegner „Gestapo-Methoden“ gegen ihn einsetzten; dass nur 5\% der Menschen Stützen der Gesellschaft seien, und der Rest von den Leistungen dieser 5\% lebe; dass Sozialprogramme die Moral einer Gesellschaft ruinierten; dass es nicht unwahrscheinlich sei, dass irgendwann in der Zukunft von der Regierung unter einem Vorwand das Notstandsrecht verhängt werde, und dass dann ein Widerstand mit Worten alleine wohl nicht mehr ausreiche; und noch einiges andere mehr. Als man Welcenbach, bei einem anderen Gespräch, fragt, woraus sein Weltbild sich zusammensetzt und ihn auf „Fox News“ anspricht, da sprudelt es abermals aus ihm heraus: „Fox News“, sagt Welcenbach, sei „East Coast Bullshit“ und in Wahrheit eine Säule des liberalen Establishments. Wenn man hingegen eine wirklich zuverlässige Informationsquelle bräuchte, könne er guten Gewissens eigentlich nur seine eigene, monatlich erscheinende Zeitung empfehlen. Sie trägt den einzigen Titel, der nach dieser Ankündigung den Ansprüchen wohl noch gerecht werden kann: „Reality News. “40 Das Abonnement sei vergünstigt zu haben, die Print-Ausgabe würde er auch auf eigene Kosten nach Deutschland schicken. Der Autor lehnt ab.

Man könnte sagen, dass Welcenbach sehr, sehr konservativ ist. Vielleicht aber wäre es jenseits aller wissenschaftlichen Objektivität auch akkurater und zutreffender zu sagen, dass er, mit Verlaub, in einer bizarren Parallelwelt lebt. Und

39 Gespräch mit Steve Welcenbach, 25. September 2014.

40 Gespräch mit Steve Welcenbach, 22. November 2012. 
doch: Welcenbach und andere die so denken wie er, sind womöglich gerade dabei, die politische Landschaft in Waukesha zu verändern. Brandtjen war nicht die einzige Kandidatin, die bei den letzten Wahlen 2012 und 2014 unterstützt wurde. Schon 2010 waren einige neue Supervisor mit Tea Party Hintergrund in das County Board gewählt worden. Manche waren schon länger aktiv, andere aber wurden vor allem durch die Protest-Welle nach 2009 politisch aktiviert. Eine große Rolle dabei spielt die national agierende, konservative Lobby-Gruppe „Americans for Prosperity“ (AfP) - durch die auch Welcenbach erst wirklich in den Kosmos des amerikanischen Konservativismus gezogen wurde. ${ }^{41}$ Die Organisation bietet nicht nur Trainings und Schulungen für lokale Aktivisten an. Wichtiger ist noch, dass sie über ihre Veranstaltungen und Maillisten überhaupt konservative Aktivisten zusammenbringt. Auf einem der Treffen von AfP ist zum Beispiel auch Jennifer Grant, Anfang 40, Finanzbuchhalterin und Mutter von vier Kindern, die von dort die Anregung erhält, sich stärker in die lokale Politik einzumischen: auch dort schließlich könne man einen Unterschied machen. 2012 kandidiert Grant für das County Board, um, wie sie selbst sagt, für ihre konservativen Werte einzustehen. ${ }^{42}$ Auch sie gewinnt mit großer Leichtigkeit ihre Wahl.

Der Prozess der Politisierung Waukeshas läuft gleichwohl nicht über Nacht ab. Im County Board etwa sind Konservative wie Brandtjen noch immer eine Minderheit: von 25 Supervisors sind es vielleicht sechs, maximal sieben, die dem Tea Party-Flügel der Republikanischen Partei zuzuordnen sind. Keineswegs stimmen sie immer im Block ab, es gibt auch wenig Koordination zwischen ihnen. ${ }^{43}$ Und bevor man Welcenbach zum genialen Strippenzieher einer groß angelegten Tea Party Offensive stilisiert, muss man sich noch einmal vergegenwärtigen, auf welch niedrigem Wahrnehmungsniveau all das stattfindet. Nach eigenem Bekunden hat Welcenbach etwa für die Wahlen zum County Board 2014 gerade mal ein paar hundert Dollar an Spenden einsammeln können. Im hochpolitisierten Dane County mit seiner sehr professionell organisierten Lokalpolitik käme man damit nicht besonders weit. Das Schwierigste sei, sagt Welcenbach, überhaupt Kandidaten zu rekrutieren, die Interesse daran hätten, Supervisor zu sein. Andererseits zeigen diese Schwierigkeiten vielleicht umso eher, welches Potenzial eine Politisierung der Lokalpolitik in Waukesha hat. Denn wo Welcenbach Kandidaten gefunden hat, haben diese in der Mehrzahl der Fälle auch reüssiert. Und das obgleich

41 Vgl. auch den Artikel von Jessica McBride: „We are an Activist Army”, Say Leaders of New Falls Taxpayers Group, in: Menomonee Falls Patch, 1. Juli 2012: http://patch. $\mathrm{com} /$ wisconsin/menomoneefalls/we-are-an-activist-army-say-leaders-of-new-falls-tax p5692ae778f (zuletzt abgerufen am 2. Juni 2015).

42 Gespräch mit Jennifer Grant, 25. Oktober 2012.

43 Gespräch mit Jennifer Grant, 26. September 2014. 
sich auch nach den Maßstäben des amerikanischen Konservativismus fragwürdige Personen unter ihnen befanden, zum Beispiel ein Mitglied der anti-semitischen „John Birch Society“, der 2014 eine langjährige Supervisorin mit Leichtigkeit besiegte. Die unterlegene Kandidatin, Pamela Meyer, hatte den Recall gegen Scott Walker unterzeichnet - in Waukesha in politischer Hinsicht ein sicheres Todesurteil. Welcenbachs kleine Gruppe hat mit dem öffentlichen Register zum Recall extrem effizient gearbeitet: Alle 3 County Board Mitglieder, die 2011 den Recall gegen Scott Walker unterzeichnet hatten, und die 2012 wieder oder neu antraten, wurden von der Gruppe ins Visier genommen. Larry Nelson, der ehemalige demokratische Bürgermeister der "City of Waukesha“, der mittlerweile im County Board sitzt, hatte den Recall wohlweislich gar nicht erst unterschrieben: Er habe gewusst, sagt Nelson, dass er danach Schwierigkeiten haben werde, noch irgendein Amt in Waukesha County auszuüben. ${ }^{44}$ Tatsächlich werden die meisten Unterzeichner des „Recall“ 2012 oder 2014 abgewählt. Ähnliche ergeht es jenen, die 2011 gegen die Resolution, die Scott Walkers Act.10 unterstütze, gestimmt hatten.

Im Grunde scheint dieser Mechanismus sehr logisch: Die meisten Menschen wissen wenig über ihre lokalen Repräsentanten, sind oft auch nicht übermäßig über die Themen lokaler Politik informiert. Gleichzeitig aber ist Waukesha extrem republikanisch und empfänglich für die Anti-Government-Rhetorik der Tea Party, auch wenn die Problemlagen auf lokaler Ebene vielleicht ganz andere sind. Unter diesen Umständen nutzen also auch Wähler bei lokalen Wahlen den „Short-Cut“ der Ideologie. Im Grunde zeigt sich damit das gleiche Muster wie in Dane County: Politisierung zahlt sich stets für jene aus, die sich mit der Ideologie der Mehrheitskultur im Bunde wissen. Sie polarisieren, während alle, die sich strukturell im Nachteil wähnen, versuchen zu depolarisieren, und Parteizugehörigkeiten ebenso wie ideologische Orientierungen in ihrer Bedeutung herunterspielen.

Auch in Waukesha wurden, wie in Dane County, die Wahlkämpfe für RichterÄmter in zuvor nicht gekannter Weise politisiert und wer als nicht hinreichend konservativ galt, war sein Amt schnell los. So erging es z.B. Richard Congden, als er 2010 für das Amt des „County Judge“ kandidierte. Congdon hatte sein Leben in Waukesha verbracht und 33 Jahre Erfahrung als Anwalt in Gerichtssälen gesammelt. 2009 war er vom damaligen Governeur des Staates, dem Demokraten Jim Doyle, nach einer Vakanz in sein Richteramt ernannt worden. Die juristische Erfahrung seines Konkurrenten Mark Gundrum bestand - neben seinem juristischen Abschluss - vor allem in einer ein paar Monate währenden Tätigkeit als Militäranwalt der amerikanischen Streitkräfte im Irak. Vor allem aber hatte Mark Gundrum über 20 Jahre als Republikaner in der State Legislature in Madison ge-

44 Gespräch mit Larry Nelson, 25.09.2014. 
sessen, er war also ein Berufspolitiker - während Congdon für einige Jahre Vorsitzender der Demokratischen Partei von Waukesha gewesen war. Es liegt in dieser Logik, dass der Wahlkampf des Republikaners Gundrum vor allem die Parteizugehörigkeit und die ideologischen Orientierungen des Kandidaten betont: Waukesha brauche jemanden mit einer ,solid, conservative view of the law.“ Und Congdon seinerseits versuchte, den Wahlkampf zu depolitisieren: „There's nothing conservative or liberal about courtroom work. If somebody needs to go to prison, you send them to prison. If somebody needs to go to prison for a long time, you send them to prison for a long time. ${ }^{, 45}$ Der Republikaner Gundrum gewann mit fast $80 \%$ der Stimmen.

So polarisiert und politisiert wie Dane County ist Waukesha trotz allem noch immer nicht. Doch die Anzeichen für eine partielle Angleichung sind nicht zu übersehen. Auch Waukeshas Lokalpolitik hat sich polarisiert und damit auch parteipolitisiert, auch wenn die hauptsächliche Konfliktlinie etwas anders verläuft: In Waukesha findet die ideologische Auseinandersetzung sehr viel stärker im eigenen politischen Lager statt. Zwar gibt es auch in Madison einen steten Überbietungsversuch, wer in reinerer Form linke Politik verkörpert. Doch Referenzpunkt aller Politik bleibt dabei der „Feind“, der weiterhin in der anderen Partei zu finden ist - und wenn dieser Feind in der eigenen Lokalpolitik auch mittlerweile vollständig marginalisiert ist, so heißt es eben, noch verstärkter über nationale und bundesstaatliche Themen die Binnenintegration aufrecht zu erhalten. In Waukesha aber zeigt sich in der Lokalpolitik im Grunde jener Split, der die Republikanische Partei auch auf nationaler Ebene derzeit prägt. Schon die bisher noch bescheidenen Geländegewinne der Tea Party Gruppierungen reichen aus, um die moderatkonservative politische Führung im County Board nervös zu machen. Der County Board Chair Paul Decker und der County Executive Dan Vrakas geben sich alle Mühe, die Tea Party-Fraktion zu kontrollieren und zu neutralisieren.

Auch Brandtjen, Grant und die anderen Tea Party Republikaner versuchen nun häufiger, Resolutionen einzubringen: etwa gegen die Einführung des Spanischen als zweite offizielle Amtssprache in den USA, oder gegen die Amnestie illegaler Einwanderer usw. Die politische Führung des Counties versucht diese Vorhaben jedes Mal im Keim zu ersticken. Sobald der County Executive Wind davon bekommt, zitiert er die Antragssteller in sein Büro und versucht sie zu überzeugen, dass das der Anfang vom Ende sei: Würde er eine Resolution unterstützten, die die Abschiebung aller Illegalen nach Mexiko vorsieht, dann käme morgen jemand,

45 Vgl. Mike Johnson: State legislator announces run for Waukesha County judgeship, in: Milwaukee Journal Sentinel, 13. November 2009: http://www.jsonline.com/news/ waukesha/70042847.html (zuletzt abgerufen am 22.06.2015). 
und lege eine Resolution gegen die Klimaerwärmung vor (was sich natürlich in Waukesha in Wahrheit niemand trauen würde). Wie wäre es denn, wenn die entsprechenden Supervisors einfach dem Präsidenten der Vereinigten Staaten ein Brief schreiben würden? Das hätte sicherlich eine ebenso große Wirkung. Den größten Unfug, sagt Vrakas, habe er auf die Weise immerhin verhindern können. ${ }^{46}$

Die moderaten Republikaner wie Vrakas, die in der Lokalpolitik von Waukesha dominierend sind, haben kein Interesse daran, die Lokalpolitik ideologisch aufzuladen: für sie sind diese Versuche Nebenkriegsschauplätze, die von dem ablenken, was tatsächlich zu den Kernaufgaben von County Government gehört sollte: „In local government you don't get into social issues. Which really more and more divide the Republican and Democratic parties. We are not getting into gay marriage and abortion. We don't get into that here. It's more business. Let's plow the streets and stuff." ${ }^{\text {"47 }}$ Aber sie vermeiden diese Themen auch, weil sie ahnen, dass es eine Dynamik in Bewegung setzen könnte, die sie am Ende selbst ihre Position kosten könnte. Paul Decker, der Nachfolger Dwyers als County Board Chair, ist wie Vrakas ebenfalls ein moderater Republikaner, der auf die Frage, ob er religiös sei, antwortet, er sei eher „spirituell“ veranlagt - nicht unbedingt die Antwort, mit der man zum Liebling der konservativen Basis avanciert. Bisher stellt ihm aber noch niemand solche Fragen, weil sich Waukeshas Lokalpolitik über solche Fragen nicht definiert.

Dass diese Neutralisierungsversuche bisher noch funktionieren, liegt wohl auch daran, dass in der Lokalpolitik die Wissens- und Kompetenzlücke zwischen dem offiziellen Verwaltungsapparat und den Amateur-Politikern einfach riesengroß ist. Nach eigenen Aussagen verwenden die meisten County-Board Mitglieder zwischen vier und sechs Stunden in der Woche für ihre Arbeit, was es schwer macht sich in aller Tiefe mit einem Thema zu beschäftigen. Auf die Ultra-Konservativen im County-Board wirkt die Expertise des Verwaltungsstabes daher extrem einschüchternd. Ständig erhalte sie „history Lessons“ sagt etwa Janel Brandtjen. Einwände gegen ihre Vorschläge bezeichnet sie als Strategie ,to get tied up in the details." Dazu kommt: Es ist grundsätzlich nicht leicht, in der Lokalpolitik hart und konfrontativ zu sein. In den Sitzungen des County Boards sitzen die Tea Party Aktivisten zwischen moderaten Republikanern und den zwei Demokraten relativ einträchtig miteinander. Man spricht über die Kinder, den letzten Urlaub, das letzte Spiel der Green Bay Packers. Es gibt keine so vollständige Gruppenbildung wie in Dane County. 90\% der Abstimmungen sind in der Tat irgendeiner Art von Konflikt nicht zugänglich, werden oft ohne Gegenstimme angenommen. Gegen dieses Klima von Kollegialität und Konsens zu verstoßen, fällt auch jenen nicht

46 Gespräch mit Dan Vrakas, 20. November 2012.

47 Gespräch mit Dan Vrakas, 20. November 2012. 
leicht, die mit dem erklären Ziel in das County Board gegangen sind, dort die Fronten zu klären. „Its not fun being the unpopular teenager in the room", sagt etwa Janel Brandtjen. ${ }^{48}$

In der Tat könnte man fragen, was überhaupt den Widerstand von Brandtjen und anderen erregt. In vielerlei Hinsicht entspricht Waukesha ja tatsächlich geradezu dem Idealbild konservativer Politik: Es ist das County mit der niedrigsten „property-tax“ in Wisconsin, das einzige County, dass keine zusätzliche „salestax" erhebt, und jenes mit den wenigsten Angestellten des öffentlichen Dienstes im Verhältnis zur Einwohnerzahl. Besonders stolz ist man darauf, dass man von den Ratingagenturen für die Haushaltsführung noch stets ein „Triple-A-Rating“ bekommen hat. Oder um es mit den Worten von Dan Vrakas zu sagen: „I believe Waukesha County government is close to groups like the Tea Party could want government to be run. ${ }^{49}$ In der Tat gibt es in Waukesha einige aufwendige soziale Einrichtungen, beispielsweise Suchtklinken, oder Frauenhäuser, die sich andere Counties in Wisconsin gar nicht leisten können. Die moderaten Republikaner, die in Waukeshas Lokalpolitik noch den Ton angeben, sind stolz darauf, diese Programme zu haben und trotzdem quasi schuldenfrei zu sein. Vielleicht wäre das eine potentielle Angriffsfläche, doch keiner aus der Tea Party-Fraktion stellt diese Programme bis jetzt in Frage. Stattdessen geht es eher um monetäre Kleinigkeiten, etwa, wenn das County beschließt, einen Fahrradweg neu zu asphaltieren, denn schließlich: wer sollte in Waukesha schon mit dem Fahrrad fahren wollen? Oder man fordert die Streichung der paar Tausend Dollar für das öffentliche Museum in der City of Waukesha, das sich schließlich auch nach den Gesetzen des freien Marktes bewähren müsse.

Der Tea-Party-Fraktion in der Lokalpolitik von Waukesha geht es vor allem anderen um Identität, darum, die Lokalpolitik zum Resonanzboden der eigenen Ideologie zu machen. Wie, fragt z.B. Jennifer Grant, sollten schließlich die Liberalen in San Francisco oder Madison fiskalische Disziplin lernen, wenn in Waukesha noch immer nicht so viel gespart werde, wie es theoretisch möglich sei? „We are of one the most conservative counties in the country [...] We should be cutting edge! ‘50

So steht am Ende der Expedition in die Hochburgen von Dane und Waukesha County eine wohl nicht wirklich überraschende Erkenntnis: Angesichts der ideologischen Aufladung der amerikanischen Politik insgesamt verändert sich auch die Lokalpolitik in Richtung einer stärkeren Parteipolitisierung. Das muss nicht unbedingt bedeuten, dass die Parteien als Organisationen dabei eine bedeutende

48 Gespräch mit Janel Brandtjen, 2. November 2012.

49 Gespräch mit Dan Vrakas, 17. Mai 2012.

50 Gespräch mit Jennifer Grant, 26. September2014. 
Rolle spielen. Gemeint ist damit eher, dass die Themen nationaler Politik sich, quasi durch die Hintertür, ihren Weg in die lokale Politik bahnen und zum anderen, dass die Sphäre politischer Neutralität kleiner wird: Im Zeitalter der Polarisierung wird auch auf diesen Ebenen den Akteuren zunehmend ein politisches Bekenntnis abverlangt, dass über die Beteuerung, reine Sachpolitik zu betreiben, hinauszugehen hat. Gleichwohl bleiben die Unterschiede markant: In Dane County ist die lokale Politik tatsächlich eine viel stärkere Reflexion der nationalen Verhältnisse - sieht man einmal von den krass-einseitigen Mehrheitsverhältnissen ab. Man kann getrost davon ausgehen, dass dieses in anderen, vergleichbaren liberalen Hochburgen, von Ann Arbor bis Boulder und Berkeley bis hin zu größeren Städten wie Austin, Portland und San Francisco ähnlich sein dürfte. Waukesha ist hingegen nicht im gleichen Maße politisiert. Doch auch hier haben lokale Aktivisten die Kommunalpolitik als Einfallstor zur Durchsetzung ihrer Vorstellungen entdeckt.

Grundsätzlich, das wurde in dieser Arbeit bereits dargelegt, muss man sich den Polarisierungskreislauf der amerikanischen Politik als Ergebnis des Zusammenspiels zwischen den Strategien politischer Eliten und den Präferenzen der Wählerschaft vorstellen. In Bezug auf die Lokalpolitik spricht allerdings - bedenkt man, dass es hier zu einer verspäteten, „nachholenden“ Polarisierung gekommen ist vieles dafür, dass hier nationale Konfliktmuster geradezu erlernt und „,nachgeahmt" wurden. Die zunehmende Parteipolitisierung ehedem relativ unparteilicher Institutionen dürfte dabei nicht nur das Repräsentanzproblem in politischen Hochburgen verstärken, da es die stille Resignation der „Minderheiten“ weiter beschleunigen dürfte.

Der durch lokale Aktivisten entfachte Druck und die eindeutigen Mehrheitsverhältnisse dürften darüber hinaus auch für eine Politik sorgen, die die Charakteristiken beider Orte weiter verstärken. Eigentlich war der Untersuchungszeitraum für das Studium der Konsequenzen dieser Entwicklung zu kurz; aber bedenkt man, dass schon der Bau eines Fahrradweges in Waukesha County politische Kontroversen auslösen kann (wie es ein Tea-Party-Aktivist bei einer vom Autor besuchten Wahlkampfveranstaltung von Mitt Romney und Paul Ryan in Waukesha ausdrückte: „Biking is Unamerican!“), und stellt dies den ganz entgegengesetzten Zielen der Lokalpolitik in Dane County gegenüber, so scheinen die praktischen Konsequenzen doch offenkundig zu sein. So spricht angesichts des Beispiels von Dane und Waukesha County auch in dieser Hinsicht sehr wenig dafür, dass die zentrifugalen Kräfte in der amerikanischen Gesellschaft, ausgelöst durch die Freiheit der Wahl, in näherer Zukunft gebändigt werden könnten. 



\title{
X. Zum Schluss: Sonderweg oder Laboratorium der Zukunft? Die ideologische Polarisierung der USA als Fall Paradoxer Individualisierung
}

\begin{abstract}
„Deep religious and class divisions separate distinct, isolated and self-contained population groups. Social communication across class and religious boundary lines is minimal. Each group has its own ideology and political organizations: political parties, labor unions, employers' associations, farmers' groups, newspapers, radio and television organizations, and schools - from Kindergarten to university."
\end{abstract}

Zugegeben: Das Beispiel separierter Kindergärten scheint doch ein wenig übertrieben. Und das ausgerechnet von Zeitungen die Rede ist, nicht aber von „Fox News“, „MSNBC“ oder der Blogosphäre, mutet ein wenig aus der Zeit gefallen an. Ansonsten aber scheint dieser Textauszug eine recht akkurate Beschreibung der gegenwärtigen ideologischen Segregationstendenzen der USA zu sein, der Entzweiung des Landes in ein „liberales“ und ein „konservatives“ Amerika.

Tatsächlich aber geht es um ein anderes Land. Zu einer anderen Zeit. Der obige Abschnitt steht am Anfang eines Buches des holländischen Politologen Arend Lijphart. Es handelt sich um einen politikwissenschaftlichen Klassiker: „The Politics of Accomodation. “1 Im Jahr 1968 beschreibt Lijphart darin die „Versäulung“ der niederländischen Gesellschaft in separate und organisatorisch abgekapselte Subkulturen (die man dort als „Säulen“ bezeichnete). Wer das Buch heute liest und gleichzeitig mit den Veränderungen in der amerikanischen Gesellschaft vertraut ist, dem fallen, trotz vieler gewiss sehr wesentlicher Unterschiede, zahlreiche Parallelen auf. So schreibt Lijphart nicht nur von den niedrigen Heiratsraten zwischen den Angehörigen verschiedener „Säulen“, was stark an die gesunkene Zahl

1 Vgl. Arend Lijphart: The Politics of Accomodation. Pluralism and Democracy in the Netherlands, Berkeley 1968, S. 1. 
von Eheschließungen zwischen Demokraten und Republikanern erinnert. Er erkannte auch, dass voneinander separierte Subkulturen mit der Zeit auch völlig andere Vorstellungen der eigenen Nationalgeschichte entwickeln. Seine Schilderung nahezu inkompatibler Versionen des Niederländischen Unabhängigkeitskrieges in den Schulbüchern calvinistischer und katholischer Schulen, ähnelt ebenfalls Vorgängen, die sich heute tagtäglich in den USA wiederholen, wo Schulkinder in Texas und Massachusetts mittlerweile sehr verschiedene Interpretationen der amerikanischen Geschichte lernen. ${ }^{2}$

Als Lijphart sein Buch 1968 veröffentlichte, hatte die niederländische Gesellschaft schon angefangen, sich zu „entsäulen“. Die stolze Organisationswelt von Katholiken, Protestanten und Sozialisten sollte in der Folgezeit in nachgerade atemberaubender Geschwindigkeit in sich zusammenbrechen, als kräftige Schübe von Individualisierung - so jedenfalls die gängige Interpretation - die Notwendigkeit einer eigenkulturellen Organisation zunehmend in Frage stellten. Heute ist nicht nur die Versäulung der niederländischen Gesellschaft Geschichte. Gleiches ließe sich auch von den politisierten Subkulturen in anderen europäischen Gesellschaften sagen.

Es dürfte kaum ein Zufall sein, dass es damit gleichzeitig zu einer Abschleifung des ehedem scharfen ideologischen Wettbewerbs zwischen den etablierten Parteien in fast allen europäischen Demokratien gekommen ist. Denn ideologische Polarisierung - so die zentrale These dieser Arbeit - ist primär als Resultat der Entstehung voneinander abgeschotteter Lebenswelten zu verstehen, in denen gänzlich andere Interpretationen von Wirklichkeit kollektiv produziert werden. Es ist diese Folie, vor deren Hintergrund das Zusammenspiel von ideologischer Polarisierung mit Prozessen gesellschaftlicher Segmentierung in den USA besonders bemerkenswert erscheint. Die Pfadumkehrung ist dabei erstaunlich. Als in den 1950er und 1960er Jahren zahlreiche Sozialwissenschaftler zu erklären versuchten, warum die angelsächsischen Demokratien so stabil waren, die Demokratien in Kontinentaleuropa jedoch weitaus fragiler erschienen, da war einer der zentralen Erklärungsmomente, dass die USA eben nicht jene geschlossenen, politisierten Subkulturen kannten, die sich in Europa um die politischen Parteien gebildet hatten. $^{3}$

2 Der bisher jüngste, national ausgefochtene Streit dieser Art entbrannte im Sommer 2015 über die Neufassung eines Lehrbuches über amerikanische Geschichte für texanische High-Schools, in dem die Sklaverei unter anderem als „side issue“ für den Ausbruch des Bürgerkrieges bezeichnet wurde.

3 Vgl. Gabriel A. Almond: Comparative Political Systems, in: Journal of Politics, Vol. 18 (3), 1956, S. 391-409, insbes. S. 406-408. 
Seymour M. Lipset schrieb 1960 im Hinblick auf Europa: „Wherever the social structure operates so as to isolate individuals or groups with the same political outlook from contact with those who hold different views, the isolated individuals or groups tend to back political extremists. “4 Amerikas vergleichsweise gemäßigte politische Kultur hingegen, so etwa David B. Truman oder Talcott Parsons, sei gerade darin begründet, dass seine Bürger über viele, sich überlappende Mitgliedschaften in zivilgesellschaftlichen Organisationen verfügten und dadurch ein breites, heterogenes Kontaktumfeld besaßen. ${ }^{5}$

Heute aber scheinen sich die Lebenswelten des konservativen und liberalen Amerikas weit auseinander entwickelt zu haben. Natürlich waren die USA historisch stets in mannigfaltiger Weise segmentiert: regional, ethnisch, konfessionell, sozial, kulturell. ${ }^{6}$ Aber neben dem Fortbestehen dieser Spaltungen scheint das primäre Differenzkriterium gesellschaftlicher Segmentierung heute Ideologie zu sein. Konservativ oder liberal zu sein, Demokrat oder Republikaner - damit korrelieren heute eine Vielzahl anderer sozialer Merkmale: Lebensstilneigungen, Wohnortpräferenzen, Mediennutzungsgewohnheiten, Heiratsverhalten, und vieles andere mehr. Dadurch ist die soziale Distanz zwischen den Parteianhängern beider Seiten beträchtlich gewachsen, und es entstanden soziale Räume, in denen primär Gleichgesinnte miteinander kommunizieren und die daher wie Echokammern funktionieren.

Sehr viel stärker allerdings als die politischen Subkulturen der europäischen Sozialgeschichte sind Amerikas Echokammern Orte der selbstgewählten Ghettoisierung. Sie handeln von einem Paradox: Je mehr Entscheidungsmöglichkeiten die Menschen haben, desto mehr entscheiden sie sich für ein Leben in Eindeutigkeit, optieren dafür, bloß nicht zu sehr mit abweichenden Werthaltungen konfrontiert zu werden. Niemand wird dazu gezwungen, immer nur „MSNBC“ oder „Fox News“ zu schauen. Im Gegenteil: niemals zuvor in der Geschichte waren in Bezug auf alternative Informationsquellen die Wahlmöglichkeiten so groß; und selten wurde davon so wenig Gebrauch gemacht. Die gewachsene Autonomie in ihrer Lebensführung hat die Bürger der USA offenkundig nicht etwa zu postmodernen

4 Vgl. Seymour Martin Lipset: Political Man. The Social Base of Politics, New York 1963, 2. Auflage, S. 76.

5 Vgl. David B Truman: The Governmental Process. Political Interests and Public Opinion, New York 1951; Talcott Parsons: Voting and the Equilibrium of the American Political System, in: Eugene Burdick/Arthur J. Brodbeck (Hg.): American Voting Behavior, Glencoe 1959. S. 90-112.

6 Claude Fischer/Greggor Mattson: Is America Fragmenting?, in: Annual Review of Sociology 35 (2009), S. 435-455. 
Flaneuren erzogen ${ }^{7}$, die flexibel zwischen verschiedenen Weltentwürfen hin-und herwechseln. Es handelt sich um einen Prozess, der in dieser Arbeit als Paradoxe Individualisierung bezeichnet wurde, da die gewonnenen Freiheiten zum Rückzug in die Echokammer eingesetzt werden: Man wählt, nicht ständig die Wahl haben zu müssen.

All dies spiegelt sich auch in Dane und Waukesha County wider, den Fallbeispielen dieser Studie: ihre Bürger sind gebildet, wohlhabend, politisch besonders interessiert und auch gut informiert - und gehören dabei doch $\mathrm{zu}$ den eifrigsten Kombattanten in Amerikas Kulturkriegen. Sie stehen paradigmatisch für einen Trend, an dem sich das Phänomen Paradoxer Individualisierung besonders deutlich zeigt: der zunehmenden Tendenz vieler US-Bürger, bei der Wahl ihres Wohnortes die Gesellschaft Gleichgesinnter zu suchen. Da es jenseits einer eher impressionistischen Alltagssoziologie wenig belastbare Beweise für diese als „Big Sort“ bezeichnete „Abstimmung mit den Füßen“ gibt, versuchte diese Arbeit, mit Hilfe einer Feldstudie diesen Prozess besser als bisher zu verstehen. Um dieses Ziel zu erreichen, wurden sehr verschiedene methodische Herangehensweisen und Empirien miteinander kombiniert: Qualitative Interviews, Feldbeobachtung, schließlich die Daten aus einer repräsentativen Umfrage. Im Folgenden sollen die wichtigsten Untersuchungsergebnisse der Studie in aller gebotenen Kürze zusammengefasst werden:

1) Auch wenn der Grund für die extreme ideologische Polarisierung der USA in Hochburgen wie Dane und Waukesha County zu finden ist: zunächst sind diese Orte auch selbst ein Produkt der Bruchlinien, die seit der zweiten Hälfte des 20. Jahrhunderts die USA durchziehen. Präziser: Die spezifische Prägung beider Countys ist auch als eine Reaktion auf die gesellschaftliche Umbruchssituation in den USA der 1960er Jahre ff. zu verstehen. In Dane County wird seitdem ein Konzept von Stadt entwickelt, in dem sich die Ideale der Neuen Linken widerspiegeln und die heute zum festen weltanschaulichen Inventar der Demokratischen Partei gehören: Die Präferenz für Diversität, die Möglichkeit individueller Selbstverwirklichung, der Schutz der Umwelt. In einer dicht besiedelten Stadt, die die suburbane Zersiedelung verhindern soll und in der möglichst viele öffentliche Güter zur Verfügung stehen, sieht man die besten Chancen, diese Postulate zu verwirklichen.

7 Vgl. Zygmunt Bauman: Flaneure, Spieler und Touristen: Essays zu postmodernen Lebensformen, Hamburg 1997. 
Waukesha wiederum ist eine konservative Reaktion auf die als solche wahrgenommenen Exzesse und Verfallserscheinungen dieser Jahre, vor allem der Rassenunruhen in der benachbarten Großstadt Milwaukee und den generellen Problemen großstädtischen Lebens. Vor den Toren der Stadt, so das Selbstverständnis vieler Bewohner Waukeshas, lässt sich weiterhin ein Leben führen, dass den amerikanischen Traum konserviert. Im Grunde fungieren beide Orte als eine Art Rückzugsidyll: Madison und Dane County als Zitadelle, in der auch nach der großen Ernüchterung der reformerische Geist der 1960er Jahre aufgehoben wird und man wartet, bis der Rest der Gesellschaft endlich auch in der Modernität angekommen ist; Waukesha als Trutzburg gegen die Verfallserscheinungen der Gegenwart, die man so lange wie möglich fern zu halten gedenkt.

2) Mit dieser Initialzündung startet der „Big Sort“: Dane und Waukesha County beginnen, Menschen mit unterschiedlichen politischen Profilen anzuziehen. Fraglos bleibt die exakte empirische Messung dieses Phänomens eine anspruchsvolle Aufgabe, für die Gewissheit wohl nur mit einer jahrzehntelangen Panel-Studie zu erreichen wäre. Aber in der Summe scheinen die empirischen Belege für die Realität des „Big Sort“ doch sehr eindeutig zu sein: Unter den Zugezogenen zu beiden Orten befand sich eine große Mehrheit von Menschen, die bereits zum Zeitpunkt des Umzuges die Parteiidentifikation der Mehrheitskultur teilten. Stark differierten die lebensstilbezogenen Präferenzen: Demokraten und Republikanern waren sehr unterschiedliche Dinge wichtig bei der Auswahl ihres Wohnortes. Und schließlich drückten die Angehörigen der Minderheitskultur nicht nur eine niedrigere Zufriedenheit mit dem Wohnort aus. Sie äußerten auch stärker den Wunsch, wegzuziehen, nicht selten unmittelbar aus politischen Gründen. In der Konsequenz dürfte dies beide Orte in der Zukunft eher noch homogener machen.

3) Insbesondere unter den Angehörigen der Mehrheitskultur tendiert die Neigung, sich fortan noch anderen Ansichten und Meinungen auszusetzen, gegen Null. Ihre persönlichen Netzwerke waren daher auch homogener als jene der Angehörigen der Minderheitskultur - ein erster Hinweis darauf, dass die Herausbildung politischer Hochburgen nicht nur Symptom, sondern vor allem Ursache von Polarisierung sein könnte. Und je stärker die Parteiidentifikation, desto stärker die Homogenität der persönlichen Netzwerke, desto stärker die Identifikation mit dem Wohnort, desto größer auch die Wahrscheinlichkeit politischer Partizipation. 
4) Dane und Waukesha County zogen nicht nur unterschiedliche Arten von Bürgern an. Sie prägten fortan auch jene sehr nachhaltig, die an diese Orte zogen. Besonders deutlich wird dieses bei der Analyse der Veränderung der Parteiidentifikation der Zugezogenen: Tendenziell wurden Menschen, die nach Dane County zogen, eher liberaler: Demokraten stärkten ihre Parteiidentifikation, bei Republikanern schwächte sie sich ab, „Independents“ neigten stärker zur Demokratischen Partei als zum Zeitpunkt ihres Umzuges. In Waukesha zeigte sich das Gleiche, nur spiegelverkehrt - wer dorthin zog, wurde tendenziell konservativer. Dies dürfte die entscheidendste Komponente des Echokammer-Effekts sein: in Amerikas politischen Hochurgen findet tatsächlich eine Verstärkung politischer Einstellungen statt. Gruppenpolarisierung ist jenseits sozialpsychologischer Experimente ein reales Phänomen. Wer von Dane oder Waukesha County aus in die Parlamente nach Madison oder Washington entsendet werden will, muss daher in einem permanenten und bisweilen bizarren Wettbewerb nachweisen, dass niemand liberaler oder konservativer ist als er oder sie.

5) Trotz der überwiegenden Ähnlichkeiten zwischen beiden Orten: Viele der vermuteten Echokammer-Effekte waren im liberalen Dane County stärker als in Waukesha. Vor allem galt dieses für die Mentalität der Minderheit: Republikaner im liberalen Dane County drückten eine geringere Zufriedenheit mit dem Wohnort aus, eine stärkere Tendenz wegzuziehen, zeigten insgesamt viel deutlichere Signale eines Rückzuges aus der Zivilgesellschaft. Dies hat verschiedene Gründe, hängt aber zunächst mit der Struktur beider Orte zusammen: Im aktivistischen, urbanen Madison ist die Politik stets anwesend; im stark privatistischen Waukesha County ist sie, außerhalb von Wahlkampfzeiten, viel weniger präsent. Kurzum: ein Republikaner in Dane County wird sehr viel häufiger an seinen Minderheitenstatus erinnert und mit den Ansichten der Mehrheitskultur konfrontiert. Ob diese Erkenntnis allerdings auf alle republikanischen oder demokratischen Hochburgen übertragbar ist, müssten weitere Studien zeigen. Da diese Unterschiede aber vor allem mit urbaner Dichte zu erklären sind - welche wiederum grundsätzlich mit Parteiidentifikation korreliert - dürfte dieses jedoch als wahrscheinlich gelten.

6) Obgleich in Waukesha wesentlich verschärft, stellen sich Probleme politischer Repräsentanz grundsätzlich für beide Counties. Dies zeigt sich nicht zuletzt in der Lokalpolitik, in der die Stimmen der „Minderheiten“ kaum noch wahrnehmbar sind. Sie ist in den letzten Jahren stark polarisiert worden und nähert sich den Konfliktmustern der nationalen Politik an. Die Betonung ideologischer Unterschiede oder überhaupt die bloße Erwähnung der Parteizugehörigkeit der Kandidaten wird dabei in beiden Fällen von der Mehrheitskultur betrieben: für sie ist 
diese Art der Parteipolitisierung eine sichere Gewinnstrategie. Ein wenig zu kurz war der Beobachtungszeitraum, um seriös einzuschätzen, inwiefern die zunehmende Ideologisierung der Lokalpolitik auch Einfluss auf die auf lokaler Ebene verabschiedeten Politiken hat. Wahrscheinlich aber ist dies der Fall - was die Orte in einer Weise prägen dürfte, die sie wiederum für manche Menschen attraktiver macht als für andere.

Der Blick, der in dieser Arbeit auf die USA geworden wurde, war in gewisser Weise ein spezifisch europäischer. Und diese Perspektive war auch so beabsichtigt. Das begründet nicht nur den Versuch, die Analogie zwischen Amerikas Echokammern der Gegenwart und Europas politisierten Subkulturen der Vergangenheit für einen Erkenntnisgewinn fruchtbar zu machen. Im Grunde verdankt sich schon die Entstehung der Arbeit dieser Perspektive: dem Wundern und Staunen darüber nämlich, dass die USA heute in jenem Zeitalter der Ideologien zu leben scheinen, das in Europa, allem populistischem Furor zum Trotz, vergangen scheint. Liest man im Jahr 2015 einige Standardwerke der Vergangenheit, wie z.B. Robert Dahls „Democracy in the United States“, dann stellt sich beinahe schon ein Gefühl des Surrealen ein. In dem Buch schreibt Dahl, ein US-Amerikaner mit gewiss profunder Kenntnis der Parteiensysteme auf beiden Seiten des Atlantiks: „Unlike parties in many European countries, both Republicans and Democrats in the United States advocate much the same ideology. [...] To a European accustomed to the sound and fury of clashing ideologies, American party battles seem tame and uninteresting." ${ }^{\prime 8}$ Der Kontrast zur Gegenwart ist so groß, dass man sich zwangsläufig die Frage stellt, wie es zu diesem kompletten Rollentausch kommen konnte.

Im Laufe eines langen Forschungsprozesses habe ich mich gleichwohl von einer genuin komparativen Perspektive, die die Suche nach den Gründen dieser Unterschiedlichkeit primär in den Vordergrund gestellt hätte, zunehmend gelöst. Natürlich wäre auch eine solche Arbeit möglich gewesen - aber mit der hier vorliegenden hätte sie dann nicht mehr viel gemein gehabt. Die Unterschiede zwischen Europa und den USA - historisch, sozial, kulturell, institutionell - sind so gewaltig, dass man ein sehr breites, allgemeines Raster für den Vergleich hätte wählen müssen.

8 Robert Dahl: Democracy in the United States: Promise and Performance, Chicago 1972, S. 261. 
Dabei aber wäre alles Spezifische, Besondere, das mir an diesem Fall wichtig erschien, und das meines Erachtens nach alleine ein tieferes Verständnis des Phänomens garantiert, zwangsläufig verloren gegangen. Für Tocqueville, der manchen immerhin als Begründer der vergleichenden Politikwissenschaft gilt, blieb natürlich stets Frankreich (und daneben England) Referenzpunkt seiner Amerika-Beobachtungen. Er suchte, in seinen Worten, in Amerika „mehr als Amerika [...]. Ich habe dort das Bild der Demokratie selbst [...] gesucht." ${ }^{\text {“9 }}$ Aber hätte er dafür, um sich einer modernen Terminologie zu bedienen, stets nur nach den perfekten „funktionalen Äquivalenten“ für einen Vergleich gesucht: er hätte sich die Reise im Grunde sparen können und wäre besser am heimatlichen Schreibtisch geblieben, um von dort aus und anhand einiger Nachschlagewerke und amtlicher Statistiken sein Werk zusammen zu kompilieren.

Kurzum: Bisweilen scheint es doch sinnvoll zu sein, einen Fall zunächst in seiner ganzen Tiefe genauer zu betrachten - um daran anschließend aber doch die Frage zu diskutieren, ob etwas Allgemeines aus ihm zu lernen und ein Transfer möglich ist. Dies soll auch hier geschehen. Also: Was bedeutet Amerikas Polarisierung für Europa? Oder anders gefragt: Welche Implikationen hat der hier beschriebene Prozess Paradoxer Individualisierung für das herrschende Verständnis von Ideologie und ideologischem Konflikt in (post-)modernen Gesellschaften insgesamt? Darauf soll eine kurze Antwort wenigstens versucht werden, die auch als Ausblick der Arbeit dienen soll.

Die Antwort hat zwei Ebenen. Die erste dieser Ebenen ist noch relativ eindeutig: Es gibt keinen linearen Zusammenhang zwischen Individualisierung und Entideologisierung. Dabei soll gar nicht abgestritten werden, dass Individualisierungsprozesse historisch oft genug zur Aushöhlung geschlossener Gemeinschaften, die über Generationen als Träger von Ideologien fungiert haben, geführt haben. Und es soll ebenfalls nicht bestritten werden, dass Individualisierung zunächst einmal Entbindung bedeutet, Freisetzung, Loslösung aus traditionellen Strukturen. Doch wirklich spannend wird es ja erst danach: Wie reagieren die „entbetteten“ Individuen auf diesen Zugewinn an Autonomie? Diese Arbeit hat hoffentlich Zweifel daran geweckt, dass auf die Kontingenzerfahrung der Moderne nur zwei politische Reaktionen möglich sind, die bei all ihrer Unterschiedlichkeit in beiden Fällen Ideologien als systematischen, holistischen Ordnungsentwürfen das Wasser abgraben: entweder ein aufgeklärter oder auch zynischer Relativismus der gehobenen Mittelkasse, oder aber eine von ohnmächtiger Überforderung geprägte Apathie eines abgehängten Prekariats.

9 Alexis de Tocqueville: Über die Demokratie in Amerika, a.a.O., S. 16. 
Das Beispiel der USA der Gegenwart zeigt überdeutlich, dass dies keineswegs das Schicksal (post-)moderner Gesellschaften zu sein hat. Denkbar ist eben auch, dass die Freiheitsgewinne, die Möglichkeiten zur Autonomisierung der eigenen Lebensführung, ganz aktiv dafür eingesetzt werden, sich die verlorene Eindeutigkeit der Welt aktiv zurückzuerobern: durch die Auswahl des richtigen Nachrichtenkanals, des passenden Freundeskreises, der richtigen Schulen für die eigenen Kinder, der passenden Kirchengemeinde - und schließlich durch die Wahl des Wohnortes. Und wenig spricht dafür, dieses als ein auf Amerika beschränktes Phänomen zu sehen, viel mehr hingegen für die Annahme, darin eine Lektion über das Leben unter gesteigerten Unsicherheitsbedingungen zu erkennen. Möglicherweise gibt es einen Punkt, an dem die Menschen moderner Gesellschaften vom Entscheidungsdruck der „Multioptionsgesellschaft ${ }^{\text {‘10 }}$ ermüdet sind und schließlich gegen die permanente „Tyrannei der Möglichkeiten“ (Hannah Arendt) aufbegehren. Schon in den 1970er Jahren deuteten Peter L. Berger und seine Co-Autoren dies als die wahrscheinlichste Option einer zunehmend entfesselten Moderne an: den Rückzug des entbetteten Individuums in eine sinngebende „Heimatwelt“, die ihm eine „Ordnung integrierender und stützender Sinngehalte liefert. “"11 Folgt man diesen Argumenten, so scheint die Entstehung von neuen, homogenen virtuellen und realen Gemeinschaften wahrscheinlich, die den Zweifel - diesen Feind und Zersetzer alles Ideologischen - aus ihren Reihen gebannt haben. Erst diese Vermeidung von Ambivalenz ist die Voraussetzung dafür, die Welt überhaupt aus einem Guss deuten zu können.

Dann ist da noch die zweite Ebene der Antwort. Und die ist weitaus vertrackter. Im erkenntnistheoretischen Idealfall würde nämlich dem Aufbrechen des einen Paradigmas nun ein alternatives Deutungsangebot folgen. Und zugegeben: Verführerisch ist es schon, aus der Widerlegung des Zusammenhangs von Individualisierung und Entideologisierung einen radikalen Gegenschluss zu ziehen: dass die Autonomiegewinne der Postmoderne in Zukunft dafür eingesetzt werden, separierte Eigenwelten zu bauen und dass somit auch Europa die Rückkehr des Ideologischen erleben wird. ${ }^{12}$ Und wo man es hineinlesen will, da könnte man die zarten Anfänge mancher der für die USA beschriebenen Entwicklungen auch hier erkennen: die Infragestellung von nationalen Leitmedien zu Gunsten sehr partikularer Informationsquellen und damit der Abschied von allgemein verbindlichen

10 Vgl. Peter Gross: Die Multioptionsgesellschaft, Frankfurt a. Main 1994.

11 Peter L. Berger/Brigitte Berger/Hansfried Kellner: Das Unbehagen in der Modernität, Frankfurt a. Main 1973, S. 61.

12 In eine nicht unähnliche Richtung argumentiert Gayil Talshir: The Phoenix of Ideology, in: Critical Review of International Social and Political Philosophy 8.2 (2005), S. 107124. 
Realitätsinterpretationen in einer „Post-Fact Society“"13; die weiter zunehmende Wichtigkeit von Lebensstildistinktionen in der politischen Auseinandersetzung zu Lasten traditionell klassenspezifischer Abgrenzungsmechanismen; die Homogenisierung - in diesem Fall in sozialer Hinsicht ebenso wie bei der Frage von Lebensstilen - von einzelnen Stadtteilen in den großen europäischen Metropolen. Entsteht daraus nicht gerade eine Konstellation, die zu einer Konfrontation konträrer Lebenswelten und damit zu ideologischer Polarisierung führen dürfte? Und erlebt Europa nicht derzeit tatsächlich den Aufstieg links- wie rechtspopulistischer Parteien, ein Prozess, der simultan zur programmatischen Annährung der etablierten Parteien verläuft? Dass es ganz so weit wie in den USA eben noch nicht ist, ließe sich im Rahmen dieses Argumentationsmusters dann einfach damit erklären, dass manche der dafür notwenigen Prozesse, etwa die Pluralisierung des Medienmarktes oder räumliche Mobilität, auf der anderen Seite des Atlantiks eben einfach weiter fortgeschritten sind - weswegen sich die Konsequenzen dort ebenfalls früher zeigen. Es wäre schließlich nicht das erste Mal, dass die amerikanische Gesellschaft als Laboratorium dient, wo mit Entwicklungen experimentiert wird, die anderswo noch in den Kinderschuhen stecken.

Allein: so einfach ist es leider nicht. Zu behaupten, Prozesse von Individualisierung würden ab einem bestimmten Steigerungspunkt automatisch eher zur Entstehung oder Verschärfung ideologischen Konfliktes führen, würde den einen Strukturdeterminismus durch einen anderen ersetzen. Denn zum einen bleibt es bei dem, was in dieser Arbeit bereits mehrfach betont wurde: Amerikas ideologische Spaltung verdankt sich einem komplexen Ursachenbündel und ist nicht auf eine einzige Erklärung zu reduzieren. Doch auch unter der Prämisse, dass der in dieser Arbeit dargestellte Prozess der Paradoxen Individualisierung dabei zentral ist: wirkungsmächtig ist er nur geworden, weil politische Eliten es verstanden, aus den daraus erwachsenden Differenzen wiederum für sich politisches Kapital zu schlagen. Das gilt vor allem für den amerikanischen Konservativismus, dem es durch die Politisierung bestimmter Lebensstile und der Vereinnahmung und Instrumentalisierung der mit ihnen verbundenen Mythologien gelang, eine Konfliktlinie zu etablieren, die sozioökonomische Differenzen erfolgreich unterlief. Eine primär auf Lebensstildifferenzen beruhende Synthese dieser Art, die in der Lage wäre, den Parteienwettbewerb dauerhaft zu strukturieren und zu polarisieren, ist in dieser Form für Europa bisher nicht zu erkennen. So bleibt diese zweite Antwort also ambivalent, und damit ein Stück weit offen: Eine stärkere ideologische Polarisierung ist auch unter den Bedingungen einer individualisierten, ,flüchtigen Moderne" möglich; zwangsläufig aber ist sie deswegen noch lange nicht.

13 Der Begriff stammt von Farhad Manjoo: True Enough. Learning to Live in a Post-Fact Society, Hoboken 2008. 
Dies scheint dafür umso klarer: Hoffen sollte man auf eine solche Entwicklung gewiss nicht. Dabei mag es auch hier zunächst reizvoll sein, gleichsam gegen den Strich zu denken und - abermals aus einer genuin europäischen Perspektive - die Vorzüge der ideologischen Polarisierung der USA zu betonen. Von den hierzulande diagnostizierten Ermüdungserscheinungen der Demokratie kann dort kaum eine Rede sein, engagieren sich doch mehr US-Bürger für die Politik als je zuvor und selbst die Wahlbeteiligung - zumindest bei Präsidentschaftswahlen - ist zuletzt wieder gestiegen. Es lässt sich auch schwerlich behaupten, dass es einen Mangel an politischen Alternativen geben würde: es sind denkbar unterschiedliche Angebote, die von Demokraten und Republikanern unterbreitet werden.

Die Schattenseiten der ideologischen Spaltung des Landes überwiegen jedoch bei weitem. Die zunehmende Dysfunktionalität des eigentlich auf Konsens ausgerichteten politischen Systems der USA ist dabei noch nicht einmal der wichtigste Punkt - parlamentarische Demokratien dürften schließlich weniger anfällig auf diesen Aspekt von Polarisierung reagieren. Entscheidender ist etwas Anderes. Streit, der produktiv sein soll, ist schließlich auf bestimmte Voraussetzungen angewiesen - unter anderem darauf, dass ein Dialog überhaupt stattfindet. Es gibt jedoch keine produktive Synthese, wo These und Antithese nicht länger aufeinandertreffen. Und eben das scheint in den USA, dem Land der politischen Echokammern, zunehmend der Fall zu sein. Demokraten und Republikaner arbeiten sich nicht länger produktiv aneinander ab, was ja dazu führen könnte, dass die schärfsten Kanten des Konfliktes langsam abgeschliffen würden. Vielmehr bleiben sie unter sich und bestätigen sich in der Gesellschaft Gleichgesinnter in der Richtigkeit der eigenen Auffassung. Es scheint zweifelhaft, dass daraus ein wirklich fruchtbarer Konflikt wachsen könnte. Zudem: im europäischen Zeitalter der Ideologien - was auch sonst die Kosten gewesen sein mögen - kam es immerhin zu einer Totalpolitisierung der Gesellschaft, durch die alle gesellschaftlichen Schichten aktiviert wurden; das aber ist in den USA nicht der Fall, wo Einkommen und Bildungsstand weiterhin extrem stark mit politischer Partizipation korrelieren.

Und schließlich - und dieses Argument wiegt wohl am stärksten - ist dieser Streit mittlerweile ja nicht mehr begrenzt auf die legitime und notwendige Auseinandersetzung um Sachfragen. Wenngleich bisher noch nicht systemgefährdend, geht es immer häufiger auch darum, der anderen Seite die politische Legitimität insgesamt abzuerkennen. An dieser Stelle ist allerdings eine ,asymmetrische Polarisierung“ nicht zu leugnen, finden sich die schrillsten Stimmen doch eindeutig auf konservativer Seite, wo Politiker der Republikanischen Partei es mindestens stillschweigend dulden, wenn die Staatsbürgerschaft des amtierenden Präsidenten der USA 
immer wieder angezweifelt wird. Mehr noch: der prominenteste Zweifler von allen, Donald Trump, wird nun sogar mutmaßlich um Obamas Nachfolge antreten. Natürlich sind die USA des Jahres 2016 bei aller Hysterie nicht Weimar 1932, die amerikanische Demokratie bei aller Lähmung und trotz aller Kassandra-Rufe noch immer stabil. Gesund aber kann ein System nicht sein, in dem Streit beginnt, sich von politischen Inhalten zu lösen und auf Fragen der Rechtmäßigkeit von Herrschaft zu konzentrieren. So möchte man am Ende dieser Arbeit Johann Wolfgang von Goethe doch einmal widersprechen: Amerika, Du hast es nicht besser. 


\section{Anhang}

\section{DANKSAGUNG}

Ausnahmsweise möchte ich diese Danksagung mit einer Institution beginnen: der Volkswagenstiftung, die meine Arbeit sechs Jahre lange mit einem „SchumpeterFellowship“ gefördert hat. Die Freiheit, die damit verbunden war, war ein großes und ganz unwahrscheinliches Glück; vermutlich auch ein unwiederholbares. Unverdient war es bestimmt.

Über all die Jahre im Projekt habe ich von der ungemeinen Verlässlichkeit, Umsicht, Beharrlichkeit und den guten Ideen von Robert Matschoß profitiert. Ohne ihn wäre ich insbesondere bei der Auswertung der Umfrage-Daten einigermaßen verloren gewesen. Immer zuverlässig zur Stelle war auch Jan Philip Clooth, vor allem beim Korrekturlesen (bei dem auch Andrea Lütjen half), transkribieren und recherchieren. Für ihre engagierte Mitarbeit im Projekt danke ich ebenfalls Esther Gardei-Schilling, Stephan Schütze und Stefan Tophofen.

Die meisten Gespräche über mein Thema habe ich mit Maik Bohne und Philipp Erbentraut geführt, deren intellektuelle Fingerabdrücke sich überall im Buch finden. Dafür und für ihre Freundschaft in dieser Zeit bin ich Ihnen sehr dankbar.

Ein guter Ort das Buch zu schreiben war das Institut für Deutsches und International Parteienrecht und Parteienforschung (PRuF) der Heinrich-Heine-Universität Düsseldorf. Für wissenschaftlichen Austausch und die große Kollegialität danke ich Ulrich von Alemann, Thomas Poguntke, Tim Spier, Jens Walther und Sebastian Roßner. Und ohne die Hilfe von Andrea Holtermann ging am PRuF für mich sowieso nichts.

On the other side of the Atlantic, I feel deeply indebted to Bill Bishop. Ever since we met in Austin in 2010 and in Düsseldorf in 2013, he and Julie Ardery have encouraged me to dig deeper into the mysteries of the „Big Sort”. Bill has shared his data and his thoughts with me and I hope that the end of this project will not mean the end of our intellectual companionship. 
Charles Franklin from Marquette University, one of the leading pollsters in Wisconsin and the nation, helped me tremendously in drafting the questionnaire for my survey. I would not have dared this journey into the unknown territory of survey research without him. At the political science department in Madison, Byron Shafer was a great host and ,sponsor" who always tried to make time to discuss my ideas and whose „big picture” perspective on American politics was most valuable.

Finally, thank you to two local journalists, who helped me access the field when I started my expedition into Dane and Waukesha: Jack Craver of the „Capital Times" and Laurel Walker of the „Milwaukee Journal Sentinel” (Oh, and thanks for regularly feeding me while I was so far far away from home, Laurel and Bob!) The only thing I regret is that my final decision to write it all down in German excludes them from seeing the multiple contributions they have made to this book. I am planning on changing that.

Dieses Buch ist die leicht überarbeitete Fassung meiner Habilitationsschrift, die ich im November 2015 an der philosophischen Fakultät der Heinrich-Heine-Universität Düsseldorf eingereicht habe. Meinen Gutachtern Ulrich von Alemann, Thomas Poguntke und Andreas Falke danke ich für die hilfreichen Hinweise zur Verbesserung des Manuskriptes.

Und schließlich geht ein großer Dank an Franz Walter und die vielen klugen Mitarbeiter des ganz einzigartigen und großartigen Göttinger Instituts für Demokratieforschung, in deren Reihe im transcript-Verlag dieses Buch erscheinen darf.

Wo man liebt und geliebt wird, da klingt ein weiteres „Danke“ nach viel zu wenig, obwohl es dafür auch in diesem Fall tausendundeinen Grund gibt. Gewidmet ist das Buch jedenfalls Anna und Thore. Einfach wegen allem.

Göttingen und Düsseldorf, Juni 2016. 


\section{LISTE DER GESPRÄCHSPARTNER}

Alexander, Joe (Bauunternehmer, Madison, Dane County): 2. Oktober 2014.

Alexander, Jennifer (Chair Greater Madison Chamber of Commerce): 28. November 2012

Basford, Michael (Chair Democratic Party of Dane County): 20. März 2012.

Belling, Marc (konservativer Radio-Moderator, schriftliche Befragung): 9. Juni 2015.

Blaska, David (Konservativer Blogger, Dane County): 21. März 2012

Blaska, Michael (Chair Dane County Board, 1992-1996): 25. Mai 2012

Brandtjen, Janel (Supervisor Waukesha County Board): 2. November 2012.

Briscoe, Stuart (Senior Pasto Elmbrook Church, Brookfield, Waukesha County):

29. November 2012.

Brown, Ross (Tea Party Aktivist, Dane County): 4. Mai 2012

Bruskewitz, Eileen (Supervisor Dane County Board): 22. März 2012.

Cieslewicz, Dave (Mayor of Madison, 2003-2011): 26. April 2012: 26. April 2012.

Clausius, Bill (Supervisor Dane County Board): 28. April 2012.

Congdon, Richard (Chair, Democratic Party of Waukesha County, 1994-2002):

21. September 2012.

Craver, Jack (Journalist, Capital Times, Madison): 14. März 2012.

Cullen, Tim (State Senator, 15th district): 24. Mai 2012.

Cumings, Norm (Director of Administration, Waukesha County): 5. Oktober 2012.

Davis, Jefferson (Tea Party Aktivist, Waukesha County): 18. Oktober 2012.

Decker, Paul (Chair Waukesha County Board): 27. September 2012.

Diaz, Luke (liberaler Aktivist aus Verona, Dane County): 3. Oktober 2014.

Dolen, Ron (Co-Founder Reach Out Wisconsin"): 2. April 2012; 30. September 2014

Dwyer, Jim (Chair Waukesha County Board 1994-2012): 11. Oktober 2012.

Eisen, Marc (freier Journalist, Dane County): 20. März 2012.

Ferrell, Ron (Supervisor Dane County Board): 18. April 2012, 1. Oktober 2014.

Grabins, Carol (Co-Founder Reach Out Wisconsin): 10. Mai 2012.

Grabins, Scott (Co-Founder Reach Out Wisconsin): 10. Mai 2012.

Grant, Jennifer (Waukesha County Board): 25.10.2012; 26.09.2014.

Grothman, Glenn (State Senator, 20 ${ }^{\text {th }}$ district): 11. Mai 2012.

Hasler, Joe P. (Mitarbeiter des republikanischen State Senators Dale Schultz): 11.

Mai 2012. 
Hagenauer, George (liberaler politischer Aktivist, Dane County): 13. November 2012.

Hendrick, John (Supervisor Dane County Board): 25. April 2012.

Herl, Mike (Chair, Republican Party of Dane County): 31. Mai 2012.

Hiniker, Steve (1000 Friends of Wisconsin, Dane County): 2. Oktober 2012

Hoffman, Christopher (Chair College democrats, University of Wisconsin, Madison): 26. November 2012.

Kelley, Suzanne (Chair Waukesha County Business Alliance): 22. September 2014.

Langill, Ellen (Waukesha County School Board): 28. September 2012.

Lightboune, George (President, Wisconsin Policy Research Institute): 13. März 2012.

Lombard, Kirsten (Tea Party Aktivistin, Dane County): 10. Mai 2012.

Lueders, Bill (Journalist Center for Investigative Journalism, Madison, Dane County): 19. März 2012

Macy, William P. (Chair Republican Party of Waukesha County): 24. September 2014.

McDonell, Scott (Dane County Board Chair): 28. März 2012.

Meyer, Pamela (Supervisor, Waukesha County Board): 23. September 2012.

Mux, Lisa (Liberale Bloggerin, Waukesha County): 15. Mai 2012.

Nelson, Larry (Supervisor Waukesha County Board): 1. Oktober 2012; 25. September 2014.

Nelson, Rick (Teilnehmer von Reach Out Wisconsin): 16. Oktober 2012.

Pas, Dick (Chair, Democratic Party of Waukesha County): 1. Oktober 2012.

Resnick, Scott (Alderman Madison City Council und Start-Up-Unternehmer, Dane County): 3. Oktober 2014.

Rickert, Chris (Journalist Wisconsin State Journal, Dane County): 20. März 2012. Risser, Fred (State Senator, 26th district): 7. Mai 2012.

Rusten, Matt (Junior Pastor, Blackhawk Church, Dane County): 7. Oktober 2012

Schultz, Dale (State Senator, 17th district): 22. Mai 2012.

Schroeder, Leslie (Einwohnerin von Madison, Dane County): 21. November 2012.

Soglin, Paul (Mayor of Madison, Dane County): 8. Oktober 2012.

Songer, Katie (Co- Founder Reach Out Wisconsin): 2. April 2012; 30. September 2014

Taylor, Don (Chair Republican Party of Waukesha County, 1979-2013): 26. September 2012.

Vogel, Schuyler (Pastor Unitarian Church Waukesha, Skype-Gespräch): 16. September 2015. 
Vrakas, Dan (County Executive, Waukesha County): 17. Mai 2012; 20. November 2012;

Waksman, Jeff (Pressesprecher, Republican Party of Waukesha County): 24. April 2012.

Waller, Cathy (executive director, Republican Party of Waukesha County): 17. Oktober 2012.

Welcenbach, Steve (Tea Party Aktivist, Waukesha County): 22. November 2012; 25. September 2014.

Wiganowski, Dave (Supervisor Dane County Board): 17. Mai 2012.

Wigderson, James (konservativer Blogger, Waukesha County): 29. September 2012. 


\section{QUELLEN- UND LITERATURVERZEICHNIS}

Abramowitz, Alan/Alexander, Brad/Gunning, Matthew: Don't Blame Redistricting for Uncompetitive Elections, in: PS. Political Science \& Politics, (1) 2006: S. 87-90.

Abramowitz, Alan: Don't Blame Primary Voters for Polarization, in: The Forum. A Journal of Applied Research in Contemporary Politics, Vol. 5 (4), 2008.

Abramowitz, Alan: The Disappearing Center. Engaged Citizens, Polarization, \& American Democracy, Yale 2010.

Abramowitz, Alan/Webster, Steven: All Politics is National: The Rise of Negative Partisanship and the Nationalization of US House and Senate Elections in the $21^{\text {st }}$ Century, Paper, Prepared for presentation at the Annual Meeting of the Midwest Political Science Association, Chicago, Illinois, April 16, 2015.

Allern, Elin H./Bale, Tim: Political Parties and Interest Groups: Disentangling Complex Relationships, in: Party Politics, Vol. 18(1) 2012: S. 7-25.

Almond, Gabriel A: Comparative Political Systems, in: Journal of Politics, Vol. 18 (3), 1956, S. 391-409.

Angster, Julia: Konsenskapitalismus und Sozialdemokratie. Die Westernisierung von SPD und DGB, München 2003.

Baldassarri, Delia: Partisan Joiners: Associational Membership and Political Polarization in America (1974-2004), in: Social Science Quarterly, Vol. 92 (3), 2011, S. 631-655.

Barber, Michael J./McCarty, Nolan: Causes and Consequences of Polarization, in:

Nathaniel Persily: Solutions to Political Polarization in America, Cambridge 2015, S. 15-58.

Bardwell, Kedron: Evangelical Free Church of America, in: Corwin E. Smidt (Hg.): Pulpit and Politics: Clergy in American Politics at the Advent of the Millennium, Waco 2004, S. 195-206.

Barone, Michael: The 49 Percent Nation, in: National Review, Vol. 33 (23) 2001:

S. 1710-1716.

Bauman, Zygmunt: Flaneure, Spieler und Touristen: Essays zu postmodernen Lebensformen, Hamburg 1997.

Bauman, Zygmunt: In Search for Politics, Stanford 1999.

Bauman, Zgmunt: Flüchtige Moderne, Frankfurt a. Main, 2003.

Baybeck, Brady: Local Political Participation, in: Donald P. Haider-Markel (Hg.):

The Oxford Handbook of State and Local Government, Oxford 2014.

Beck, Ulrich: Die Erfindung des Politischen, Frankfurt a. Main 1997.

Bell, Daniel: The End of Ideology: On the Exhaustion of Political Ideas in the Fifties, New York 1960. 
Berger, Peter L./Berger, Brigitte/Kellner, Hansfried: Das Unbehagen in der Modernität, Frankfurt a. Main 1973.

Berger, Peter L./Luckmann, Thomas: Die gesellschaftliche Konstruktion der Wirklichkeit. Eine Theorie der Wissenssoziologie, Frankfurt a. Main 2003.

Bernstein, Jonathan H.: The Expanded Party in American Politics, Dissertation, Berkeley 1999.

Berry, Christopher R.: Imperfect Union: Representation and Taxation in Multilevel Governments, Cambridge 2009.

Bishop, Bill/Cushing, Robert: The Big Sort. How the Clustering of Like-Minded Americans is Tearing us Apart, New York 2008.

Blaise, Pascal: Gedanken. Mit einem Vorwort von Eduard Zwierlein, Berlin 2012.

Bohne, Maik: Vibrant Spaces. Dynamik und Struktur von Parteiräumen in USamerikanischen Wahlkämpfen, Opladen 2011.

Boorstin, Daniel J.: The Genius of American Politics, Chicago 1953.

Bourdieu, Pierre: Die feinen Unterschiede, Berlin 1987.

Brady, David/Hahrie Han/Jeremy C. Pope: Primary Elections and Candidate Ideology: Out of Step with the Primary Electorate?, in: Legislative Studies Quarterly, 32, 2007: S. 79-105.

Braun, Mark Edward: Suburban Sprawl in Southeast Wisconsin: Planning, Politics, and the Lack of Affordable Housing, in: Matthew J. Lindstrom / Hugh Bartling (Hg.): Suburban Sprawl. Culture, Theory and Politics, Lanham 2003, S. 257-272.

Brewer, Marc D./Stonecash Jeffrey: Split. Class und Cultural Divides in American Politics, Washington 2007.

Briscoe, Stuart: Flowing Streams. Journeys of a Life Well Lived, Grand Rapids 2008.

Brocker, Manfred: Integration durch Partizipation. Soziale Bewegungen im politischen System der USA. In: Zeitschrift für Politikwissenschaft 19/2, 2009, S. 237-274.

Broder, David S.: The Party's Over. The Failure of Politics in America, New York 1972;

Brownstein, Ronald: The Second Civil War. How Extreme Partisanship has Paralyzed Washington and Polarized America, New York 2008.

Bryce, Viscount James: The American Commonwealth, Indianapolis 1888.

Burden, Barry: The Polarizing Effects of Congressional Primaries, in: P. F. Galderisi/M. Lyons (Hg.): Congressional Primaries and the Politics of Representation, Baltimore 2001.

Burden, Barry: Candidate Positioning in US Congressional Elections, in: British Journal of Political Science 34, 2004: S. 211-227. 
Burns, Jennifer: Goddess of the Market. Ayn Rand and the American Right, Oxford 2009.

Cain, Bruce E.: Sorting It Out, Review of the Big Sort, in: The California Journal of Politics and Policy, Vol. 1, 2009: S. 1-4.

Cairncross, Frances: The Death of Distance, Boston 1997.

Campbell, Angus/Converse, Philip/Miller, Warren: The American Voter, Chicago 1960.

Campbell, David E.: Why We Vote. How Schools and Communities Shape Our Civic Life, Princeton 2006.

Carmines, Edwards/Stimson, James: Issue Evolution: Race and the Transformation of American Politics, Princeton 1990.

Carsey, Thomas M./Layman, Geoffrey C.: Changing Sides or Changing Minds? Party Identification and Policy Preferences in the American Electorate, in: American Journal of Political Science, 50 (2), 2006: S. 464-477.

Carson, Jamie L./Michael H. Crespin/Charles J. Finocchiaro/David W. Rohde: Redistricting and Party Polarization in the U.S. House of Representatives, in: American Politics Research, Vol. 35 (6), 2007, S. 878-904.

Cheney, Robert W.: American Politics in the Gilded Age, 1868-1900, Wheeling 1997.

Clayton, Nall/Mummolo, Jonathan: Why Partisans Don't Sort: How Neighborhood Quality Concerns Limit Americans Pursuit of „Like-Minded Neighbors", Working Paper, 02.10.2013. Online abrufbar unter: http://web.stanford.edu/ nall/docs/gp2.1.pdf (zuletzt abgerufen am 20.07.2015).

Committee on the Political Parties. Toward A More Responsible Two-Party System. A Report of the Committee on Political Parties, American Political Science Association, 1950.

Conger, Kimberly/Green, John: Spreading out and Digging in. Christian Conservatives and State Republican Parties, in: Campaigns and Elections, Februar 2002.

Cox, Garry/Mathew McCubbins: Setting the Agenda: Responsible Party Government in the U.S. House of Representatives, New York 2005.

Cox, Kevin: The Spatial Structuring of Information Flows and Partisan Attitudes, in: Mattei Dogan und Stein Rokkan (Hg.): Quantitative Ecological Analysis in the Social Sciences, Cambridge 1969, S. 343-370.

Cramer-Walsh, Kathrin: Talking Politics. Informal Groups and Social Identity in American Life, Chicago 2004.

Crotty, Willam J.: American Parties in Decline, Boston 1980.

Crouch, Colin: Postdemokratie, Frankfurt a. Main, 2003. 
Dahl, Robert: Democracy in the United States: Promise and Performance, Chicago 1972.

Dalton, Russel J./Martin P. Wattenberg (Hg.): Parties without Partisans: Political Change in Advanced Western Democracies, Oxford 2002.

Dalton, Russel J./McAllister, Ian/Wattenberg, Martin P.: The Consequences of Partisan Dealignment, in: Russell J. Dalton/Martin P. Wattenberg (Hg.): Parties without Partisans: Political Change in Advanced Western Democracies, Oxford 2002: S. 37-63.

Dalton, Russel J.: Social Modernization and the End of Ideology Debate: Patterns of Ideological Polarization, in: Japanese Journal of Political Science, Vol. 7 (1) 2006, 1-22

Di Salvo, Daniel: Engines of Change. Party Factions in American Politics, Oxford 2012.

Dierenfield, Bruce J.: Civil Rights Movement, revised edition, Edinburgh 2008.

Dionne, Eugene Joseph: Our Divided Political Heart. The Battle for an American Idea in an Age of Discontent, New York 2012.

Dochuk, Darren: From Bible Belt to Sun Belt. Plain-Folk Religion, Grassroots Politics, and the Rise of Evangelical Conservatism, New York 2010.

Durkheim, Émile: Die elementaren Formen des religiösen Lebens, Frankfurt am Main 2007.

Eagleton, Terry: Ideologie. Eine Einführung, Stuttgart 1993.

Ehrenberg, Alain: Das Unbehagen in der Gesellschaft, Berlin 2011.

Eisenstadt, Shmuel N.: Die Vielfalt der Moderne, Weilerswist 2000.

Epstein, Leon: Political Parties in the American Mold, Wisconsin 1986.

Erbentraut, Phillipp/Lütjen, Torben: Eine Welt zu gewinnen. Entstehungskontext, Wirkungsweise und Narrationsstruktur des „Kommunistischen Manifests“, in: Johanna Klatt und Robert Lorenz, Manifeste. Geschichte und Gegenwart des politischen Appells, Bielefeld 2011. S. 73-98.

Fabbrini, Sergio: Compound Democracies. Why the United States and Europe are Becoming Similar, Oxford 2007.

Falter, Jürgen W./Winkler, Jürgen R.: Wahlgeographie und Politische Ökologe, in: Jürgen W. Falter/Harald Schoen: Handbuch Wahlforschung, Wiesbaden 2014, S. 135-168.

Farber, David: The Rise and Fall of Modern American Conservatism. A Short History, Princeton 2010.

Fiorina, Morris P./Abrams, Samuel J./Pope, Jeremy C.: Culture War? The Myth of a Polarized America, New York 2005.

Fiorina, Morris P.: The „Big Sort” That Wasn't: A Skeptical Reexamination, in: PS: Political Science \& Politics, Vol. 45 (2) 2012: S. 203-210. 
Fischel, William A.: The Homevoter Hypothesis: How Home Values Influence Local Government Taxation, School Finance and Land-Use Policies, Cambridge 2004.

Fischer, Claude/Mattson, Greggor: Is America Fragmenting?, in: Annual Review of Sociology, 35 (2009), S. 435-455.

Florida, Richard: The Rise of the Creative Class, New York 2002.

Flyvbjerg, Bent: Five Misunderstandings about Case-Study Research, in: Qualitative Inquiry, Vol. 12 (2) 2006: S. 219-245.

Foley, Michael: American Credo. The Place of Ideas in US Politics, Oxford (UK) 2007.

Fowler, Robert Booth: Wisconsin Votes: An Electoral History, Madison 2008.

Frank, Thomas: What's the Matter with Kansas? How Conservatives Won the Heart of America, New York 2004

Franklin, Mark N.: Voter Turnout and the Dynamics of Electoral Competition in Established Democracies since 1945, Cambridge 2004.

Frei, Norbert: 1968. Jugendrevolte und globaler Protest, München 2008.

Fukuyama, Francis: America in Decay, in: Foreign Affairs, Vol. 93 (5), 2014, S. 3-26.

Gainsborough, Juliet F.: Fenced Off: The Suburbanization of American Politics, Washington D.C. 2011.

Gelman, Andrew: Red State, Blue State, Rich State Poor State, Princeton 2010.

Gerring, John: Party Ideologies in America 1828-1996, Camebridge 1963.

Gieryn, Thomas F.: A Space for Place in Sociology, in: Annual Review of Sociology, Vol. 26, 2000, S. 463-496.

Gilens, Martin: Why American Hate Welfare: Race, Media, and the Politics of Antipoverty Policy. Studies in Communication, Media, and Public Opinion, Chicago 2000.

Gilman, Nils: Mandarins of the Future: Modernization Theory in Cold War America, Baltomore 2003.

Gimpel, James G./Schuknecht, Jason E.: Patchwork Nation: Sectionalism and Political Change in America, Ann Arbor 2004.

Grant, Keneshia: Relocation and Realignment: How the Great Migration Changed the Face of the Democratic Party, Dissertation, 2014, Syracuse University.

Green, Donald/Palmquist, Brad/Schickler, Eric: Partisan Hearts and Minds. Political Parties and Social Identities of Voters, Yale 2002.

Gross, Peter: Die Multioptionsgesellschaft, Frankfurt a. Main 1994.

Gumbrecht, Blake: The American College Town, Camridge 2008. 
Gurda, John: Leaving the Middle Behind. Wisconsin's Turning Point, in: Refocus Wisconsin, Policy-Paper, herausgegeben vom Wisconsin Policy Research Institute, S. 2-18, abrufbar unter: http://www.wpri.org/WPRI-Files/Special-Reports/Reports-Documents/WPRI_Refocus_Digest_FNL_090710.pdf. (zuletzt abgerufen am 27.02.2015)

Gurda, John: The Making of Milwaukee, Milwaukee 1999.

Haidt, Jonathan: The Righteous Mind. Why Good People are Divided by Politics and Religion, New York 2013.

Hartman, Andrew: A War for the Soul of America. A History of the Culture Wars, Chicago 2015.

Hartz, Louis: The Liberal Tradition in America, New York 1991.

Hayek, Friedrich: The Road to Serfdom, London 1944.

Hayward, Steven F.: The Age of Reagan. The Fall of the Old Liberal Order 19641980, New York 2001.

Heaney, Michael T. et. al.: Polarized Networks: The Organizational Affiliations of National Party Convention Delegates, in: American Behavioral Scientist, Vol. 56 (12) 2012: S. 1654-1676.

Helfferich, Cornelia: Die Qualität qualitativer Daten. Manual für die Durchführung qualitativer Interviews, 3. Auflage, Wiesbaden 2009.

Higham, John: The Cult of the „American Consensus”: Homogenizing Our Past, in: Commentary, 27, February 1959, S. 93-101.

Hirano, Shigeo/Snyder Jr., James M./Ansolabehere, Stephen Daniel/Hansen/Mark, John: Primary Elections and Partisan Polarization in the U.S. Congress, in: Quarterly Journal of Political Science 5(2), 2010, S. 169-191.

Hochgeschwender, Michael: Freiheit in der Offensive? Der Kongreß für kulturelle Freiheit und die Deutschen, München 1998.

Hofstadter, Richard: A Long View: Goldwater in History, in: The New York Review of Books, 8. Oktober 1964.

Hofstadter, Richard: Anti-Intellectualism in American Life, New York 1963.

Hofstadter, Richard: The Age of Reform. From Bryan to FDR, New York 1955.

Hofstafter, Richard: Goldwater and Pseudo-Conservative Politics, in: ders. (Hg.) The Paranoid Style in American Politics and other Essays, New York 2008, S. 93-141.

Hogue, Andrew P.: Stumping God. Reagan, Carter, and the Invention of Political Faith, Waco 2012.

Hradil, Stefan: Sozial Ungleichheit in Deutschland, 8. Auflage, Wiesbaden 2005.

Dormehl, Luke: The Apple Revolution: Steve Jobs, the Counterculture and how the Crazy Ones Took Over the World, New York 2013. 
Huckfeldt, Robert/Sprague, John: Citizens, Politics and Social Communication. Information and Influence in an Election Campaign, Cambridge 1995.

Hunter, James, Davison: Culture Wars: The Struggle to Define America, New York 1991.

Huntington, Samuel P.: American Politics and the Promise of Disharmony, Cambridge 1981.

Ingelehart, Ronald/Abramson, Paul R.: Value Change in Global Perspective, Michigan 1995.

Isserman, Maurice/Kazin, Michael: America Divided. The Civil War of the 1960s, Oxford 2004.

Iyengar, Shanto/Hahn, Kyu S.: Red Media, Blue Media: Evidence of Ideological

Selectivity in Media Use, in: Journal of Communication, 59 (1), (2009): S. 1939.

Iyengar, Shanto/Gaurav, Sood/Yphtach Lelkes: Affect, Not Ideology: A Social Identity Perspective on Polarization, in: Public Opinion Quarterly, Vol. 76 (3) 2012: S. 405-431.

Iyengar, Shanto/Westwood, Sean J.: Fear and Loathing across Party Lines. New

Evidence of Group Polarization, in: American Journal of Political Science, Vol. 59 (3), 2014, S. 690-707.

Jacobson, Garry: Polarization in American Politics: A Background Paper, in:

Presidential Studies Quarterly, Vol. 34 (4) 2013: S. 688-707.

Jacoby, Russel: The End of Utopia, New York 1999.

Jahoda, Marie/Lazarsfeld, Paul Felix/Zeisel, Hans: Die Arbeitslosen von Marient-

hal. Ein soziographischer Versuch über die Wirkungen langandauernder Arbeitslosigkeit, Leipzig 1933.

Janik, Erika: Madison - A History of a Model City, Charleston 2010.

Judis, John B./Teixeira, Ruy: The Emerging Democratic Majority, New York 2002.

Kazin, Michael: The Populist Persuasion. An American History, New York 1995.

Kennedy, David M: Freedom from Fear. The American People in Depression and War 1929-1945, Oxford 1999.

Kirchheimer, Otto: Der Wandel des Westeuropäischen Parteiensystems, in: Politische Vierteljahresschrift, Vol. 6 (1) 1965, S. 20-41.

Klofstadt, Casey A./McClurg, Scott D./Rolfe, Meredith: Measurement of Political Discussion Networks. A Comparison of Two Name Generator Procedures, in: Public Opinion Quarterly, Vol. 73 (3) 2009, S. 462-483.

Kloppenberg, James T.: Requiescat in Pacem: The Liberal Tradition of Louis Hartz. In: Hulliung, Mark (Hg.): The American Liberal Tradition Reconsidered. The Contested Legacy of Louis Hartz, Kansas 2010, S. 90-124. 
Koger, Gregory/Masket, Seth/Noel, Hans: Partisan Webs: Information Exchange and Party Networks, in: British Journal of Political Science, Vol. 39, 2009, S. 633-653.

Krebs, Timothy B.: Local Campaigns and Local election, in: Donald P. HaiderMarkel (Hg.): The Oxford Handbook of State and Local Government, Oxford 2014, S. 189-211.

Kriechbaumer, Robert: Die großen Erzählungen der Politik. Politische Kultur und Parteien in Österreich von der Jahrhundertwende bis 1945, Böhlau 2001.

Kruse, Kevin: White Flight. Atlanta and the Making of Modern Conservatism, Princeton 2005.

Lane, Robert E.: The Decline of Ideology in a Knowledgeable Society, in: American Sociological Review, Vol. 31 (4), 1966, S. 649-662.

Lasch, Christopher: The Culture of Narcissism, New York 1979.

Layman, Geoffrey C./Carsey, Thomas M.: Party Polarization and „Conflict Extension" in the American Electorate, in: American Journal of Political Science, Vol. 46, No. 4 (Oct., 2002), S. 786-802.

Layman, Geoffrey: The Great Divide. Religious and Cultural Conflict in American Party Politics, New York, Chichester, West Sussex 2011.

Lepsius, Rainer Maria: Parteiensystem und Sozialstruktur. Zum Problem der Demokratisierung der Deutschen Gesellschaft, in: Gerhardt Ritter (Hg.): Deutsche Parteien vor 1918, Köln 1973, S. 65-80.

Lessig, Lawrence: Republic Lost: How Money Corrupts Congress - and a Plan to stop it, New York 2011.

Levendusky, Matthew S.: The Microfoundations of Mass Polarization, in: Political Analysis, 17 (2009): S. 162-176.

Levendusky, Matthew: The Partisan Sort. How Liberals Became Democrats and Conservatives Became Republicans, Chicago 2009.

Levendusky, Matthew: How Partisan Media Polarize America, Chicago 2013.

Levin, Matthew: Cold War University. Madison and the New Left in the Sixties, Madison 2013

Levine Einstein, Katherine: Divided Regions: Race, Political Segregation, and the Polarization of Metropolitan America, Paper, Presented at the Annual Meeting of the American Political Science Association, September 1-4, 2011.

Lewis-Beck, Michael S.: The American Voter Revisited, Ann Arbor 2009.

Lienish, Michael: Redeeming America: Piety and Politics in the New Christian Right, Chapel Hill 1993.

Lijphart, Arend: Politics of Accommodation: Pluralism and Democracy in the Netherlands, 2. Auflage, Los Angeles 1975. 
Lipset, Seymour M.: Political Man. The Social Base of Politics, New York 1963, 2. Auflage

Lipset, Seymour M./Rokkan, Stein: Party Systems and Voter Alignments: CrossNational Perspectives. New York 1967.

Lijphart, Arend: The Politics of Accomodation. Pluralism and Democracy in the Netherlands, Berkeley 1968.

Lipset, Seymour Martin/Rokkan, Stein: Cleavage Structures, Party Systems and Voter Alignments, in: Seymour Martin Lipset (Hg.): Consensus and Conflict. Essays in Political Sociology, New Brunswick 1985: S.113-185.

Lipset, Seymour Martin: A Concept and its History: The End of Ideology, in: Ders.

(Hg.), Consensus and Conflict. Essays in Political Sociology, New Brunswick 1985, S. 81-109.

Lipset, Seymour Martin/Marks, Gary: It Didn't Happen Here: Why Socialism Failed In The United States, New York 2001.

Lorwin, Val R.: Segmented Pluralism: Ideological Cleavages and Political Cohesion in the Smaller European Democracies, in: Comparative Politics, Vol. 3 (2) 1971: S. 141-175.

Luhr, Eileen: Witnessing Suburbia: Conservatives and Christian Youth Culture, Los Angeles 2009;

Lupu, Noam: Party Polarization and Mass Partisanship: A Comparative Perspective, in: Political Behaviour, Vol. 37, 2015: S. 331-356.

Lütjen, Torben: Vom „Gospel of Efficiency“ zum „War of Ideas“. Zum Verhältnis von Wissenschaft, Politik und Ideologien in den Vereinigten Staaten, in: Archiv für Sozialgeschichte, Bd. 50, 2010.

Lütjen, Torben: Barack Obama und das Charisma der Fremdheit, in: Universitas, September 2012, Heft 9, S. 19-27.

Lütjen, Torben: Jenseits der Parteilichkeit? Zum Anspruch der Freien Wähler auf Ideologiefreiheit, in: Martin Morlok, Thomas Poguntke und Jens Walther (Hg.): Politik an den Parteien vorbei. Freie Wähler und kommunale Wählergemeinschaften als Alternative, Baden-Baden 2012.

Lütjen, Torben: Aufstieg und Anatomie des amerikanischen Konservativismus. Ein Forschungsbericht, in: Archiv für Sozialgeschichte, Band 54, Bonn 2014.

Lütjen, Torben/Matschoß, Robert: Ideological Migration in Partisan Strongholds: Evidence from a Quantitative Case Study, in: The Forum. A Journal of Applied Research in Contemporary Politics, Vol. 13 (2), 2015, S. 311-346.

Macy, Michael/DellaPosta, Daniel J./Shi, Yongren: Why do Liberals Drink Lattes?, in: American Journal of Sociology, Vol. 120 (5) 2015: S. 1473-1511. 
Magleby, David B./Nelson, Candice J./Westlye, Mark C.: The Myth of the Independent Voter Revisited, in: Paul Sniderman/Highton, Benjamin (Hg.): Facing the Challenge of Democracy: Explorations in the Analysis of Public Opinion and Political Participation, Princeton 2011, S. 238-262.

Mair, Peter: The Challenge to Party Government, in: West European Politics, Vol. 31 2008: S. 211-234.

Mair, Peter: Ruling The Void. The Hollowing of Western Democracy, London 2013

Mancini, Paolo/Hallin, Daniel C.: Comparing Media Systems, Cambridge 2004.

Manjoo, Farhad: True Enough. Learning to Live in a Post-Fact Society, Hoboken 2008.

Mann, Thomas E.: Polarizing the House of Representatives: How much does Gerrymandering matter? In: Pietro S. Nivola/David W. Brady (Hg.): Red and Blue Nation? Characteristics and Causes of America's Polarized Politics, Washington D.C. 2006.

Mannheim, Karl: Ideologie und Utopie, Bonn 1929.

Maraniss, David: They Marched into Sunlight: War and Peace, Vietnam and America October 1967, New York 2004.

Marden, George: Understanding Fundamentalism and Evanglicalism, Grand Rapids 1991.

Martinson, Tom: American Dreamscape. The Pursuit of Happiness in Postwar Suburbia, New York 2000.

Marx-Engels-Werke, Bd.4, Institut für Marxismus und Leninismus beim ZK der SED, Berlin 1977.

Masket, Seth E: No Middle Ground. How Informal Party Organizations Control Nominations and Polarize Legislatures, Ann Arbor 2009.

Mayring, Philipp: Kombination und Integration qualitativer und quantitativer Ansätze, in: Forum Qualitative Sozialforschung (online journal), Heft 1, 2001, abrufbar unter http://www.qualitative-research.net/index.php/fqs/ article/view/967/2111 (zuletzt abgerufen am 12.10.2014).

McAdam, Doug: The Framing Function of Movement Tactics: Strategic Dramaturgy in the Civil Rights Movement, in: Doug McAdam, John D. McCarthy, Mayer N. Zald (Hg.): Comparative Perspectives on Social Movements. Political Opportunities, Mobilizing Structures, and Cultural Framings, Ann Arbor 1996.

McDonald, Ian: Migration and Sorting in the American Electorate: Evidence from the 2006 Cooperative Congressional Election Study, in: American Politics Research, Vol. 39 2011: S.512-533. 
McGirr, Lisa: Suburban Warriors. The Origins of the New American Right, Princeton 2001.

McPherson, Miller/Smith-Lovin, Lynn/Cook, James M.: Birds of a Feather - Homophily in Social Networks, in: Annual Review of Sociology, Vol. 27 2001, S. 415-444.

Meeropol, Michael/Markowitz, Gerald: Neighborhood Politics, in: Paul Buhle (Hg.): History and the New Left. Madison 1950-1970, Philadelphia 1990, S.210-215.

Micklethwait, John/Wooldridge, Adrian: The Right Nation, New York 2005.

Miller, Warren E.: One-Party Politics and the Voter, in: American Political Science Review, Vol. 50 (3) 1956: S. 707-725.

Miroff, Bruce: The Liberals' Moment. The McGovern Insurgency and the Identity Crisis of the Democratic Party, Lawrence 2007.

Mollenhoff, David V.: Madison - A History of the Formative Years, Madison 1982.

Molloy, Raven/Smith, Christopher L./Wozniak, Abigail K.: Internal Migration in the United States, in: Journal of Economic Perspectives, Vol 25(3), 2011, S.173-196.

Mommsen, Wolfgang: Max Weber und die deutsche Politik 1890-1920, Tübingen 1974.

Moscovi, Serge/Zavalloni, Marisa: The Group as a Polarizer of Attitudes, in: Journal of Personality and Social Psychology, Vol. 12 (2) 1969, S. 125-135.

Mouffe, Chantal: Über das Politische. Wider die kosmopolitische Illusion, Frankfurt a. Main 2007.

Mutz, Diana C./Mondak, Jeffrey J.: The Workplace as a Context for Cross-Cutting Political Discourse, in: The Journal of Politics, Vol. 1, Feb. 2006, S. 140-155.

Mutz, Diana C.: Facilitating Communication across Lines of Political Difference - The Role of Mass Media, in: American Political Science Review, Vol. 1 2001, S. 97-114.

Mutz, Diana C.: Hearing the Other Side. Deliberative versus Participatory Democracy, Cambridge 2006.

Nackenoff, Carol: Locke, Alger, and Atomistic Individualism Fifty Years Later: Revisiting Louis Hartz's Liberal Tradition in America, in: Studies in American Political Development 19 (2), 2005, S. 206-215.

Nall, Clayton: The Road to Division: How Interstate Highways Caused Geographic Polarization, Paper, 24. März 2013, abrufbar unter: http://web.stanford.edu/ nall/docs/gp2.1.pdf (zuletzt abgerufen am 29.04.2015).

Nash, George H: The Intellectual Conservative Movement in America since 1945, Wilmington 2006. 
Neuman, Russel W./Just, Marion R./Crigler, Ann N.: Common Knowledge: News and the Construction of Political Meaning, Chicago 1992.

Nichols, John: Uprising. How Wisconsin Renewed the Politics of Protest from Madison to Wall Street, New York 2012.

Nolte, Paul: Was ist Demokratie? Geschichte und Gegenwart, München 2012.

Oliver, J. Eric/E. Ha, Shang/Callen, Zachary: Local Elections and the Politics of Small-Scale Democracy, Princeton 2012.

Osterhammel, Jürgen: Die Verwandlung der Welt. Eine Geschichte des 20. Jahrhunderts, München 2011 (Sonderausgabe).

Otte, Gunnard/ Rössel, Jorg: Lebensstile in der Soziologie, in: Dies.(Hg.): Lebensstilforschung. Sonderheft der Kölner Zeitschrift für Soziologie und Sozialpsychologie, Wiesbaden 2011, S. 7-34.

Painter, Nell Irvin: Standing at Armageddon: A Grassroots History of the Progressive Era, 2nd, New York 2008.

Papke, David Ray: Keeping the Underclass In Its Place: Zoning, the Poor, and Residential Segregation, in: The Urban Lawyer, Vol. 41 (4) 2009.

Pariser, Eli: The Filter Bubble: What the Internet Is Hiding from You, New York 2011.

Parsons, Talcott: Voting and the Equilibrium of the American Political System, in: Eugene Burdick/Arthur J. Brodbeck (Hg.): American Voting Behavior, Glencoe 1959. S. 90-112.

Patterson, James T.: Grand Expectations. The United States, 1945-1974, Oxford 1996.

Paulson, Arthur C.: Realignment and Party Revival: Understanding American Electoral Politics at the Turn of the Twenty-First Century. Westport 2000.

Perlstein, Rick: Before the Storm: Barry Goldwater and the Unmaking of the American Consensus, New York 2001.

Pew Report, 12 Juni 2014: Political Polarization in the American Public. How Increasing Ideological Uniformity and Partisan Antipathy Affects Politics, Compromise and Everyday Life: http://www.peoplepress.org/files/2014/06/6-12-2014-Political-Polarization-Release.pdf (zuletzt abgerufen am 14. April 2015).

Pew Report, 12. Mai 2015: America's Changing Religious Landscape, abrufbar unter: http://www.pewforum.org/2015/05/12/americas-changing-religiouslandscape/ (zuletzt abgerufen am 03.08.2015).

Pfaff, Steven: The Religious Divide: Why Religion Seems to Be Thriving in The United States and Waning in Europe, in: Jeffrey Kopstein/Sven Steinmo (Hg.): Growing Apart: America and Europe in the Twenty-First Century, New York (2008), S. 24-52. 
Philips-Fein, Kim: Invisible Hands: The Business Men's Crusade against the New Deal, New York 2010.

Poguntke, Thomas: Parteiorganisation im Wandel, Wiesbaden 2000.

Poguntke, Thomas/Webb, Paul (Hg.): The Presidentialization of Politics, Oxford 2005.

Prior, Markus: Post-Broadcast Democracy: How Media Choice Increases Inequality in Political Involvement and Polarizes Elections, New York 2007.

Putnam, Robert D./Campbell, David E.: American Grace: How Religion Divides and Unites Us, New York 2010.

Putnam, Robert D.: Bowling Alone: The Collapse and Revival of American Community, New York 2000.

Rae, Nicol C.: Be Careful what you Wish for - The Rise of Responsible Parties in American National Politics, in: Annual Review of Political Science, Vol. 10 (2) 2007: S. 169-191.

Rae, Nicole C.: The Decline and Fall of the Liberal Republicans: From 1952 to the Present, Oxford 1989.

Ribuffo, Leo: The Old Christian Right. The Protestant Far Right form the great depression to the Cold War, Philadelphia 1983.

Richter, Rudolf: Die Lebensstilgesellschaft, Wiesbaden 2005.

Robert N. et al.: Habits of the Heart: Individualism and Commitment in American Life, Los Angeles 1985.

Robinson, Tony/Noriega, Stephen: Voter Migration as a Source of Electoral Change in the Rocky Mountain West, in: Political Geography, 2010 (1), S. 28-39.

Rodgers, Daniel T.: Age of Fracture, Cambridge 2012.

Rohe, Karl: Wahlen und Wählertraditionen in Deutschland. Kulturelle Grundlagen deutscher Parteien und Parteiensysteme im 19. und 20. Jahrhundert, Frankfurt a. Main 1992.

Roszak, Theodore: The Making of a Counter Culture: Reflections on the Technocratic Society and Its Youthful Opposition, Berkeley 1969.

Ruff, Allen/Will, Tracy: Forward! A History of Dane County, Madison 2000.

Rusk, David: Sprawl, Race, and Concentrated Poverty in Southeast Wisconsin, Paper der Federal Reserve Bank Chicago, 2001.

Sander, Uwe/Meister, Dorothee M.: Medien und Anomie. Zum relationalen Charakter von Medien in modernen Gesellschaften, in: Wilhelm Heitmeyer (Hg.): Was treibt die Gesellschaft auseinander? Bundesrepublik Deutschland: Auf dem Wege von der Konsens- zur Konfliktgesellschaft, Band 1, Frankfurt am Main 1997, S. 196-241. 
Sartori, Giovanni: Ideology and Belief Systems, in: American Political Science Review, Vol. 63, Issue 2, 1969, S. 398-411.

Schäfer, Axel R.: Counter Cultural Conservatives: American Evangelicalism from the Postwar Revival to the New Christian Right, Wisconsin 2011.

Schaffner, Brian F./Streb, Matthew/Wright, Gerald: Teams Without Uniforms The Nonpartisan Ballot in State and Local Elections, in: Political Research Quarterly, Vol. 54 (1) 2001: S. 1-30.

Schaffner, Brian/Streb, Matthew J./Wright, Gerald C.: A New Look at the Republican Advantage in Non-Partisan Elections, in: Political Research Quarterly, Vol. 60 (2) 2007, S. 240-249.

Schmitt, Hermann: Partisanship in Nine Western Democracies. Causes and Consequences, in: John Bartle/Paolo Belluci (Hg.): Political Parties and Partisanship. Social Identity and Individual Attitudes, Abingdon 2009, S. 75-87.

Schmitt-Beck, Rüdiger: Better Late Than Never: Campaign Deciders at the 2005 German Parliamentary Election, paper, vorgestellt auf der 5th ECPR General Conference, Potsdam September 2009.

Schoen, Harald: Wenn ich mich recht erinnere. Zur Validität von Rückerinnerungsfragen, in: Harald Schoen/Gabriel, Oscar W. (Hg.): Vom Interview zur Analyse. Methodische Aspekte der Einstellungs- und Wahlforschung, BadenBaden 2009, S. 259-279.

Schroer, Markus: Das Individuum und die Gesellschaft. Synchrone und diachrone Theorieperspektiven, Frankfurt a. Main 2000.

Schwarzmantel, John: Ideology and Politics, London 2008.

Seliger, Martin: Ideology and Politics, London 1976.

Shafer, Bryon E.: Quiet Revolution. The Struggle for the Democratic Party and the Shaping of Post-Reform Politics, New York 1983.

Sinclair, Barbara: Party Wars. Polarization and the Politics of National Policy Making, Oklahoma 2006.

Skinner, Richard M.: George W. Bush and the Partisan Presidency, in: Political Science Quarterly, Vol. 123 (4) 2009: S. 605-622.

Smith, Rogers M.: Beyond Tocqueville, Myrdal, and Hartz. The Multiple Traditions in America, in: American Political Science Review, 87 (3), 1993, S. 549566.

Sniderman, Paul/Highton, Benjamin (Hg.): Facing the Challenge of Democracy: Explorations in the Analysis of Public Opinion and Political Participation, S. 238-262, Princeton 2011.

Stein, Jason /Marley, Patrick: More Than They Bargained For: Scott Walker, Unions and the Fight for Wisconsin, Madison 2013. 
Sternsher, Bernhard: Consensus, Conflict, and American Historians. Bloomington 1970.

Sunstein, Cass S.: Going to Extremes. How Like Minds Divide and Unite, Oxford 2009.

Talshir, Gayil: The Phoenix of Ideology, in: Critical Review of International Social and Political Philosophy Vol 8 (2), 2005, S. 1.

Tam Cho, Wendy K./Gimpel, James G./Hui, Iris S.: Voter Migration and the Geographic Sorting of the American Electorate, in: Annals of the Association of American Geographers 2012: S. 1-16.

Tanenhaus, Sam: The Death of Conservatism, New York 2009.

Tenfelde, Klaus: Historische Milieus - Erblichkeit und Konkurrenz, in: Ders. (Hg.): Arbeiter, Bürger, Städte. Zur Sozialgeschichte des 19. Und 20. Jahrhunderts, Göttingen 2012, S. 343-363.

Theriault, Sean M.: Party Polarization in Congress, New York 2008.

Thomassen, Jacques: The European Voter: A Comparative Study of Modern Democracies, Oxford 2005.

Thompson, Jonathan: Progressive Innovation in the 1970s: Madison, Wisconsin, and the Conference on Alternative State and Local Public Policies, in: Progressive Planning, winter issue 2007: S. 22-25.

Tiebout, Charles: A Pure Theory of Local Expenditures, in: Journal of Political Economy, Vol. 64 (5) 1956, S. 416-424.

Tocqueville, Alexis de: Über die Demokratie in Amerika, Beide Teile in einem Band, Deutscher Taschenbuch-Verlag, München 1976.

Troy, Gil: The Reagan Revolution. A Very Short Introduction, Oxford 2009.

Truman, David B.: The Governmental Process. Political Interests and Public Opinion, New York 1951.

Turner, Fred: From Counterculture to Cyberculture. Stuart Brand, the Whole Earth Network, and the Rise of Digital Utopianism, Chicago 2006.

Turner, Frederick Jackson: The Frontier in American History, New York 1921. Vaisse, Justin: Neoconservatism. The Biography of a Movement, Cambridge (MA) 2010.

Van Biezen, Ingrid/Mair, Peter/Poguntke, Thomas: Going, going, gone? The Decline of Party Membership in Contemporary Europe, in: European Journal of Political Research, Vol. 51 (1) 2012: S. 24-56.

Wald, Kenneth D./Calhoun-Brown, Allison: Religion and Politics in America, 6. Auflage, Lanham 2011.

Walker, Scott Unintimidated. A Governor's Story and a Nation's Challenge, New York 2014. 
Walter, Franz/Dürr, Tobias: Die Heimatlosigkeit der Macht. Wie die Politik in Deutschland ihren Boden verlor, Berlin 2000.

Ware, Alan: American Exceptionalism, in: Richard S. Katz/ William J. Crotty: Handbook of Party Politics, London 2006, S. 270-277.

Waxman, Chaim I.: The End of Ideology Debate, Touchstone 1969.

Weber, Max: Wirtschaft und Gesellschaft. Grundriss der verstehenden Soziologie, Tübingen 1972, S. 140ff.

Westen, Dew: The Political Brain. The Role of Emotions in Deciding the Fate of the Nation: How We Make Up Our Minds Without Using Our Heads, New York 2006

White, Jonathan/Ypi, Lea: Rethinking the Modern Prince: Partisanship and the Democratic Ethos, in: Political Studies 58 (4), 2010: S. 809-828.

White, Theodore: The Making of the President 1964, New York 1965.

Whiteley, Paul: Is the Party Over? The Decline of Party Activism and Membership Across the Democratic World, in: Party Politics, Vol. 17 (1) 2001: S. 24

Wiebe, Robert W.: The Search for Order, New York 1967.

Wilcox, Clyde: Onward Christian Soldiers?, Boulder 1996.

Wilentz, Sean: American Political Histories. History and Historians since 1907. In: Organization of American Historians (OAH) Magazine of History, 21 (2), 2007, S. 23-27.

Wilford, Justin: Sacred Subdivisions-The Postsuburban Transformation of American Evangelicalism, New York 2012.

Williamson, Thad: Sprawl, Justice, and Citizenship. The Civic Costs of the American Way of Life, New York 2009.

Williamson, Thad: Sprawl, Spatial Location, and Politics: How Ideological Identification Tracks the Built Environment, in: American Politics Research, Volume 36 Number 6, November 2008.

Zelinsky, Wilbur: Not Yet A Placeless Land: Tracking an Evolving American Geography, Boston 2011. 


\section{ZEITUNGSARTIKEL/BLogs/ONLINE-MEDIEN}

Berry, David: An Off-Color Rift, in: Washington Post, 19. Dezember 2004, http://www.washingtonpost.com/wp-dyn/articles/A218-2004Dec14.html (zuletzt abgerufen am 15.06.2015)

Glauber, Bill /Johnson, Mike: New Berlin residents divided on racism's role in city's housing decision, in: Milwaukee Journal Sentinel, 10. Juli 2011: http://www.jsonline.com/news/waukesha/125323453.html, (zuletzt abgerufen am 27.11.2014)

Bishop, Bill: No, We Didn't: America Hasn't Changed as Much as Tuesday's Results Would Indicate, in: Slate, 4. November 2008:

http://www.slate.com/blogs/bigsort/2008/11/04/no_we_didn_t_america_didn_t_change_as_much_as_tuesday_s_results_would_indicate.html (zuletzt abgerufen am 27.04.2015).

Blaska, David: Madison Chamber Lands High Draft Pick in Zach Brandon, in: Blaska's Bring It!, 12. November 2012.http://www.ibmadison.com/Blogger/Bring-It/November-2012/Madison-Chamber-lands-high-draft-pick-inZach-Brandon (zuletzt abgerufen 27.01.2015).

Bosman, Julie: 2016 Ambitions Seen in Walker's Push for University Cuts in Wisconsin, in: New York Times, 16. Februar 2015:

http://www.nytimes.com/2015/02/17/us/politics/scott-walker-university-wisconsin (zuletzt abgerufen am 01.05.2015).

Buchanan, Jeff: My Epic Journey: An insider's look at what makes Dane County's biggest company tick, in: Capital Times, 7. Mai.2014 http://host.madison.com/news/local/my-epic-journey-an-insider-s-look-at-what-makes/article_06e96295-13ed-51ef-9821-be0da8fc31dd.html\#ixzz3Q1IRnYZw (zuletzt abgerufen am 27.01.2015).

Burns, Kenneth: Rallying the Faithful - Advocates for and against the proposed gay marriage ban tap into the wellspring of religious conviction, in: Isthmus, 5. Oktober 2006: http://www.isthmus.com/news/cover-story/rallying-thefaithful/ (zuletzt abgerufen am 1. Mai 2015).

Comp, Nathan J.: Andrew Schauer crushes 10-term incumbent David Wiganowsky as liberals increase Dane County Board majority, in: Isthmus, 2. April 2014. http://www.isthmus.com/news/news/andrew-schauer-crushes-10-termincumbent-david-wiganowsky-as-liberals-increase-dane-county-board-majority (zuletzt abgerufen am 4. Juni 2015). 
Craver, Jack: Conservatives are nearly extinct in Dane County Government, in: Capital Times,5. Juni 2013, http://host.madison.com/news/local/writers/jack_craver/consevatives-are-nearly-extinct-in-dane-county-government/article_7bc00739-e387-5cf1-9c2b-0163f07c8dd9.html (zuletzt abgerufen am 15.06.2015).

Craver, Jack: Progressives County Board Majority Likeley to Grow, in: Capital Times, 4. Februar 2012, http://host.madison.com/news/local/govt-and-politics/politiscope/madison-politiscope-progressives-county-board-majority-likely-to-grow/article_88d97036-4eac-11e1-ab01-001871e3ce6c.html (zuletzt abgerufen am 4. Juni 2015).

Craver, Jack: The Madison company that contributed to Romney's Super PAC, in: Capital Times, 12. März 2014: http://host.madison.com/news/local/writers/jack_craver/the-madison-company-that-contributed-to-romney-s-superpac/article_c2bad788-a95c-11e3-91b10019bb2963f4.html\#ixzz3Q1AAkRv8

Douthat, Ross: The Obama Realignment, in: New York Times vom 7. 11.2012, abrufbar: http://campaignstops.blogs.nytimes.com/2012/11/07/douthat-theobama-realignment/ (zuletzt abgerufen am 12.08.2014)

Edsall, Thomas B: How Fragile is the New Democatic Voter Coalition?, in: New York Times, 3. September 2012 http://opinionator.blogs.nytimes.com/2013/09/03/how-fragile-is-the-new-democratic-coalition/?_r=0 (zuletzt abgerufen am 14. April 2015).

Eisen, Marc: EPIC Opportunity, in: Isthmus, 20. Februar 2014. http://www.isthmus.com/news/cover-story/epic-opportunity-the-software-giant-is-positioning-dane-county-for-an-economic-breakthrough/ (zuletzt abgerufen am: 15.06.2015).

Eisen, Marc: What the hell do they do? Tech Leaders Get Little Help From Wisconsin Manufacture \& Commerce, in: Isthmus, 18. September 2014, http://www.isthmus.com/news/cover-story/tech-leaders-get-little-help-from-wis consin-manufacturers-and-commerce/ (zuletzt abgerufen am 20.06.2015).

Ferolie, Jim: Alder Resigns Over „Political Climate“, in: Verona Press, 26. April 2013, abrufbar unter: http://connectverona.com/articles/2013/04/26/alder-resigns-over-political-climate (zuletzt abgerufen: 24.04.2015).

Gilbert, Craig, Democratic, Republican Voters Worlds Apart in Divided Wisconsin, in: Milwaukee Journal Sentinel vom 3. Mai 2014:

http://www.jsonline.com/news/statepolitics/democratic-republican-voters-wor lds-apart-in-divided-wisconsin-b99249564z1-255883361.html (zuletzt abgerufen am 05. Juni 2015). 
Gilbert, Craig: Far from creating fatigue. Partisan battles energize voters, in: Milwaukee Journal Sentinel, 10. Mai 2014, http://www.jsonline.com/news/statepolitics/far-from-creating-fatigue-partisan-battles-energize-votersb99256305z1-258676961.html (zuletzt abgerufen am 15.0.2015).

Gilbert, Craig: Top vote-getters in US House hail from neighboring Wisconsin districts, in: Milwaukee Journal Sentinel, 13. Januar 2015, http://www.jsonline.com/blogs/news/288475091.html, (zuletzt abgerufen am 15.06.2015).

Glauber, Bill: Waukesha County's Republican Party's Longtime Leader is Stepping Down, in: Milwaukee Journal Sentinel, 27. Februar 2013, abrufbar unter: http://www.jsonline.com/news/waukesha/waukesha-countys-republican-partyslongtime-leader-stepping-down-o48v0vb-193707341.html (zuletzt abgerufen am 29.04.2015).

Gunn, Eric: The Happy Warrior, in: Milwaukee Magazine, 28. September 2007, http://www.milwaukeemag.com/2007/09/28/TheHappyWarrior/ (zuletzt abgerufen am 16.06.2015).

Ivey, Mike: Businesses are turning backs on WMC, in: BIZTIMES.com, 07.07.2008: http://www.biztimes.com/article/20080707/BLOGS/307079990/

Ivey, Mike: New Opportunities for New Urbanism, in: Capital Times, 1. Juni 2011: http://host.madison.com/business/biz_beat/new-opportunities-for-newurbanism/article_daeb45fe-8bc8-11e0-b2dd-001cc4c03286.html (zuletzt abgerufen am 15.06.2015).

Johnson, Dirk: From Firebrand to a Bit of a Grump, a „Hippie Mayor” Evolves, in: New York Times, 10. September 2011. http://www.nytimes.com/2011/ 09/11/us/11mayor.html?_r=0

Johnson, Mike: State legislator announces run for Waukesha County judgeship, in: Milwaukee Journal Sentinel, 13. November 2009:

http://www.jsonline.com/news/waukesha/70042847.html (zuletzt abgerufen am 22.06.2015).

Karol, David: Charles Schumer's flawed diagnosis of polarization, in: Washington Post, 23.Juli 2014, abrufbar unter http:/www.washingtonpost.com/ blogs/monkey-cage/wp/2014/07/23/charles-schumers-flawed-diagnosis-ofpolarization/ (zuletzt abgerufen am 20.03.2015)

Kaufman, Dan: Note on the Cheddar Revolution, in: The New Yorker, 22. Februar 2011, http://www.newyorker.com/news/news-desk/notes-on-the-cheddar-revolution (zuletzt abgerufen am 18.Juni 2015).

Lueders, Bill: Dane County's Secrtet GOP Chair, in: Isthmus, 13. November 2008, abrufbar unter: http://www.isthmus.com/news/news/dane-countys-secretgop-chair/ (zuletzt abgerufen am 20.06.2015). 
Tarr, Joe: Mark Clear and Lisa Subeck battle for liberal cred in west-side Assembly race: Will the real progressive please stand up? in: Isthmus, 17. Juli 2014, abrufbar unter: http://www.isthmus.com/news/news/mark-clear-and-lisa-subeck-battle-for-liberal-cred-in-west-side-assembly-race/ (zuletzt abgerufen am 28.04.2015).

Marley, Patrick: 9 lawmakers want to arrest U.S. officials who implement Obamacare, in: Milwaukee Journal Sentinel, 13. November 2012, http://www.jsonline.com/news/statepolitics/nine-lawmakers-back-charging-fe deral-officials-who-implement-obamacare-here-n47kl10-179180251.html (zuletzt abgerufen am 17.06.2015).

McBride, Jessica: 'We are an Activist Army,' Say Leaders of New Falls Taxpayers Group, in: Menomonee Falls Patch, 1. Juli 2012: http://patch.com/wisconsin/menomoneefalls/we-are-an-activist-army-say-leaders-of-new-fallstaxp5692ae778f (zuletzt abgerufen am 2. Juni 2015).

Montopoli, Brian: Tea Party Supporters: Who They are and what They Believe, CBS News ,12. Dezember 2012, http://www.cbsnews.com/news/tea-partysupporters-who-they-are-and-what-they-believe/ (zuletzt abgerufen am 28.09.2015).

Mukherji, Nayantara: Ellen Berz bests Walker-appointed judge, Roger Allen, in Dane County Circuit Court Primary, in: Isthmus, 22. Februar 2012. http://www.isthmus.com/news/news/ellen-berz-bests-walker-appointedjudge-roger-allen-in-dane-county-circuit-court-primary/ (zuletzt abgerufen am 4. Juni 2015).

Pulliam Bailey, Sarah: A startling number of Americans still believe President Obama is a Muslim, in: Washington Post, 14. September 2015, https://www.washingtonpost.com/news/acts-of-faith/wp/2015/09/14/a-startlingnumber-of-americans-still-believe-president-obama-is-a-muslim/ (zuletzt abgerufen am 22.09.2015)

Rickert, Chris: Dane County Rediscricting not that different from State, in: Wisconsin State Journal, 25. Februar 2012, http://host.madison.com/news/lo$\mathrm{cal} /$ chris_rickert/chris-rickert-dane-county-redistricting-not-that-differentfrom-state/article_1dbe2386-5f3d-11e1-be4b-0019bb2963f4.html (zuletzt abgerufen am 4. Juni 2015).

Rickert, Chris: Reach out Wisconsin not Reaching Many Liberal These Days, in: Wisconsin State Journal, 19. Oktober 2014, http://host.madison.com/news/lo$\mathrm{cal} /$ columnists/chris-rickert/chris-rickert-reach-out-wisconsin-not-reachingmany-liberals-these/article_321093f5-cfc4-5e0b-8d4a-af07eba4169e.html (zuletzt abgerufen am 29.06.2015). 
Sauer, Abe: As Goes Wisconsin, so Goes Hell, in: The Awl, 12. April 2012, http://www.theawl.com/2012/04/as-goes-wisconsin-so-goes-hell (zuletzt abgerufen am 28.06.2015).

Schneider, Pat: Do neighborhood associations have too much voice in development decisions? in: Captital Times, 2. August 2010, http://host.madison.com/news/local/do-neighborhood-associations-have-too-much-voice-indevelopment-decisions/article_55cb7dc6-9dc6-11df-8352$001 \mathrm{cc} 4 \mathrm{c} 03286 . \mathrm{html}$ (zuletzt abgerufen am 25.06.2015).

Schneider, Pat: Mayor Paul Soglin Wants City Contractors to Disclose Lobbying Contributions, in: Capital Times, 08. Mai 2013:

http://host.madison.com/news/local/writers/pat_schneider/mayor-paul-soglinwants-city-contractors-to-disclose-lobbying-contributions/article_5e72743eb772-11e2-9130-0019bb2963f4.html (zuletzt abgerufen am 26.01.2015).

Scrimma, Jeff: Let's trust Waukesha citizens, in: Milwaukee Journal Sentinel, 10. Juli 2010, http://www.jsonline.com/news/opinion/98142654.html (zuletzt abgerufen am 09.12.2014)

Senator Charles Schumer: End Partisan Primaries, Save America, in: New York Times vom 21.07.2014, http://www.nytimes.com/2014/07/22/opinion/charlesschumer-adopt-the-open-primary.html (zuletzt abgerufen am 14.02.2015)

Shaper, David: Wisconsinites 'Reach Out' To Heal Partisan Divide, Sendung auf NPR vom 4. Juni 2012, http://www.npr.org/2012/06/04/154305938/wisconsinites-reach-out-to-heal-partisan-divide (zuletzt abgerufen am 14. April 2014).

Silver, Nate: As Swing Districts Dwindle, Can a Divided House Stand? in: New York Times, 27. Dezember 2012: http://fivethirtyeight.blogs.nytimes.com/2012/12/27/as-swing-districts-dwindle-can-a-divided-housestand/ (zuletzt abgerufen am 12.06.2015).

Silver, Nate: In Silicon Valley, Technology Talent Gap Threatens G.O.P. Campaigns, in: New York Times, 28. November 2012, abrufbar unter:

http://fivethirtyeight.blogs.nytimes.com/2012/11/28/in-silicon-valley-technology-talent-gap-threatens-g-o-p-campaigns (zuletzt abgerufen am 23. April 2015).

Silver, Nate: The Most Diverse Cities are often the most Segregated, http://fivethirtyeight.com/features/the-most-diverse-cities-are-often-themost-segregated/ (zuletzt abgerufen am 15.07.2015).

Spicuzza, Mary: Scott Walker may stop filling Dane County judge vacancies after 2nd appointee loses, in: Wisconsin State Journal, 4. April 2013. 
http://host.madison.com/news/local/govt-and-politics/scott-walker-may-stop-fil ling-dane-county-judge-vacancies-after/article_f182e392-9cad-11e2-8a3c001a4bcf887a.html (zuletzt abgerufen am 04.06.2015).

Tarr, Joe: Antiabortion Activist Bob Lenz Uninvited from Brat Fest After Pushback from Public Officials, in: Isthmus, 19. Mai 2014.

http://www.isthmus.com/news/news/antiabortion-activist-bob-lenz-uninvitedfrom-brat-fest-after-pushback-from-public-officials/ (zuletzt abgerufen am 27.02.2015)

Treleven, Ed: City Council Rejects Mayor's Plan to Require Contractors to Disclose Certain Contributions, in: Wisconsin State Journal, 19. Juni 2013: http://host.madison.com/news/local/govt-and-politics/city-council-rejects-ma yor-s-plan-to-require-contractors-to/article_e2714918-ba90-587f-bd4817b33b425a7c.html\#ixzz3Q17NFggS (zuletzt abgerufen am 02.06.2015)

Verburg, Steven: Dane County Board conservatives seek influence by threatening borrowing resolution, in: Wisconsin State Journal, 18. September 2011, http:/host.madison.com/news/local/govt-and-politics/dane-county-boardconservatives-seek-influence-by-threatening-borrowing-resolution/article_e8ceaaa6-e22d-11e0-aa4c-001cc4c002e0.html (zuletzt abgerufen am 04.06.2015).

Walker, Laurel: Waukesha County Board Endorses Walker's Budget Action, in: Milwaukee Journal Sentinel, 23. März 2011:

http://www.jsonline.com/news/waukesha/118508684.html (zuletzt abgerufen am 05.05.2015).

Walker, Laurel: Waukesha County Supervisors spar over Board Size, in: The Milwaukee Journal Sentinel, 14. Februar 2011, http://www.jsonline.com/news/waukesha/116192734.html (zuletzt abgerufen am 2. Juni 2015).

Will, George: Why Liberals Love Trains, in: Newsweek, 27. Februar 2011, http://www.newsweek.com/will-why-liberals-love-trains-68597 (zuletzt abgerufen am 21.03.2011).

Wisconsin Republican Hotbed Running Out of Water, in: Daily Kos, 19. Oktober 2013, abrufbar unter: http:/www.dailykos.com/story/2013/10/19/1248963/Wisconsin-Republican-Hotbed-Out-of-Water\# (zuletzt abgerufen am 09.12.2014).

Wittkopf, Scott: Blame Waukesha: The GOP's Answer to Liberal Dane County Swings Elections to the Right, in: Isthmus, 3. Januar 2011. abrufbar unter: http://www.isthmus.com/news/news/blame-waukesha-the-gops-answer-to-libe ral-dane-county-swings-elections-to-the-right/ (zuletzt abgerufen am 29.04.2015). 



\section{FRAGEBOGEN DER \\ DANE-WAUKESHA-POLARIZATION-STUdY (DWPS)}

LHK Partners Incorporated

Job \#2078

Newtown Square, Pennsylvania

July 22, 2013

HHU Düsseldorf Wisconsin Poll - July 22-28, 2013

Good (afternoon/evening), I'm calling from The American Institute of Consumer Studies.

We're conducting a survey about important issues and the quality of life in DANE/WAUKESHA (Waw-'kuh-sha) County today.

IF PROBED: Your participation is completely voluntary and your responses will be kept confidential. No one will ever try to sell you anything as a result of your responses.

(READ ONLY IF NEEDED: This survey should only take a few minutes of your time.)

\section{RESPONDENT SELECTION}

S1. May I please speak with the (male/female) adult member of your household, currently at home, age 18 or older, with the most recent birthday?

(IF SELECTED RESPONDENT NOT CURRENTLY AT HOME AND AVAILABLE, ASK FOR THE (FEMALE/MALE) CURRENTLY AT HOME.)

1 Correct household member on phone (CONTINUE)

2 Will put correct member of household on phone (RE-READ INTRO AND CONTINUE WITH S2.)

3 No household member age 18 or over is currently available (PLACE HOUSEHOLD INTO CALLBACK)

4 No one in household age 18 or older (TERMINATE)

S2. Record Gender: (DO NOT ASK. RECORD ONLY ONE RESPONSE)

1 Male

2 Female 
S3a.Do you currently live in Wisconsin?

1 Yes

2 No (TERMINATE)

S3b. Which county do you live in?

(DO NOT READ)

1 Dane (continue)

2 Waukesha (continue)

3 Other (TERMINATE)

\section{SUBSTANTIVE QUESTIONS}

II.1. Partisanship and political involvement

Q1. Generally speaking, do you usually think of yourself as a Republican, a Democrat, or an Independent?

1 Republican

2 Democrat

3 Independent (DO NOT READ)

4 Other/No preference

8 Don't Know

9 Refused

[ASK Q3.]

[ASK Q3.]

[ASK Q2.]

[ASK Q2.]

[ASK Q2.]

[ASK Q2.]

${ }^{* *}$ Author note: Ask Q2 if 3, 4, 8, or 9 in Q1.

Q2. Do you think of yourself as closer to the Republican Party or to the Democratic Party?

1 Republican

2 Democrat

(DO NOT READ)

3 Neither/Just Independent (VOL)

8 Don't know

9 Refused

**Author note: Ask Q3 if 1 or 2 in Q1. 
Q3. Would you call yourself a strong (REPUBLICAN/DEMOCRAT) or a not very strong (REPUBLICAN/DEMOCRAT)?

\author{
1 Strong \\ 2 Not very strong \\ (DO NOT READ) \\ 8 Don't Know \\ 9 Refused
}

Q4. In 2012, President Barack Obama ran for reelection on the Democratic ticket against Governor Mitt Romney for the Republicans. Do you remember for sure whether or not you voted in that election?

1 Voted [ASK Q5]

2 Did not vote [ASK Q6]

(DO NOT READ)

8 Don't know/Can't remember [ASK Q6]

9 Refused [ASK Q6]

**Author note: Ask Q5 if "Voted" in Q4.

Q5. IF VOTED: Did you vote for Obama, Romney or someone else?

01 Obama

02 Romney

97 Other candidate (specify) (DO NOT READ)

95 Didn't vote for President.

98 Don't know/Can't remember

99 Refused

Q 6. Some people seem to follow what's going on in politics most of the time, whether there's an election going on or not. Others aren't that interested. Would you say you follow what's going on in politics most of the time, some of the time, only now and then, or hardly at all?

1 Most of the time

2 Some of the time

3 Only now and then

4 Hardly at all

(DO NOT READ)

8 Don't know

9 Refused 
Q 7. During the 2012 campaign, did you wear a campaign button, put a campaign sticker on your car, or place a sign in your window or in front of your house?

$\begin{array}{ll}1 & \text { Yes } \\ 2 & \text { No } \\ \text { (DO NOT READ) } \\ 8 \quad \text { Don't know } \\ 9 \quad \text { Refused }\end{array}$

\subsection{Social capital, cross-cutting exposure, deliberation}

\section{Discussant Generator:}

From time to time, people discuss government, elections, and politics with other people. We'd like to know the first names or just the initials of people you talk with about these matters. These people might be from your family, from work, from the neighborhood, from some other organization you belong to, or they might be from somewhere else.

Q 8 Who is the person you've talked with most about politics?

IF PROBED: And we just need a first name or initials; remember all information is confidential.

(Discussant \#1)

(DO NOT READ)

95 We don't talk politics. [SKIP TO Q11]

98 Don't know [SKIP TO Q11

99 Refused [SKIP TO Q11]

Q 8.a Is he/she (READ LIST)

1 A Family member

2 Somebody you work with

3 Somebody from the neighborhood

4 A Friend who lives close by

5 A Friend who lives at a different place

6 Other

(DO NOT READ)

8 Don't know

9 Refused 
Q 8.b Compared with [Discussant \#1], would you say that your political views are much the same, somewhat different, or very different?

1 Much the same

2 Somewhat different

3 Very different

(DO NOT READ)

8 Don't know

9 Refused

Q 8.c Do you think [Discussant \#1] normally favors Republicans or Democrats, or both, or neither?

1 Republicans

2 Democrats

3 Both

4 Neither

(DO NOT READ)

8 Don't know

9 Refused

Q8.d Which presidential candidate, if any, did [Discussant \#1] prefer? Romney, Obama or some other candidate?

$\begin{array}{ll}1 & \text { Romney } \\ 2 & \text { Obama } \\ 3 & \text { Other } \\ \text { (DO NOT READ) } \\ 8 & \text { Don't know } \\ 9 & \text { Refused }\end{array}$

Q 9 Aside from this person/[Discussant \#1], who is the person you've talked with most about politics?

IF PROBED: And we just need a first name or initials; remember all information is confidential.

\section{(DO NOT READ)}

(Discussant \#2)

99 There are no others/Refused [SKIP TO Q11]

Q 9.a Is he/she (READ LIST)

1 A Family member

2 Somebody you work with

3 Somebody from the neighborhood

4 A Friend who lives close by 
5 A Friend who lives at a different place

6 Other

(DO NOT READ)

8 Don't know

9 Refused

Q 9.b Compared with [Discussant \#2], would you say that your political views are much the same, somewhat different, or very different?

1 Much the same

2 Somewhat different

3 Very different

(DO NOT READ)

8 Don't know

9 Refused

Q 9.c Do you think [Discussant \#2] normally favors Republicans or Democrats, or both, or neither?

$\begin{array}{ll}1 & \text { Republicans } \\ 2 & \text { Democrats } \\ 3 & \text { Both } \\ 4 & \text { Neither } \\ \text { (DO NOT READ) } \\ 8 & \text { Don't know } \\ 9 & \text { Refused }\end{array}$

Q 9.d Which presidential candidate, if any, did [Discussant \#2] prefer? Romney, Obama or some other candidate?

$\begin{array}{ll}1 & \text { Romney } \\ 2 & \text { Obama } \\ 3 & \text { Other } \\ \text { (DO NOT READ) } \\ 8 & \text { Don't know } \\ 9 & \text { Refused }\end{array}$

Q 10. Aside from anyone you've already mentioned, is there anyone else you've talked with about politics?

IF PROBED: And we just need a first name or initials; remember all information is confidential. 
(DO NOT READ)

99 There are no others/Refused [SKIP TO Q11]

Q 10.a Is he/she (READ LIST)

1 A Family member

2 Somebody you work with

3 Somebody from the neighborhood

4 A Friend who lives close by

5 A Friend who lives at a different place

6 Other

(DO NOT READ)

8 Don't know

9 Refused

Q 10.b Compared with [Discussant \#3], would you say that your political views are much the same, somewhat different, or very different?

1 Much the same

2 Somewhat different

3 Very different

(DO NOT READ)

8 Don't know

9 Refused

Q 10.c Do you think [Discussant \#3] normally favors Republicans or Democrats, or both, or neither?

1 Republicans

2 Democrats

3 Both

4 Neither

(DO NOT READ)

8 Don't know

9 Refused

Q 10.d Which presidential candidate, if any, did [Discussant \#3] prefer? Romney, Obama or some other candidate?

1 Romney

2 Obama

3 Other

(DO NOT READ)

8 Don't know

9 Refused 
${ }^{* *}$ Author Note: Skip Q11 through Q11d, if respondent was able to name Discussant \#3.

$Q$ 11. (If the respondent cannot give a name in Q8) Can you give me the first name of the person you were most likely to have informal conversations with during the course of the past few months?

(If the respondent gives a name in Q8) Aside from who you have already mentioned, can you give me the first name of the person you were most likely to have informal conversations with during the course of the past few months?

IF PROBED: And we just need a first name or initials; remember all information is confidential.

\section{(Q11 Discussant)}

\section{(DO NOT READ)}

99 No one/No others/Refused [SKIP TO Q12]

\section{Q 11.a Is he/she (READ LIST)}

1 A Family member

2 Somebody you work with

3 Somebody from the neighborhood

4 A Friend who lives close by

5 A Friend who lives at a different place

6 Other

(DO NOT READ)

8 Don't know

9 Refused

Q 11.b Compared with [Q11 discussant], would you say that your political views are much the same, somewhat different, or very different?

1 Much the same

2 Somewhat different

3 Very different

(DO NOT READ)

8 Don't know

9 Refused 
Q 11.c Do you think [Q11 discussant] normally favors Republicans or Democrats, or both, or neither?

$\begin{array}{ll}1 & \text { Republicans } \\ 2 & \text { Democrats } \\ 3 & \text { Both } \\ 4 & \text { Neither } \\ \text { (DO NOT READ) } \\ 8 & \text { Don't know } \\ 9 & \text { Refused }\end{array}$

Q 11.d Which presidential candidate, if any, did [Q11 discussant] prefer? Romney, Obama or some other candidate?

$\begin{array}{ll}1 & \text { Romney } \\ 2 & \text { Obama } \\ 3 & \text { Other } \\ \text { (DO NOT READ) } \\ 8 & \text { Don't know } \\ 9 & \text { Refused }\end{array}$

Q 12. Is there anyone you have stopped talking with about politics due to disagreements over politics over the last years?

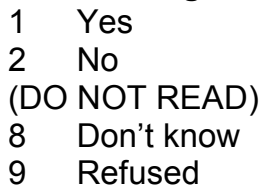

**Author note: Scramble list, always ask G last ${ }^{* *}$

Q 13. Next, I am going to mention various types of groups and organizations that people might belong to. For each type, please tell me whether or not you belong to any organization like it. (First/next), do you belong to... (READ ITEM)

a. A political party, club or association?
1 Yes
2 No
(DO NOT READ)
8 Don't know
9 Refused 
b. A trade union or professional association?

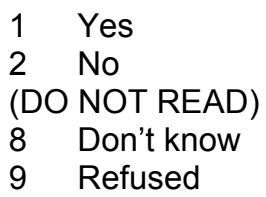

c. A church or other religious organization?
1 Yes
2 No
(DO NOT READ)
8 Don't know
9 Refused

d. A sports group, hobby or leisure club?
1 Yes
2 No
(DO NOT READ)
8 Don't know
9 Refused

e. A charitable organization or group?
1 Yes
2 No
(DO NOT READ)
8 Don't know
9 Refused

f. A neighborhood association or group?
1 Yes
2 No
(DO NOT READ)
8 Don't know
9 Refused

g. Other associations or groups?

$\begin{array}{ll}1 & \text { Yes } \\ 2 & \text { No }\end{array}$ 
(DO NOT READ)

8 Don't know

9 Refused

${ }^{* *}$ Author note: Questions 14-16 are follow-up questions if respondent answered "Yes" in Q 13.a), b), c), d), e), f), or g).

Q 14. You mentioned you belong to (Q13 group/organization). How frequently do you participate in meetings and other activities of this group? Do you participate often, sometimes, rarely, or never?

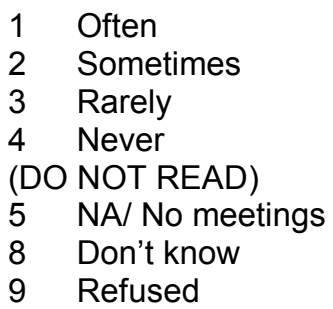

Q 15. Would you say that political discussions in this group occur often, sometimes, rarely, or never?

1 Often

2 Sometimes

3 Rarely

4 Never

(DO NOT READ)

8 Don't know

9 Refused

Q 16. When talking politics, do you and the people in this group: (READ LIST)

1 Always agree

2 Agree most of the time

3 Sometimes agree and sometimes disagree

4 Disagree most of the time

5 Always disagree

(DO NOT READ)

8 Don't know

9 Refused 
11.3. Migration and Satisfaction with living in Dane and Waukesha County

**Author note: Present county from QS3

Q 17. What city/town or village in (Dane County/Waukesha (Waw'kuh-sha) County) do you live in?

${ }^{* *}$ Author note: Insert city/town/village list for county respondent lives in (QS3)

998 Don't know/Undecided

999 Refuse

**Author note: Present county from QS3

Q 18. In what year did you move to (Dane County/Waukesha (Waw'kuh-sha) County)?

Year:

(DO NOT READ) 9997 I lived all my life here. (SKIP TO Q 23, Version B) 9998 Don't know (SKIP TO Q 23, Version B)

9999 Refused (SKIP TO Q 23, Version B)

**Author note: Present county from QS3

Q 19a. Before moving to (Dane County/Waukesha (Waw-'kuh-sha) County), which state did you live in? Or did you move from within Wisconsin?

${ }^{* *}$ Author note: Pre-coded list of 50 states and DC (DO NOT READ)

97 Outside of U.S. (SKIP TO Q20)

98 Don't know (SKIP TO Q20)

99 Refused (SKIPTO Q20)

Q19b. And which county in (insert state in Q19a) did you live in before moving to (Dane County/Waukesha (Waw-'kuh-sha) County)?

\section{PROBE FOR CORRECT COUNTY SPELLING IF NECESSARY}

${ }^{* *}$ Author note: Pre-coded list for Wisconsin, Minnesota, lowa, Michigan, and Illinois. Open ended list for all other states. If county given, skip to Q20.

(DO NOT READ)

9998 Don't know

9999 Refused

**Author note: Present county from QS3 
Q20. Thinking back to the time when you moved to (Dane County/Waukesha (Waw-'kuh-sha) County), which party did you identify with back then? Did you think of yourself as a Republican, Democrat or Independent?

1 Republican (SKIP TO Q22)

2 Democrat (SKIP TO Q22)

3 Independent (ASK Q21)

(DO NOT READ)

4 Other/no preference

8 Don't know (ASK Q21)

9 Refused (ASK Q21)

**Author note: Ask Q21 if Q20 $=3,4,8$, or 9

Q21. Back then, did you think of yourself as closer to the Republican Party or to the Democratic Party?

\author{
1 Republican \\ 2 Democrat \\ (DO NOT READ) \\ 3 Neither/Just Independent (VOL) \\ 8 Don't know \\ 9 Refused
}

**Author note: Ask Q22 if Q20 = 1 or 2

Q22. Back then, would you have called yourself a strong (REPUBLICAN/DEMOCRAT) or a not very strong (REPUBLICAN/DEMOCRAT)?

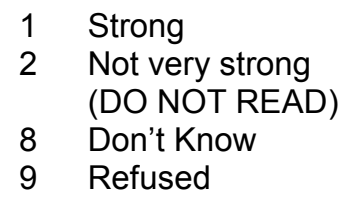

Q23. VERSION A (for movers; those who named a year in Q18):

Many people consider multiple places before choosing where they will live. Thinking back to when you moved to your current residence, what sort of factors affected your choice of neighborhood? For each of the following factors, please tell me whether they were "very important"," somewhat important"," not too important" or "not important at all" to you.

The (first/next) factor is (INSERT ITEM). How important is this factor to you? (REREAD FACTOR AND SCALE AS NECESSARY) 
Q23. VERSION B (for non-movers; those who answered "I lived here all my life" or "Don't know" or refused in Q 18): People have different ideas on what is important for the quality of life in their neighborhood. I will now read a list to you with different factors that people might consider important. For each of these factors, please tell me whether they are "very important", "somewhat important", "not too important", or "not important at all" to you.

The (first/next) factor is (INSERT ITEM). How important is this factor to you? (REREAD FACTOR AND SCALE AS NECESSARY)

${ }^{* *}$ Author Note: scramble list ${ }^{* *}$

a. Low taxes

1 Very important

2 Somewhat important

3 Not too important

4 Not important at all

(DO NOT READ)

8 Don't know

9 Refused

\section{b. Safety}

1 Very important

2 Somewhat important

3 Not too important

4 Not important at all

(DO NOT READ)

8 Don't know

9 Refused

c. Affordable housing

1 Very important

2 Somewhat important

3 Not too important

4 Not important at all

(DO NOT READ)

8 Don't know

9 Refused

d. Availability of locally produced or organic food at nearby grocers

1 Very important

2 Somewhat important

3 Not too important

4 Not important at all

(DO NOT READ) 
8 Don't know

9 Refused

e. Businesses, such as restaurants, coffee places or movie theatres that are within walking distance

1 Very important

2 Somewhat important

3 Not too important

$4 \quad$ Not important at all

(DO NOT READ)

8 Don't know

9 Refused

f. A local church near the neighborhood

1 Very important

2 Somewhat important

3 Not too important

4 Not important at all

(DO NOT READ)

8 Don't know

9 Refused

g. Not having to use the car all the time

1 Very important

2 Somewhat important

3 Not too important

4 Not important at all

(DO NOT READ)

8 Don't know

9 Refused

h. A neighborhood where people share your political views

1 Very important

2 Somewhat important

3 Not too important

4 Not important at all

(DO NOT READ)

8 Don't know

9 Refused

i. Good public infrastructure, such as good public transportation, bike paths, and public libraries

1 Very important

2 Somewhat important

3 Not too important 
$4 \quad$ Not important at all

(DO NOT READ)

8 Don't know

9 Refused

j. All shopping facilities are easily accessible by car

1 Very important

2 Somewhat important

3 Not too important

4 Not important at all

(DO NOT READ)

8 Don't know

9 Refused

k. Living in a neighborhood where people display their patriotism, for example by putting up flags on national holidays

1 Very important

2 Somewhat important

3 Not too important

4 Not important at all

(DO NOT READ)

8 Don't know

9 Refused

${ }^{* *}$ Author note: Present county from QS3

Q 24 Generally speaking, how satisfied are you with living in (Dane County/Waukesha (Waw-'kuh-sha) County) Are you very satisfied, satisfied, dissatisfied or very dissatisfied?

1 Very satisfied

2 Satisfied

3 Dissatisfied

4 Very dissatisfied

(DO NOT READ)

8 Don't know

9 Refused

${ }^{* *}$ Author note: Present county from QS3

Q 25 For each of the following statements about life in (Dane County/Waukesha (Waw-'kuh-sha) County), please tell me whether you strongly agree, agree, disagree, or strongly disagree.

The (first/next) statement is (READ ITEM). How much do you agree or disagree with this statement? (REREAD ITEM AND SCALE AS NECESSARY)

${ }^{* *}$ Author note: scramble list, do not make E or F first ${ }^{* *}$ 


\section{a. The people around here and I share the same values}

1 Strongly agree

2 Agree

3 Disagree

4 Strongly disagree

(DO NOT READ)

8 Don't know.

9 Refused

b. I like the diversity of the place

1 Strongly agree

2 Agree

3 Disagree

4 Strongly disagree

(DO NOT READ)

8 Don't know.

9 Refused

c. Family values are taken very serious in this community

1 Strongly agree

2 Agree

3 Disagree

4 Strongly disagree

(DO NOT READ)

8 Don't know.

9 Refused

d. I am well connected in my community and have many friends

1 Strongly agree

2 Agree

3 Disagree

4 Strongly disagree

(DO NOT READ)

8 Don't know.

9 Refused

e. People here are too conservative

1 Strongly agree

2 Agree

3 Disagree

4 Strongly disagree

(DO NOT READ)

8 Don't know.

9 Refused 
f. People here are too liberal

1 Strongly agree

2 Agree

3 Disagree

4 Strongly disagree

(DO NOT READ)

8 Don't know.

9 Refused

**Author note: Present county from QS3

Q 26. Do you sometimes think about moving away from (Waukesha (Waw-'kuh-sha) County/Dane County)?

1 Yes (ASK Q 27)

2 No (MOVE TO Q 28)

(DO NOT READ)

8 Don't know (MOVE TO Q 28)

9 Refused (MOVE TO Q 28)

Q 27. Is this because you dislike the political views of the people in (Dane County/Waukesha (Waw-'kuh-sha) County)?

1 Yes

2 No

8 Don't know.

9 Refused

Q 28. If you had to move to a different county within Wisconsin, which one would you prefer?

${ }^{* *}$ Author note: Pre-code list of Wisconsin counties and cities, omit county where currently reside (QS3B).

$\begin{array}{ll}997 & \text { City not assignable } \\ 998 & \text { Don't know/undecided } \\ 999 & \text { Refuse }\end{array}$

Q 29. Which county or city within Wisconsin would you rather avoid moving to?

${ }^{* *}$ Author note: Pre-code list of Wisconsin counties and cities, omit county where currently reside (QS3B) and mentions in Q28.

$997 \quad$ City not assignable

998 Don't know/undecided

999 Refuse 
Q 29a At the present time, are you employed, that is, are you doing something for which you earn money outside of the home?

9 Refused (Skip to F3)

$\begin{array}{ll}1 & \text { Yes (Ask Q30) } \\ 2 & \text { No (Skip to F3) }\end{array}$

Q 30 How long is your commute to work?

$1 \quad 0-10$ Minutes

2 10-20 Minutes

3 20-44 Minutes

445 Minutes to an hour

5 More than an hour

(DON'T READ)

8 Don't know

9 Refused

\section{BACKGROUND/DEMOGRAPHICS}

TRANSITION SCREEN:

The following questions are for classification purposes only.

F3. What is the highest level of education you completed? (READ LIST)

01 Elementary school only

02 Some high school but did not finish

03 Completed high school

04 Some college but didn't finish

05 Two year college degree

06 Four year college degree

07 Some graduate work

08 Completed masters or professional degree

09 Advanced graduate work or $\mathrm{PhD}$

(DO NOT READ)

98 Don't know

99 Refused

F4. What is your age? (Record actual age in years).

$\overline{99 \text { Refused [ASK F4A] }}$

F4A. [If Refused] Are you... (READ LIST)

1 18-29 years old

2 30-44 years old 
3 45-59 years old

460 years old or more

(DO NOT READ)

8 Don't know

9 Refused

F5. Are you currently married, widowed, divorced, separated, or have you never been

married?

1 Married

2 Widowed

3 Divorced

4 Separated

5 Never Married

(DO NOT READ)

8 Don't know

9 Refused

F6. Are you of Hispanic or Latino origin, such as Mexican, Puerto Rican, Cuban or some other Spanish background?

1 Yes

2 No

(DO NOT READ)

8 Don't know

9 Refused

F7. Would you describe yourself as White, African American or Black, Asian, Native American, of more than one race or some other race?

01 White

02 African American or Black

03 Asian, South Asian, or Pacific Islander

04 Native American or American Indian

05 More than one race

97 Other, Specify

(DO NOT READ)

06 Hispanic or Latino

98 Don't know

99 Refused

F8. Aside from weddings and funerals, how often do you attend religious services... more than once a week, once a week, once or twice a month, a few times a year, seldom, or never? 
1 More than once a week

2 Once a week

3 Once or twice a month

4 A few times a year

5 Seldom

6 Never

(DO NOT READ)

8 Don't know

9 Refused

F9. What is your religious preference - are you Protestant, Roman Catholic, Jewish, Muslim, another religion or no religion?

IF RESPONDENT NAMES ANYTHING ELSE, ASK:

Would that fall under the general category of Protestant religions, is it a Christian religion, but not Protestant, or is it something else?
01 Protestant
02 Roman Catholic
03 Jewish
04 Muslim/Islam
05 Mormon/Latter-Day Saints
06 Other Christian Religion
07 Other Non-Christian Religion
08 No Religion/Atheist/Agnostic
(DO NOT READ)
98 DON'T KNOW
99 REFUSED

${ }^{* *}$ Author Note: There is NO F10 in this instrument.

F13. In general, would you describe your political views as... (READ LIST)

1 Very conservative

2 Conservative

3 Moderate

4 Liberal

5 Very liberal

(DO NOT READ)

8 Don't know

9 Refused

F11. Last year, that is in 2012, what was your total family income from all sources, before taxes? Just stop me when I get to the right category. (READ LIST) 
01 Less than $\$ 10,000$

0210 to under $\$ 20,000$

0320 to under $\$ 30,000$

0430 to under $\$ 40,000$

0540 to under $\$ 50,000$

0650 to under $\$ 75,000$

0775 to under $\$ 100,000$

08100 to under $\$ 150,000$

$09 \$ 150,000$ or more

(DO NOT READ)

98 Don't know

99 Refused

The survey is now complete. Thank you for your time and cooperation. 
Studien des Göttinger Instituts für Demokratieforschung zur Geschichte politischer und gesellschaftlicher Kontroversen

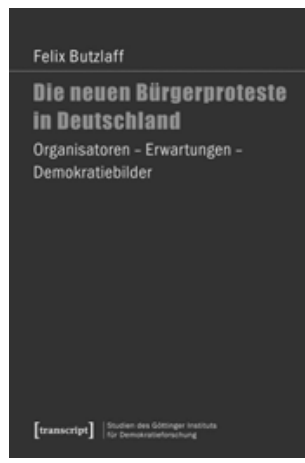

Felix Butzlaff

Die neuen Bürgerproteste in Deutschland

Organisatoren - Erwartungen -

Demokratiebilder

20I5, 304 Seiten, kart., 32,99 €,

ISBN 978-3-8376-334I-2

Lars Geiges

Occupy in Deutschland

Die Protestbewegung und ihre Akteure

20I4, 376 Seiten, kart., zahlr. Abb., 33,99€,

ISBN 978-3-8376-2946-0

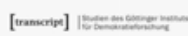

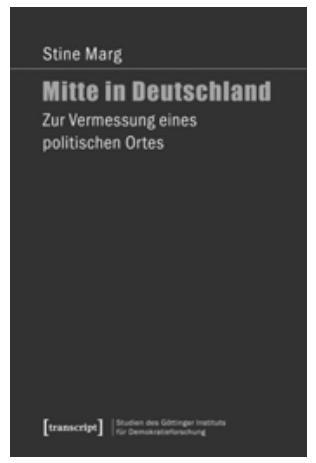

Stine Marg

Mitte in Deutschland

Zur Vermessung eines politischen Ortes

20I4, 296 Seiten, kart., 32,99 €,

ISBN 978-3-8376-2728-2

Leseproben, weitere Informationen und Bestellmöglichkeiten finden Sie unter www.transcript-verlag.de 


\section{Studien des Göttinger Instituts für Demokratieforschung}

zur Geschichte politischer und gesellschaftlicher Kontroversen

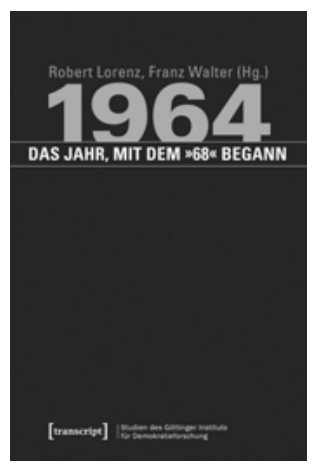

Robert Lorenz, Franz Walter (Hg.) I964 - das Jahr, mit dem »68« begann

20I4, 378 Seiten, kart., 29,99€,

ISBN 978-3-8376-2580-6

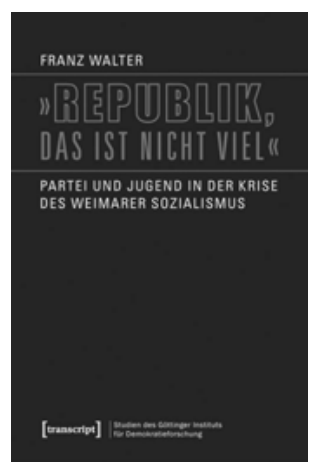

Franz Walter

»Republik, das ist nicht viel «

Partei und Jugend in der Krise

des Weimarer Sozialismus

20II, 454 Seiten, kart., 29,80 €,

ISBN 978-3-8376-I832-7

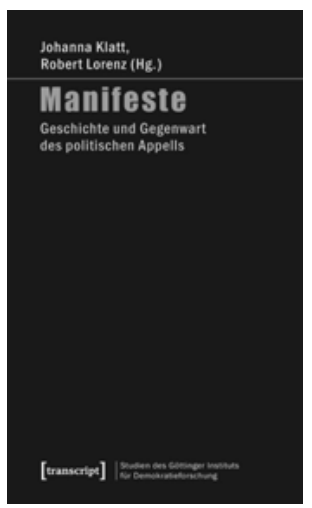

Johanna Klatt, Robert Lorenz (Hg.)

Manifeste

Geschichte und Gegenwart

des politischen Appells

20I0, 446 Seiten, kart., 32,80 €,

ISBN 978-3-8376-I679-8

Leseproben, weitere Informationen und Bestellmöglichkeiten finden Sie unter www.transcript-verlag.de 